\title{
Review of Australasian Chonocephalus Wandolleck (Diptera: Phoridae)
}

\author{
R. Henry L. Disney \\ Department of Zoology, University of Cambridge, UK
}

Copyright (C) 2015 Horizon Research Publishing All rights reserved.

\begin{abstract}
Chonocephalus Wandolleck are described. C. tertius Schmitz is synonymised with $C$. secundus Schmitz. A key to males and a partial key to the females of the Australasian Regions species are provided.
\end{abstract}

Keywords Diptera, Phoridae, Chonocephalus, New Species, Keys, Australasian Region

\section{Introduction}

The tiny scuttle flies of the genus Chonocephalus Wandolleck are noted for their sexual dimorphism, with the females being flightless but the males being normally winged. Many species breed in ripe fruits, while some exploit other sources of fermenting detritus or plant material, and some are fungivores. The males transport females to suitable larval pabula during nuptial flights (Disney [7]).

Many casual collectors seem unaware of the sexual dimorphism in this genus and consequently have tended to collect only one sex. The naming of undescribed species on the basis of one sex only created taxonomic chaos. The growing list of undescribed males and females had become such that I am now naming undescribed males but assigning code numbers only to undescribed females not yet associated with their males. Such a policy runs the risk that we may describe as new some named species already known in the female sex only. As these are associated with their males, we will thereby create some synonyms. This is probably a smaller price to pay than a confusing proliferation of species (described from males alone) known by code numbers only alongside a smaller list of females known only by code letters. Museum collections abound in misidentified specimens and many species awaiting description. In order to provide the basis for moving forward, all named species in literature were reviewed and keys to the Nearctic and Palaearctic species were provided. Furthermore this revision of the 43 previously recognised species on the world list reduced this to 32 valid species, with the possibility that some only known in the female sex might be the missing females of some species only known in the male sex (Disney [10]). Subsequently six new species were added, one further synonym was proposed when the Afrotropical species were revised (Disney [11]) and another subsequently synonymised (Disney [13]). This was followed by revisions of the Neotropical species (Disney [12]) and Oriental species (Disney [14]).

The western boundary of the Australasian Region is debatable. Some authors (e.g. Lincoln et al. [16]) prefer Wallace's Line while others (e.g. Oosterbroek [17]) favour Weber's Line. The fact is that Wallacea, which is the region between these two, embraces elements of the faunas of both regions as well as elements peculiar to itself. An Afrotropical and Oriental group found in Wallacea but not beyond Weber's Line is the fungus growing termites. As there are many termitophilous Phoridae associated with these termites it has been considered sensible to arbitrarily opt for Weber's Line as the boundary between the two regions as far as Phoridae are concerned (Disney [8]). Consequently species from Sulawesi are covered by the review of Oriental species of Chonocephalus (Disney [14]).

\section{Methods}

The identification of members of this genus requires slide mounted specimens. Indeed the females can only be reliably identified by means of internal features of the abdomen (see below). The preferred mounting medium is the so called Berlese Fluid gum chloral medium, used with coverslips of $10 \mathrm{~mm}$ and $6 \mathrm{~mm}$ diameter (Disney [5] \& [7]). Upton ([21]) has advised 
against use of this mountant, but some of his criticisms are based on a number of dubious assumptions and misapprehensions (Disney [9]).

For males, the recognition of the species depends primarily on the details of the hypopygium. These are best detached from the rest of the fly and mounted under a separate $6 \mathrm{~mm}$ coverslip with the underside uppermost. When several specimens are available then it is useful if some are mounted to display the left face of the hypopygium. Females are mounted whole with the dorsal face uppermost. When several specimens are available it is useful to detach the legs from at least one specimen and mount these under separate coverslips.

Some museum specimens had been mounted dry on pins. These have been remounted on slides following treatment in Barber's Fluid (see Disney [9]). However, some of the males in particular had suffered damage when they were glued to card points or placed in a drop of glue on the side of a pin. In particular the hypoppygium was sometimes fractured and its processes were sometimes broken off. This means that the illustration of some critical features has not always been possible.

\section{Genus Chonocephalus Wandolleck}

Chonocephalus Wandolleck, 1898 [22]: 428.

Type species. C. dorsalis Wandolleck, by monotypy.

\section{Diagnosis}

Male: Ocelli present. Wings with costa clearly exceeding half wing length, vein 3 unforked, base of vein 4 missing, vein 6 not deflected forwards in middle third, microsetae of rear margin about three times as long as distance between adjacent microsetae, and without axillary bristles. Hypopygium with short anal tube and at least one gonopod. Mid mesopleural ridge present and at least one and usually at least three small hairs near rear margin of mesopleuron. Tibiae lack near-dorsal longitudinal hair palisades and pre-apical isolated bristles.

Female:Ocelli absent. Wings and halteres absent. Abdominal tergites $1 / 2$ to 7 well developed. Four supra-antennal bristles present. At least most of sternite 8 and all of S9 (furca) are internal, and the single spermatheca is typically lightly sclerotised. Tibiae lack near-dorsal longitudinal hair palisades and pre-apical isolated bristles.

\section{Males}

The recognition of species depends primarily on the details of the hypopygium, which is at first sight very complex. However, if one ignores the, often elaborate, penis complex (X), the details of the epandrium (E) and hypandrium (H) that are referred to in the key below are indicated in Fig. 1. This represents a generalised, stylized, hypopygium. While the anal tube (A) is seldom utilised in the recognition of species it is a useful point of reference. Any one of the labelled structures may be modified and may sometimes be very elaborate in form. In the inferred ground plan state the rear margin of the hypandrium bears four processes. These are the gonopods $(\mathrm{G})$ and a pair of median lobes (L). In the plesiomorphic state the gonopods articulate with the dorsal face of the hypandrium, but more frequently they arise from it. One (usually the left) or both may be reduced or absent. The median lobes (L) may form a single bilobed structure or be reduced to a single lobe (which may be greatly elongated) or be lost altogether. Ventrally each side of the epandrium (E) typically bears an anterior process (AP) and a posterior process (PP). In some species the anterior processes (AP) may appear to be appendages (attaching to the inner face of the epandrium) rather than simple projections of the epandrium. A presumed true left surstylus or clasper is frequently present (C in Fig. 1) variably fused to the epandrium, and is sometimes elaborate. Occasionally it is fused to the bridge (B), which is sometimes present and probably represents sternite 10. The most anterior (lower) bristle of the left side of the epandrium is sometimes modified into a spine (S), which may be further modified. 


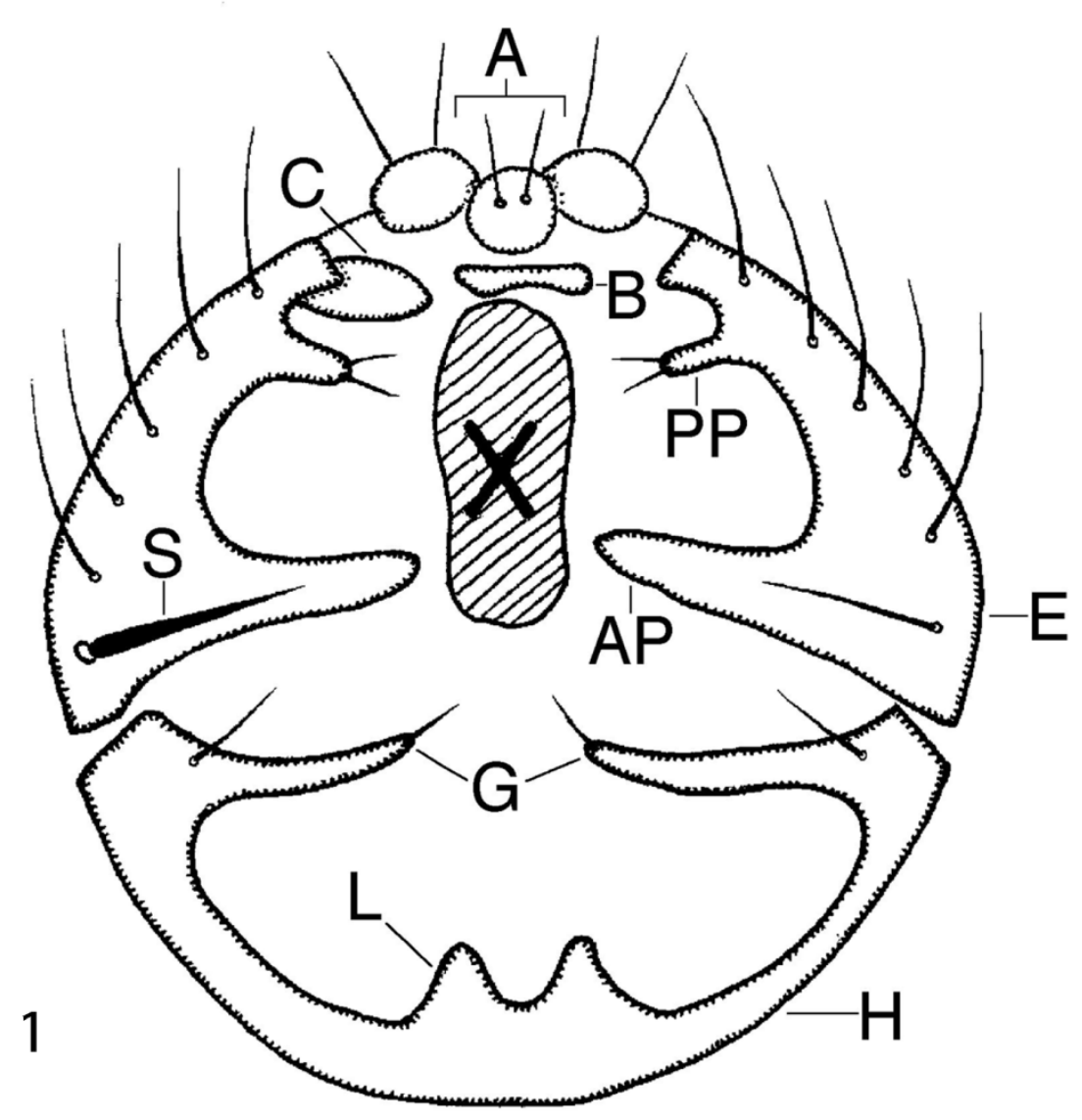

Figure 1. Chonocephalus male hypopygium, diagrammatic ventral view of a generalised species. $\mathrm{A}=$ anal tube (with median hypoproct and paired cerci); $\mathrm{E}=$ epandrium; $\mathrm{H}=$ hypandrium; $\mathrm{X}=$ penis complex (simplified). $\mathrm{AP}, \mathrm{PP}=$ anterior and posterior processes (probably $=$ subepandrial sclerites) of epandrium; $\mathrm{L}=$ lobe(s) of hypandrium; $\mathrm{G}=$ gonopods; $\mathrm{B}=$ bridge (probably = sternite 10); $\mathrm{C}=$ left surstylus (clasper); $\mathrm{S}=$ spine (modified bristle) of epandrium.

\section{Females}

The morphology of the females has been discussed elsewhere (Disney [6], [10]). It was concluded that the first, long, abdominal tergite is a composite of T1 + T2 fused together, and that the last, also relatively long, fully developed tergite is T7 (Fig. 2). The microtrichia, lying between the hairs on these tergites (Fig. 93) are frequently reduced in size and consequently tend to be more densely packed and only discernible at higher magnifications. Otherwise the taxonomically useful features are mainly the form and size of the modified abdominal tergite (T8) and sternite 8 (S8), the internalised sternite 9 (furca) and the spermatheca. Typically the remnants of T9 are variably fused to the anterolateral apodemes of T10. These structures are most fully developed in C. blackithorum (Figs 3-4). The form and dimensions of sternite 8 have proved to be especially valuable taxonomically. This sternite has seemingly evolved from an isosceles triangular sternite whose anterior end continues internally as an anteriorly directed apodeme (Fig. 4). In many species the external sternite is greatly reduced or lost while the internal apodeme has increased in length. In some species a small sternite is retained as an externally visible projection. Tergite 8 is frequently reduced or seemingly absent. In the latter case it is present but only very lightly pigmented (e.g. Fig. 91).Its presence may be discerned in many such cases by locating a minute hair at each posterolateral corner. However, these hairs are sometimes absent. There can be some confusion between the furca and spermatheca. Both are typically subcircular structures lying close to each other between T8 (when present) and S8. The spermatheca is typically a lightly pigmented bowl shaped structure, as in Fig. 4, while the furca is hoop shaped and paler (S9 in Fig. 3). However in many species one or other or both these structures may be very pale and it may require critical adjustment of the microscope's lighting in order to discern them both. In observing a female mounted on a slide with its dorsal side uppermost, as one focuses downwards the sequence of encounter is T8 - furca (S9) - spermatheca - S8. Where an egg is in place ready for laying, then it lies below T8 and the furca but above the spermatheca and S8. Indeed the furca is often displayed to view most clearly against the background of such an egg. When no egg is in this position the furca may be tilted sideways on (as viewed from above or below). 


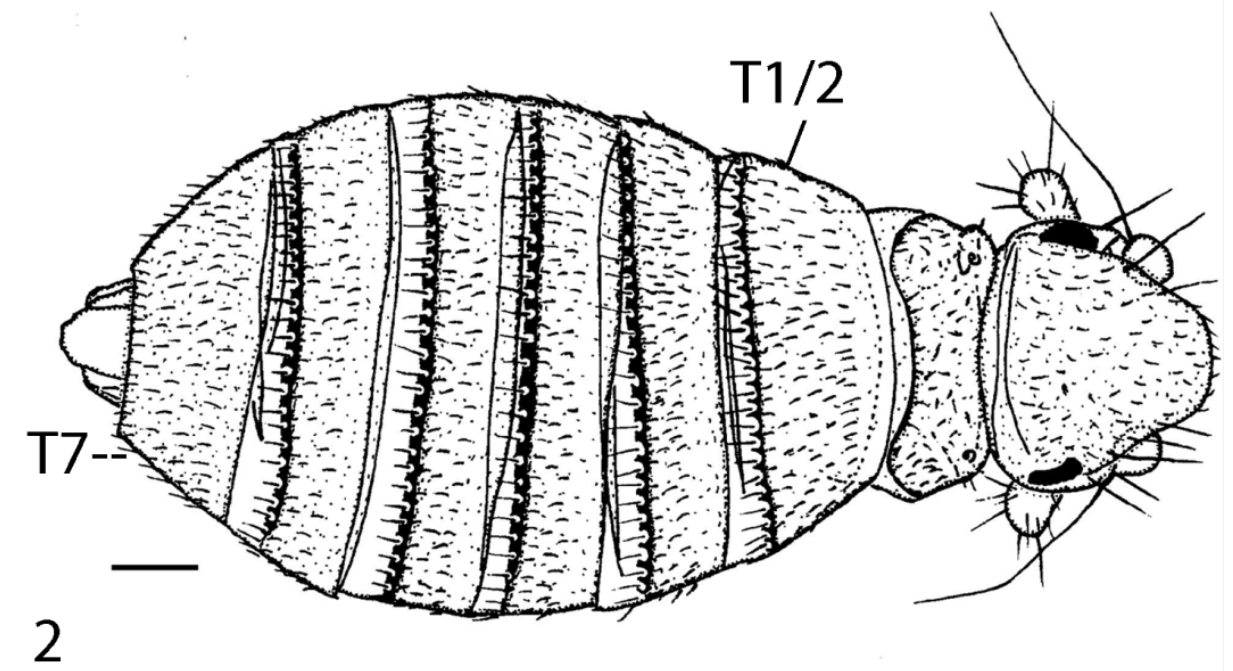

Figure 2. Chonocephalus female $(\mathrm{T} 1 / \mathrm{T} 2=$ fused tergites 1 and $2, \mathrm{~T} 7=$ tergite 7$)$. Scale bar $=0.1 \mathrm{~mm}$.

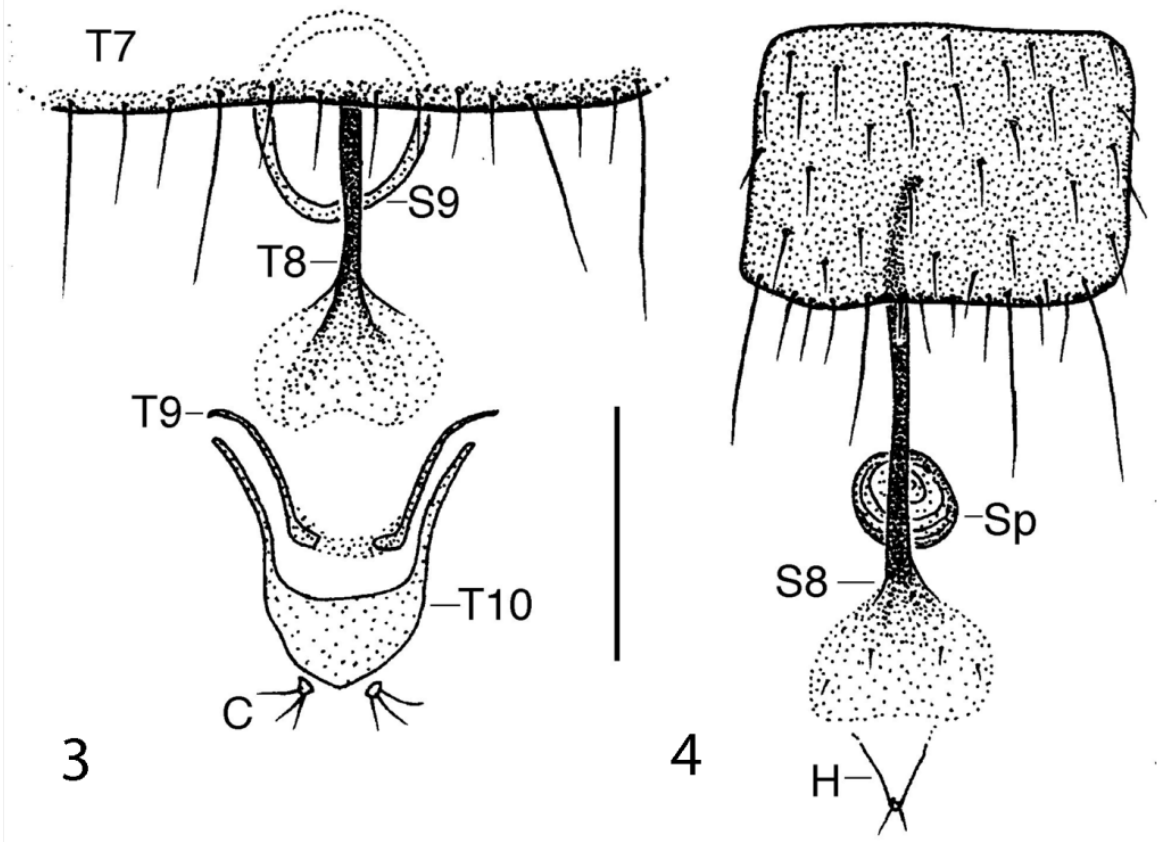

Figures 3-4. Chonocephalus blackithorum female, details of terminal segments of abdomen: (3) from above (c $=$ cercus, $\mathrm{S} 9=$ sternite 9 (furca), T7-T10 $=$ tergites 7-10); (4) from below $(\mathrm{H}=$ hypoproct, $\mathrm{S} 7-\mathrm{S} 8=$ sternites 7-8, $\mathrm{sp}=$ spermatheca). Scale bar $=0.1 \mathrm{~mm}$.

\section{Review of species}

The descriptions of the new species are brief as the significant features of the males are largely restricted to the details of the hypopygia. Likewise in the females there are relatively few features that distinguish the species apart from the details of the abdominal terminalia. The formal diagnoses, therefore, are the features used to distinguish the species in the keys below.

The depositories of the material examined are as follows. Cambridge University Museum of Zoology (CUMZ); Department of Environmental Biology, University of Guelph, Canada (DEBU); Natural History Museum, Los Angeles County (LACM); Museum Koenig, Bonn (MKB); Queensland Museum, Brisbane (QMB); The final reference number given after the code for the depository, e.g. 16-34, is the reference written on the slide mount and refers to my notebook entry and page number. In this example this means notebook 16 page 34.

The detailed references for the synonyms are listed by Disney ([10]) except where indicated.

\section{Chonocephalus aduncus Schmitz}




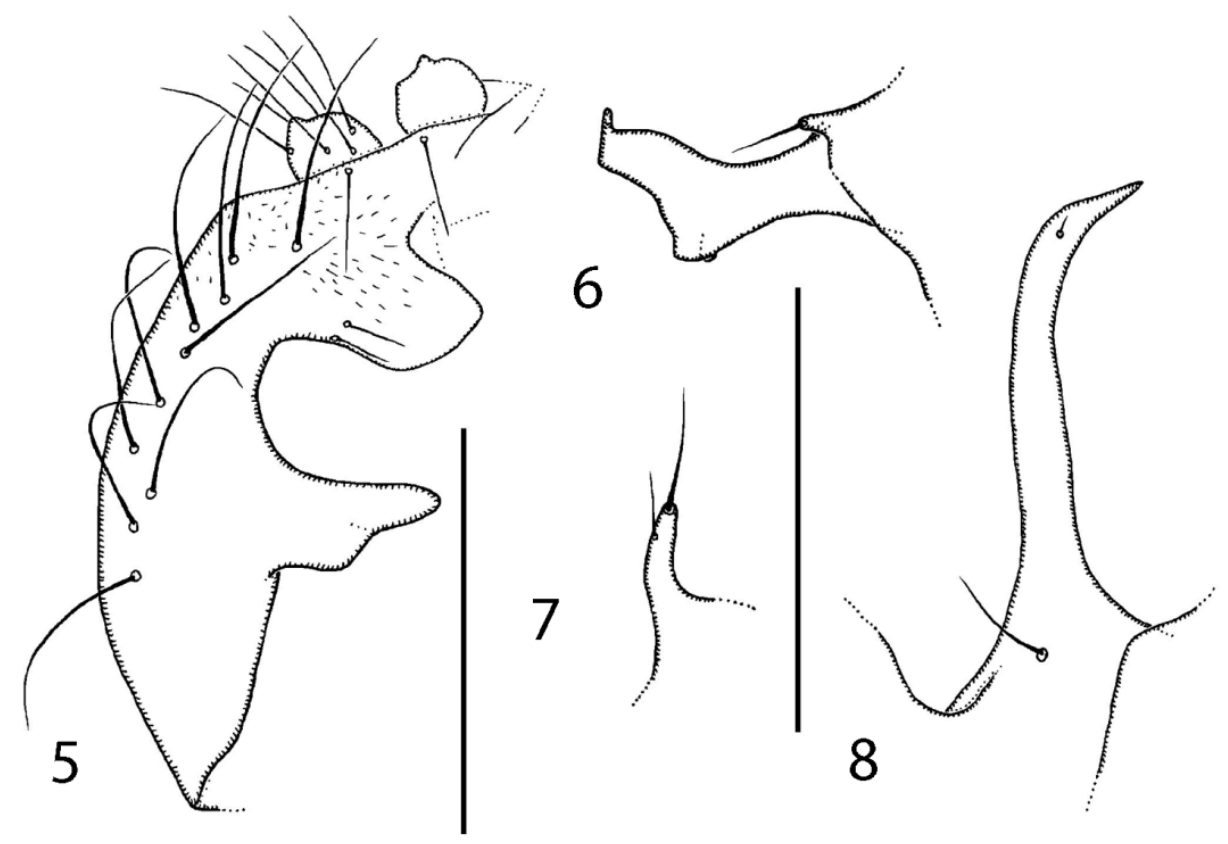

Figures 5-8. Chonocephalus aduncus male, details of hypopygium: (5) left side of epandrium and left cercus; (6) right process of epandrium; (7) left gonopod; (8) right gonopod. Scale bars $=0.1 \mathrm{~mm}$.

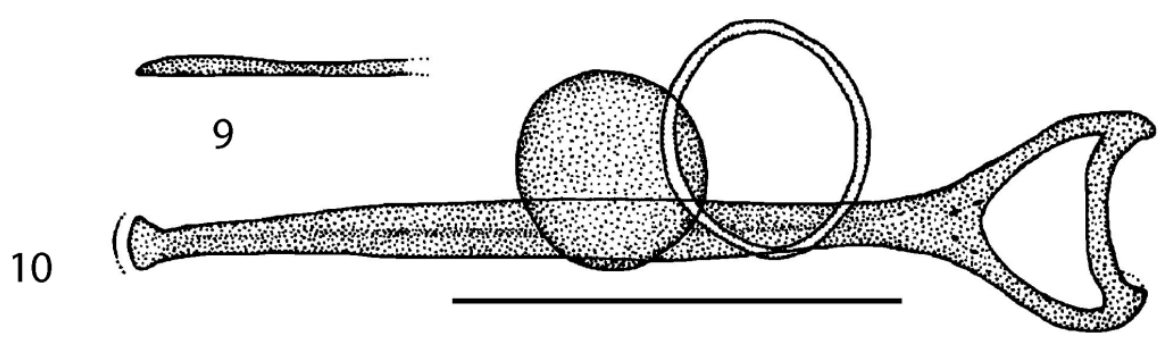

Figures 9-10. Chonocephalus aduncus female, details of abdomen: (9) tergite 8; (10) sternite 8, furca and spermatheca. Scale bar $=0.1 \mathrm{~mm}$.

Chonocephalus aduncus Schmitz, 1928 [9]: 92 (part).

Chonocephalus hirsutus Bohart, 1947: 409.Disney, 2002 [10]: 7.

Chonocephalus sp. C Disney, 1986 [6]: 80. Disney, 2002 [10]: 7.

A lectotype has been designated (Disney [10]).

\section{Material}

5 males, Australia, Queensland, Innisfail, Pin Gin Hill, water trap, 14-17 February 1982, D. Howse (CUMZ, 6-133).Lectotype male, Bismarck Archipelago, Neupommern (MKB, 27-134). 1 male, Fiji, Suva, water trap, January 1997, A. van Harten (CUMZ, 32-71).Holotype female and allotype male of C. hirsutus, Guam, near Agana, October 1945, from pig dung, G. E. Bohart and J. Gressitt (USNM, 57994 - 26-64).1 male, Papua New Guinea, Laing, 2 June 1982, P. Grootaert (CUMZ, 3-137).Also recorded from the Oriental Region and Japan.

\section{Natural history}

Reared from rotting ripe figs and from the frass of a cerambycid beetle in a $\log$ (Disney [6]).Two males have been reported on carrion (Schmitz [19]).

\section{Chonocephalus americanus Borgmeier}



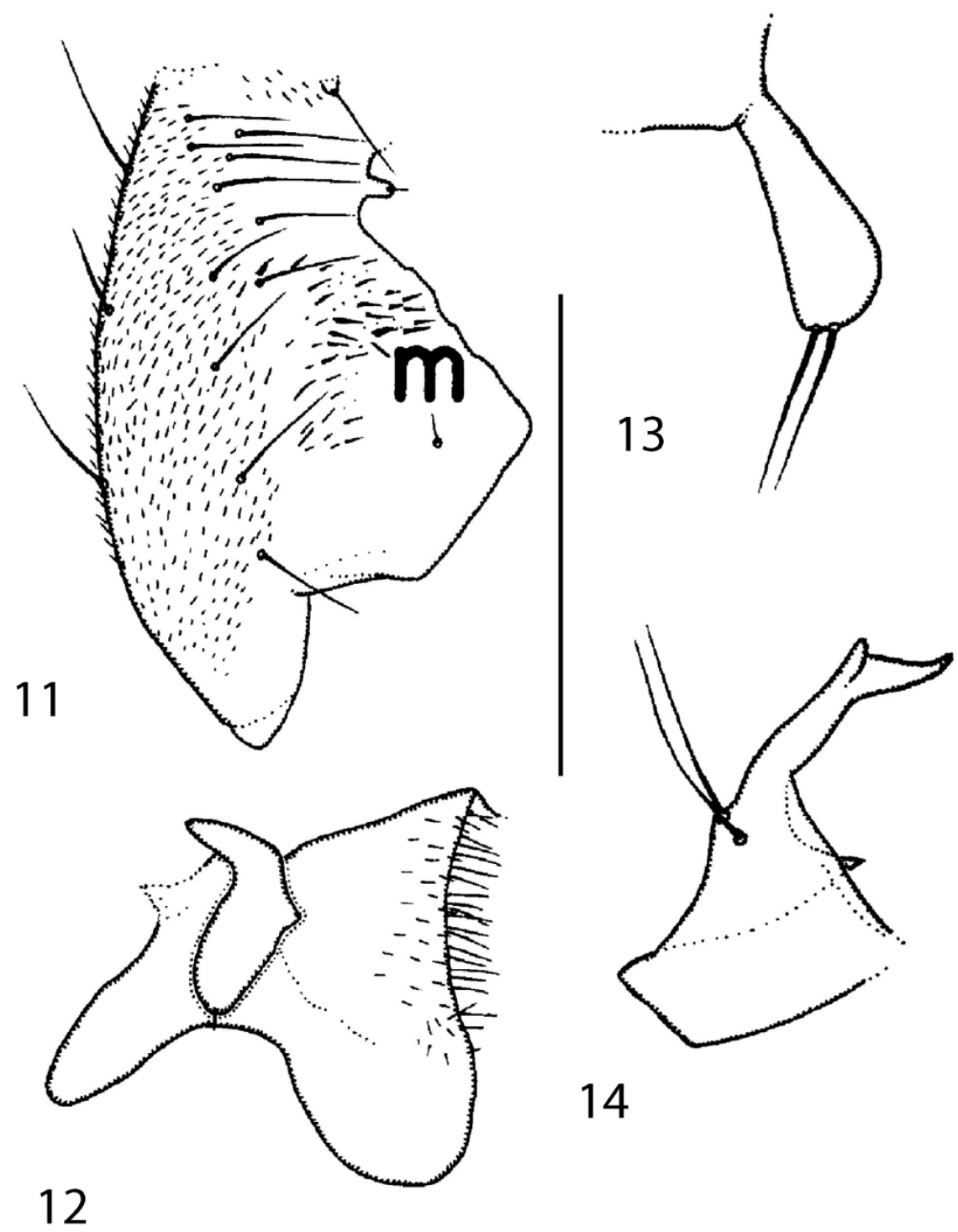

14

Figures 11-14. Chonocephalus americanus male, details of hypopygium from below: (11) left side of epandrium from below; (12) hypandrial lobes, deflected forwards so that upper (inner) face is exposed to view; (13) left gonopod; (14) right gonopod. Scale bar $=0.1 \mathrm{~mm}$. 

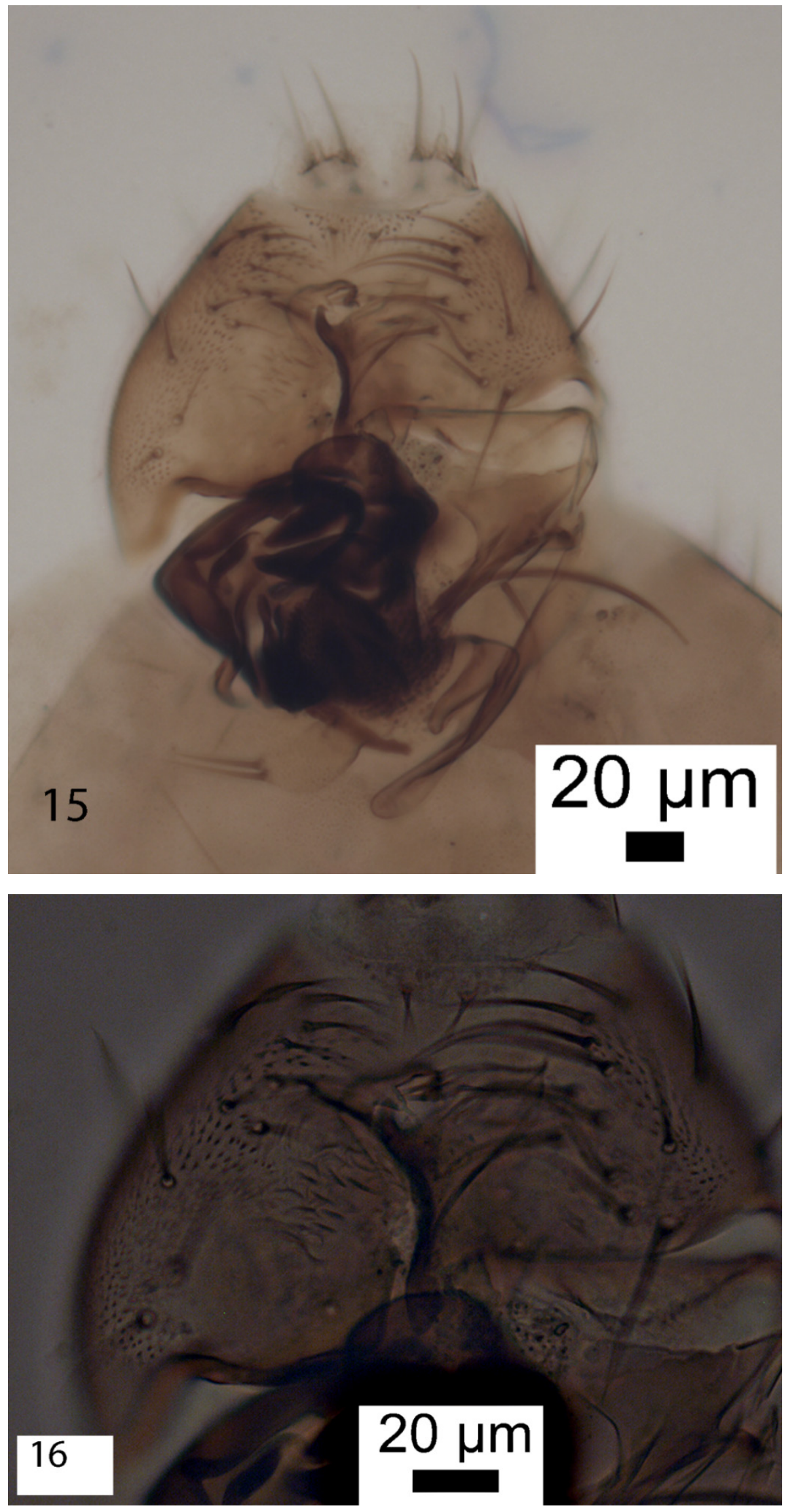

Figures 15-16. Chonocephalus americanus male hypopygium. (15) from below; (16) detail of epandrium from below. 


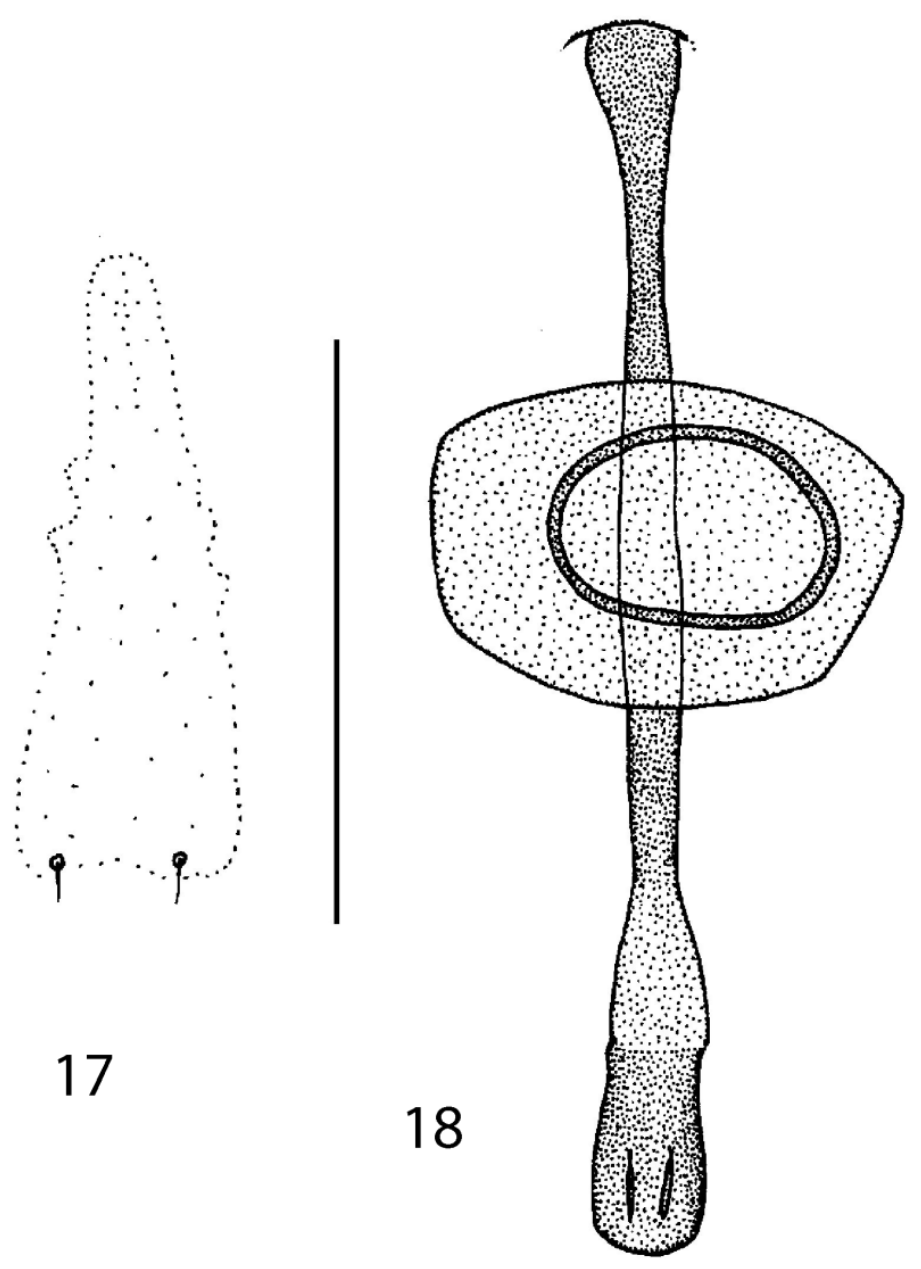

Figures 17-18. Chonocephalus americanus female, details of abdomen: (17) tergite 8; (18) sternite 8, furca and spermatheca. Scale bar $=0.1 \mathrm{~mm}$.

Chonocephalus americanus Borgmeier, 1963: 250.

Chonocephalus digitalis Borgmeier, 1967 [3]: 207 (part).Disney, 2002 [13]: 9.

This species has been transported around the world to every Biogeographic Region, except the Palaearctic. It is probably Nearctic in origin.

A specimen from Taiwan differs from typical specimens in that the postpedicel is broader than long, whereas it is normally a little longer than broad. However, its hypopygium is indistinguishable from that of typical specimens. Whether this difference is typical of specimens from Taiwan or merely a feature of this single specimen is not known.

\section{Material}

9 males, 3 females, Fiji, Suva, November 1994-May 1995, August-November 1996, January 1997, Malaise traps, A. van Harten (CUMZ, 2-61-62, 68-72).

\section{Chonocephalus andersoni sp. nov.}




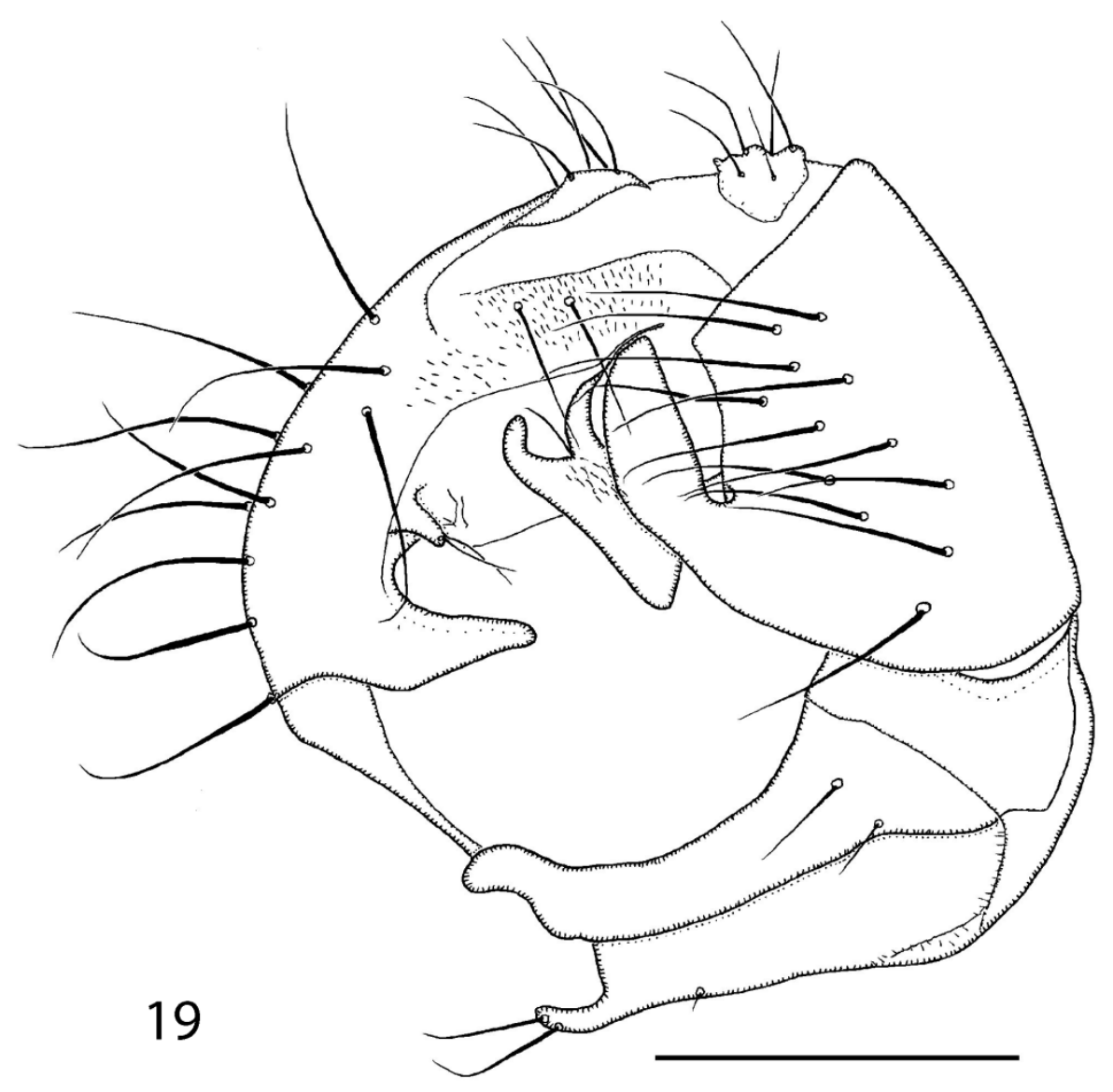

20

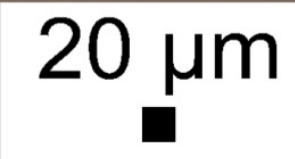



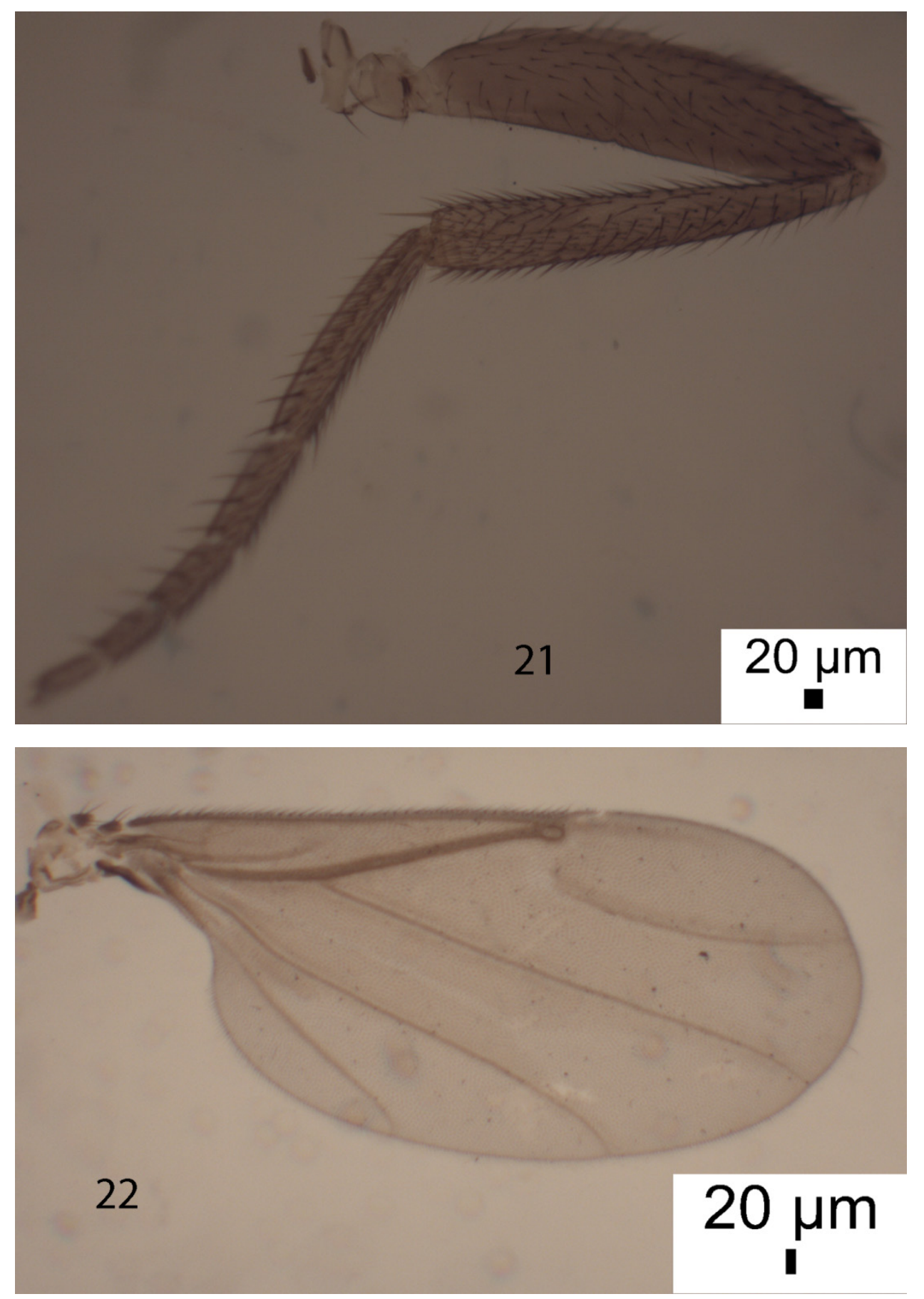

Figures 19-22. Chonocephalus andersoni male. (19) hypopygium (Scale bar $=0.1 \mathrm{~mm}$ ); (20) front leg; (21) hind leg; (22) wing.

Male

A generally brown species with a pale abdominal venter. The brown postpedicel only about 1.1 times as long as its greatest breadth. Palp about 2.1 times as long as greatest breadth. The hairs of the abdominal tergites are fineand are a little longer on T6. Venter hairs smaller and finer. Hypopygium mainly brown and as Fig. 19.Legs brown. Front leg as Fig. 20, the tarsus with a posterodorsal hair palisade on segments 1-4. Hind leg as Fig. 21. Wing (Fig. 22) $1.5 \mathrm{~mm}$ long. Costal index 0.6. Haltere brown.

\section{Material}

Holotype male, Papua New Guinea, Rogut Gorok, 2200 m, 18-23 September 1985, T. Anderson \& R. S. George (CUMZ, 3-140).

Etymology: the name refers to the collector of the specimen. 
Chonocephalus baitabagensis sp. nov.

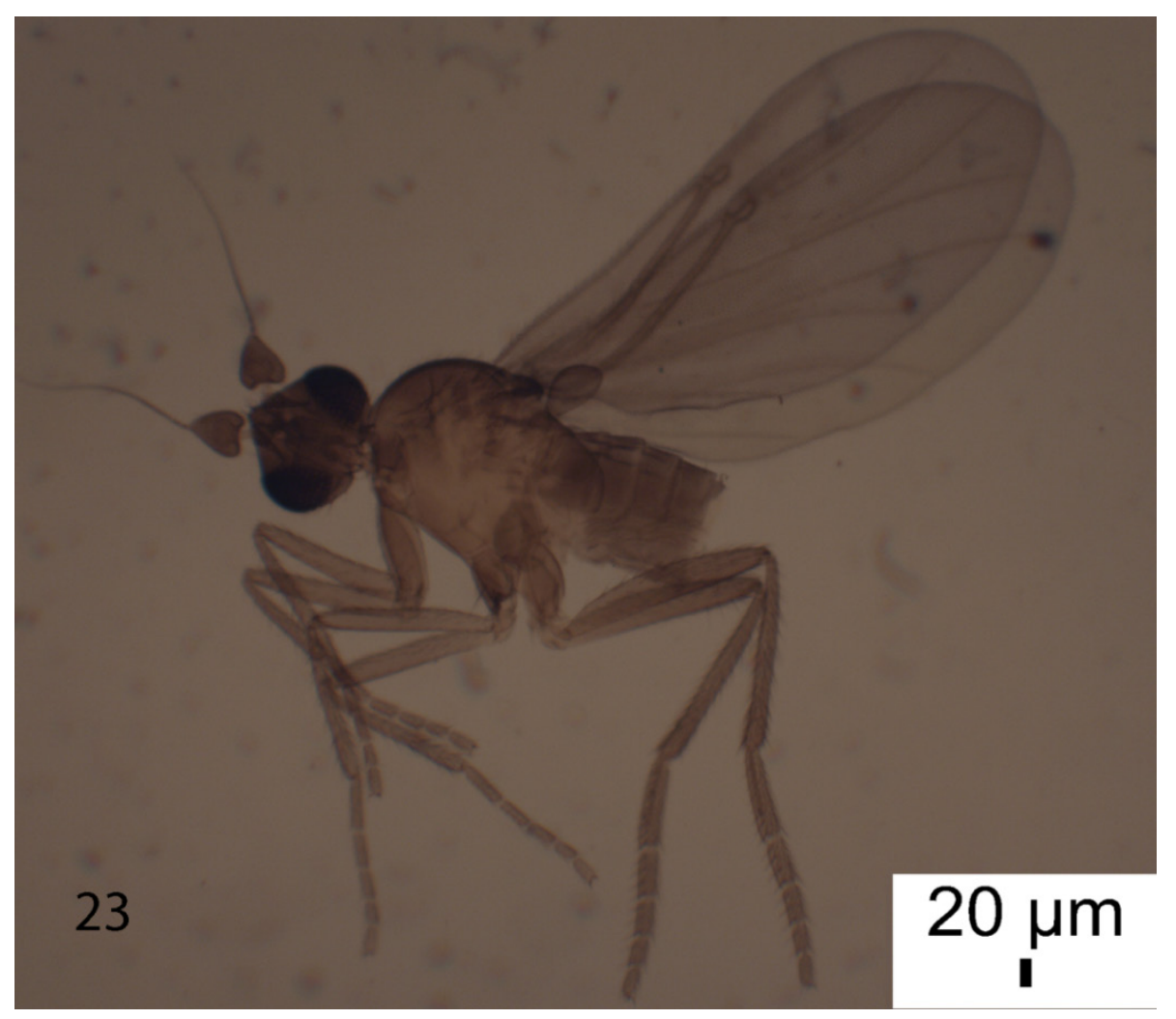

24

$20 \mu \mathrm{m}$ 

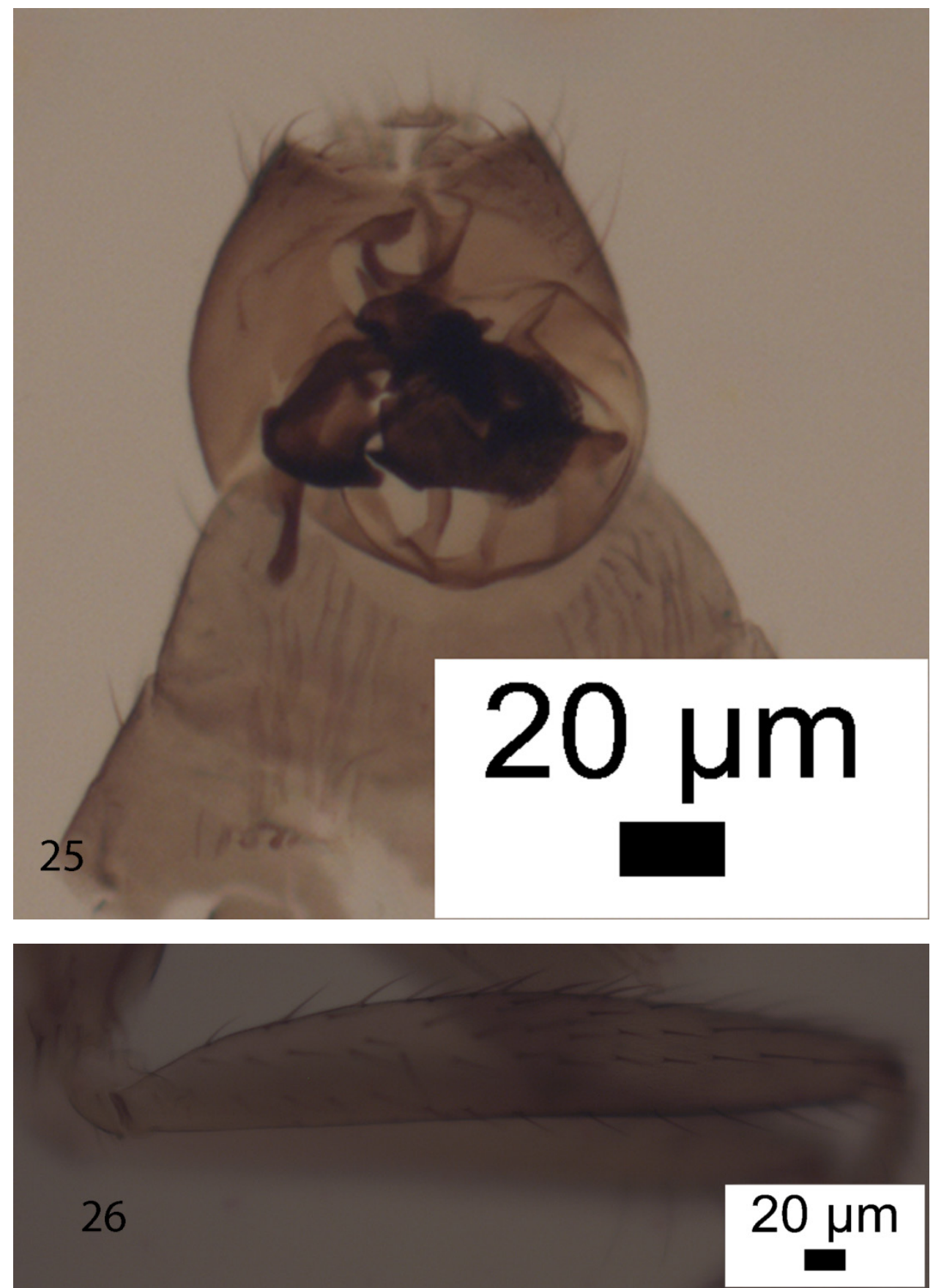

Figures 23-26. Chonocephalus baitabagensis male. (23) whole fly minus hypopygium; (24) ventral face of head; (25) hypopygium; (26) hind femur.

\section{Male}

As Fig. 23. Head as Fig. 24. The hairs of the abdominal tergites, apart from on $\mathrm{T} 1$ and T2, are restricted to the hind margins. Venter hairs fine. Hypopygium as Fig. 25. Legs as Fig. 23. Front tarsus with a posterodorsal hair palisade on segment 1-4 and segment 5 longer than 4. Mid tibia coloured as femur or a little paler. Hind femur as Fig. 26. Wing 1.0-1.1 mm long. Costal index $0.44-0.45$. Tip of vein 3 clearly reaches beyond tip of costa (Fig. 23). Haltere brown.

\section{Material}

Holotype male, Papua New Guinea, Mandang Province, Baitabang Village, Kau Wildlife Area, 50 m, primary forest, 508'S, 145²46'E, 21 November to 22 December 1999, L. Cízek (CUMZ, 29-65).

Etymology: the name refers to the type locality.

\section{Chonocephalus brevisetarum sp. nov.}




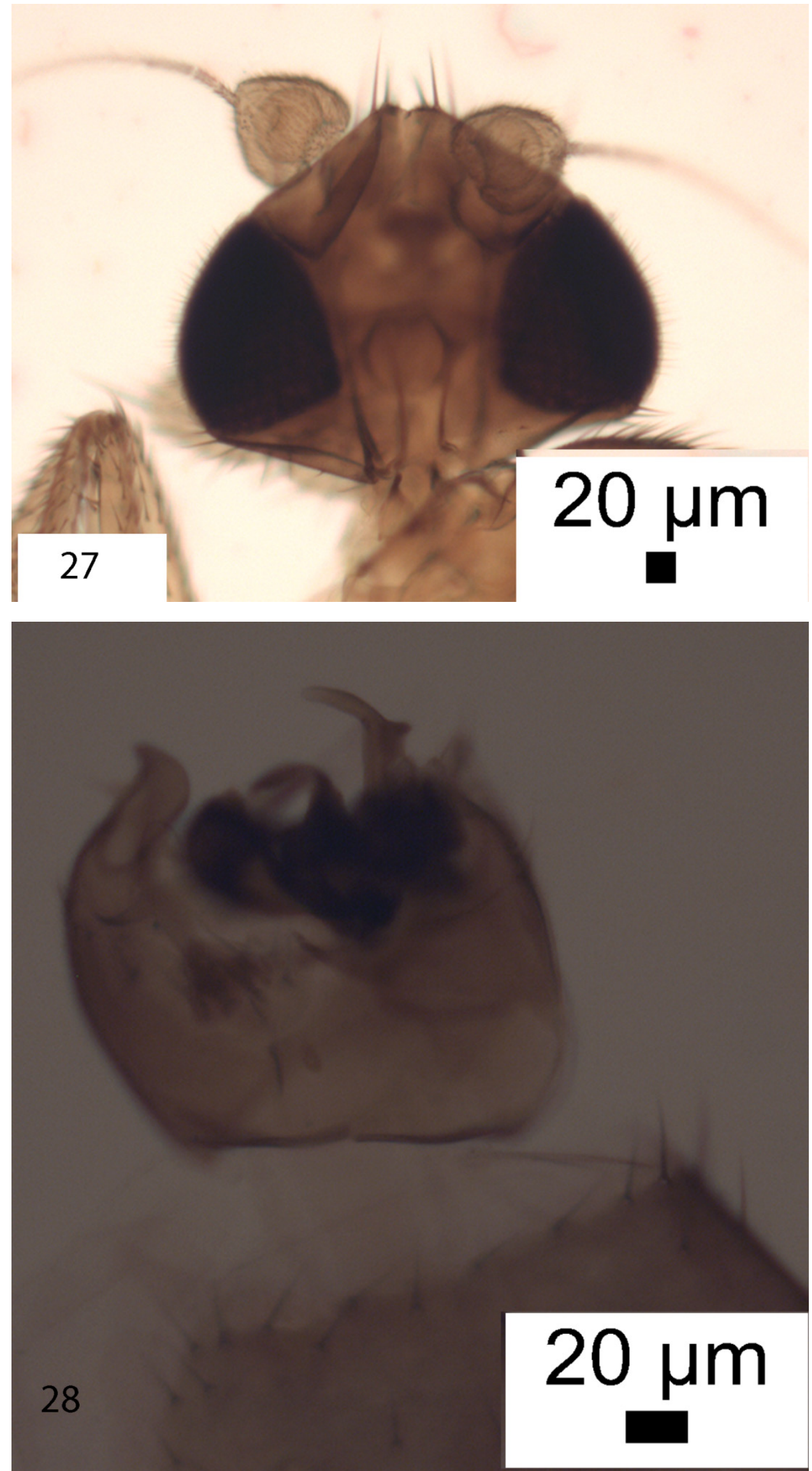




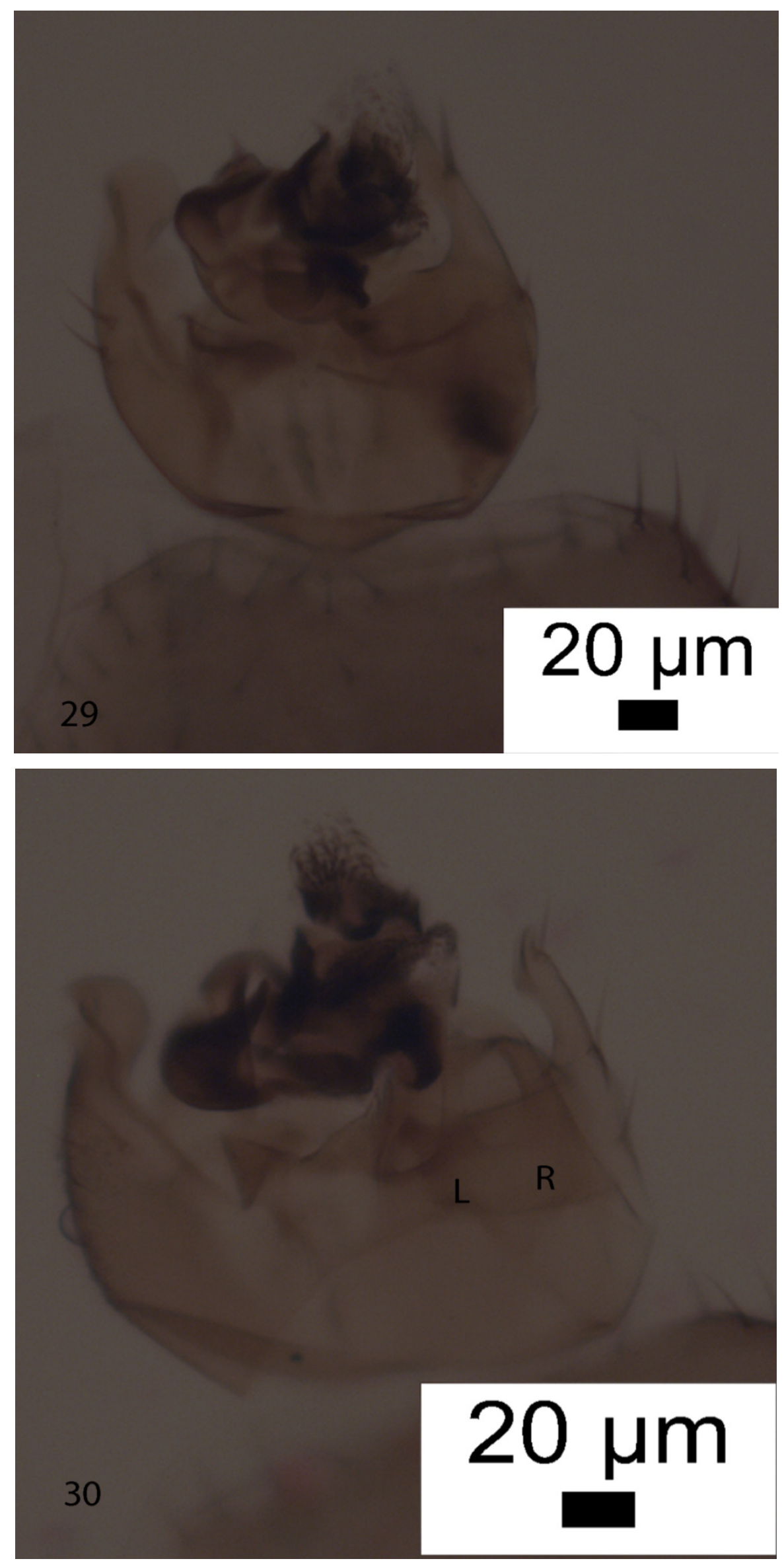



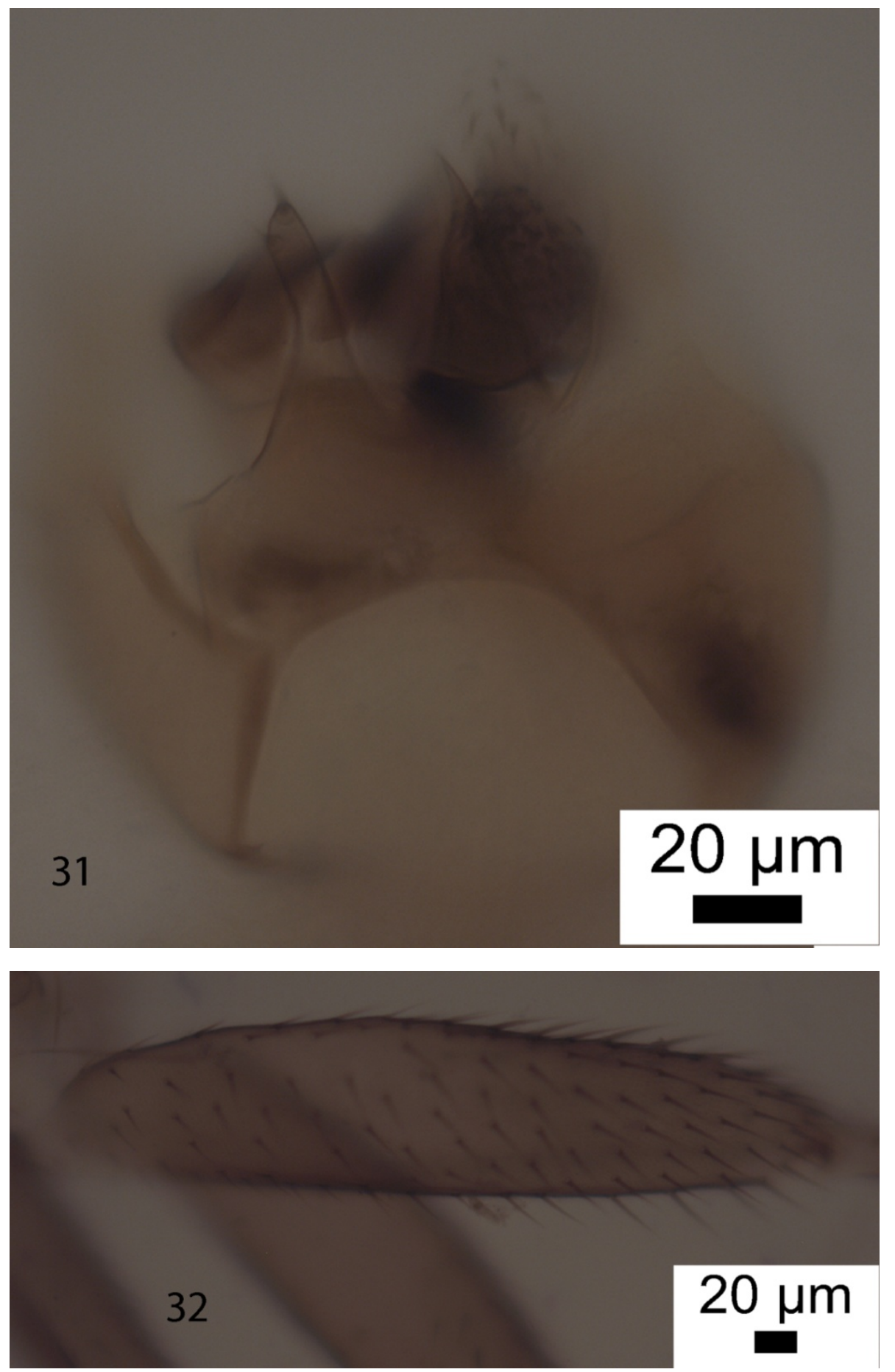


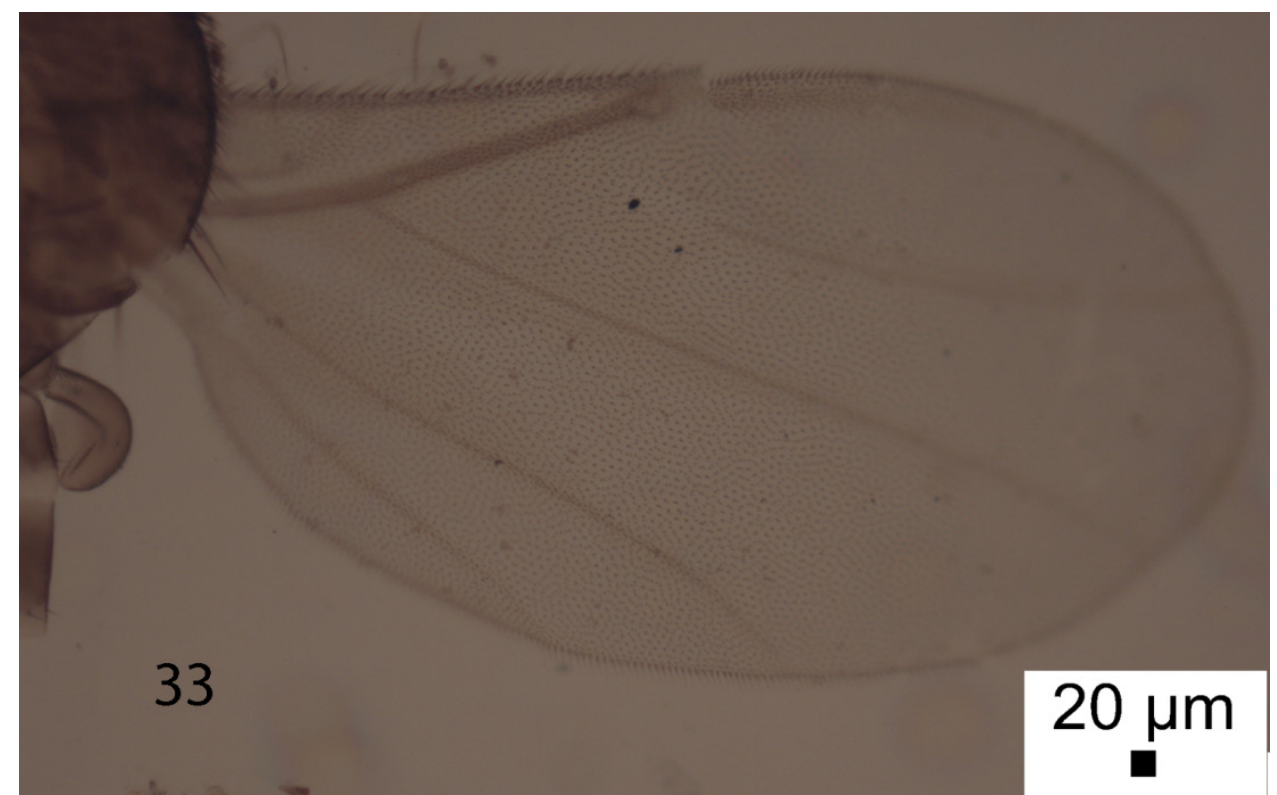

Figure 27-33. Chonocephalus brevisetarum male. (27) head; (28- 31) hypopygium ( 30 - L and R = left and right hypandrial lobes; enlarged in 31); (32) hind femur; (33) wing.

\section{Male}

A generally brown species but often pale. Head as Fig. 27. Palp about 2.5 times as long as greatest breadth with a longer hair at tip (about $0.05 \mathrm{~mm}$ long). The hairs of the abdominal tergites are fine and not restricted to the hind margins. Venter lacks hairs. Hypopygium as Figs 28-31. Legs light brown or paler. Front tarsus with a posterodorsal hair palisade on segments 1 to 4 and segment 5 longer than 4. Hind femur as Fig. 32. Wing as Fig. 33 and 1.0 mm long. Costal index 0.54-0.55. Haltere brown (Fig. 33).

\section{Material}

Holotype male, Fiji, Suva, water trap, January 1997, A. van Harten (CUMZ, 32-71. Paratypes, 6 males as holotype. 1 male, Papua New Guinea, Port Moresby, 25 November 1995, A. van Harten (CUMZ, 2-62).

Etymology: the name refers to the relatively short hairs on the epandrium.

\section{Chonocephalus contrarius sp. nov.}

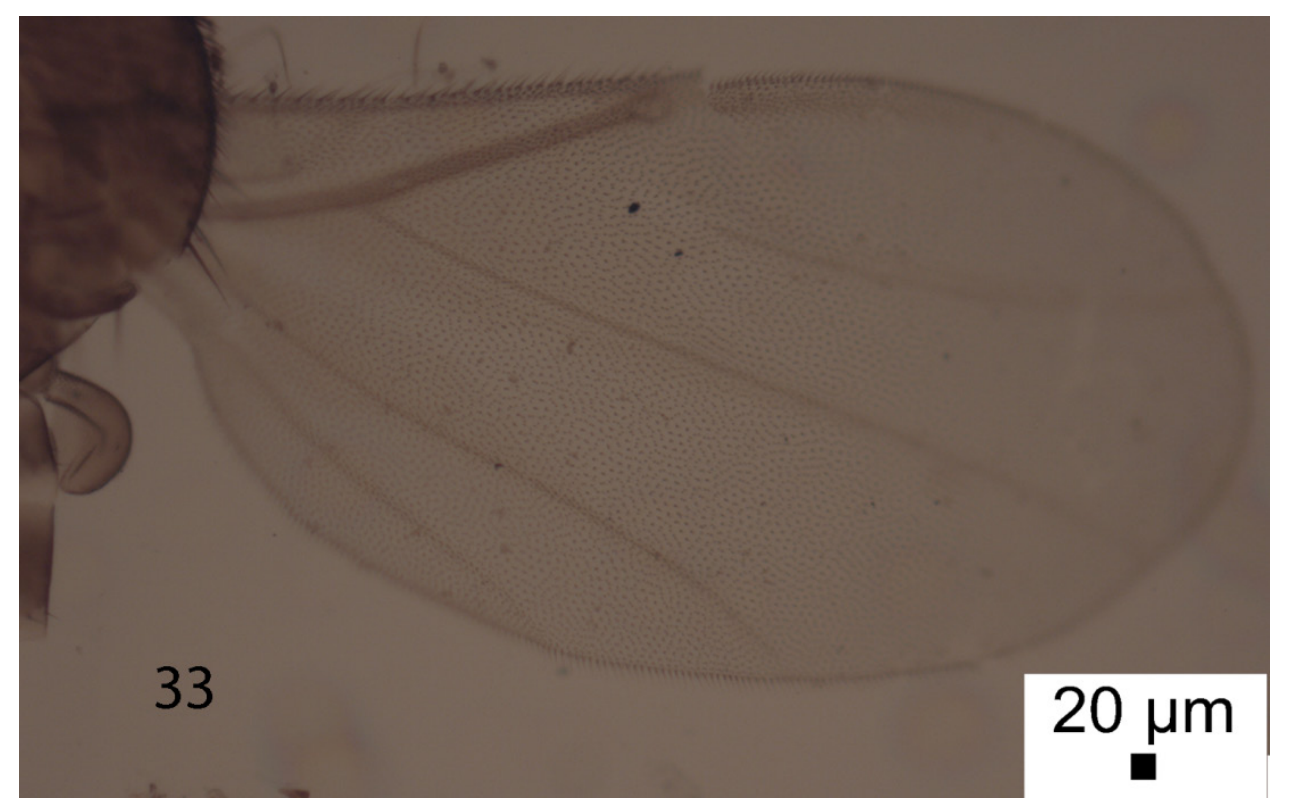



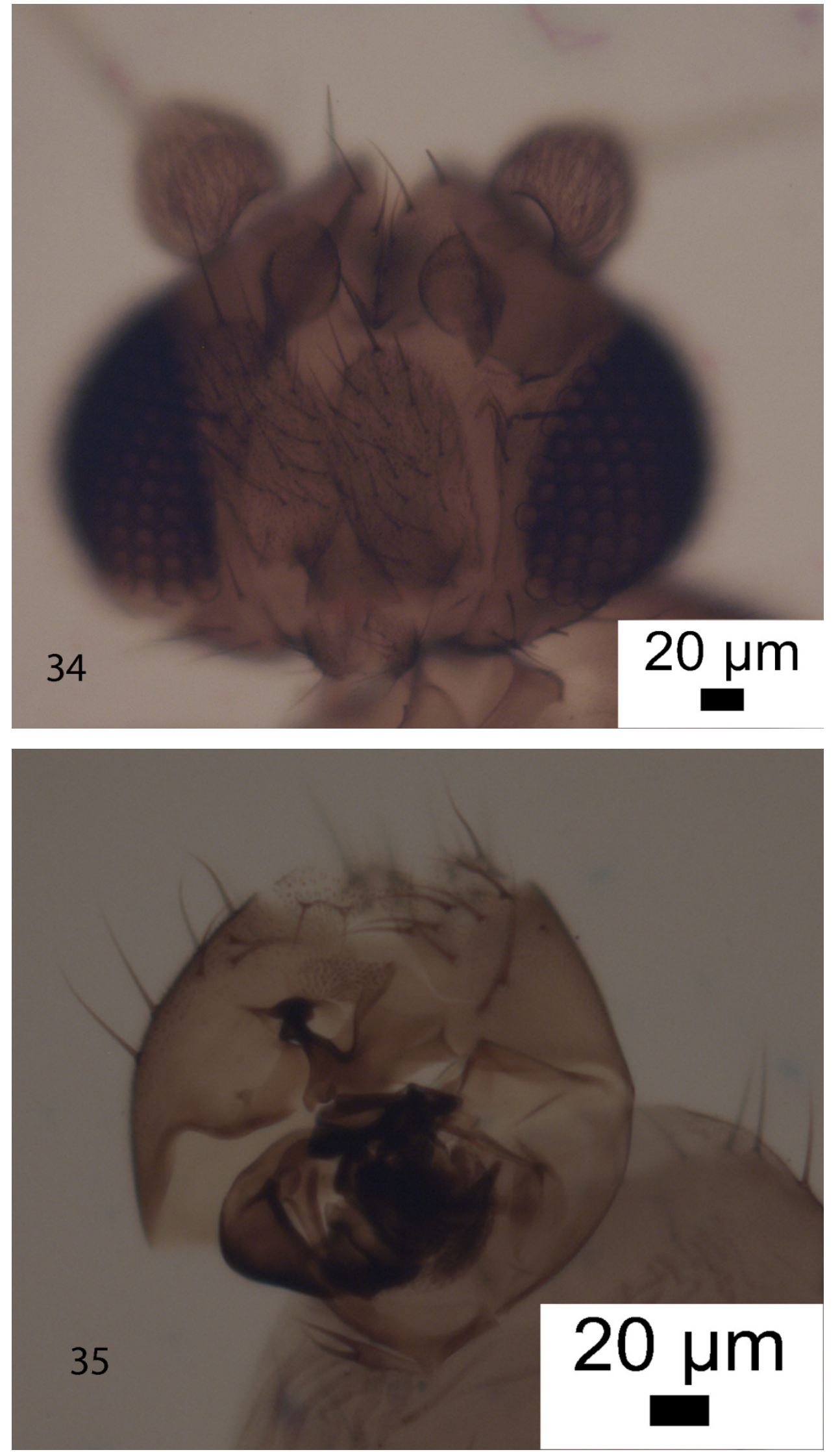

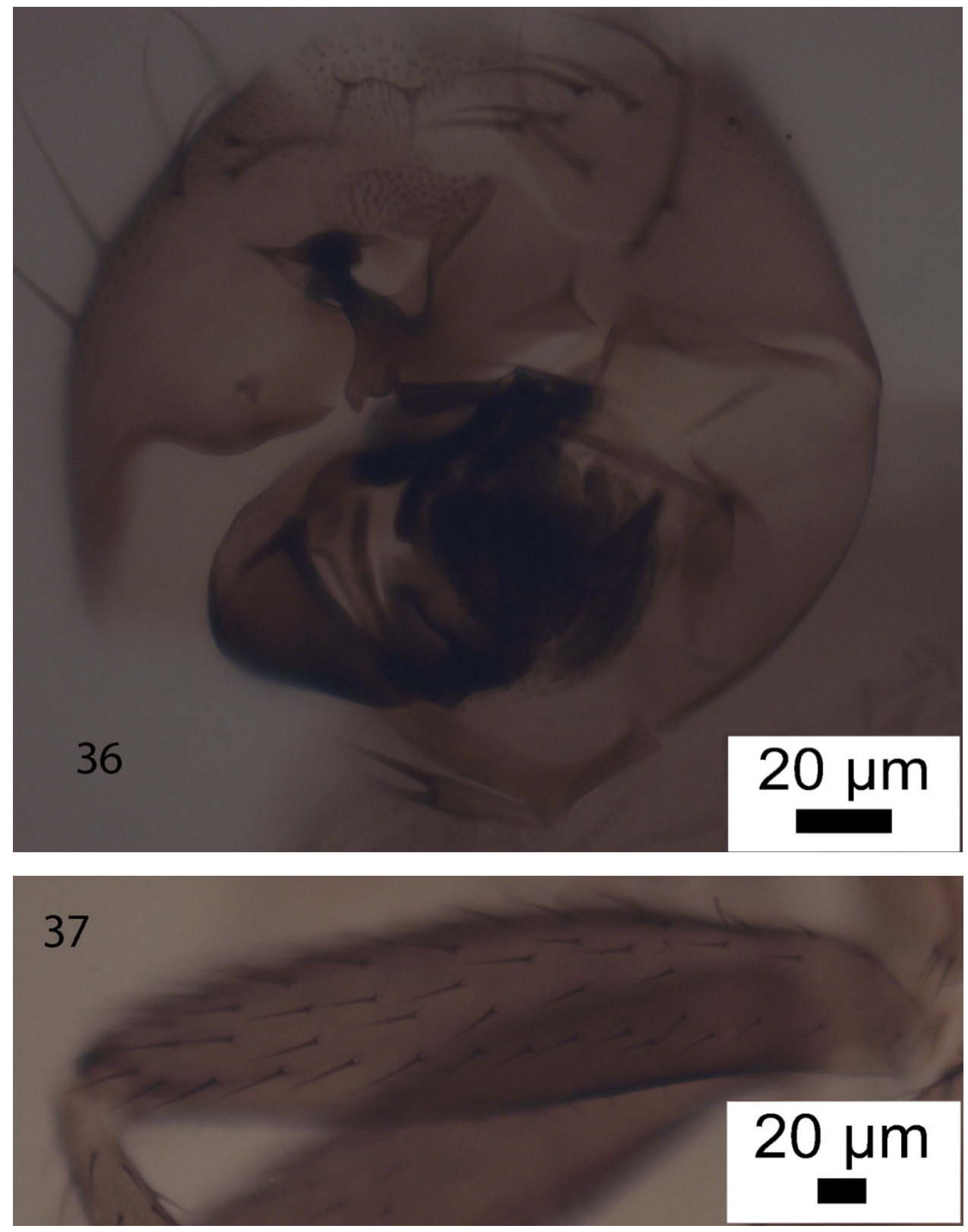

38

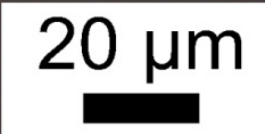

Figure 34-38. Chonocephalus contrarius male. (34) head; ( 35 \& 36) hypopygium; (37) hind femur; (38) tips of costa and vein 3 of wing. 


\section{Male}

A generally brown but not dark species. Head as Fig. 34. Postpedicel about as long as its greatest breadth. Palps as Fig. 34. The hairs of the abdominal tergites are fine and, apart from on T1, are not largely restricted to the hind margins. They are longest on T6. Venter hairs also fine or more so. Hypopygium as Figs 35 and 36. Legs brown but, apart from femora, only pale brown and tarsi even paler. Fronttarsus with posterodorsal hair palisade on segments 1 to 4 and segment 5 longer than 4 . Hind femur as Fig. 37. Wing $0.4 \mathrm{~mm}$ long. Costal index 0.5. Tip of costa and vein 3 as Fig. 38. Thick veins light brown, thin veins a little paler, 7 very pale and membrane tinged brownish grey. Haltere brown.

\section{Material}

Holotype male, Papua New Guinea, Gulf of Ivimka, $7.73^{\circ} \mathrm{S}, 146.76^{\circ}$ E, Malaise trap, 1-10 March 1997, K. Merg (CUMZ $-26-83)$.

Etymology: the name refers to the opposed tips of the costa and vein 3.

\section{Chonocephalus dahli Schmitz}

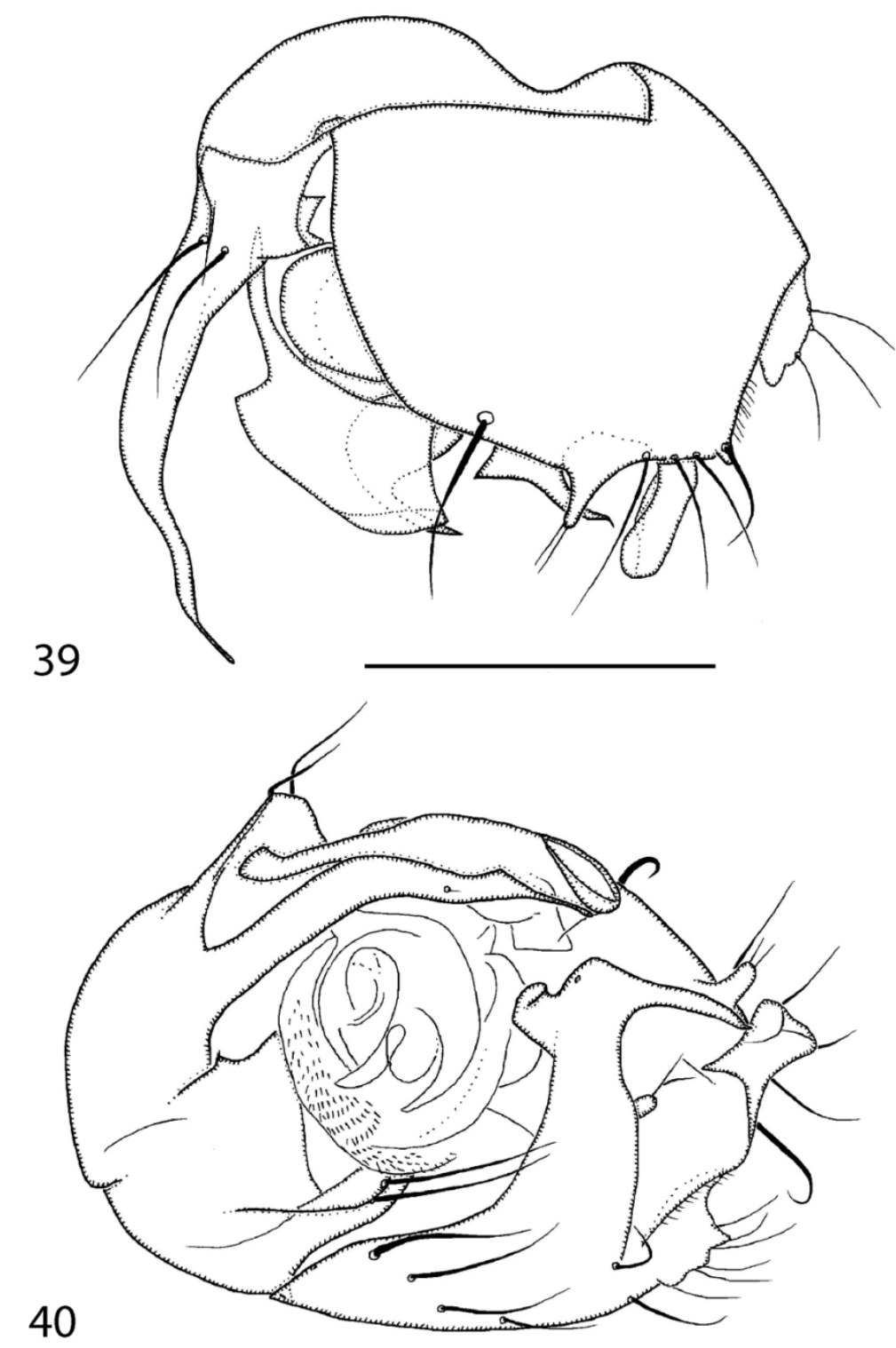

Figures 39-40. Chonocephalus dahli male hypopygium. (39) left face; (40) ventral view. Scale bar $=0.1 \mathrm{~mm}$.

Chonocephalus dahli Schmitz, 1928 [19]: 91.

The type material is mounted on 4 slides without any locality data or collection dates. Five localities and dates were listed by Schmitz. I have designated one of the cotypes (see below) as the lectotype.

A female caught at carrion at the same place and time as the specimen referred to below is assigned to C. secundus below. 
The latter, therefore, may be the unknown female of this species.

\section{Material}

Lectotype male and 11 cotype males, Bismarck Archipelago, (MKB - 27-134).

Natural history

It was reported on carrion (Schmitz [19]).

\section{Chonocephalus dimidiatus Borgmeier}
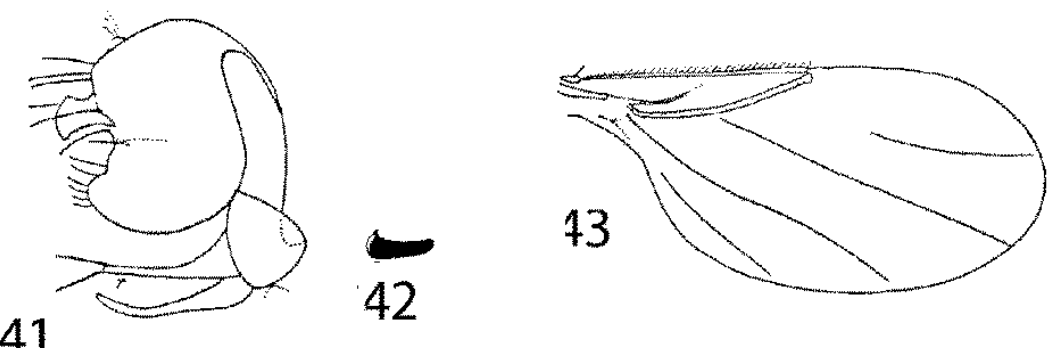

Figure 41-43. Chonocephalus dimidiatus male. (41) right face of hypopygium; (42) spine (S) of left side of epandrium; (43) wing. (From Borgmeier, 1967).

Chonocephalus dimidiatus Borgmeier, 1967 [3]: 208.

\section{Material}

Holotype male, Samoa, Pago Pago, light, W. R. Kellen (USNM - 26-64).

\section{Chonocephalus dorsalis Wandolleck}

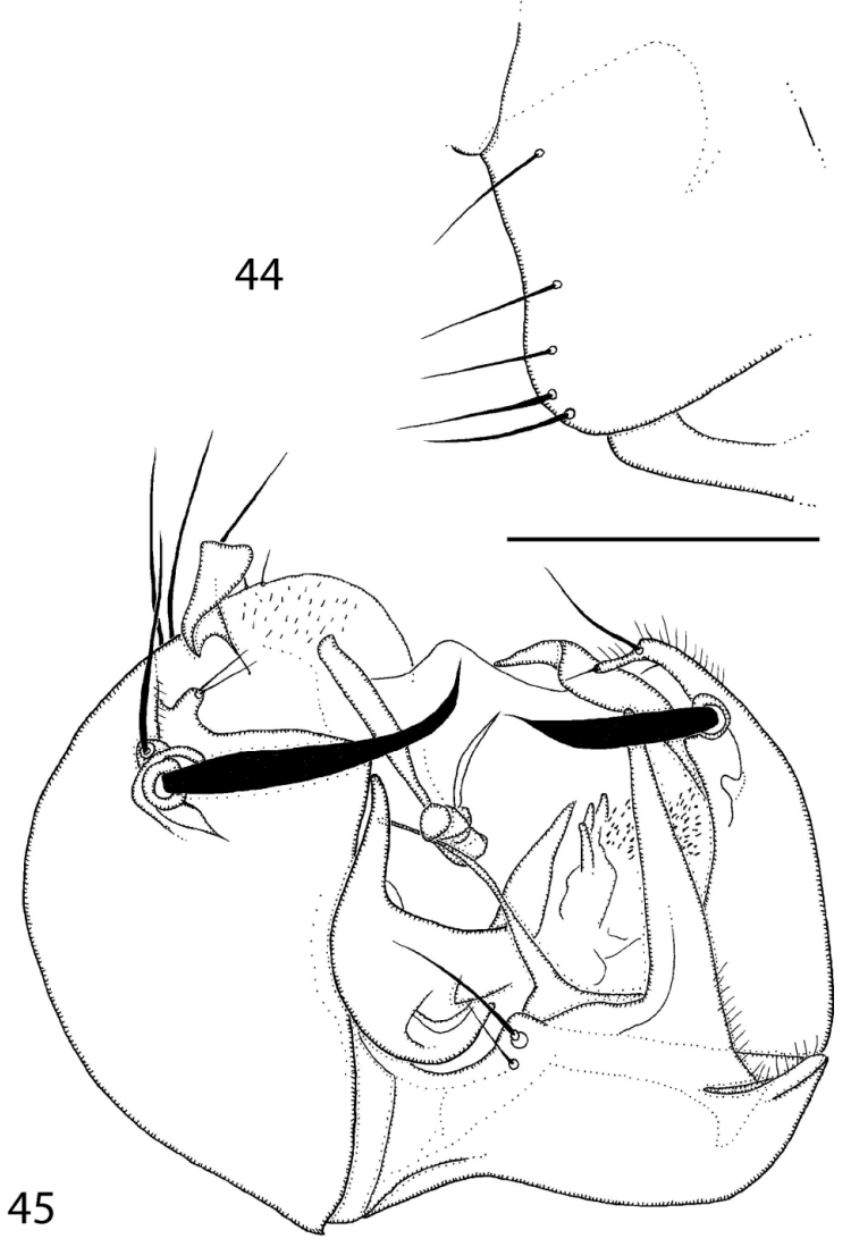



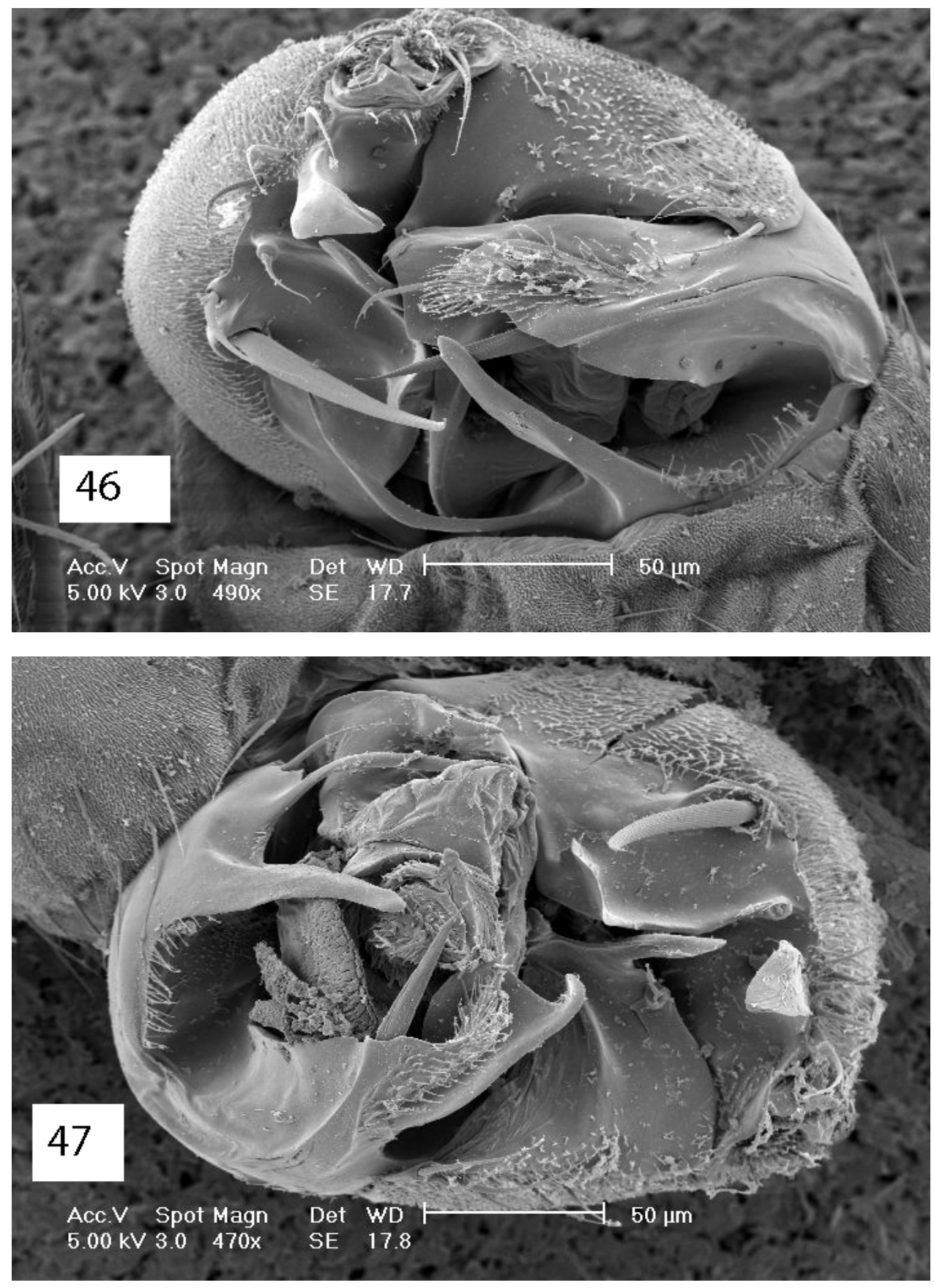


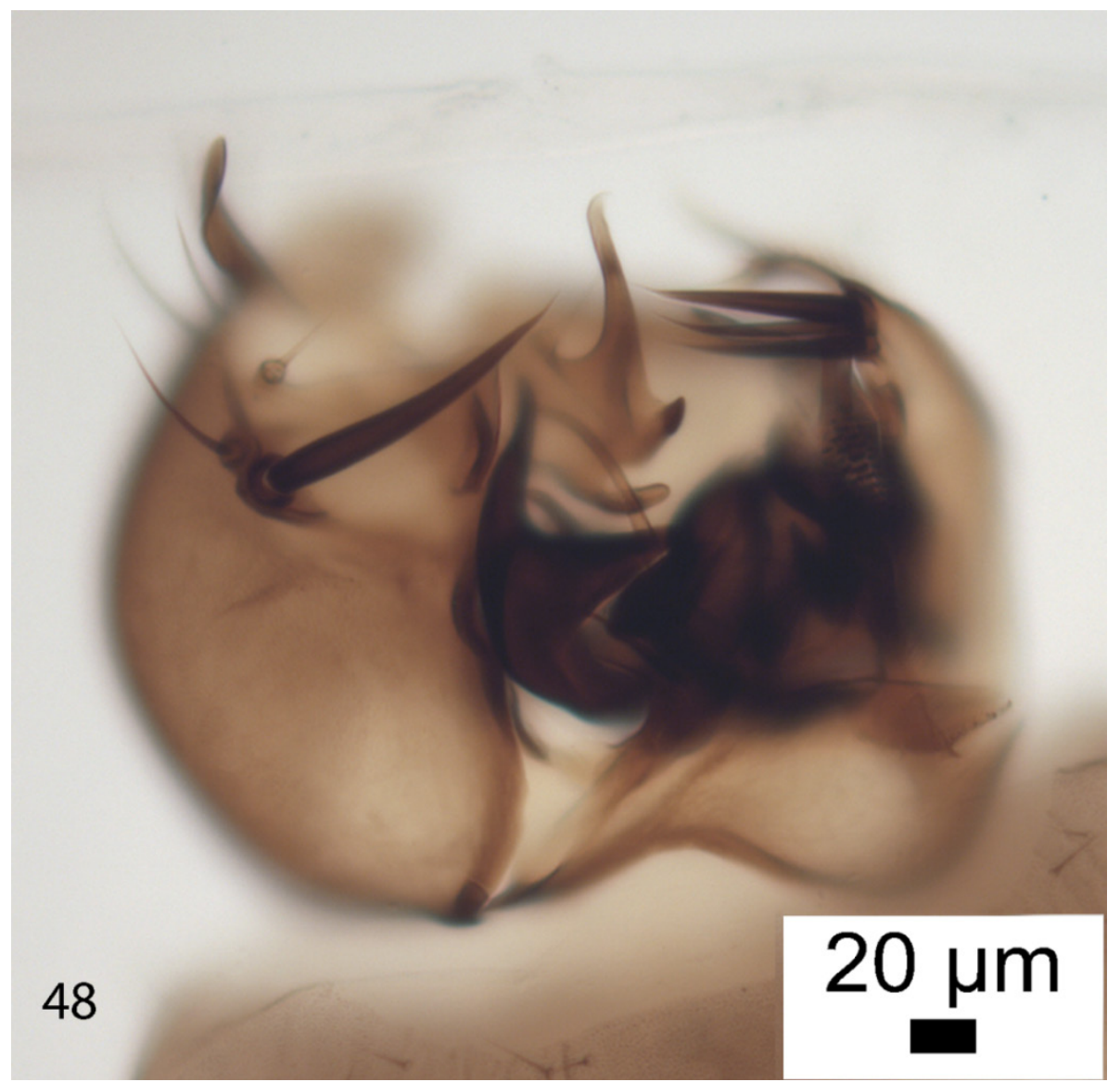

Figures 44-48. Chonocephalus dorsalis male, hypopygium: (44) right side of epandrium; (45) ventral view of hypopygium tilted a little to its right; scale $\mathrm{bar}=0.1 \mathrm{~mm}$; (46-47) ventral views; (48) variant with 3 spines on right gonopod.

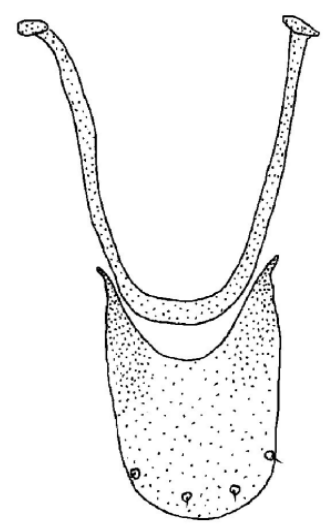

49

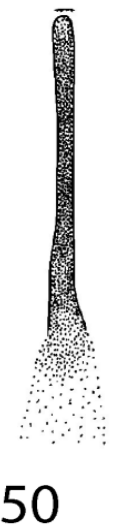

50

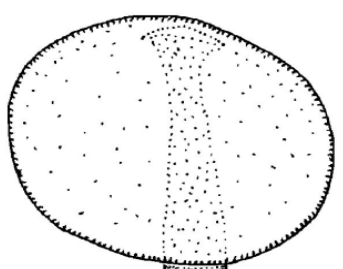

51 


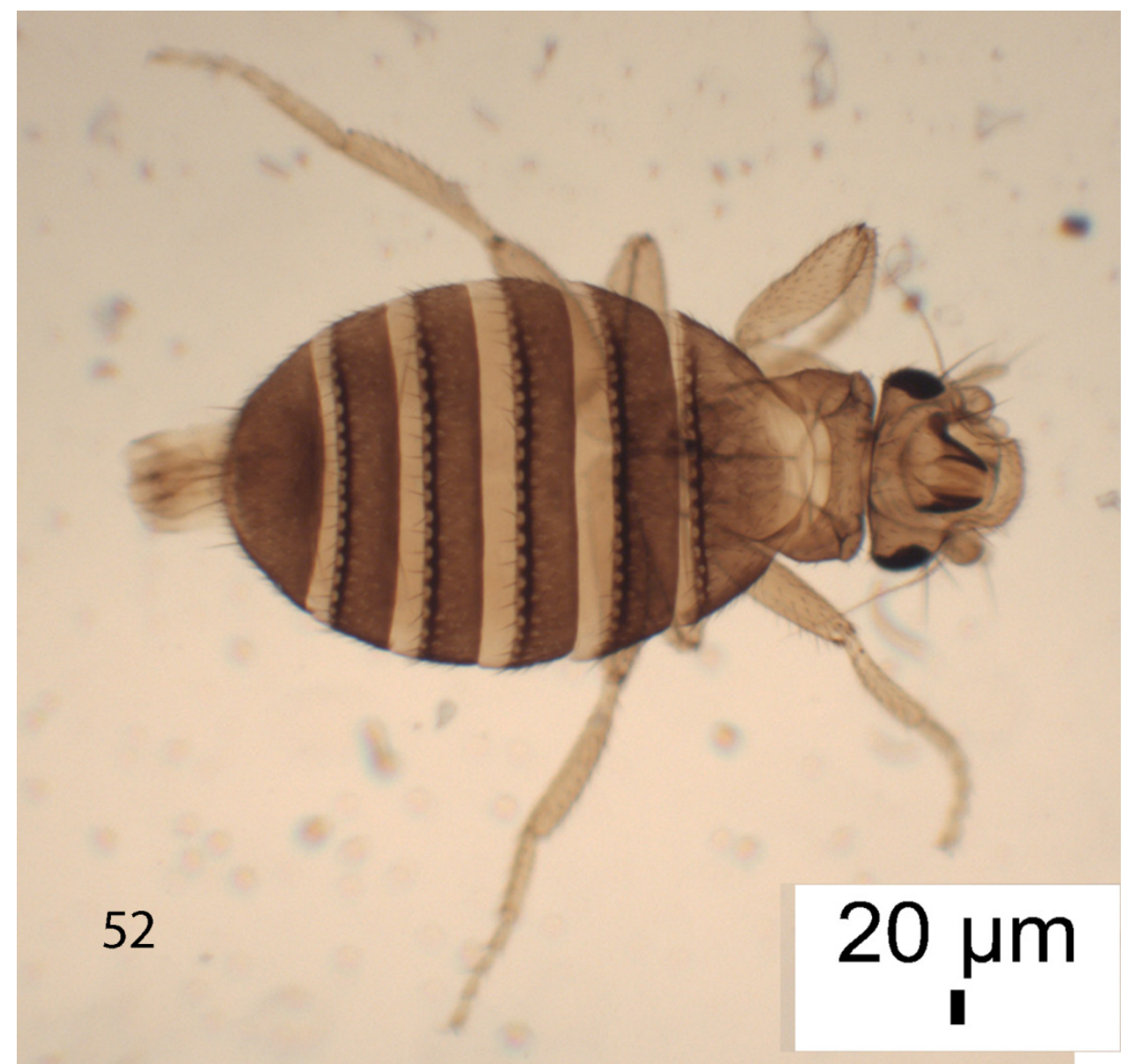

Figures 49-52. Chonocephalus dorsalis female, details of abdomen: (49) tergites 9 and 10; (50) tergite 8; (51) sternite 8, spermatheca and furca (Scale bar $=0.1 \mathrm{~mm}(52)$ dorsal view of female.

Chonocephalus dorsalis Wandolleck, 1898 [22]: 448.

Chonocephalus bispinosus Borgmeier, 1967 [3]: 207. Disney, 2002 [10]: 18.

This is the type species of the genus. It was described from females only. The type material was apparently destroyed by Wandolleck during the course of the dissections undertaken in order to make his detailed anatomical and morphological studies. A female from Fiji has been designated as the neotype (Disney [10]).

One of the many males from Fiji has three equally strong strong spines on the right gonopod where there is normally only one (Fig. 48).

\section{Material}

Type series females, Bismarck Archipelago (destroyed). Female neotype, Fiji, Suva, November-December 1994, A. van Harten (151) (CUMZ, 2-61). 42 males (3 on slides), 2 females, same locality, April to May 1995, A. v H. (CUMZ, 2-62 \& 72); I male, November 1996, A. v H. (CUMZ, 32-67); 14 males (4 on slides); water traps, January 1997, A. v H. (CUMZ, 32-71). 9 males, Henderson Island, June 1986, Deborah Proctor (CUMZ, 9-13); 3 males, North Beach, $24^{\circ} 04^{\prime} \mathrm{S}, 129^{\circ} 07^{\prime} \mathrm{W}$, 17-20 May 1987, W. N. Mathis (CUMZ, 7-23). Holotype male, 4 male paratypes of C. bispinosus, Samoa, Pago Pago, light, January 1958, W. R. Kellen (USNM - 26-64).

\section{Chonocephalus elaboratus sp. nov.}



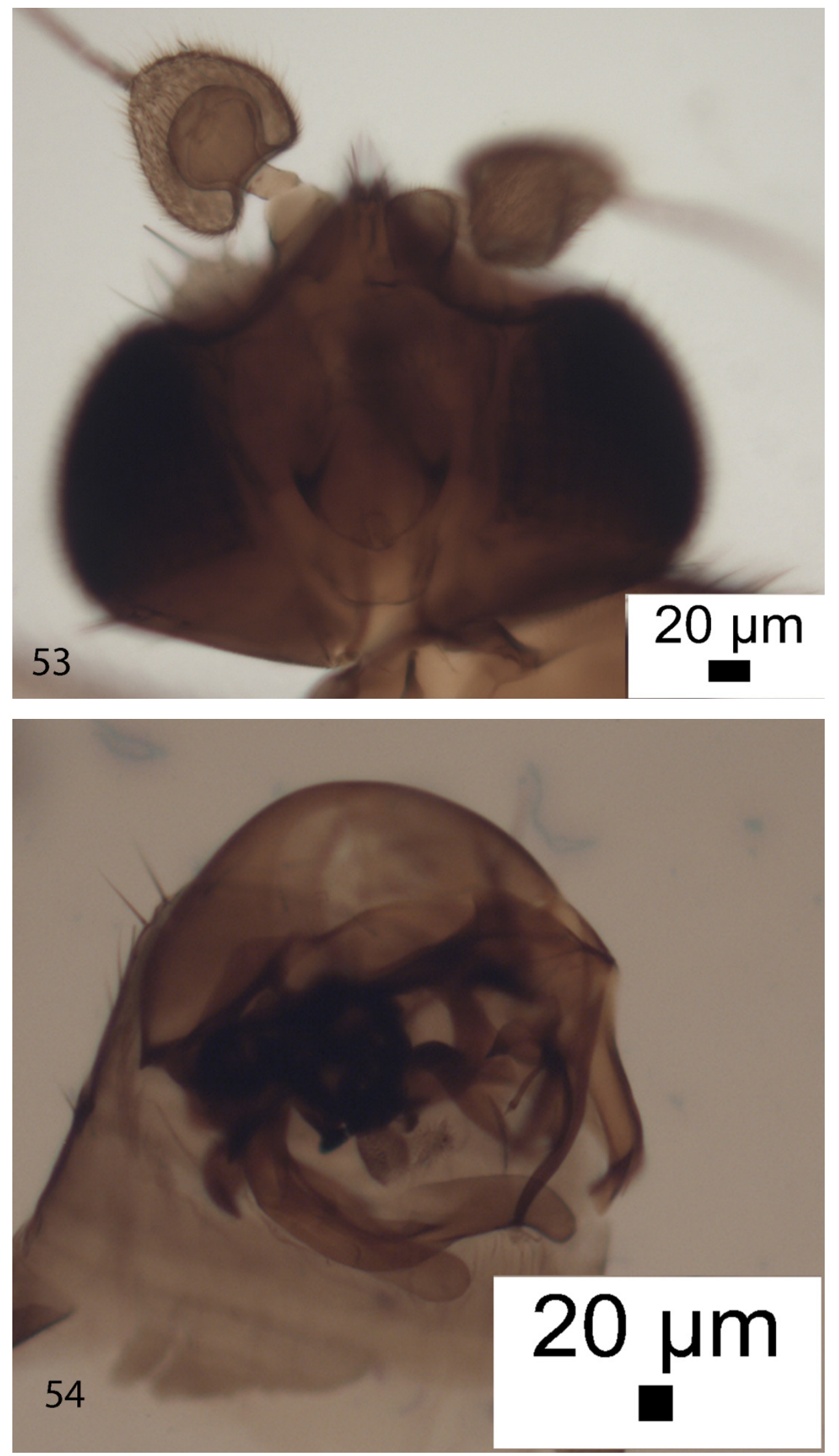

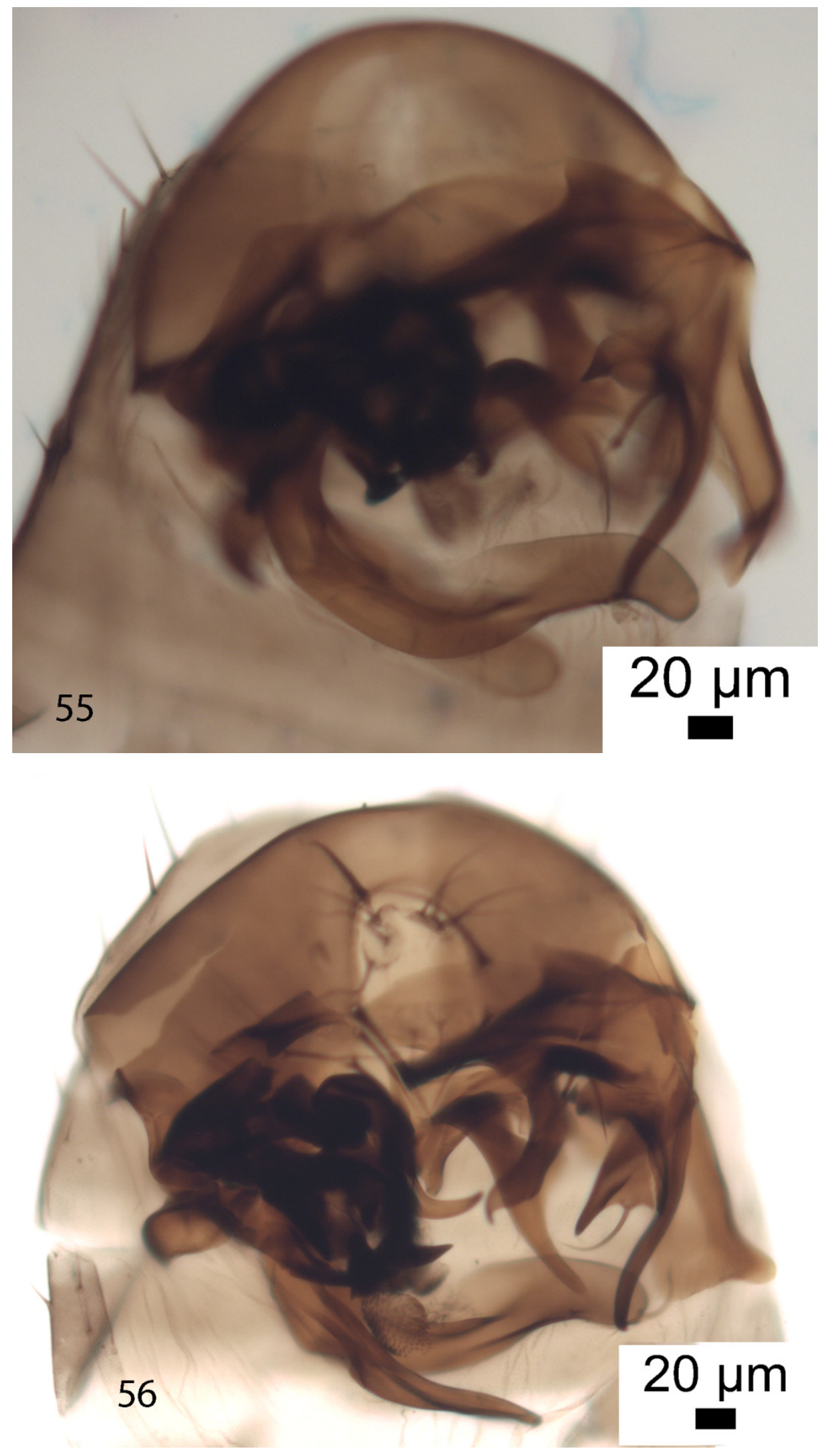

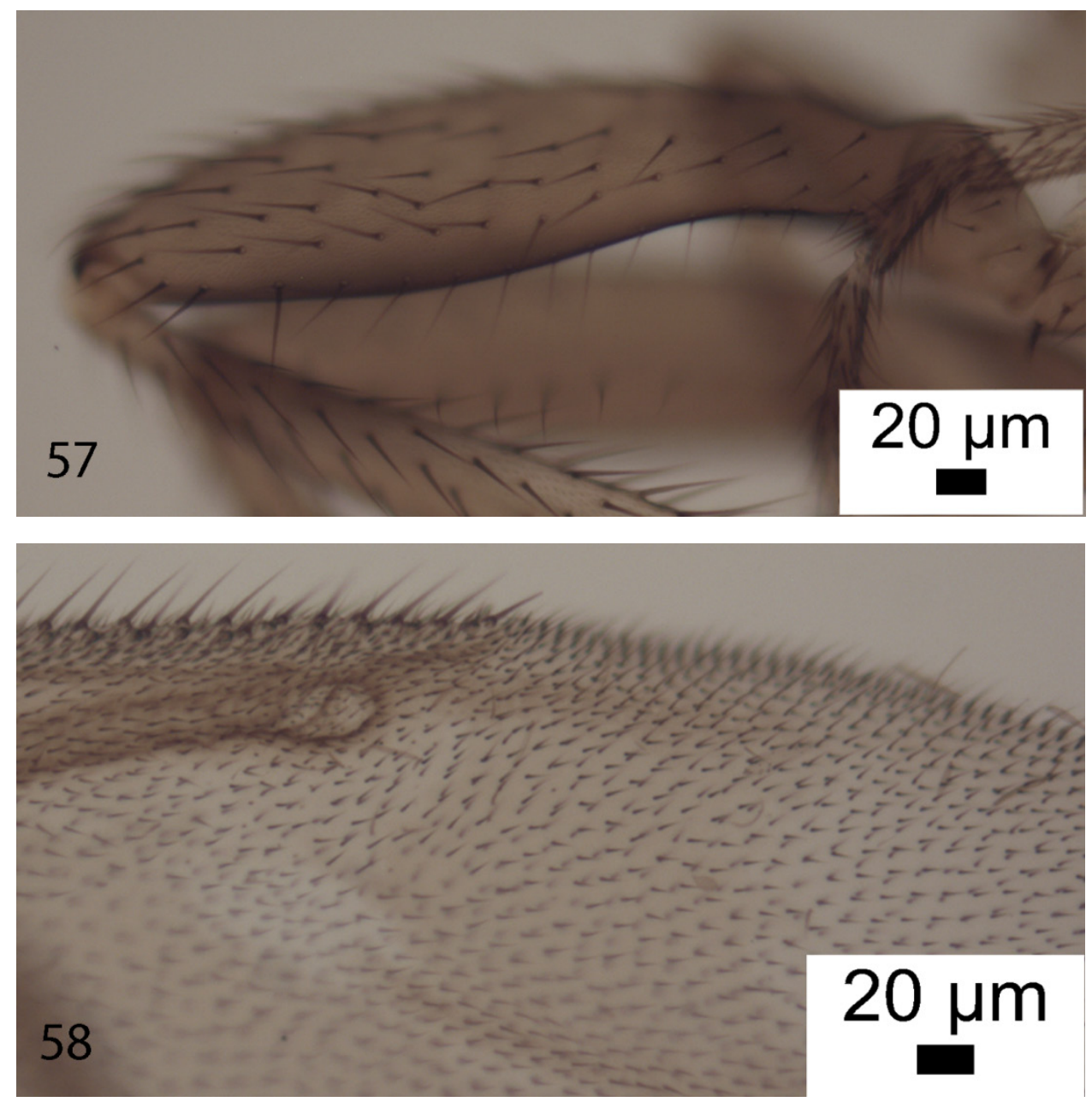

Figure 53-58. Chonocephalus elaboratus male. (53) ventral view of head; (54-56) hypopygium; (57) hind femur; (58) tips of costa and vein 3.

Male

A generally light brown species with a paler brown abdominal venter. Head as Fig. 53. The hairs of the abdominal tergites are fine and largely restricted to the hind margins except on T2 and T6. They are longest on T6. Venter hairs even more fine. Hypopygium as Figs 54-56. Legs with moderately brown femora but otherwise only lightly tinged brown. Front tarsus with posterodorsal hair palisades on segments 1-4 and segment 5 longer than 4 . Hind femur as Fig. 57 . Wing $1.10 \mathrm{~mm}$ long. Costal index 0.72 , with the tip of costa extending beyond tip of vein 3 (Fig. 58). Thick veins light brown, thin veins paler and 7 paler still. Membrane tinged light brownish grey. Haltere brown.

\section{Material}

Holotype male, Papua New Guinea, Gulf of Ivimka, $7.73^{\circ} \mathrm{S}, 146.76^{\circ} \mathrm{E}$, Malaise trap, 9 December 1996 to 10 January 1997 , K. Merg (CUMZ - 26-85). Paratype male, same locality, 110 m, 1-8 December 1996, R. Snelling (LACM, 26-71).

Etymology: the name refers to the elaborate hypopygium.

\section{Chonocephalus elongatus Schmitz}



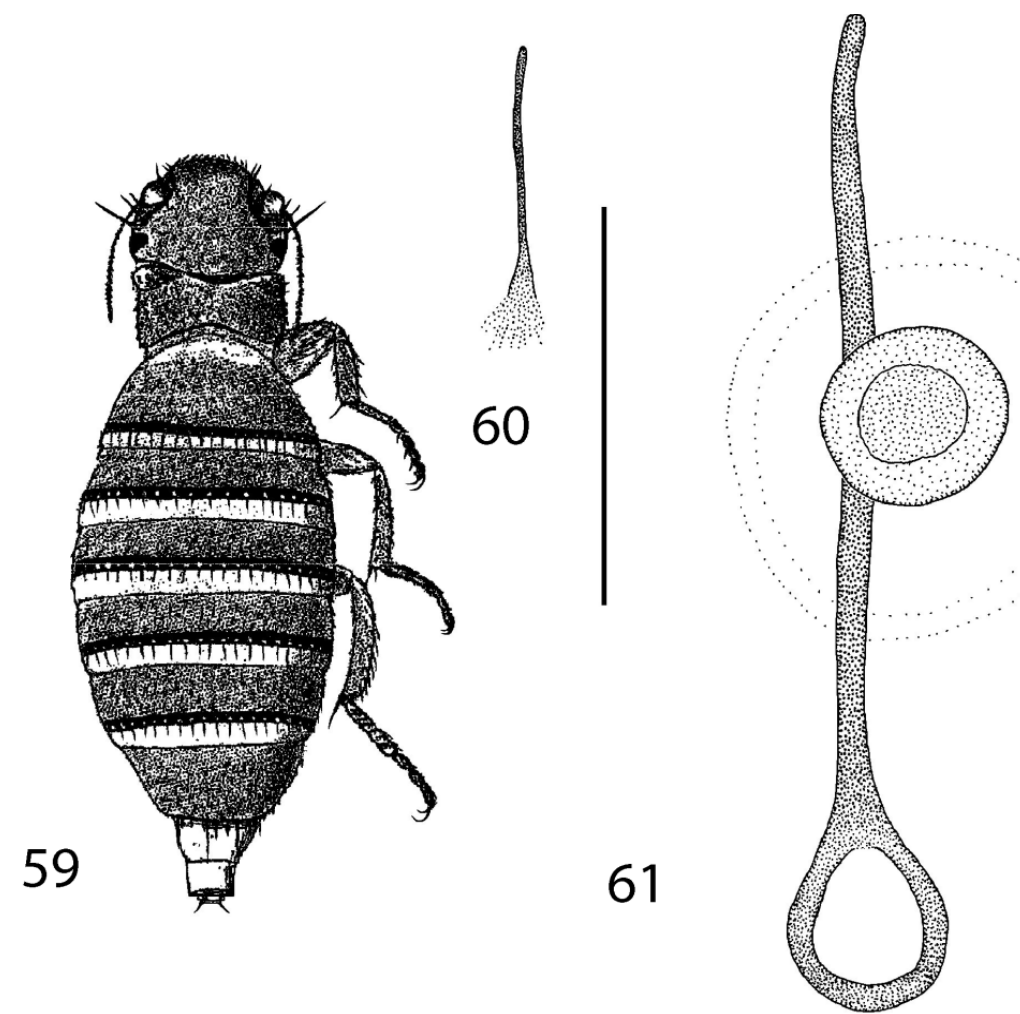

Figures 59-61. Chonocephalus elongatus female. (59) whole fly from above, with legs of left side omitted) (From Schmitz, 1950); (60) tergite 8; (61) sternite 8 , spermatheca and presumed furca. Scale bar for 60 and $61=0.1 \mathrm{~mm}$.

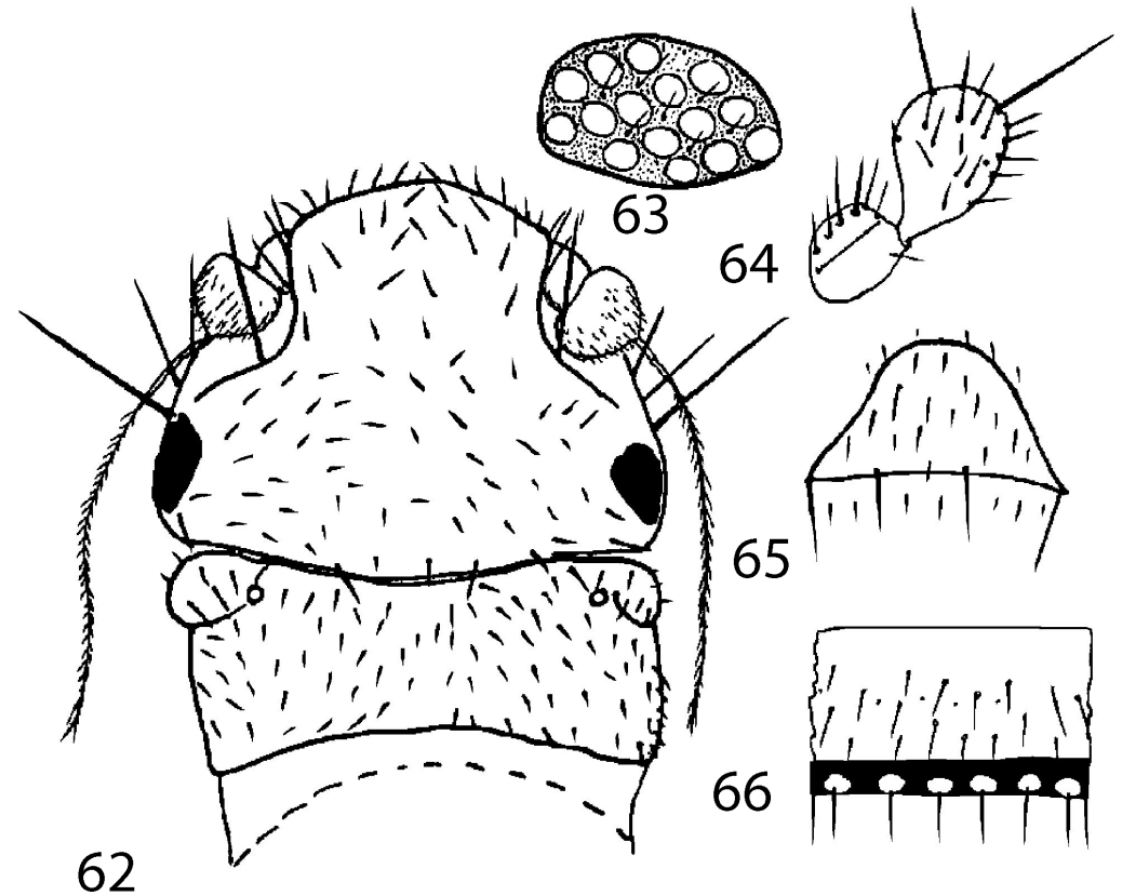

Figures 62-66. Chonocephalus elongatus female. (62) head and thorax from above; (63) eye enlarged; (64) palp; (65) sternite 7; (66) median region of an abdominal tergite. (After Schmitz, 1950).

Chonocephalus elongatus Schmitz, 1950 [20]: 21.

Two females on separate slides (in the MKB) were both labelled 'Holotype'! One of these has since been labelled as a paratype (Disney [10]).

Material

Holotype female, paratype female, New Guinea, Tinschhafen, under bark near termite nest, 16 May 1944, F. S. Ross 
(MKB - 27-134).

\section{Natural history}

The type series was from a nest of a termite.

Chonocephalus fastigatus sp. nov.
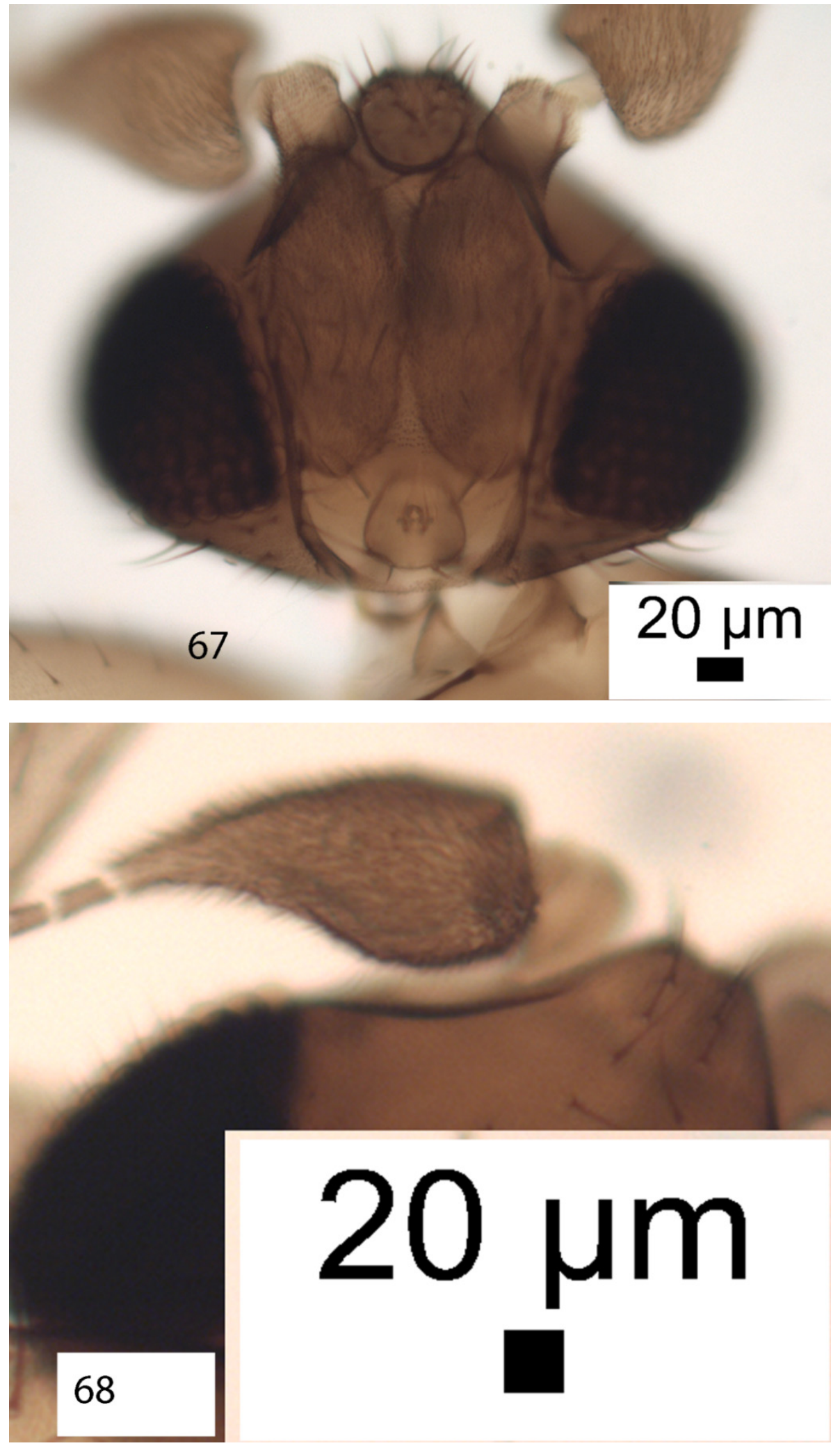

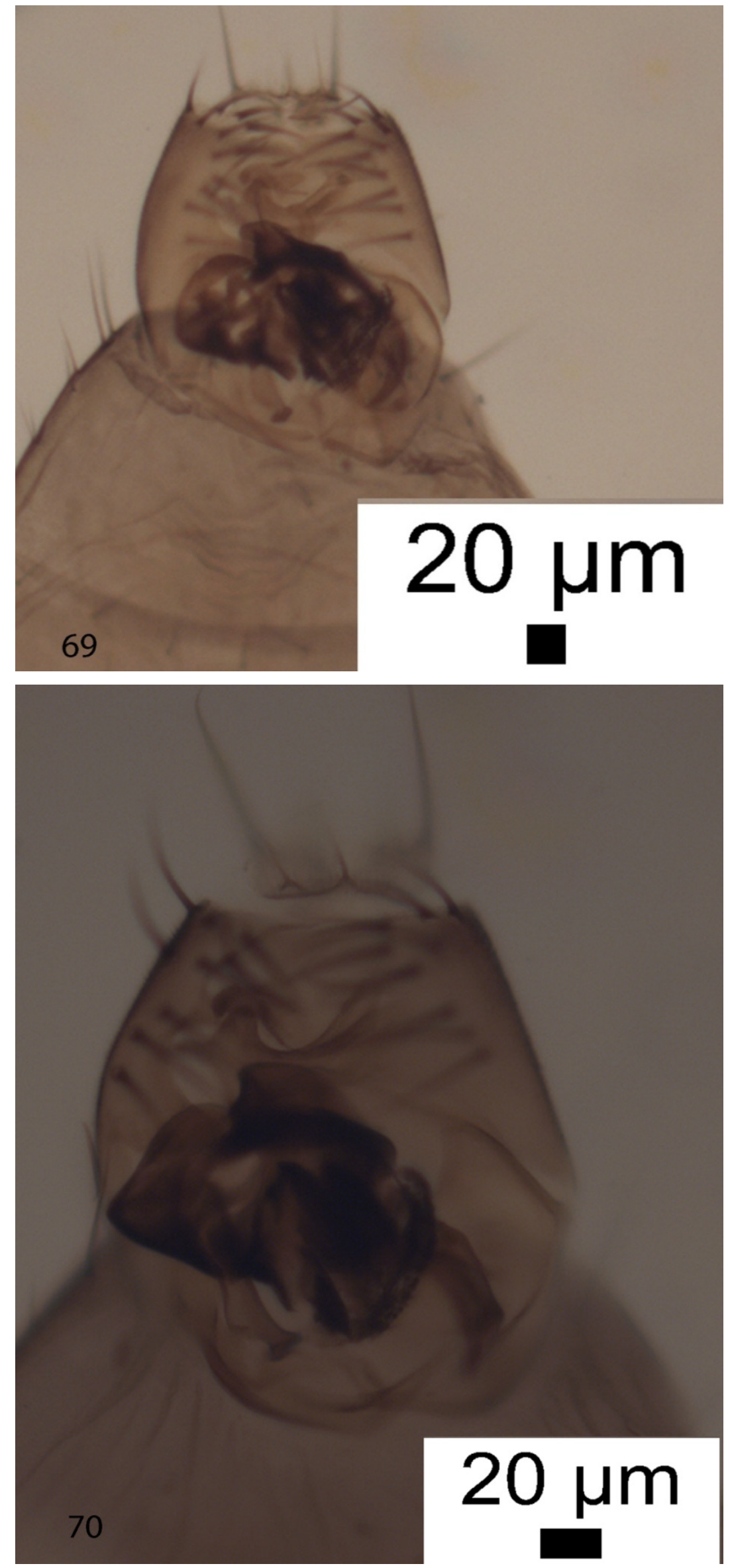

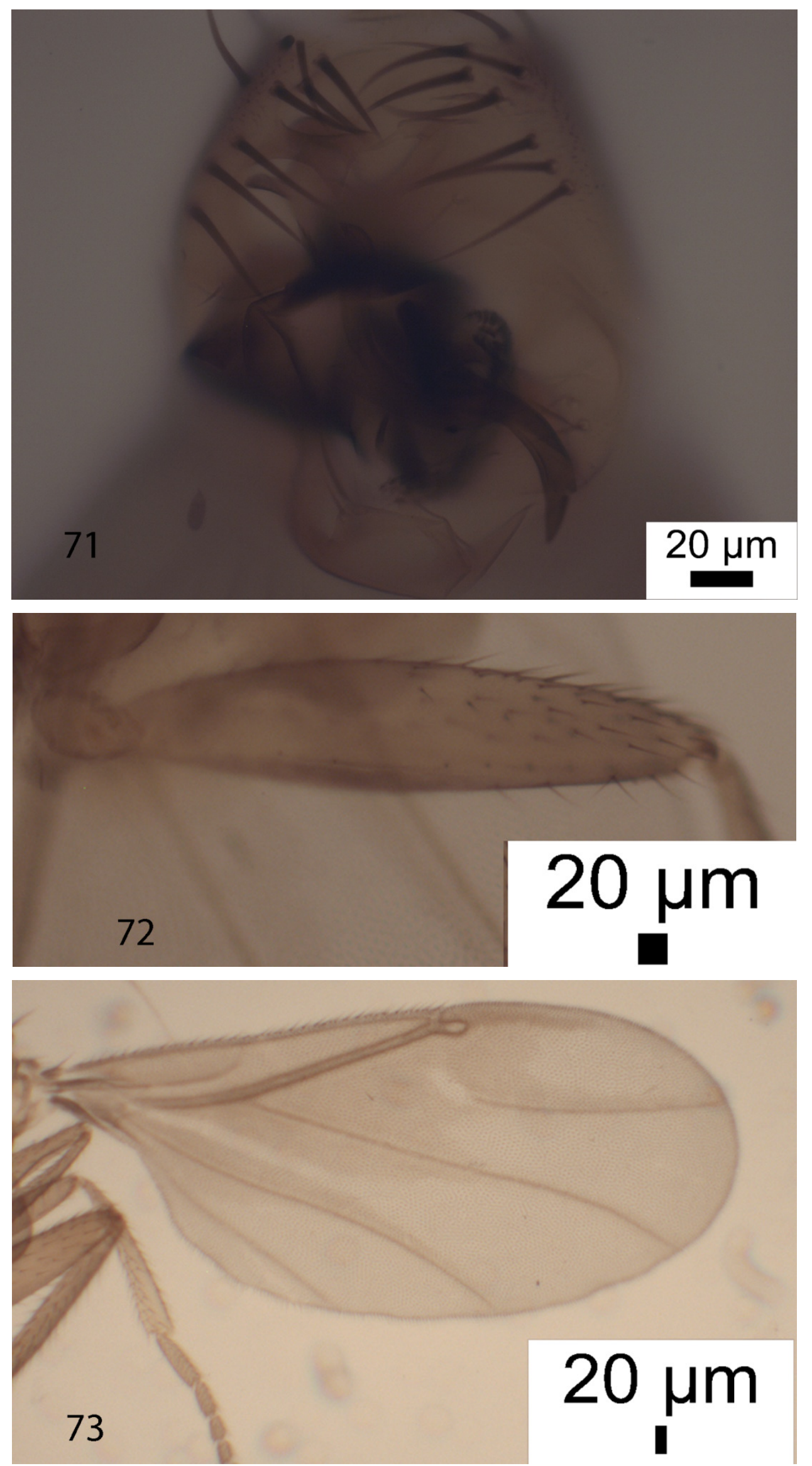

Figures 67-73. Chonocephalus fastigatus male. (67) palps; (68) antenna; (69-71) hypopygium; (72) hind femur; (73) wing. 


\section{Male}

A generally brown species, but sometimes somewhat pale, and venter only lightly tinged. Postpedicel as Fig. 68. Palps as Fig. 67. The hairs of the abdominal tergites 2 to 6 are fine and, apart from on T6, are largely restricted to the hind margins. They are longest on T6. Venter hairs very fine and short. Hypopygium as Figs 69-71. Legs with brown hind femora and the rest lightly tinged brown apart from pale tarsi. Front tarsus with posterodorsal hair palisades on segments 1-4 and segment 5 longer than 4. Hind femur as Fig. 72. Wing 1.16-1.17 mm long and as Fig. 73. Costal index 0.56-0.57. Haltere brown.

\section{Material}

Holotype male, Papua New Guinea, Gulf of Ivimka, $7.73^{\circ} \mathrm{S}, 146.76^{\circ} \mathrm{E}$, Malaise trap, 9 December 1996 to 10 January 1997 , K. Merg (CUMZ - 26-84). Paratypes, 1 male as holotype except, 2 males, same locality, 10-20 March 1997 (CUMZ, 26-83), 1 male as holotype except, 1-8 December 1996, R. Snelling (LACM, 26-71); 2 males as holotype except, 30 January to 10 February 1997, K. Merg (LACM, 26-72). I male, Mandang Province, Baitabang Village, Kau Wildlife Area, 50 m, primary forest, 508'S, $145^{\circ} 46^{\prime} \mathrm{E}, 10$ October to 8 November 1999, L. Cízek (CUMZ, 29-65).

Etymology: the name refers to the pointed right gonopod.

\section{Chonocephalus gonocurvatus sp. nov.}

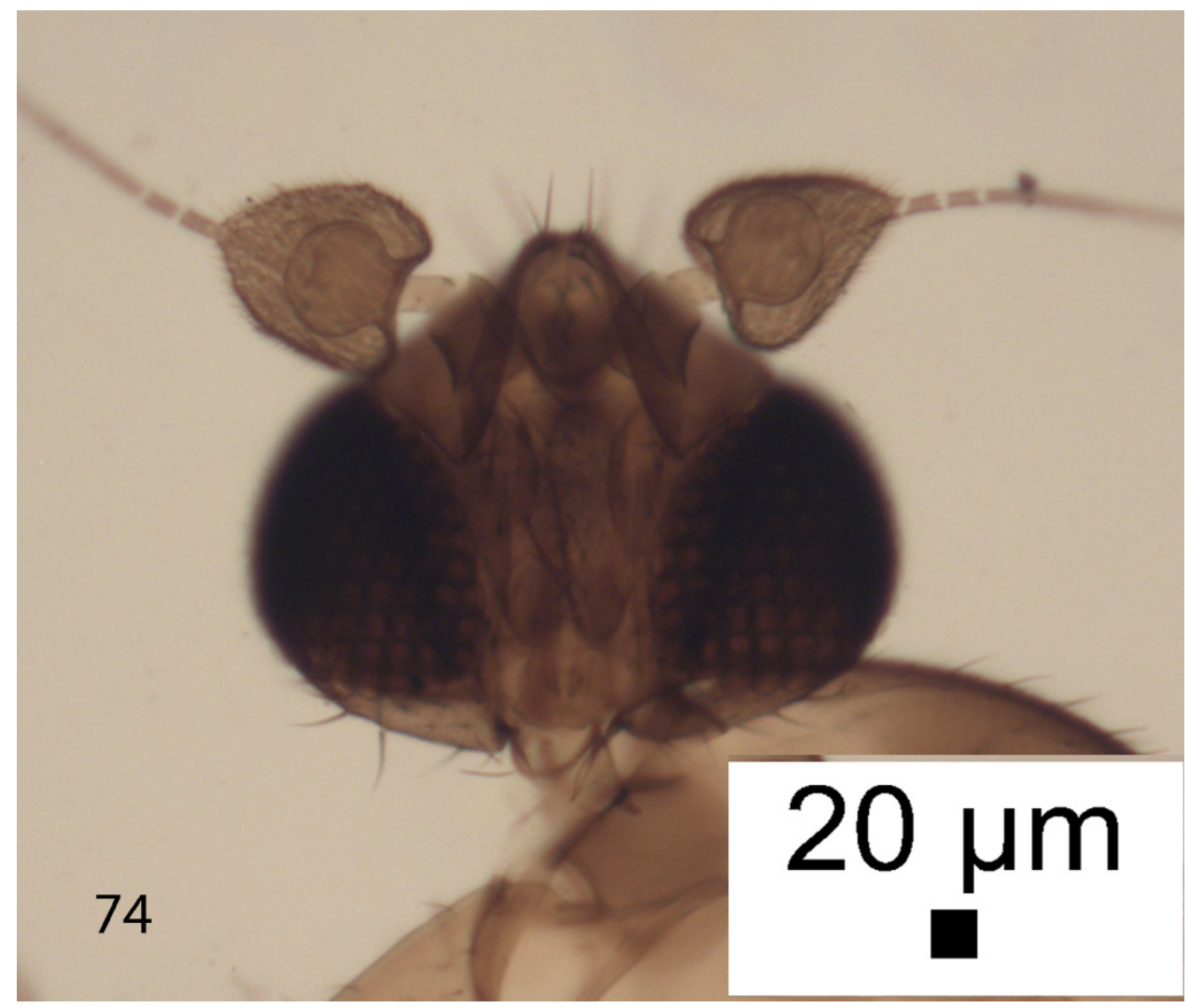



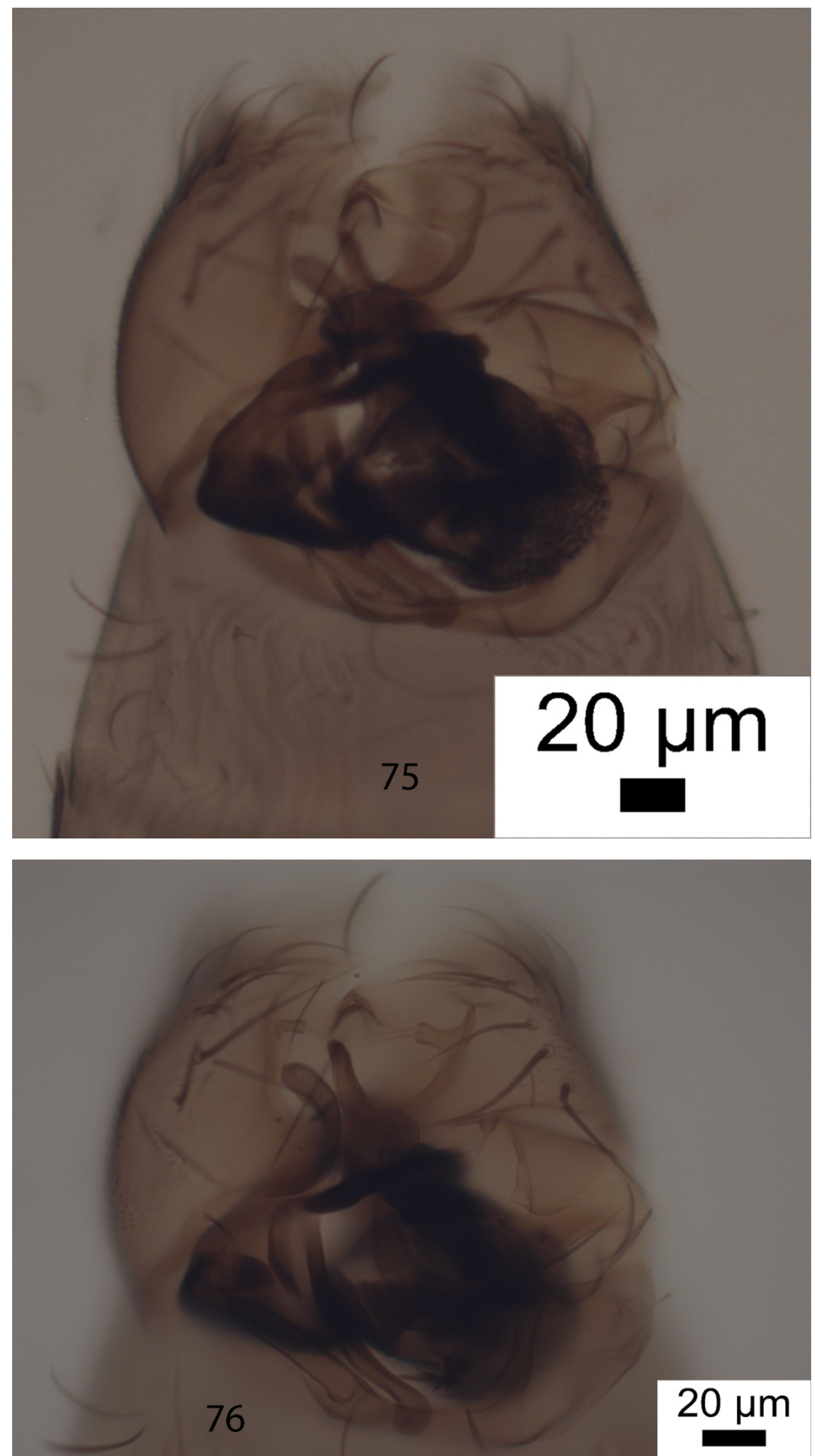

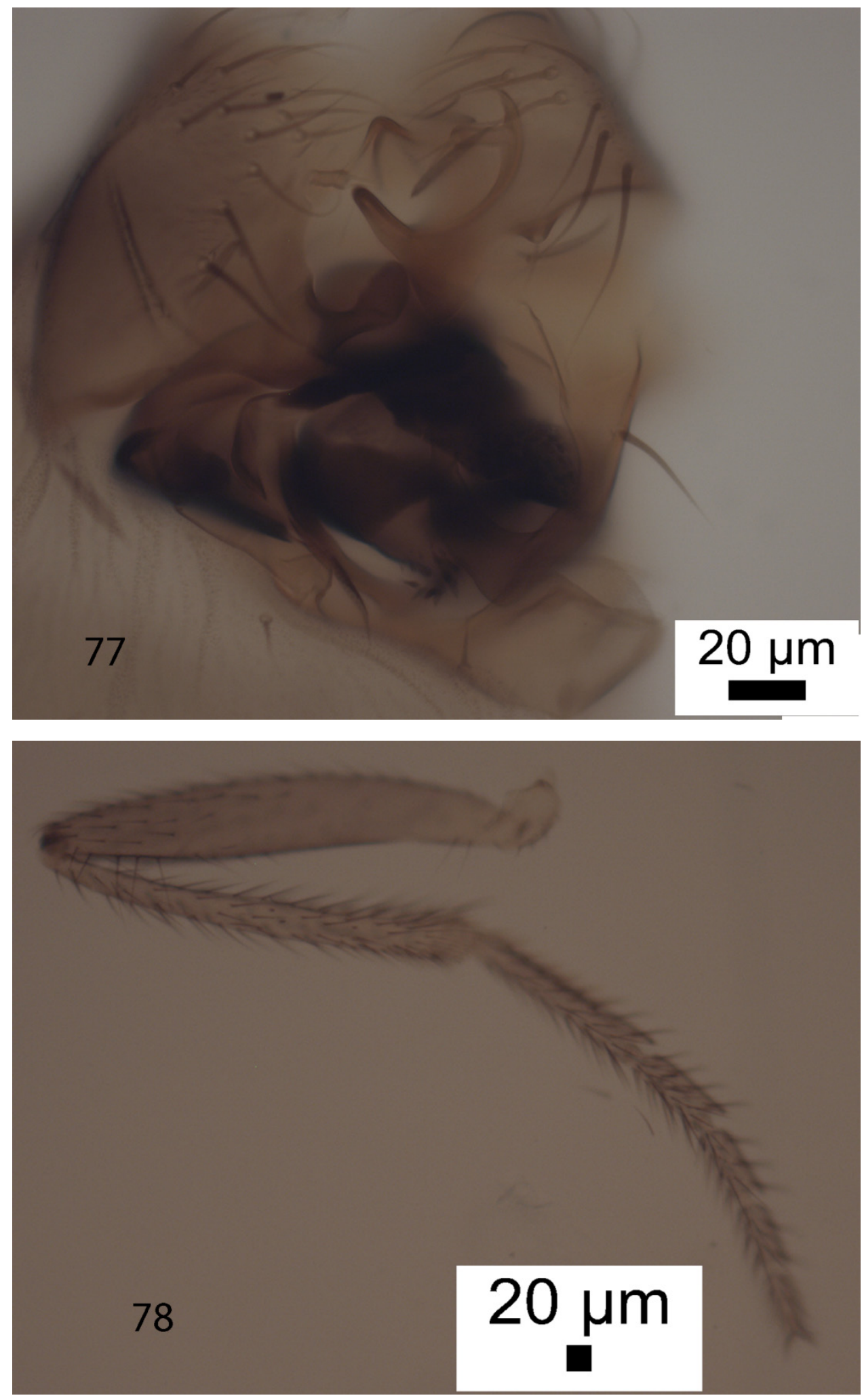


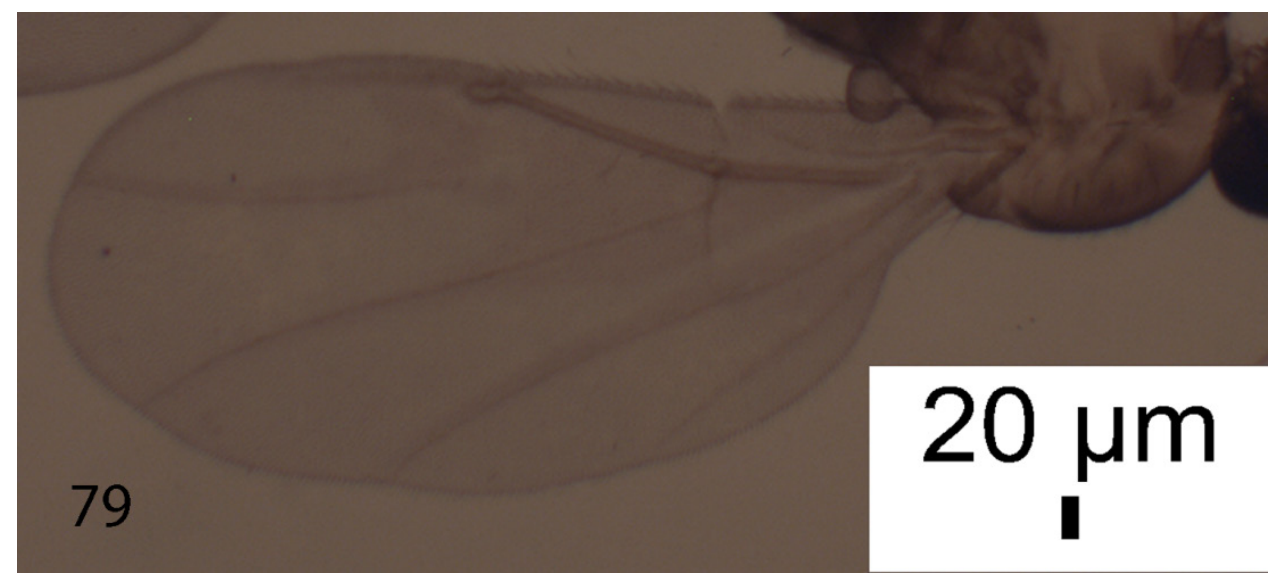

Figures 74-79. Chonocephalus gonocurvatus male. (74) head; (75-77) hypopygium; (78) hind leg; (79) wing.

Male

A generally pale brown species with whitish sides to thorax and pale grayish brown abdominal venter. Head as Fig. 74. Palp about 2.9 times as long as greatest breadth. The hairs of the abdominal tergites T2 to T6 are fine and, apart from on T6, are largely restricted to the hind margins. They are longest on the rear margins of T5 and T6. Venter hairs also fine but shorter. Hypopygium as Figs 75-77. Legs with hind and mid femora light brown, otherwise only slightly tinged brown. Front tarsus with posterodorsal hair palisades on segments 1 to 4 and segment 5 a little longer than 4. Hind leg as Fig. 78. Wing (Fig. 79) $1.15-1.16 \mathrm{~mm}$ long. Costal index 0.51.Haltere brown.

\section{Material}

Holotype male, Papua New Guinea, Gulf of Ivimka, $7.73^{\circ} \mathrm{S}, 146.76^{\circ} \mathrm{E}, 110 \mathrm{~m}$, Malaise trap, 11-20 November 1996, R. Snelling (CUMZ - 26-82). Paratype male, same data as holotype.

Etymology: the name refers to the strongly curved right gonopod.

\section{Chonocephalus guineaensis sp. nov.}

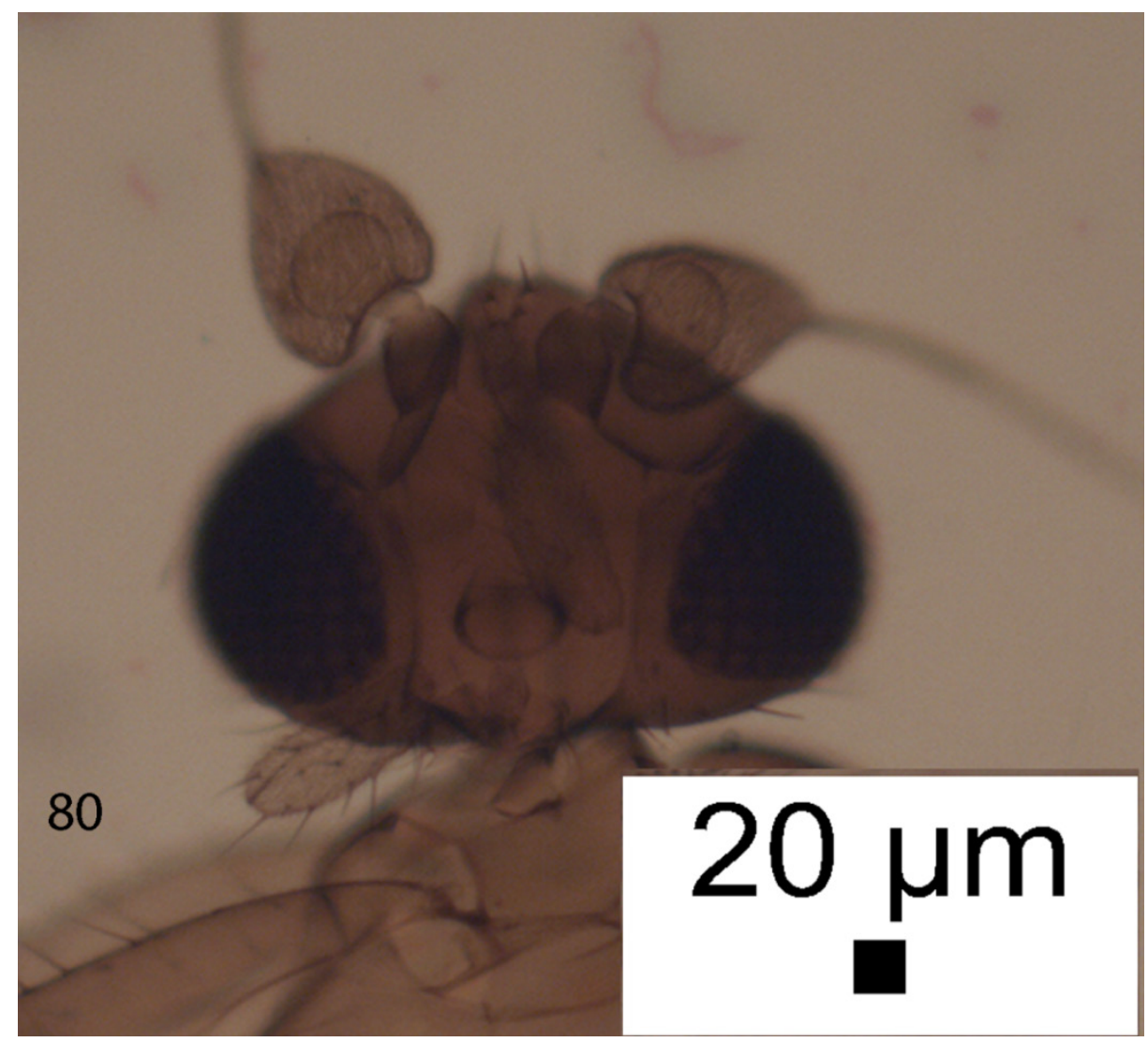



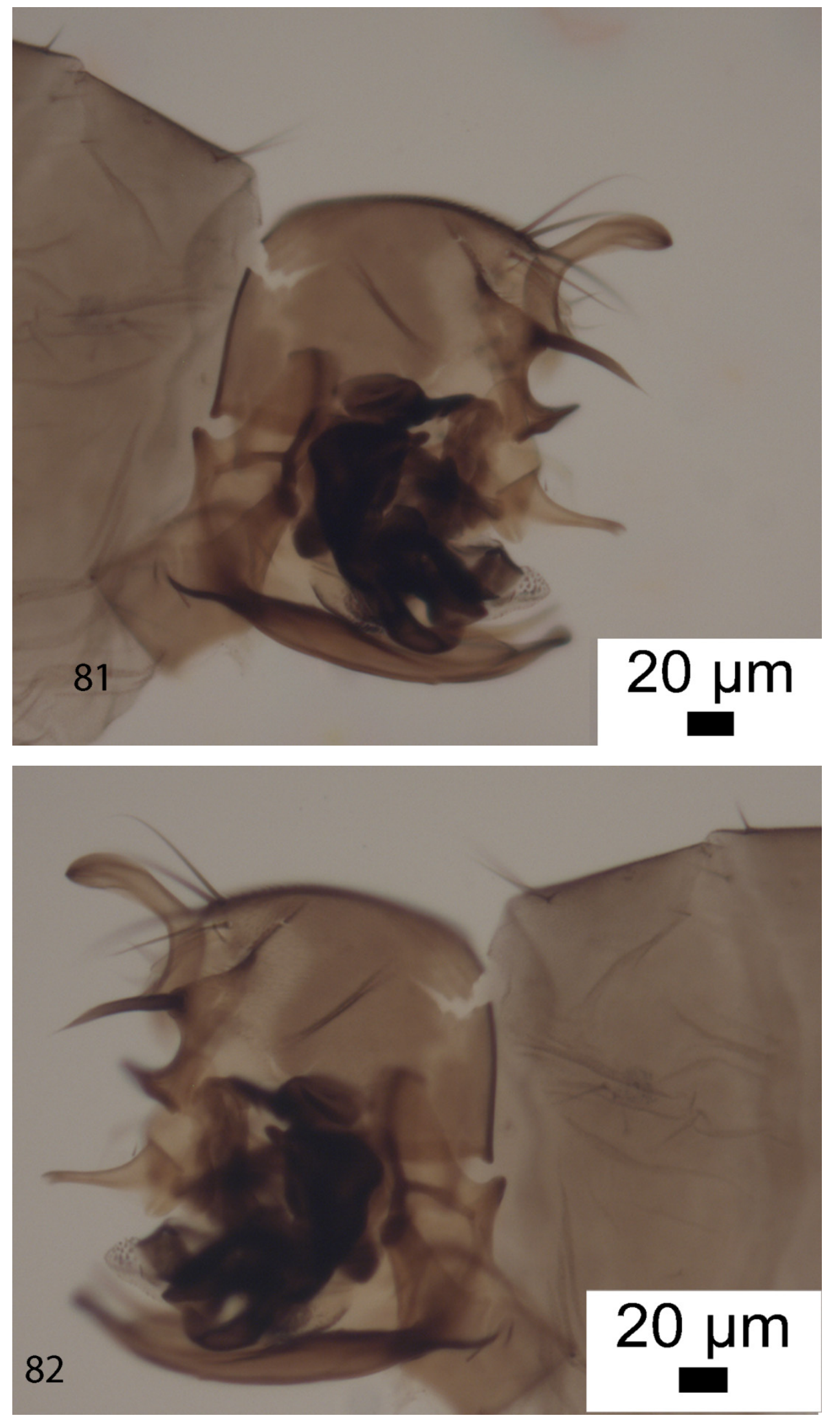

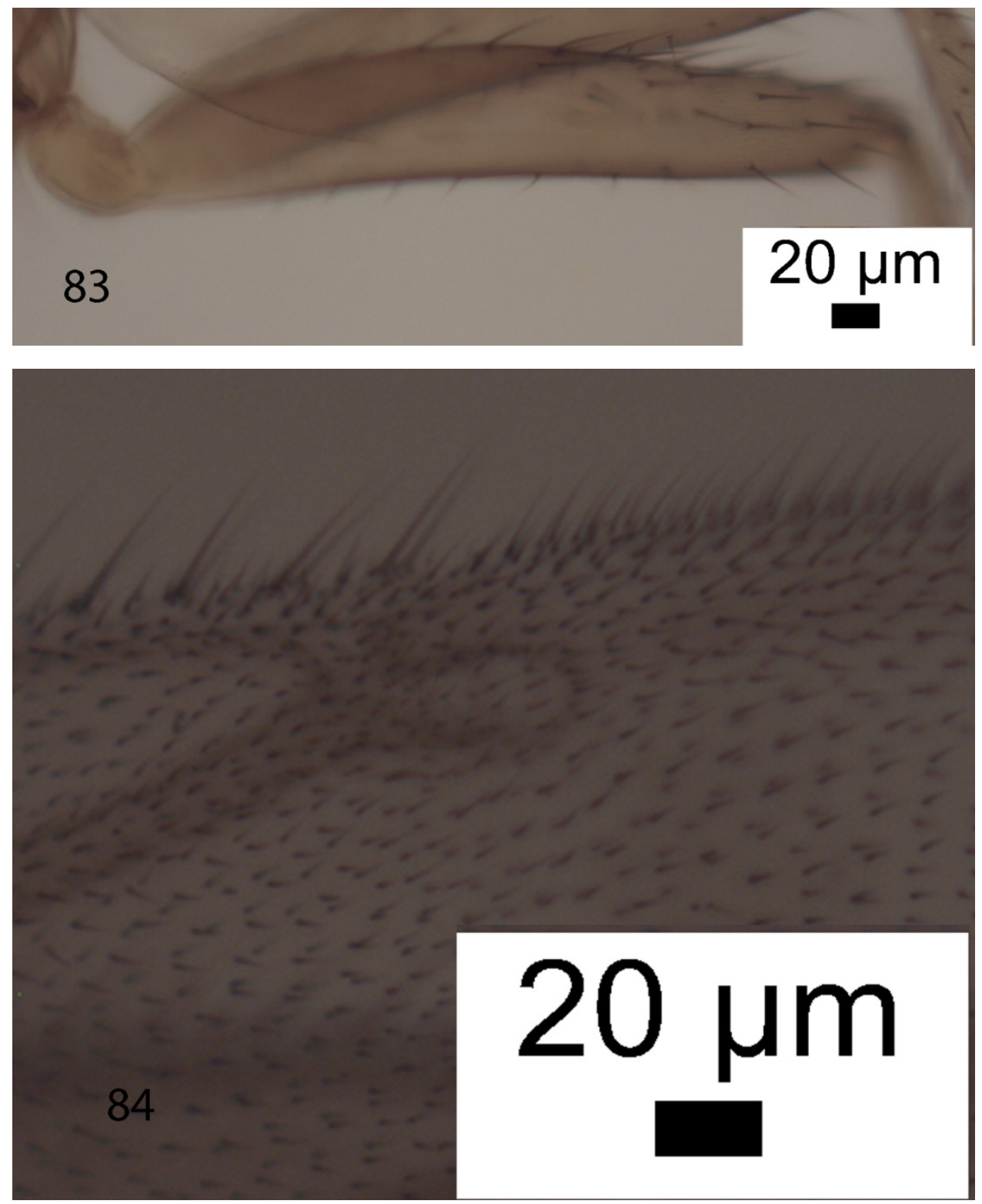

Figures 80-84. Chonocephalus guineaensis male. (80) head; (81-82) hypopygium; (83) hind femur; (tips of costa and vein 3.

Male

A generally light brown species with a pale grayish venter. Head as Fig. 80. The hairs of the abdominal tergites are fine and restricted to the hind margins of T2 to T6. They are longest on T6. Venter hairs very fine, shorter and few in number. Hypopygium as Figs 81 and 82. Legs with coxae to tibiae light brown and tarsi paler. Front tarsus with posterodorsal hair palisades on segments 1 to 4 and segment 5 longer than 4. Hind femur as Fig. 83. Wing 0.8-0.9 mm long. Tips of costa and vein 3 as Fig. 84. Thick veins light brown, thin veins paler and membrane tinged brownish grey. Haltere brown.

\section{Material}

Holotype male, Papua New Guinea, Gulf of Ivimka, $7.73^{\circ} \mathrm{S}, 146.76^{\circ} \mathrm{E}$, Malaise trap, 10-20 February 1997, K. Merg (LACM, 26-72).

Etymology: the name refers to the type locality.

\section{Chonocephalus heymonsi Stobbe}




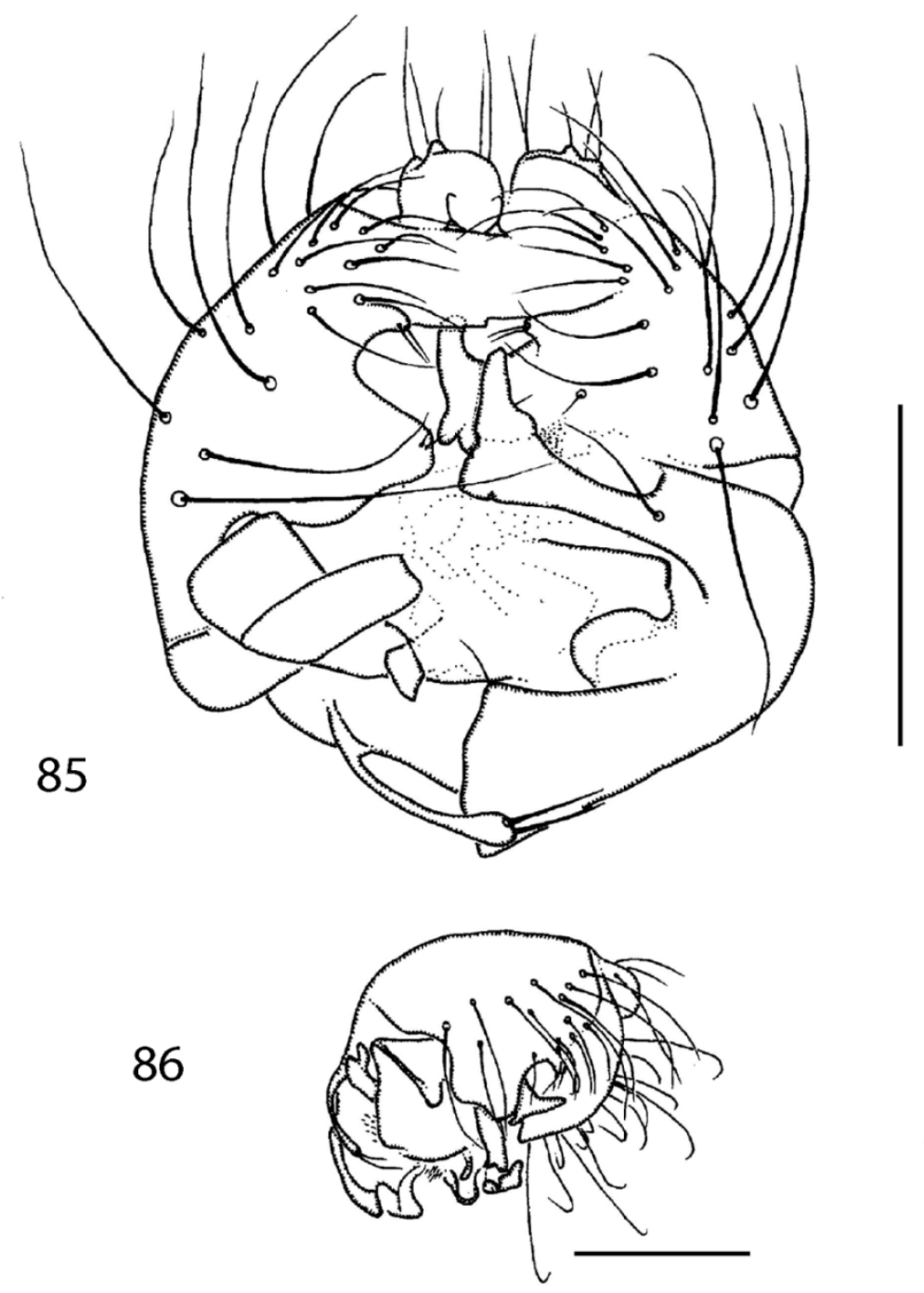

Figures 85-86. Chonocephalus heymonsi male, hypopygium: (85) from below; (86) left face. Scale bars $=0.1 \mathrm{~mm}$.

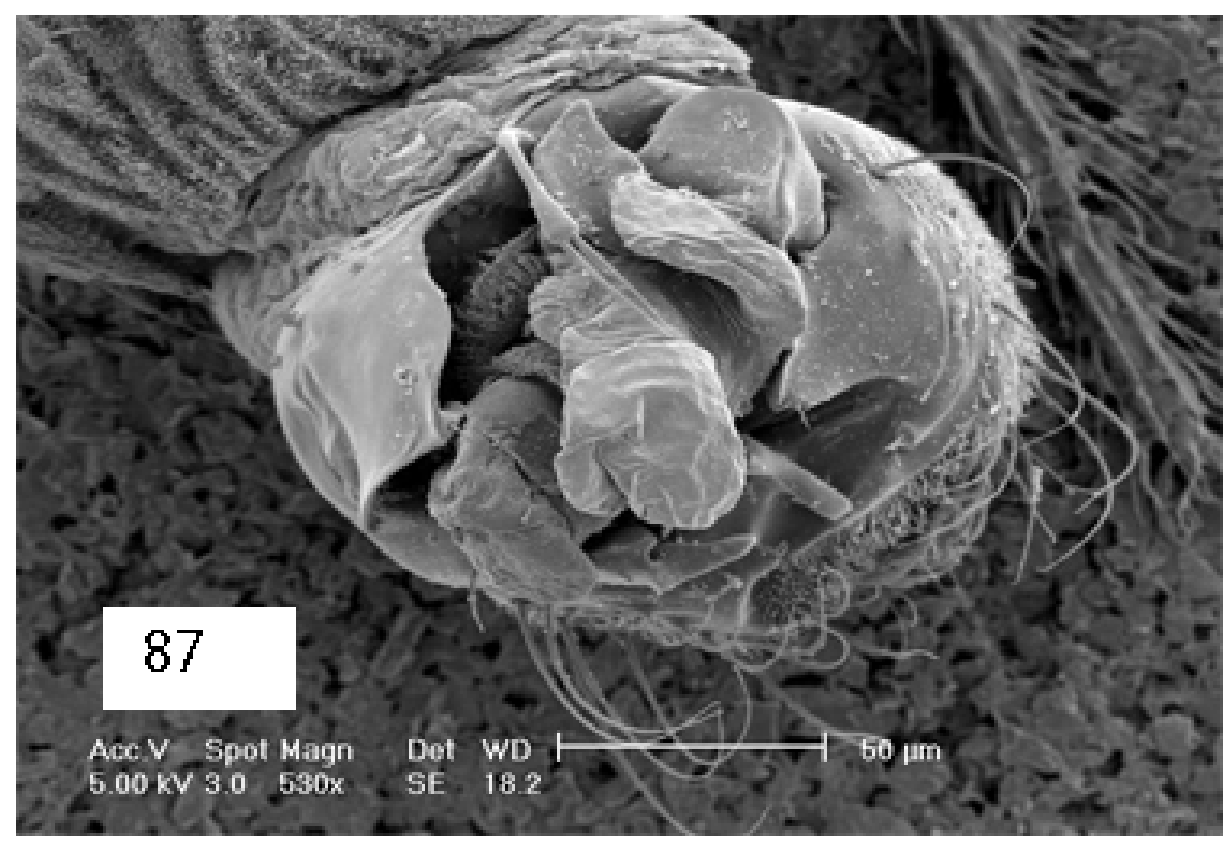

Figure 87. Chonocephalus heymonsi male, hypopygium. 


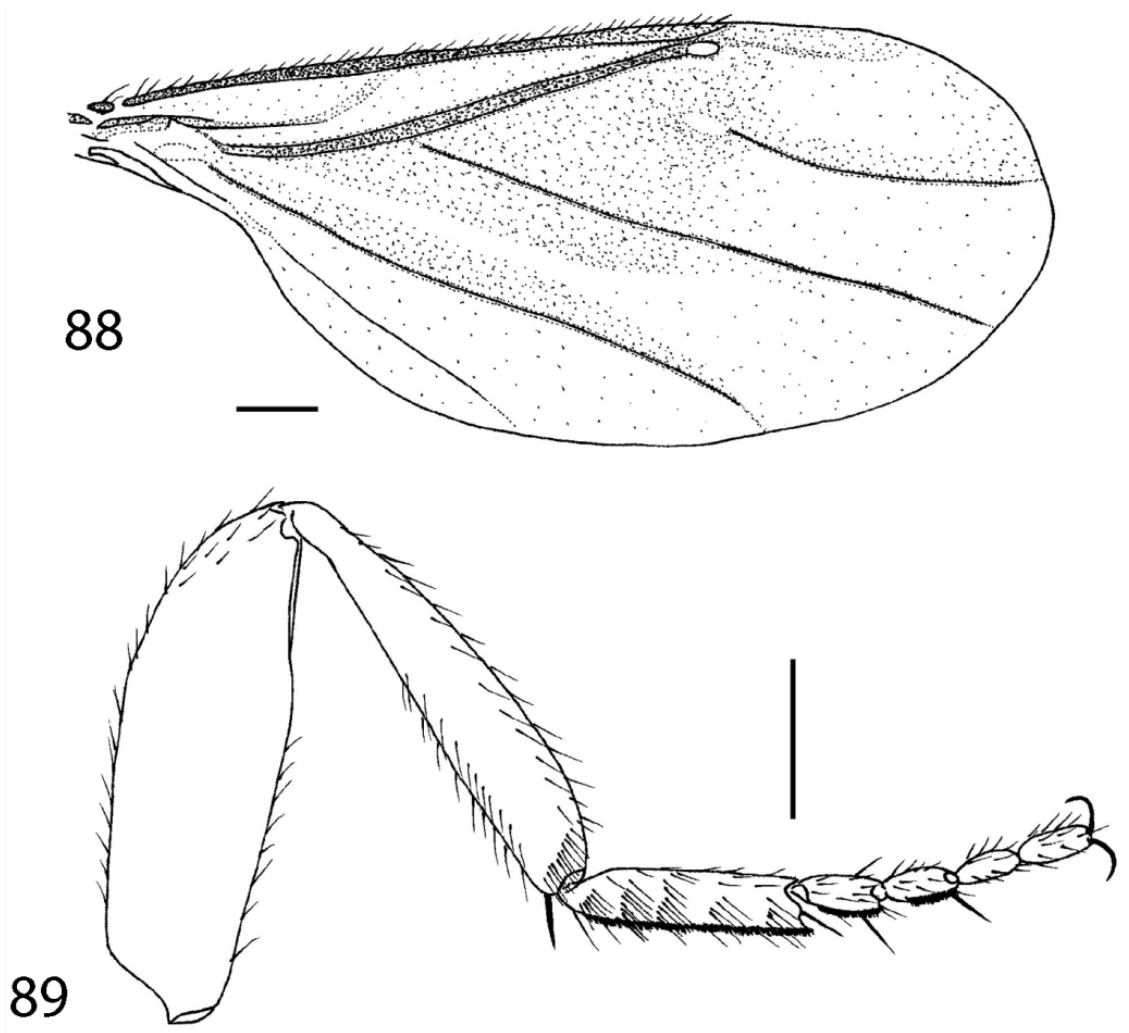

Figures 88-89. Chonocephalus heymonsi: (88) male, right wing; (89) female, posterior face of hind leg from femur onwards. Scale bars $=0.1 \mathrm{~mm}$.

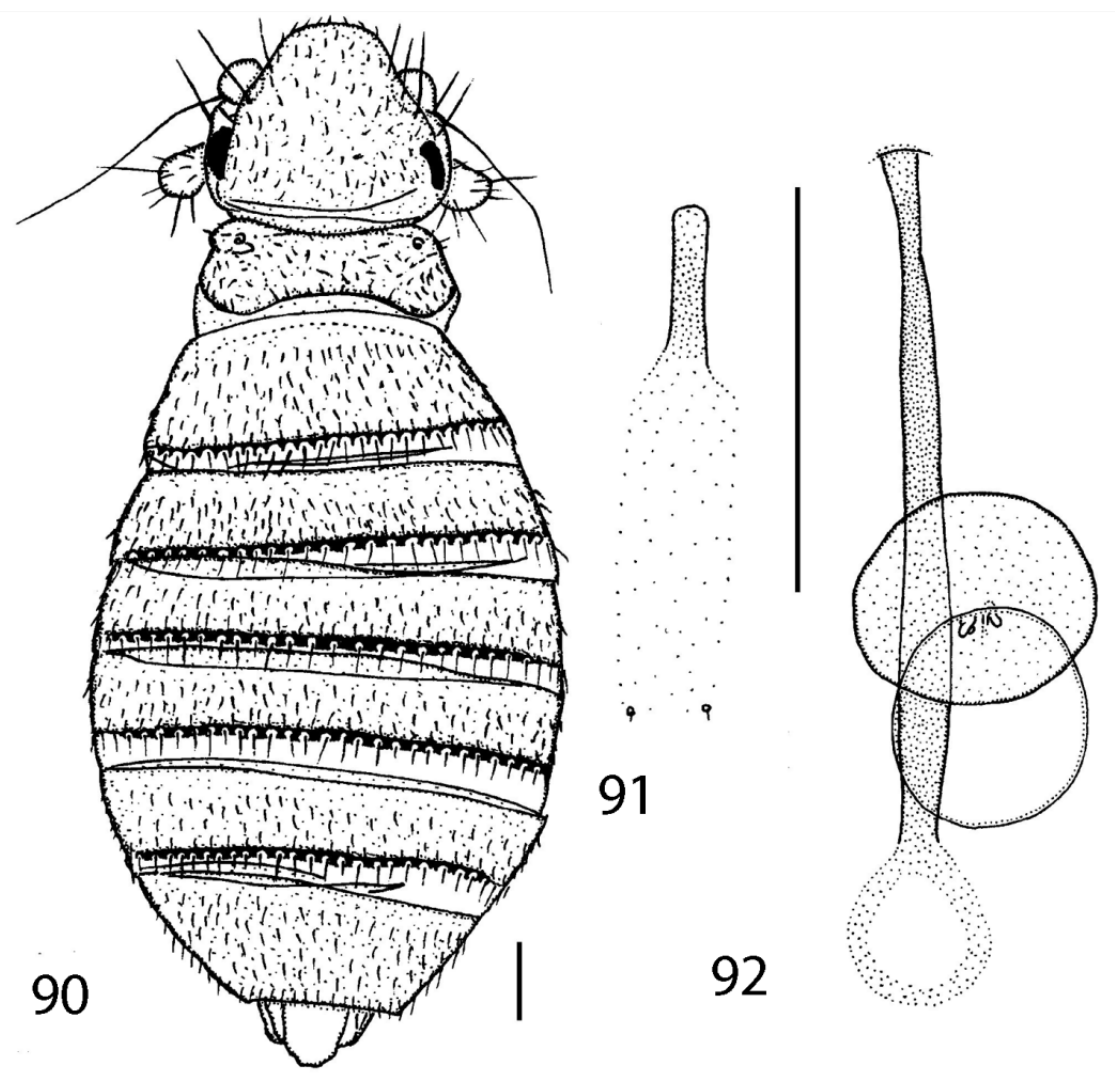

Figures 90-92. Chonocephalus heymonsi female: (90) whole fly from above; (91) tergite $8 ;(92)$ sternite 8 , furca and spermatheca. Scale bars $=0.1 \mathrm{~mm}$. 


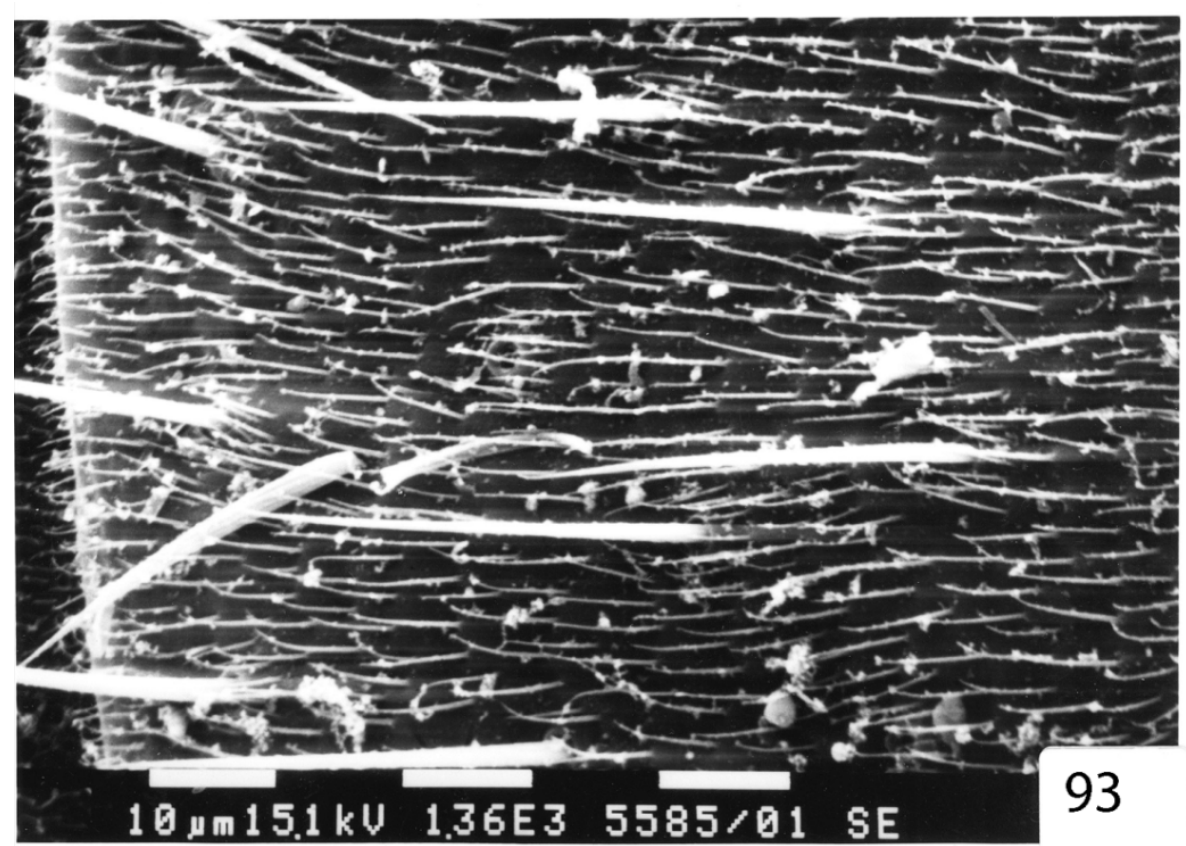

Figure 93. Chonocephalus heymonsi female, hairing and microtrichia of abdominal tergites.

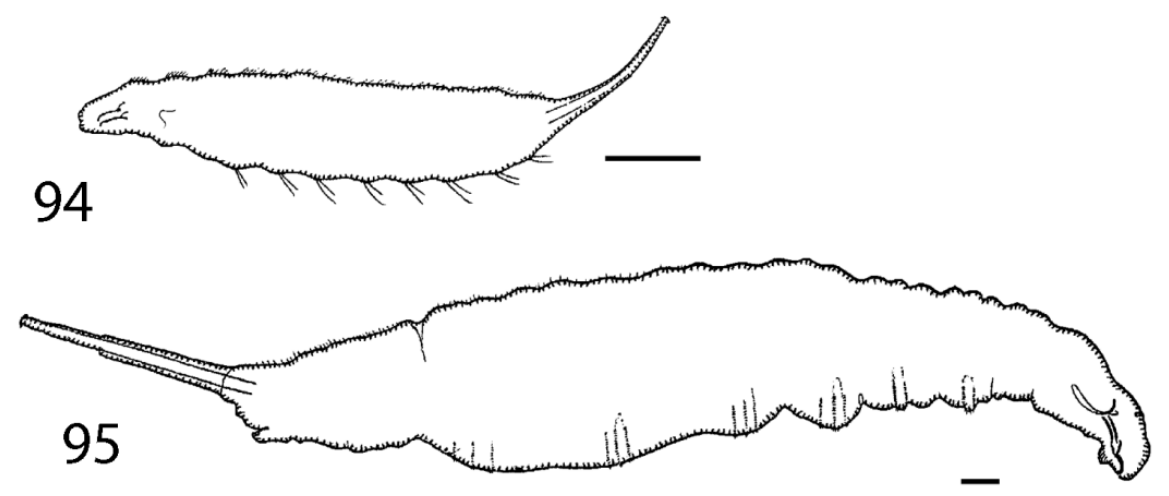

Figures 94-95. Chonocephalus heymonsi larvae. (94) first instar; (95) third instar. (After Borgmeier, 1935).

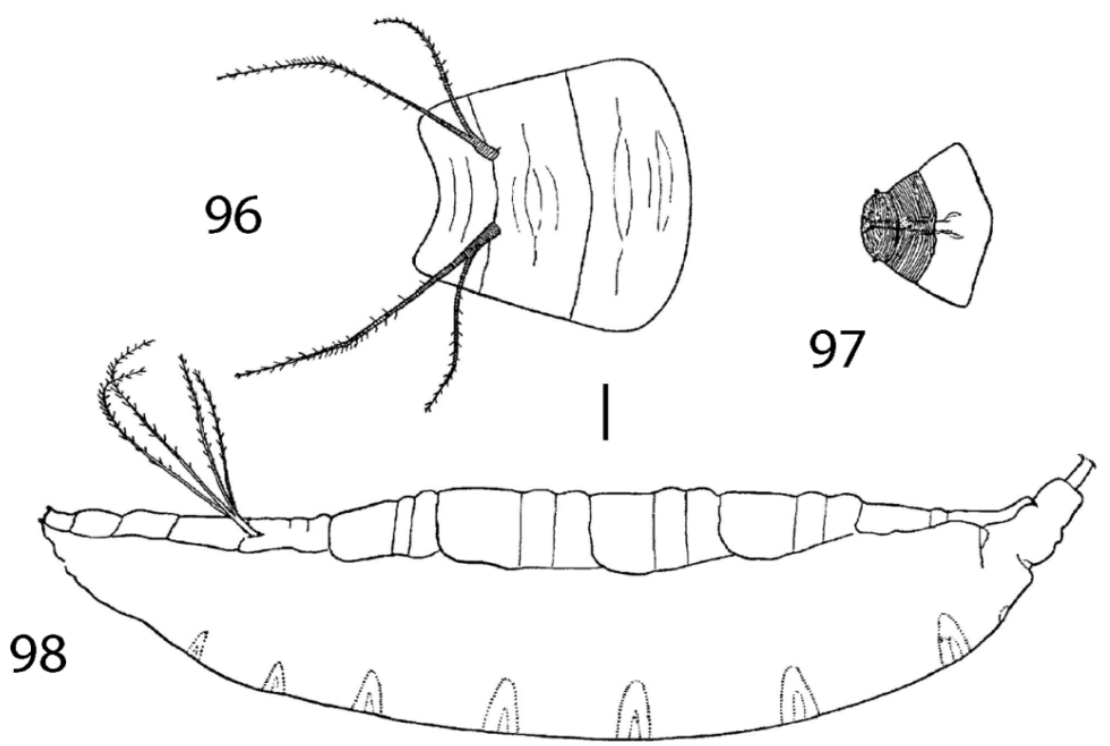

Figures 96-98. Chonocephalus heymonsi pupa. (96) eclosion plate of puparium; (97) anterior cap of puparium; (98) left face of pupa.. (After Borgmeier, 1935). 
Chonocephalus heymonsi Stobbe, 1913: 131 (female only).

Chonocephalus similis Collin, 1912: 105, part (one female only) nec Brues, 1905. Misidentification.

Chonocephalus jamaicensis Brues, 1915: 102. Disney, 1981 [4]: 207.

Chonocephalu spunctifascia Borgmeier, 1935 [2]: 257 (both sexes). Prado, 1976: 587.

Chonocephalus vadoni Paulian, 1958: 11. Prado, 1976: 587.

Chonocephalus brisbanensis Beyer, 1960: 85. Disney, 2002 [10]: 23.

Chonocephalus digitalis Borgmeier, 1967 [3]: 207 (part). Misidentifications.

This tramp species has been carried around the world by man. It has accordingly been repeatedly misidentified. It has been recorded from every Biogeographical Region (except the Antarctic), but is seemingly most abundant in Africa south of the Sahara (Disney [11]). Through the agency of man it is now reported throughout the warmer parts of the world and in glasshouses in temperate regions (Disney [4], [10]).

\section{Material}

2 males (including holotype of $C$, brisbanensis) Australia, Queensland, Brisbane, 13 and 20 February 1955, E. J. Reye (QMB, 25-48); 7 males, 4 females, (1 pair in copula), New South Wales, Berowra, Yallambee Road, water traps in garden, 28 February 2002, R. H. L. Disney (CUMZ, 25-49). 2 males, Fiji, Suva, April to May 1995, A. van Harten (CUMZ, 2-62 \& 72); 3 males, same locality, water traps, January 1997, A. v H. (CUMZ, 32-71). 1 male (as C. dorsalis), Samoa Islands, Apia, Upolu, February 1925, on fowl dung, P. A. Buxton \& G. H. Hopkins (NHM - BM1935-536, 2-73).

\section{Natural history}

The larvae and puparium were described by Borgmeier ([2]) (Figs 94-98). A female caught on the edible paddy straw mushroom Volvariella (Plutaceae) was probably ovipositing on an over ripe sporophore, as was the case with the females recorded on rotting Termitomyces (Amanitaceae) on a termite mound. It has also been reared from bread fruit (Artocarpus altilis (Parkinson) Fosberg, Moraceae) (Disney [7]). The series collected at turmeric (Curcuma longa L., Zingiberaceae) infested with larval Dichocrocis punctiferalis (Guenée) (Lepidoptera, Pyralidae) were possibly attracted to diseased or moribund caterpillars. Likewise a series reared from acocoon mass of Apanteles flavipes (Cameron) (Braconidae) were probably feeding on moribund pupae.

\section{Chonocephalus howseae sp. nov.}

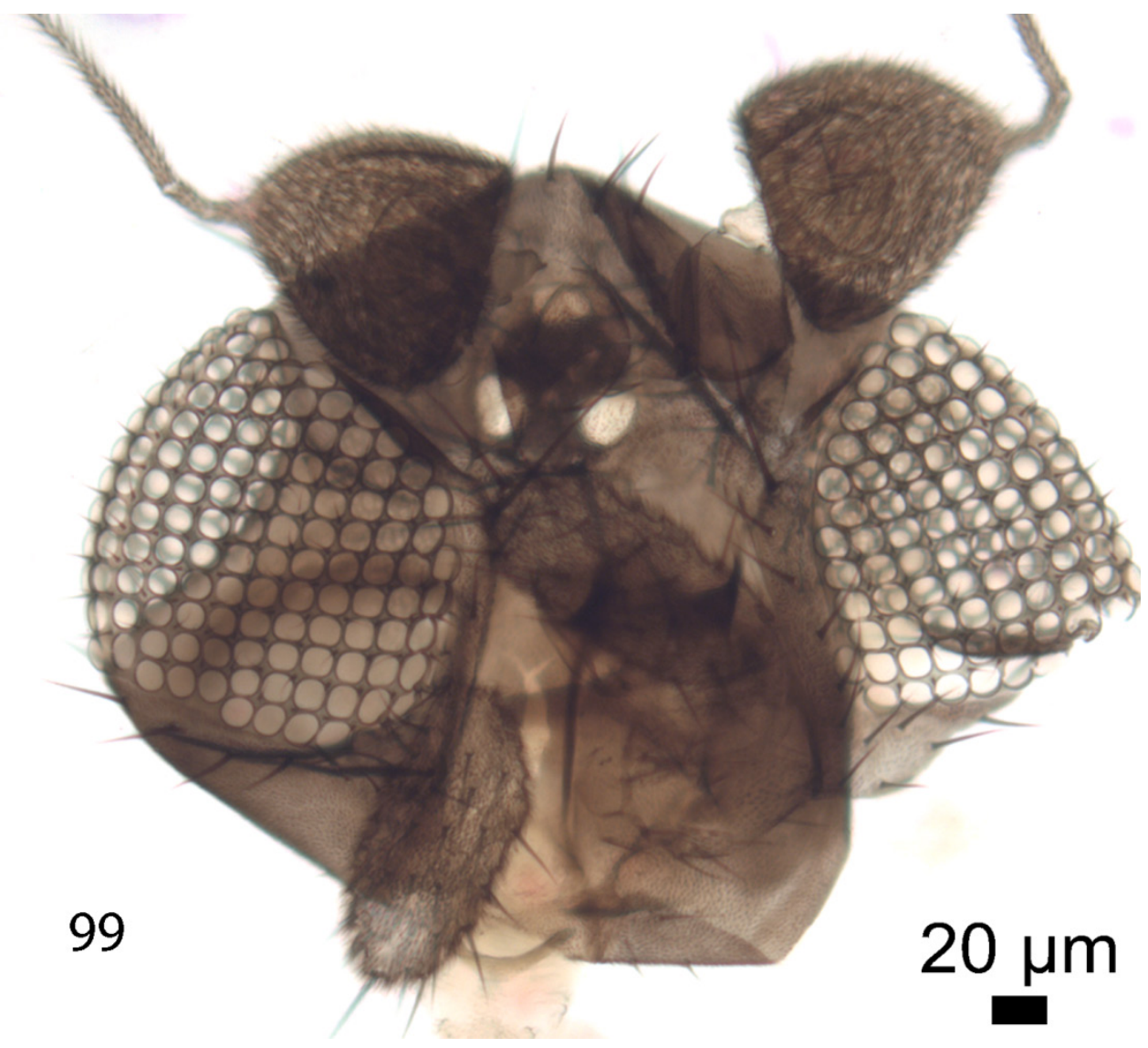



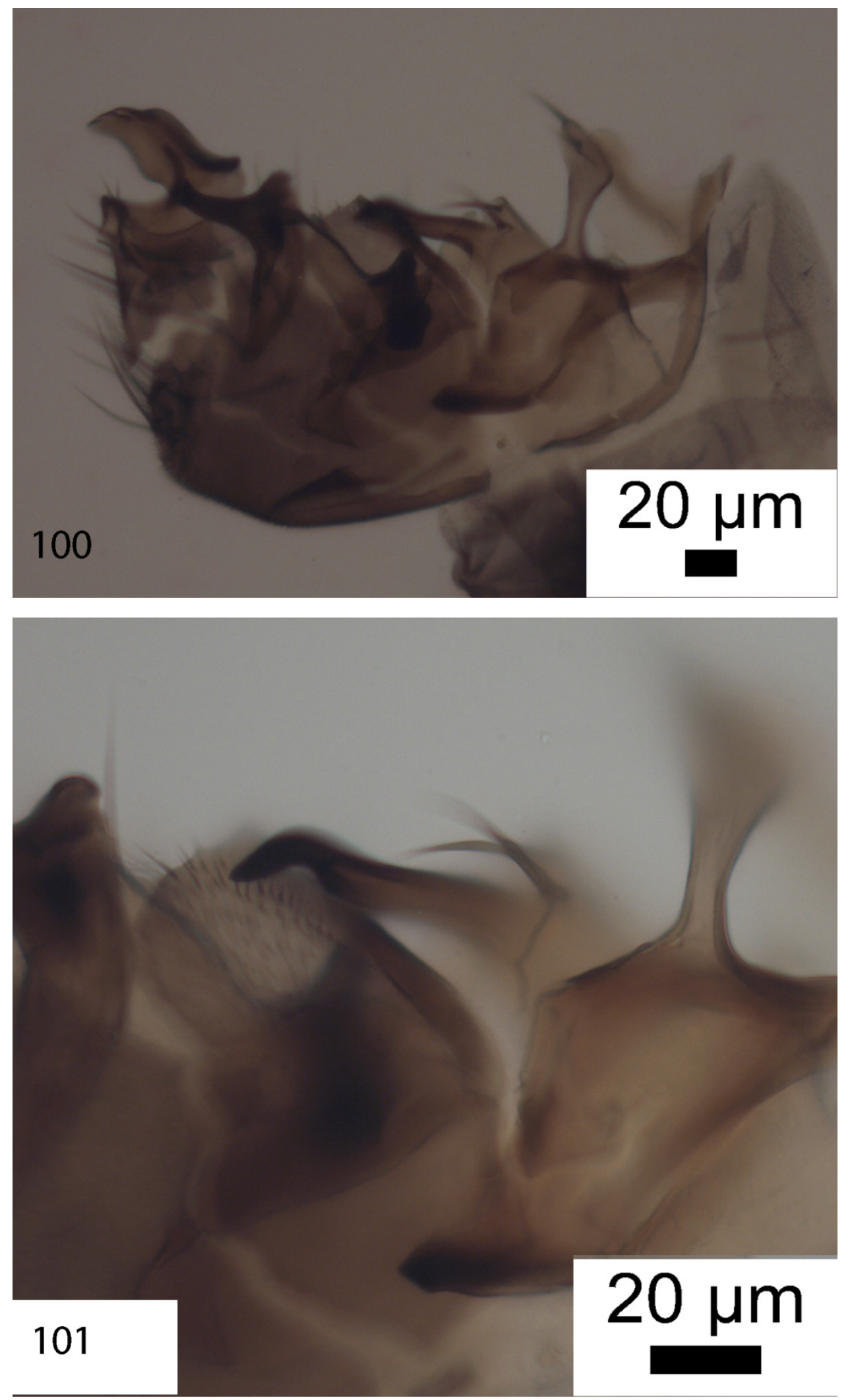

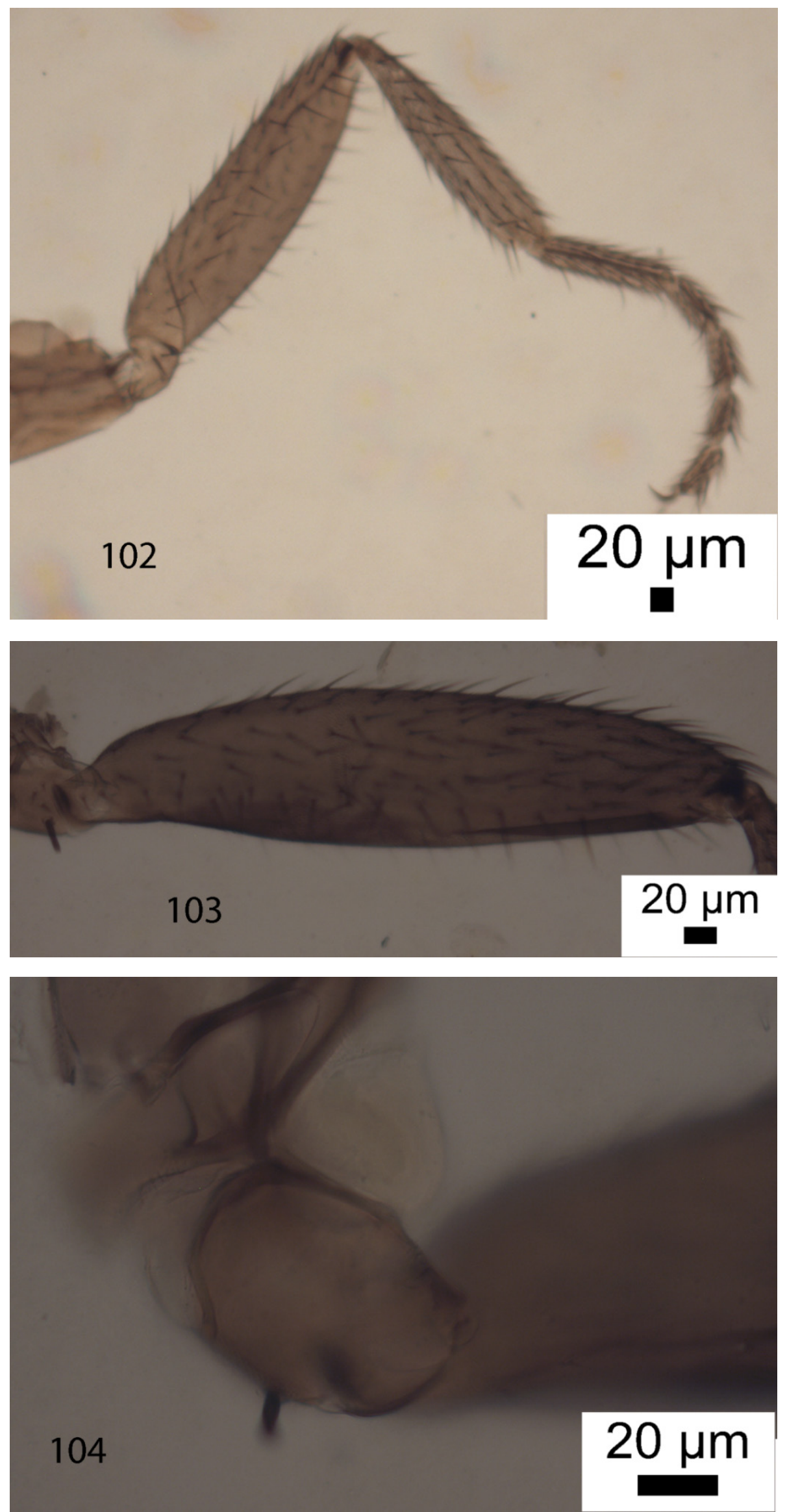


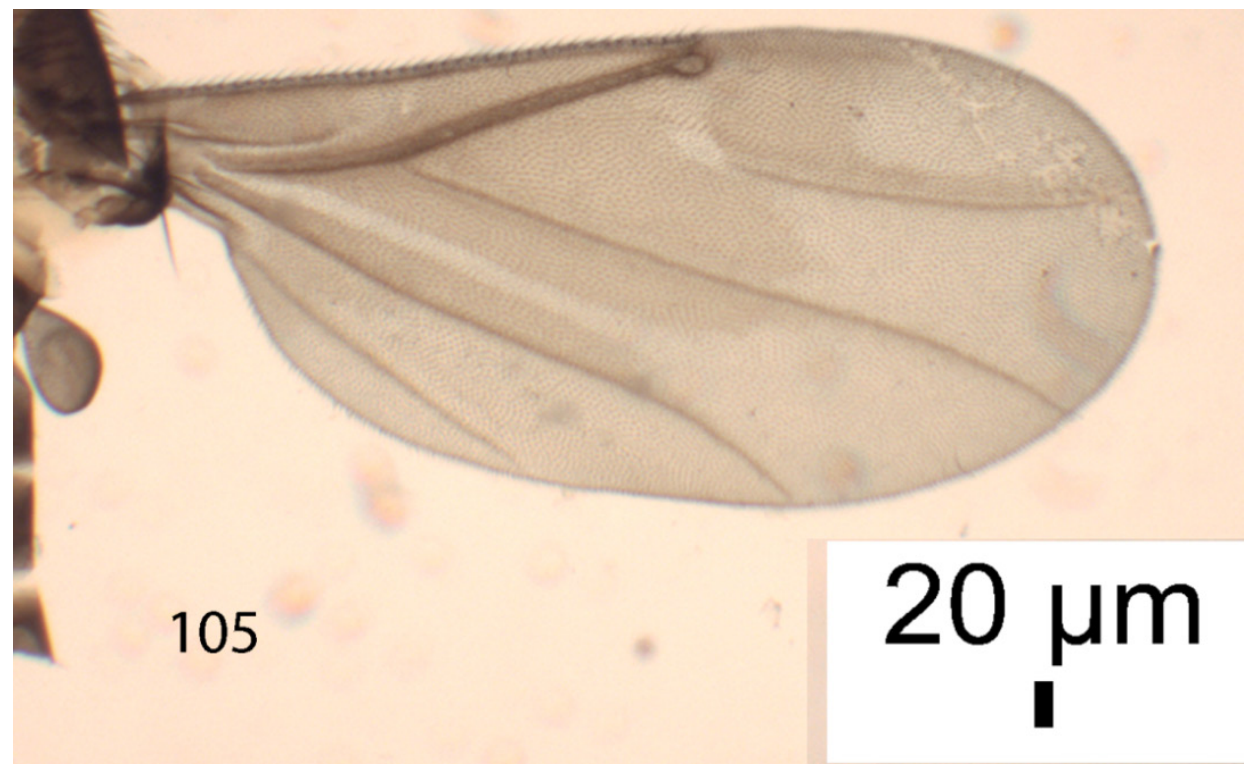

Figures 99-105 Chonocephalus howseae male. (99) head; (100-101) hypopygium; (102) front leg; (103) hind femur; (104) hind coxa; (105) wing.

Male

A generally brown species, but with a pale gray abdominal venter. Head as Fig. 99. The hairs of the abdominal tergites are moderately fine and are longest on T6. Venter hairs much finer and shorter. Hypopygium aas Figs 100-101. Legs brown. Front leg as Fig 102, the tarsus having posterodorsal hair palisades on segments 1 to 4 . Hind femur as Fig. 103, and coxa with a small curved spine (Fig. 104). Wing (Fig. 105) $1.16 \mathrm{~mm}$ long. Costal index 0.52. Haltere (Fig. 105) brown.

\section{Material}

Holotype male, Australia, Queensland, Innisfail, Pin Gin Hill, 14-17 February 1982, D. Howse (CUMZ, 6-133).

Etymology: the name refers to the Diane Howse, who collected the holotype.

\section{Chonocephalus immutotibia sp. nov.}

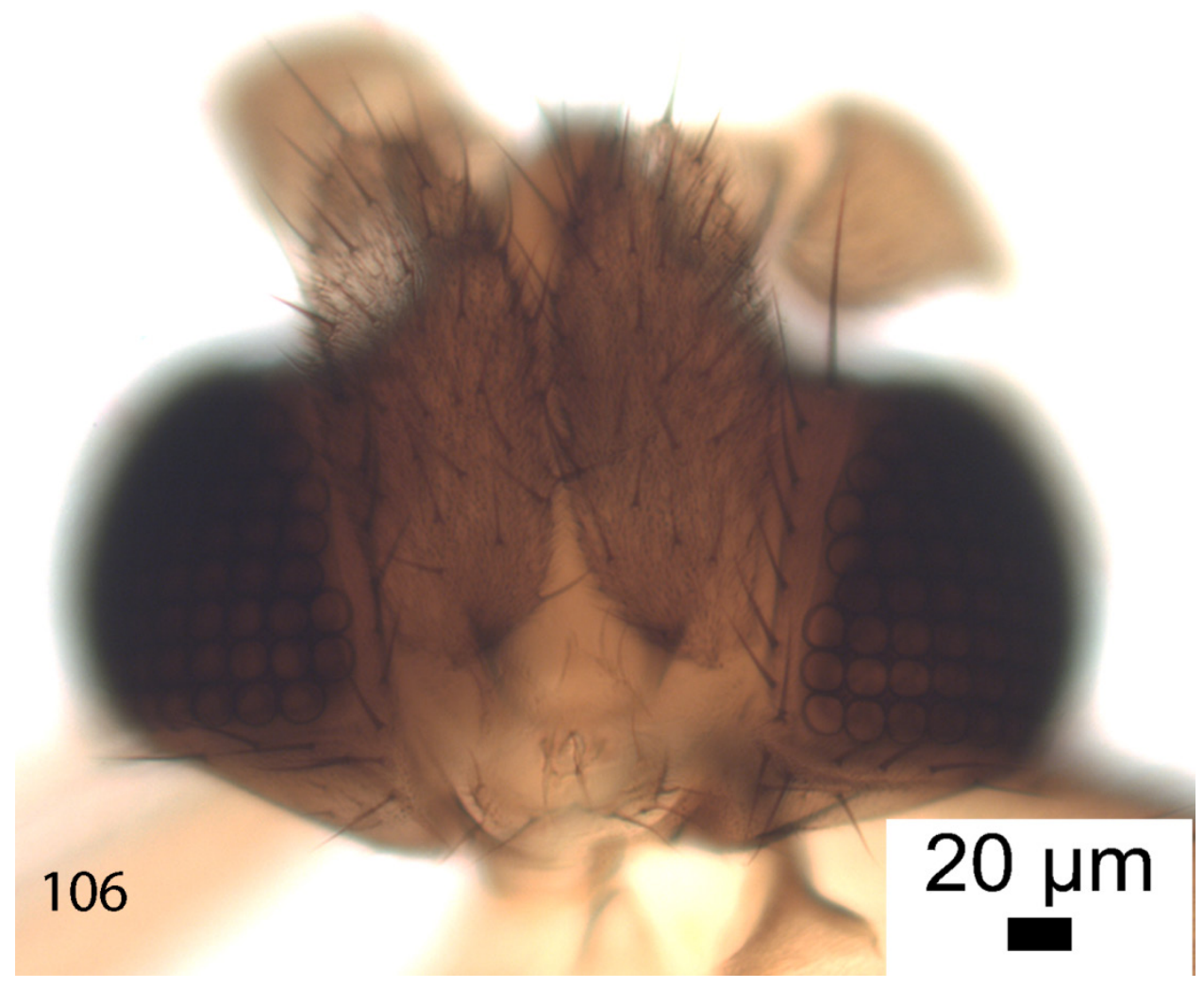



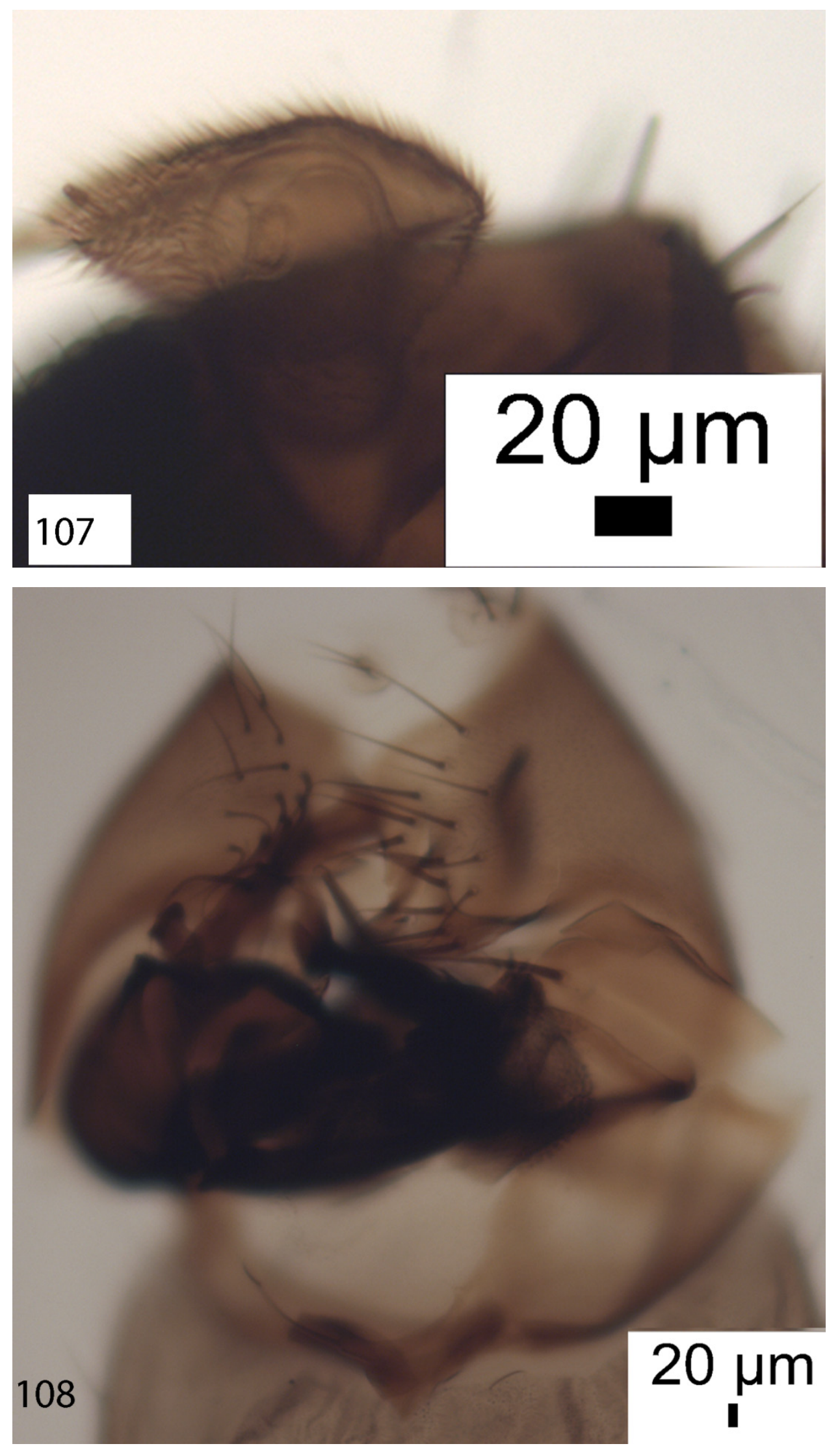

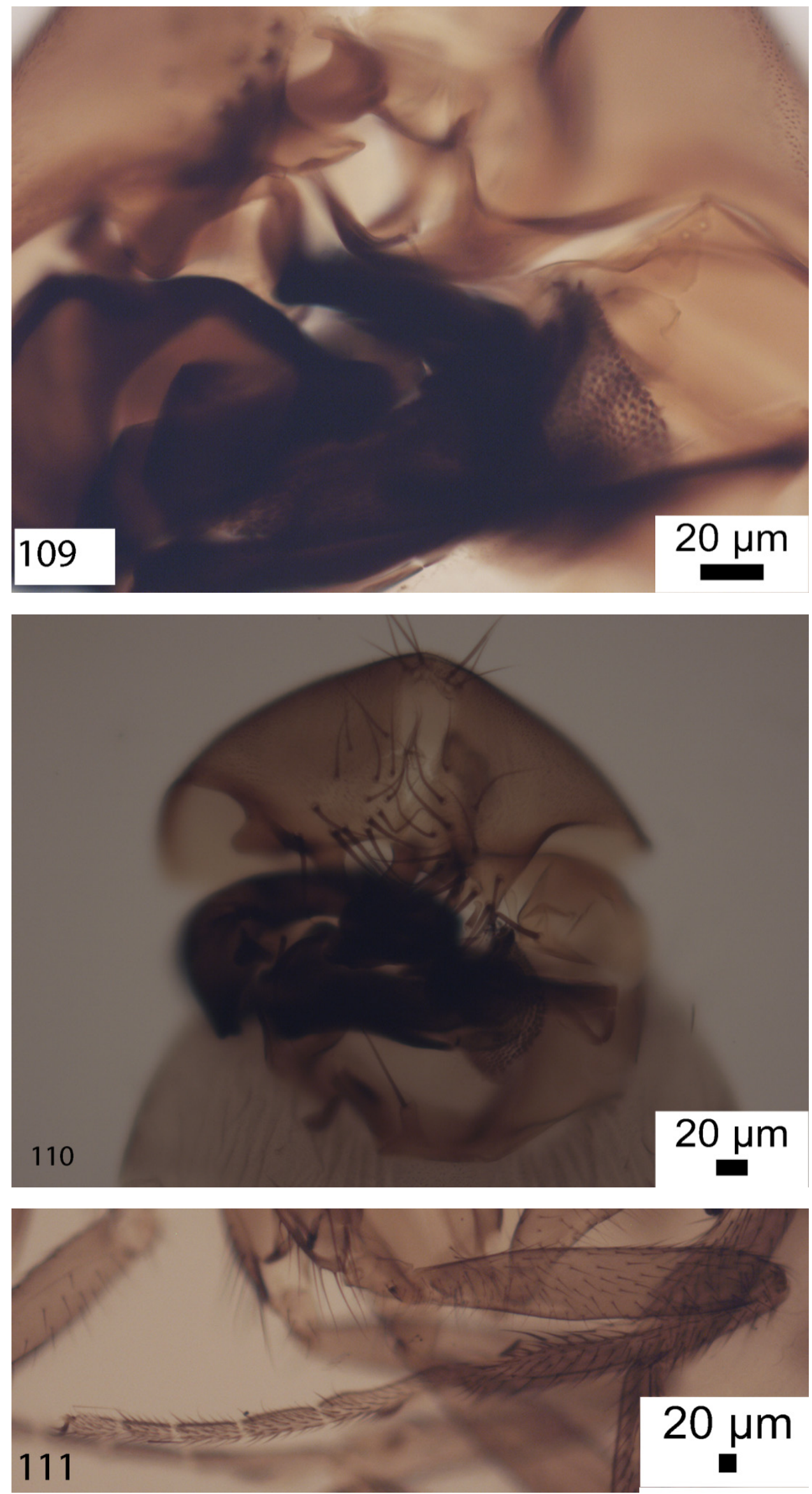

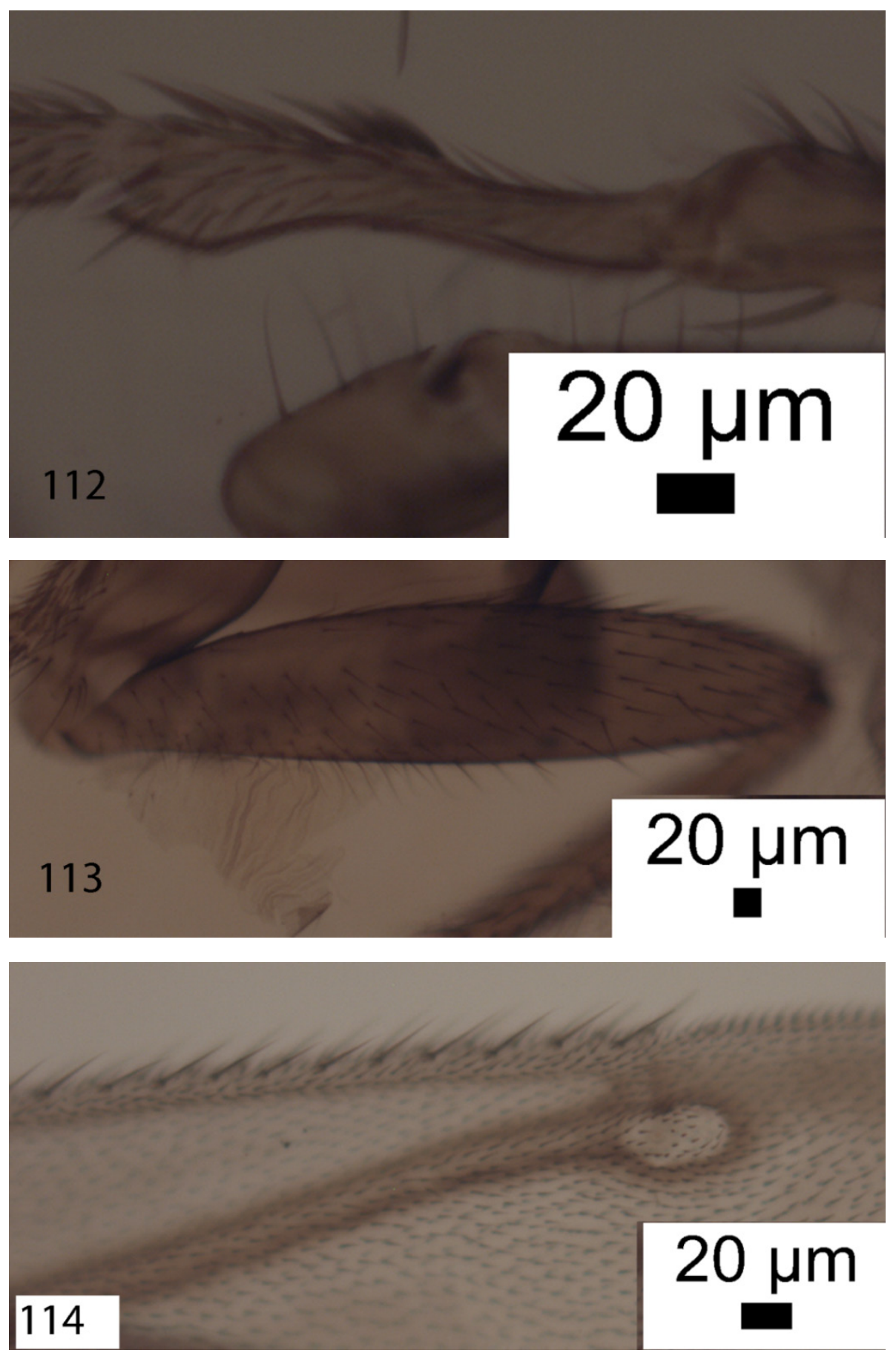

Figures 106-114. Chonocephalus immutotibia male. (106) palps; (107) postpedicel; (108-110) hypopygium; (111) middle leg; (112) tip of mid tibia and basitarsus; (113) hind femur; (114) tips of costa and vein 3.

\section{Male}

A generally brown but not dark species, with sides of thorax pale and abdominal venter light grayish brown. Postpedicel as Fig. 107. Palps as Fig. 106. The hairs of the abdominal tergites are fine and are largely restricted to the hind margins except on T6. They are longest at the rear of T6. Venter hairs finerand shorter. Hypopygium as Figs 108-110. Legs with brown, but not dark, femora and tibia and pale tarsi. Front tarsus with a posterodorsal hair palisade on segment 1 to 4 and segment 5 almost as long as 4. Middle leg as Figs 111-112, the tip of tibia and basitarsus as Fig. 112. Hind femur as Fig. 113. Wing $1.4 \mathrm{~mm}$ long. Costal index 0.55 . Thick veins light brown with tip of costa and vein 3 as Fig. 114, thin veins grayish brown and membrane tinged brownish grayy. Haltere brown.

\section{Material}

Holotype male, Indonesia, Irian Jaya, Wapoga Camp, 3.14 ${ }^{\circ}$, $136.57^{\circ} \mathrm{E}, 1050$ m, 19-26 June 1998, R. Snelling (LACM, 
26-70). Paratype male as holotype except (CUMZ, 26-70).

Etymology: the name refers to the modified tip of the mid tibia.

Chonocephalus irianensis sp. nov.
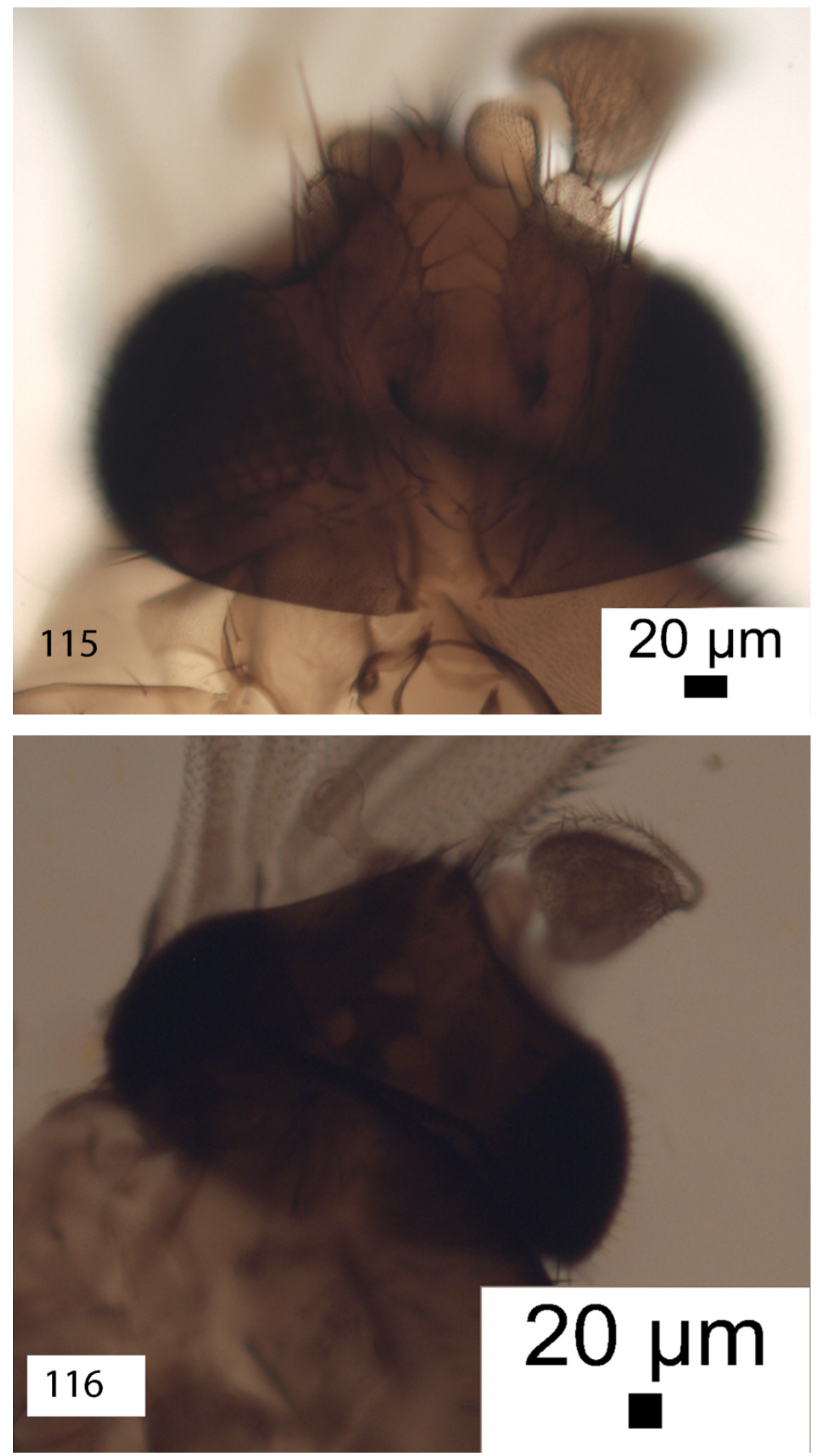


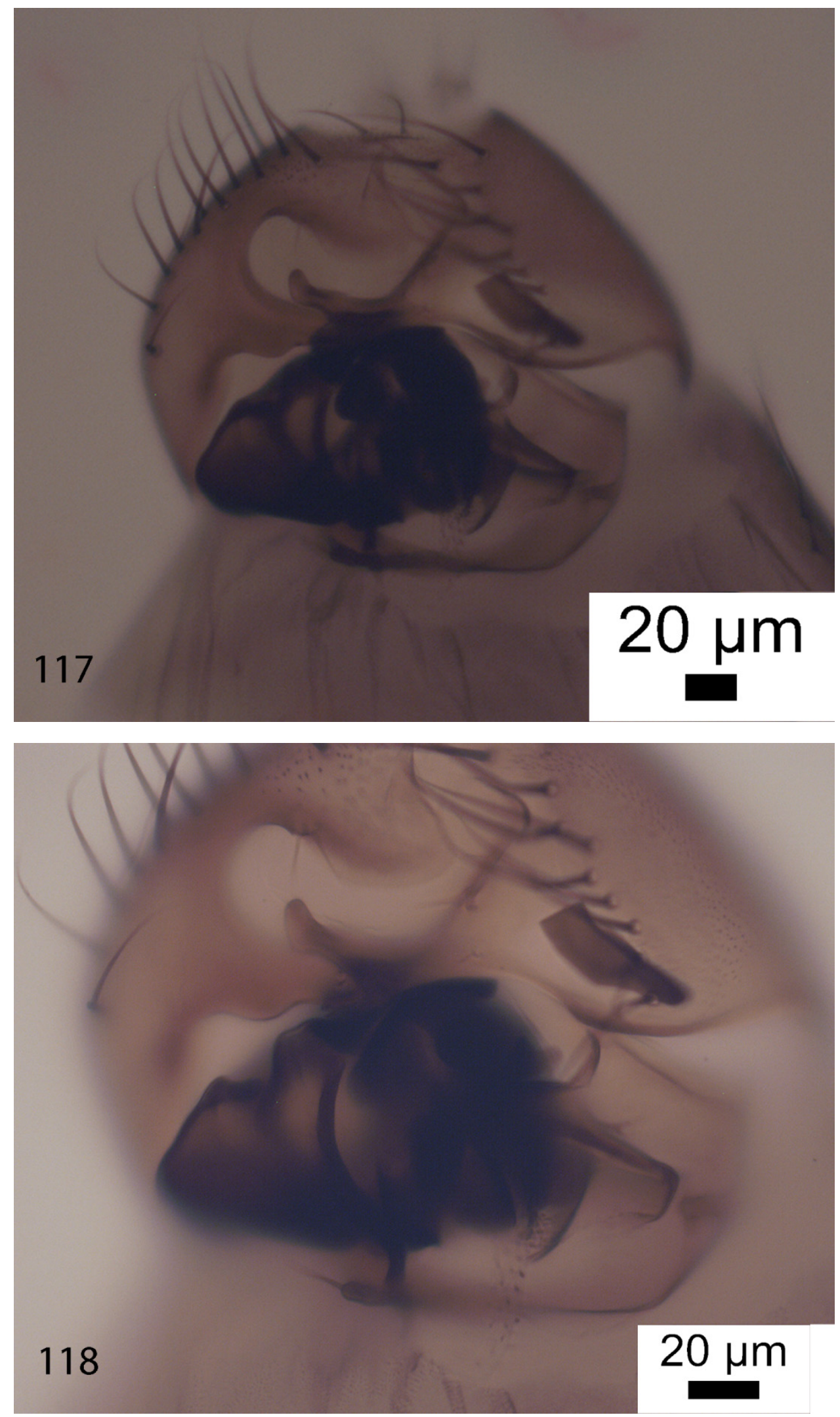




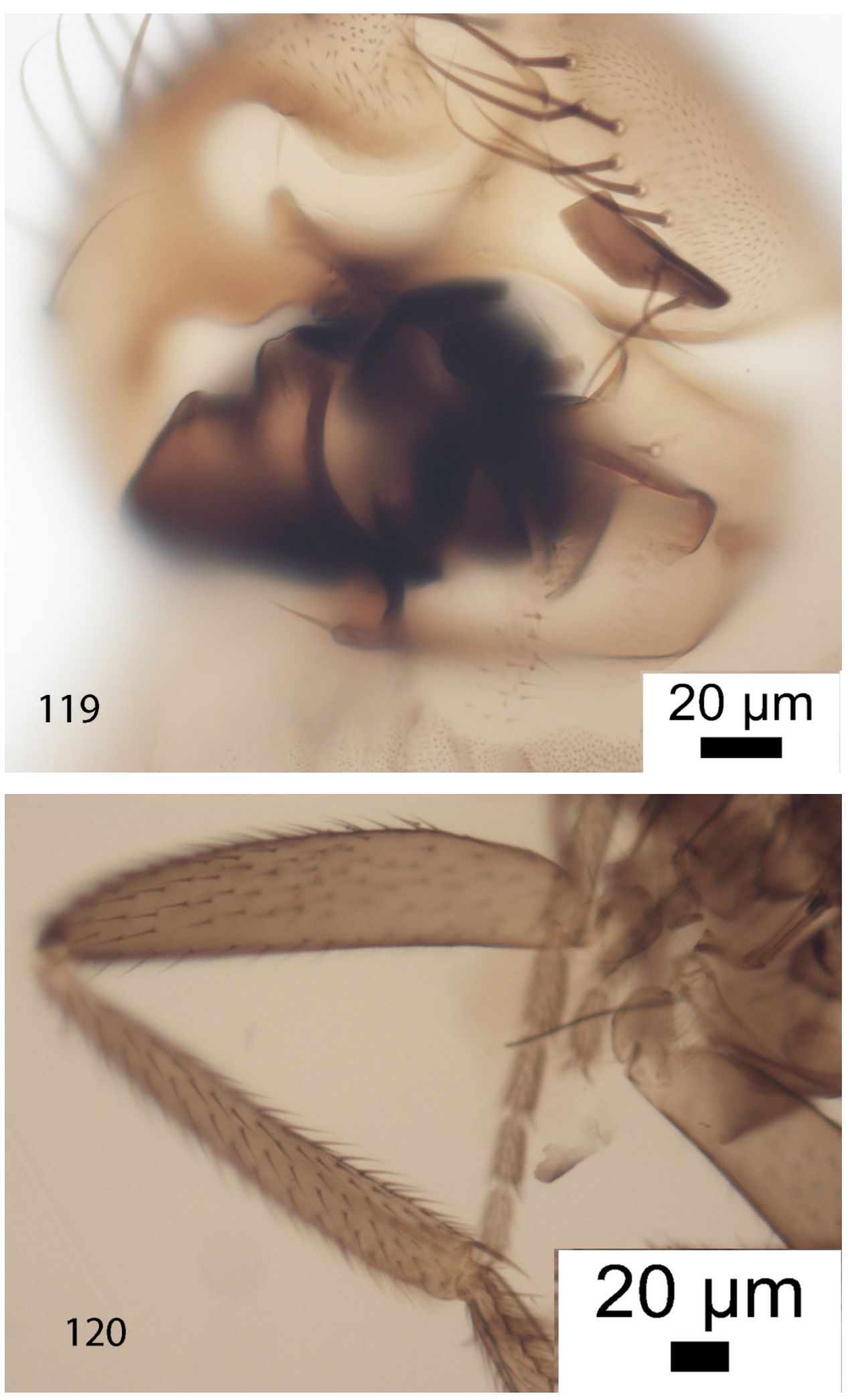




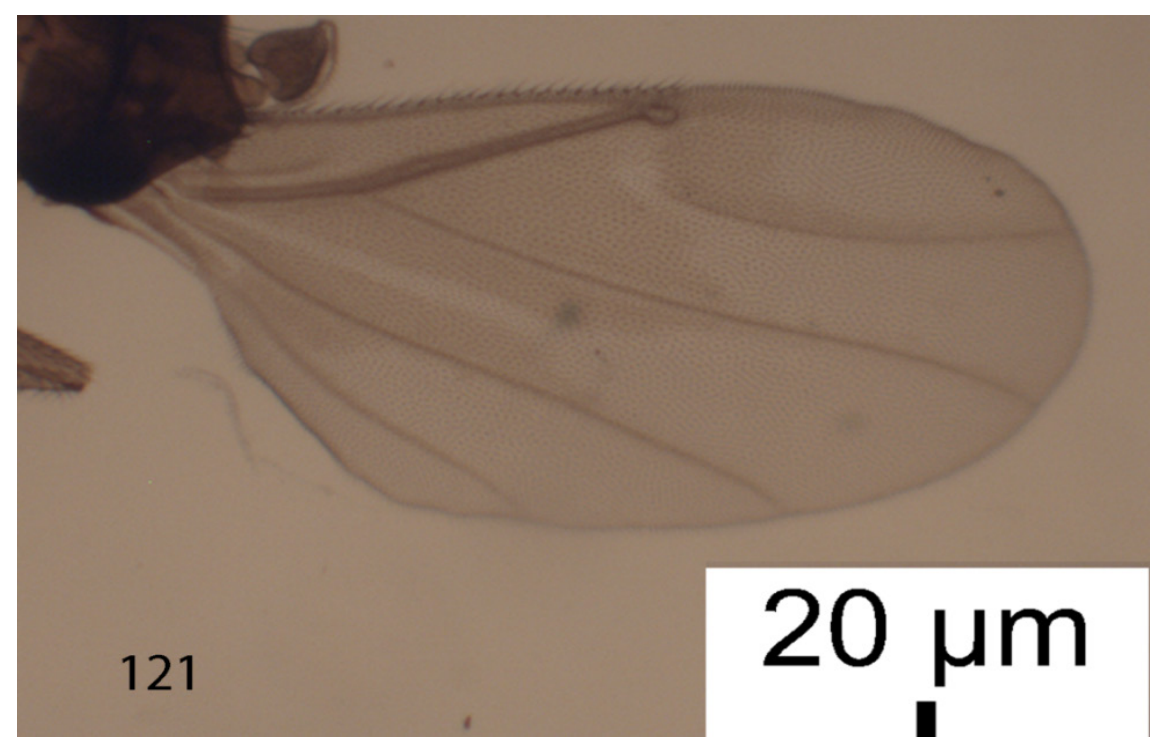

Figures 115-121. Chonocephalus irianensis male. (115) palps; (116) postpedicel; (117-119) hypopygium; (120) hind femur and tibia; (121) wing. Male

A generally brown but not dark species, with paler sides to the thorax and a light brown abdominal venter. Postpedicels as Fig. 1116. Palps as Fig. 115. The hairs of the abdominal tergites are fine and, apart from on T1, are largely restricted to the hind margins. They are longest on T6. Venter hairs also fine but shorter. Hypopygium as Figs 117-119. Legs with femora and tibiae light brown and the rest only lightly tinged pale brown. Front tarsus with posterodorsal hair palisades on segments 1 to 4 and segment 5 longer than 4. Hind femur and tibia as Fig. 120. Wing (Fig. 121) 1.09-1.10 mm long. Costal index 0.58-0.59. Haltere brown

\section{Material}

Holotype male, Indonesia, irian Jaya, Wapoga Camp, 3.14 ${ }^{\circ} \mathrm{S}, 136.57^{\circ} \mathrm{E}, 1050 \mathrm{~m}, 19-26$ June 1998, R. Snelling (LACM, 26-70).

Etymology: the name refers to the type locality.

\section{Chonocephalus ivimkaensis sp. nov.}

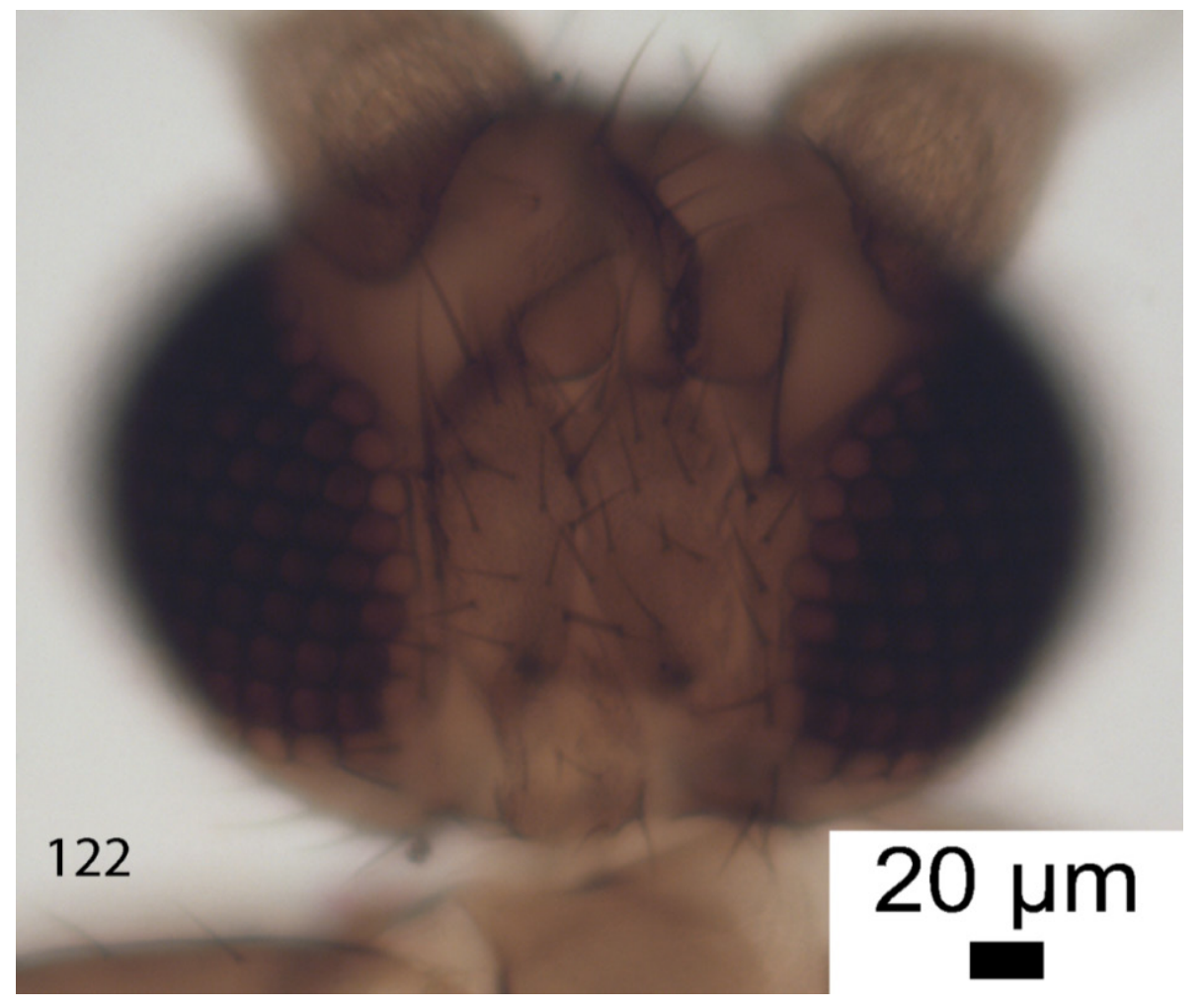



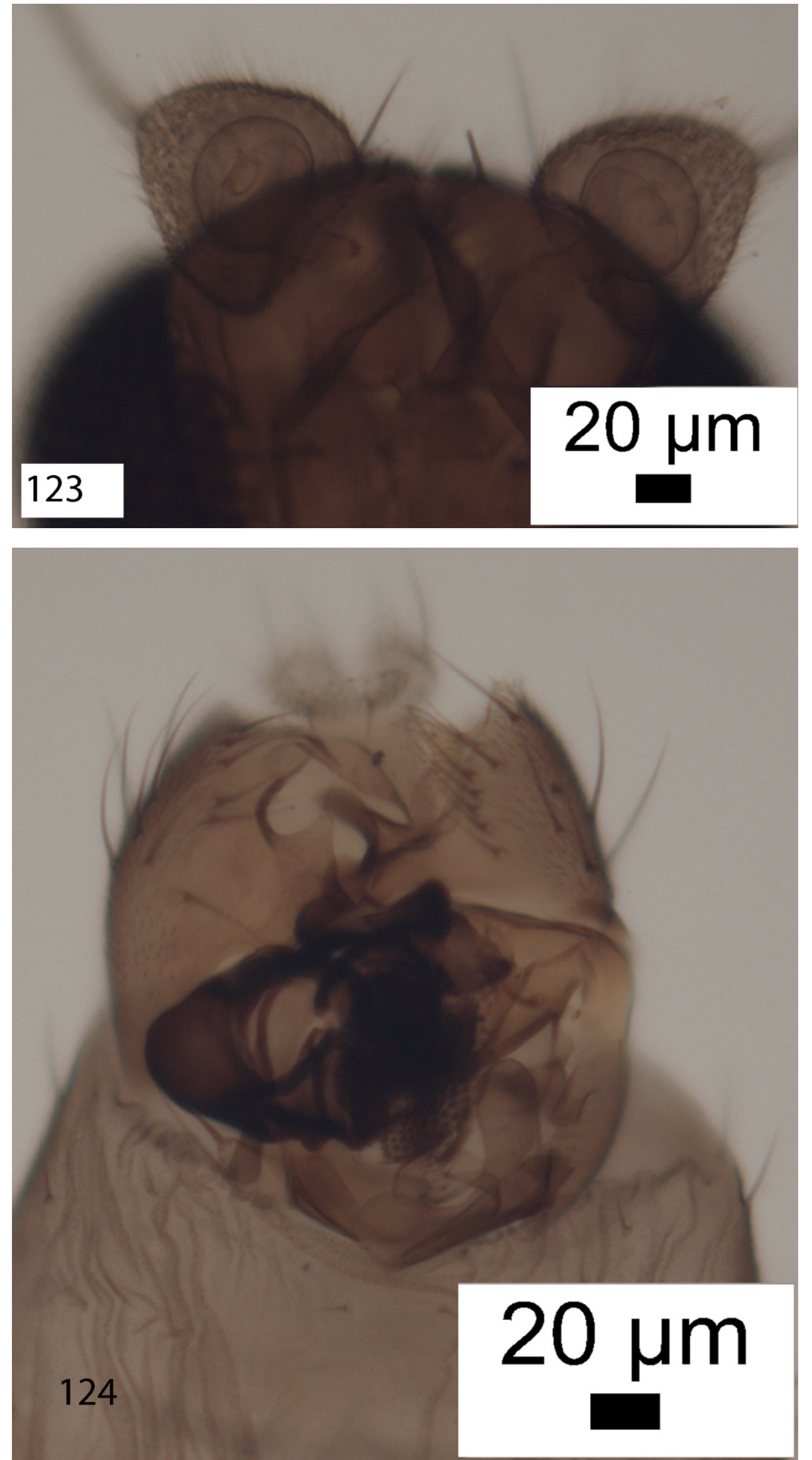

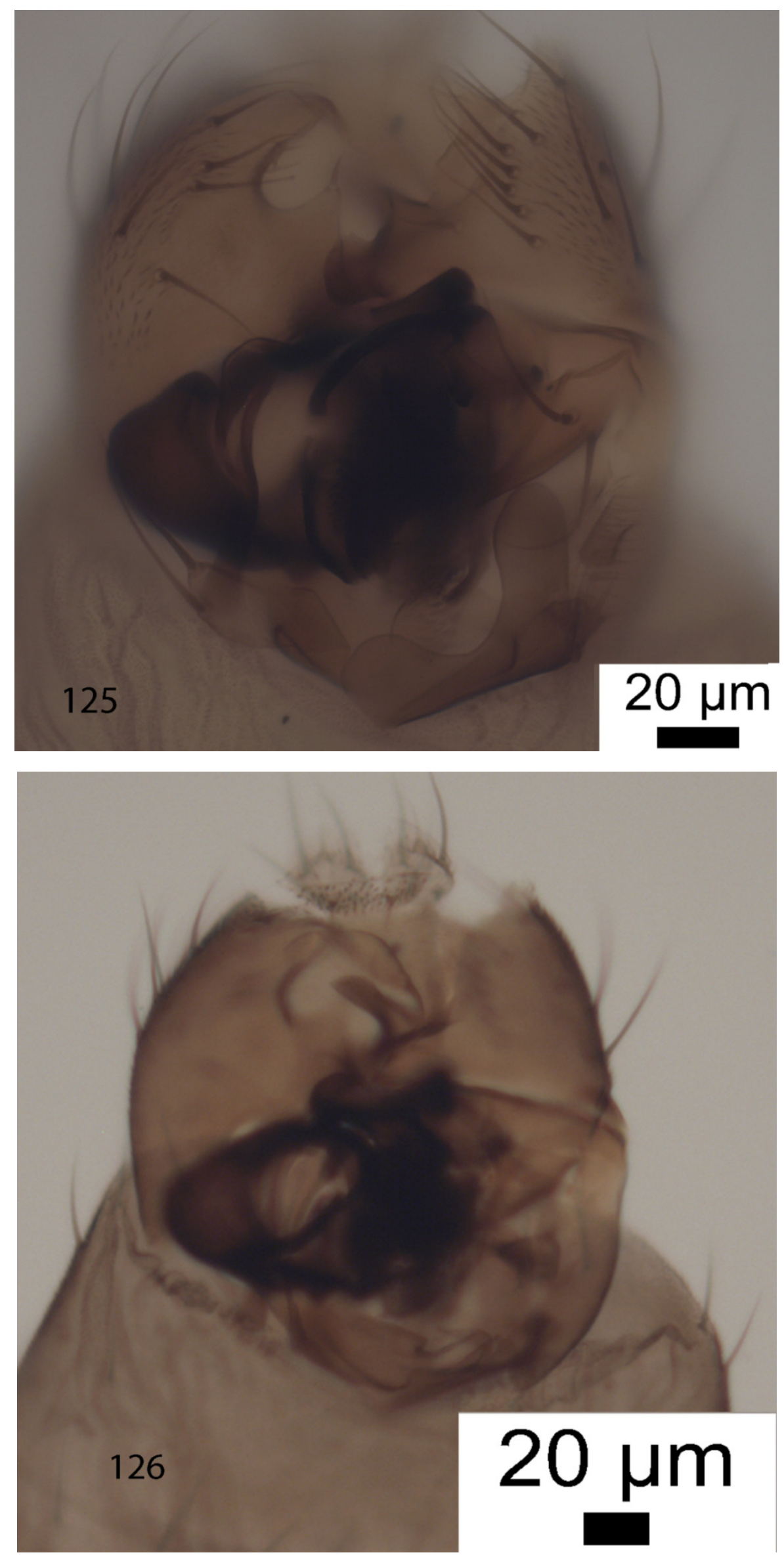

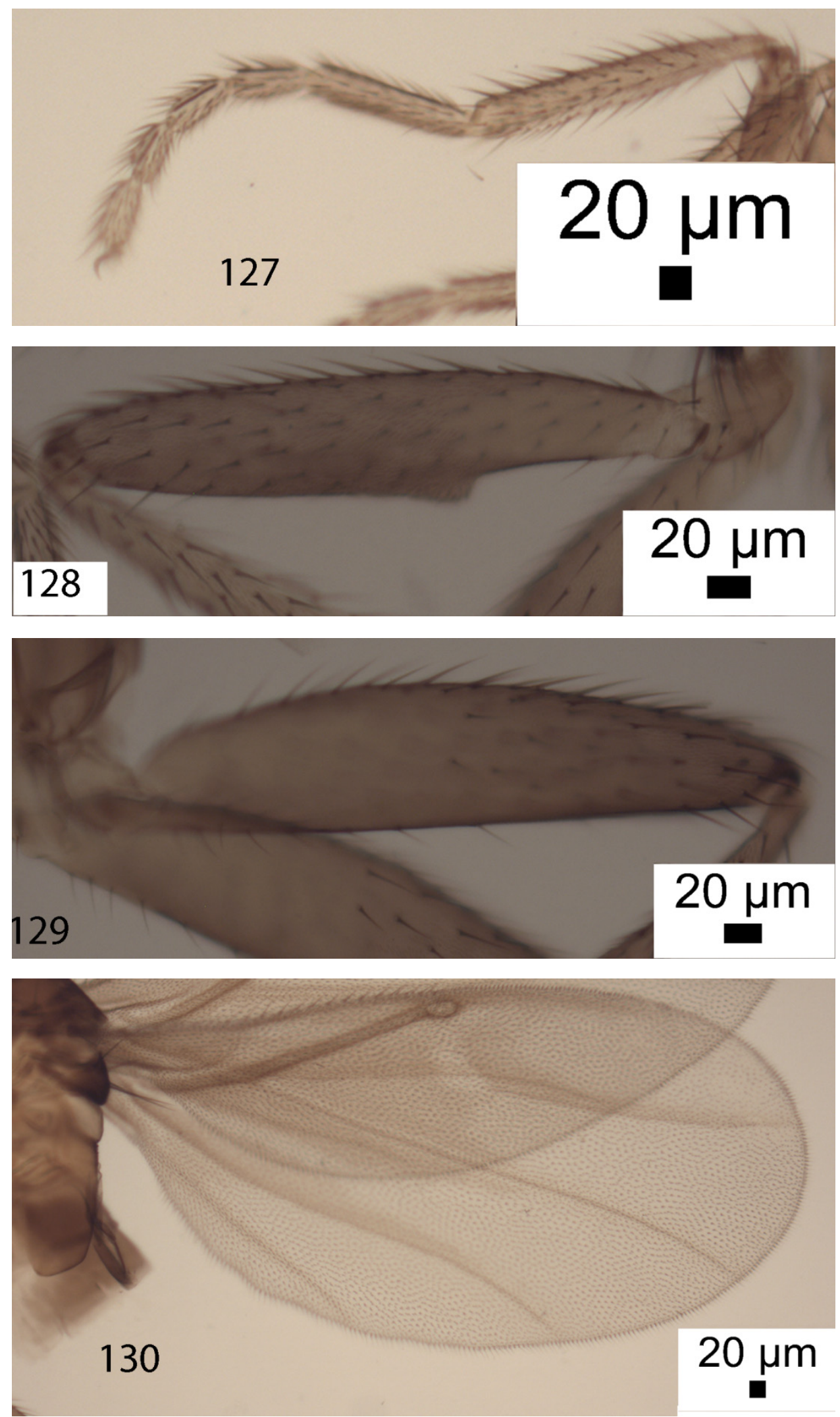

Figures 122-130. Chonocephalus ivimkaensis male. (122) palps; (123) postpedicels; (124-126) hypopygium; (127) front tarsus; (128) mid femur; (129) hind femur; (130) wing.

\section{Male}

A generally brown but not dark species, with pale sides to thorax and a pale gray abdominal venter. Postpedicel s as Fig. 
123. Palps as Fig. 122. The hairs of the abdominal tergites 2-6 are fine. They are longest on T5. Venter hairs very fine, minute and few in number. Hypopygium as Figs 124-126. Legs with coxae, femora and hind tibia brown, the rest only lightly tinged brown or paler. Front tarsus as Fig. 127. Mid femur as Fig. 128. Hind femur as Fig. 129. Wing (Fig. 130) 0.09 mm long. Costal index 0.50-0.51 Haltere brown.

\section{Material}

Holotype male, Papua New Guinea, Gulf of Ivimka, $7.73^{\circ} \mathrm{S}, 146.76^{\circ} \mathrm{E}$, Malaise trap, 10-20 1997, K. Merg (CUMZ 26-83).

Etymology: the name refers to the type locality.

\section{Chonocephalus jayaensis sp. nov.}
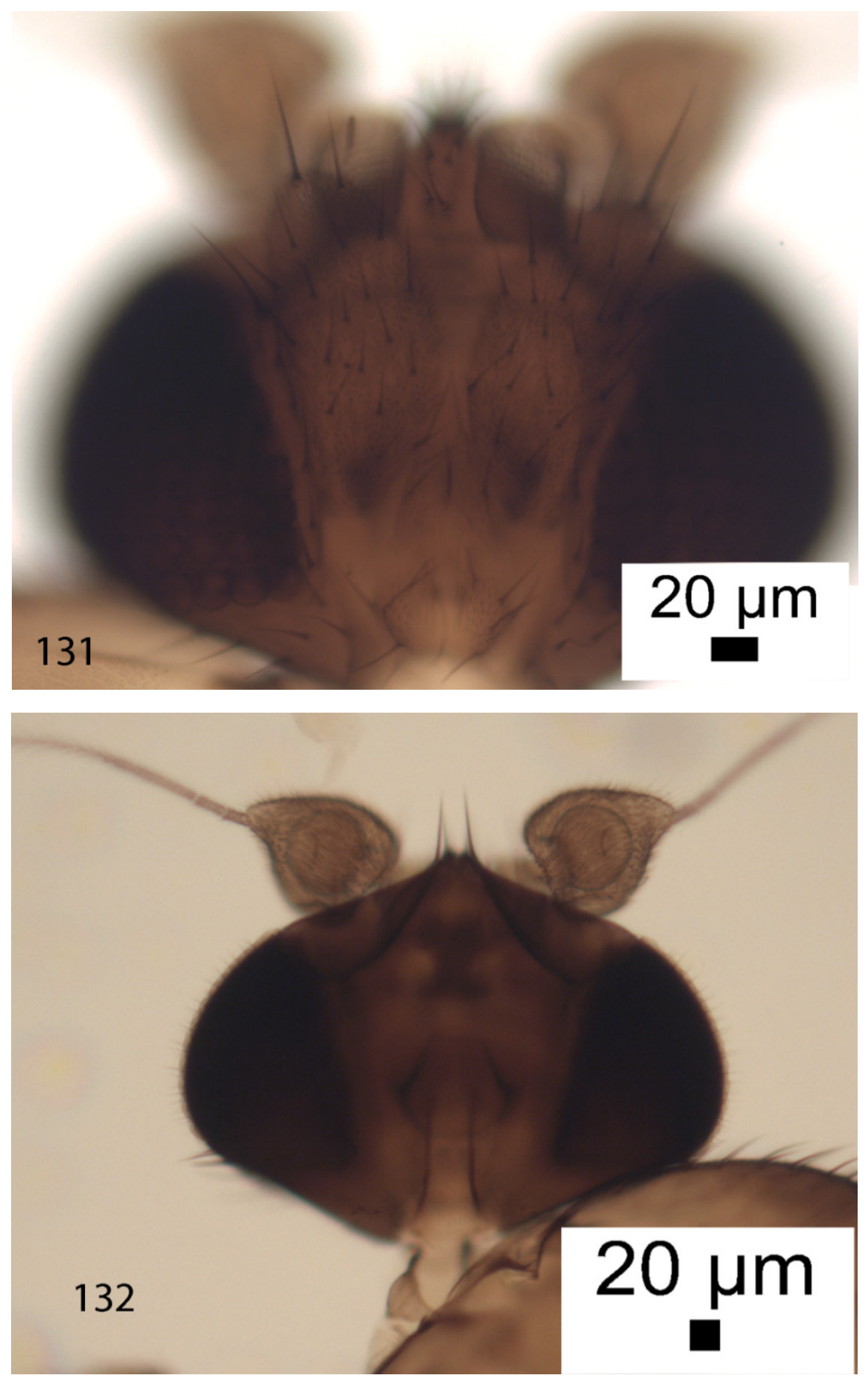

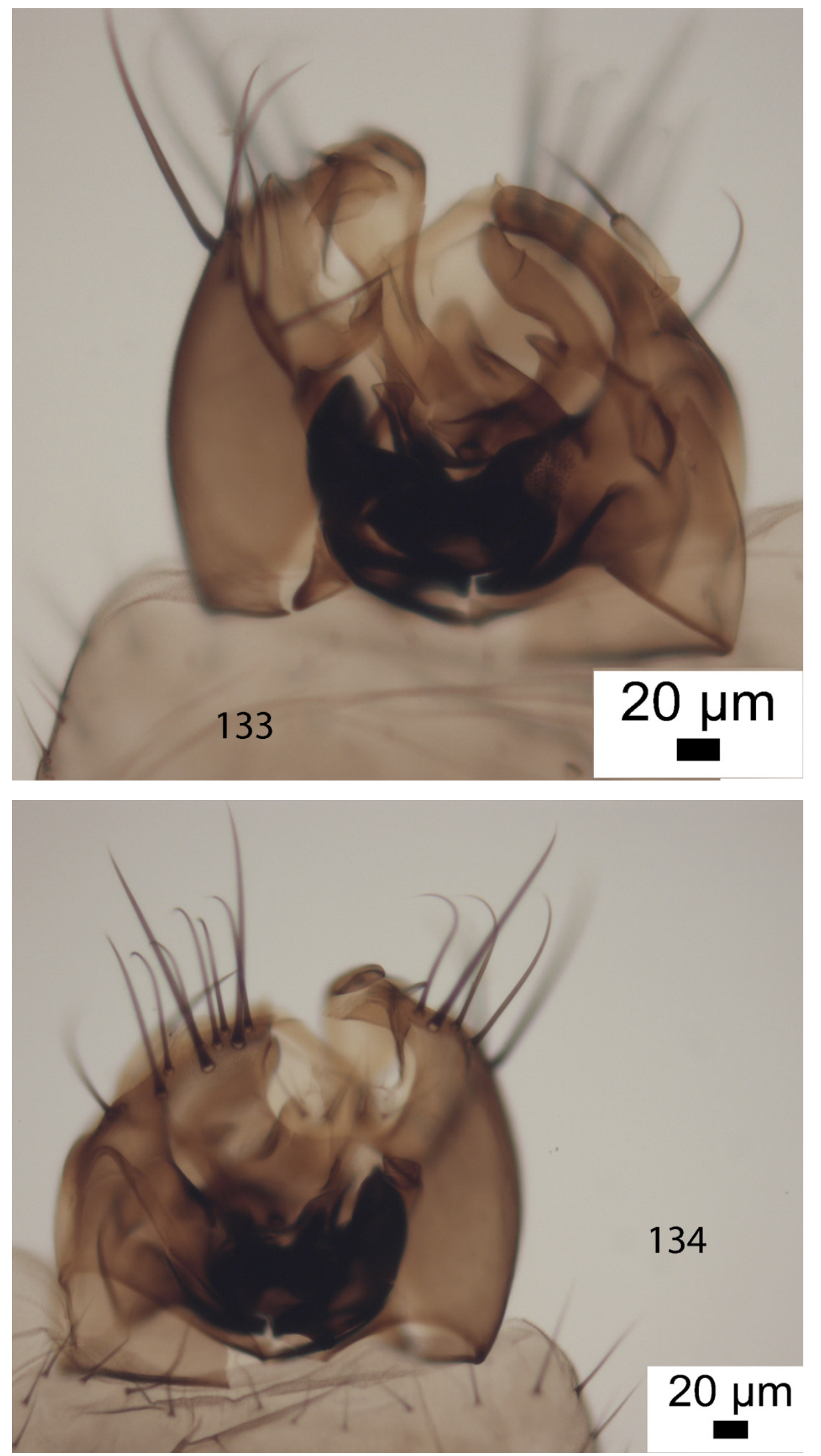

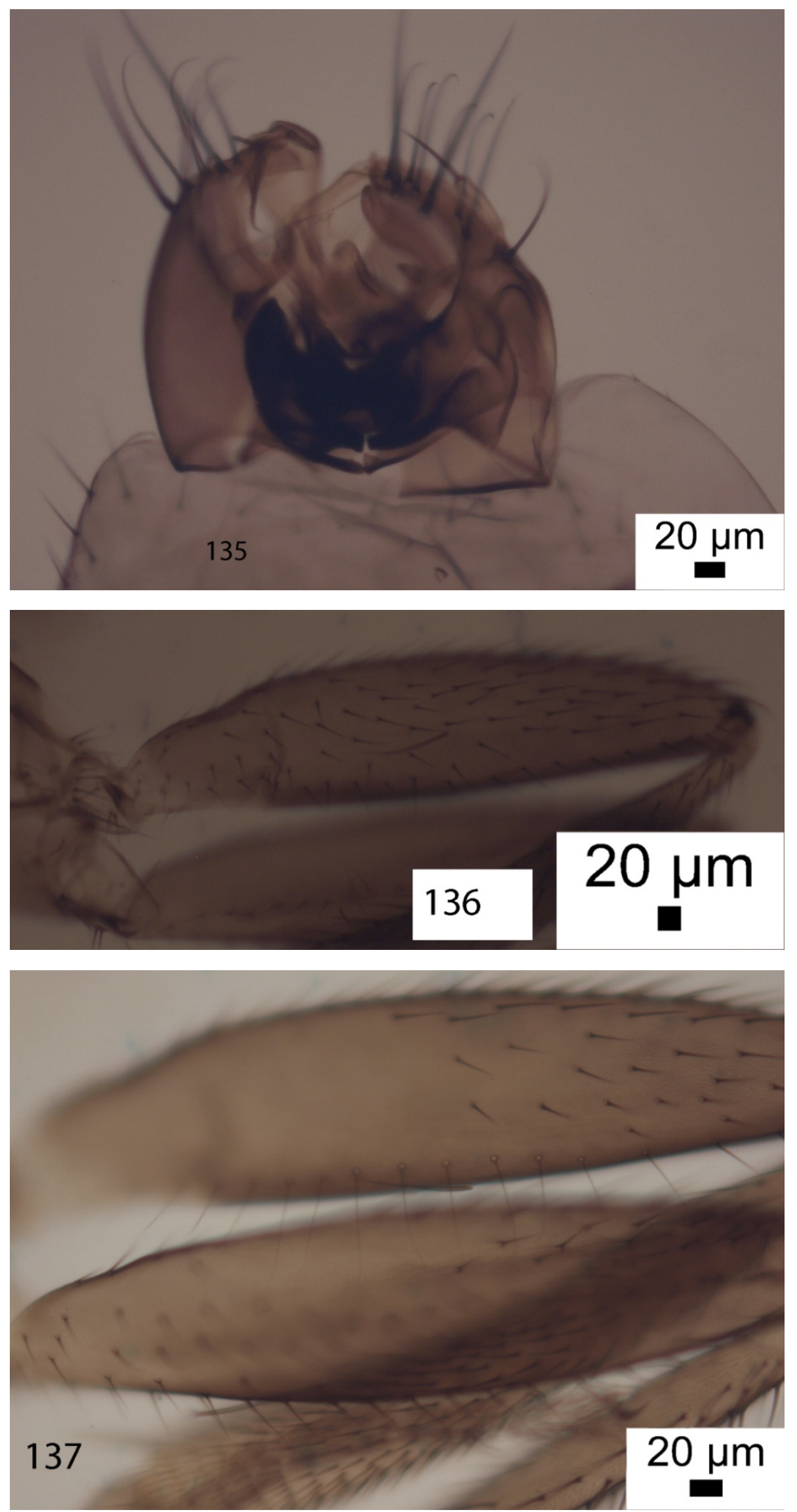


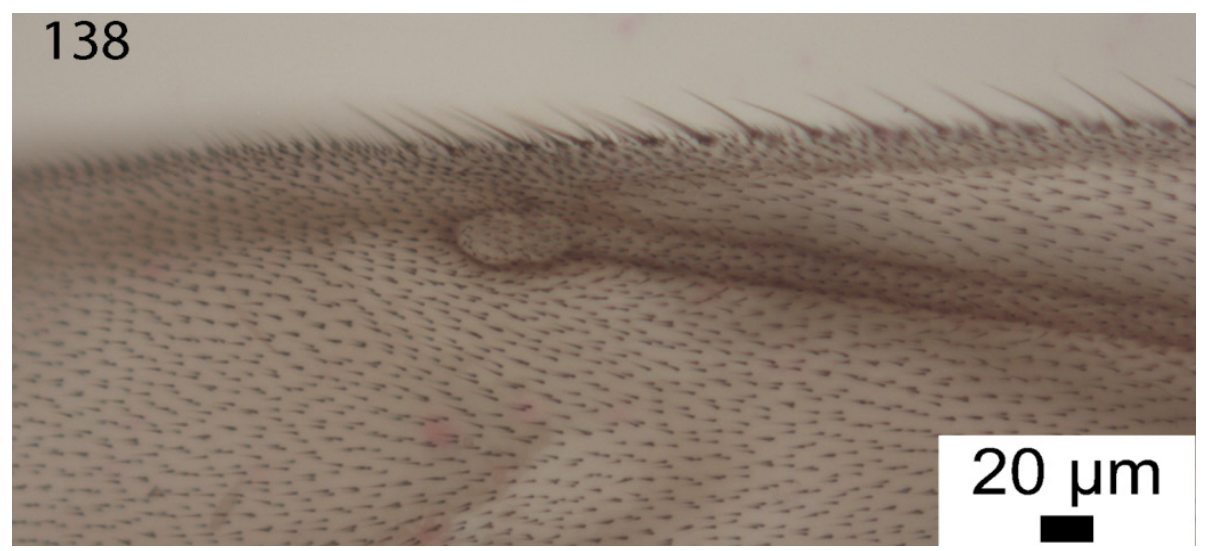

Figures 131-138. Chonocephalus jayaensis male. (131) palps; (132) postpedicels; (133-135) hypopygium (134 dorsal view); (136) hind femur; (137) the hairs of the ventral face of hind femur; (138) tips of costa and vein 3.

A generally brown but not dark species with pale sides to the thorax and a pale gray abdominal venter. Postpedicels as Fig. 132. Palps as Fig. 131. The hairs of the abdominal tergites 2-6are fine and are restricted to the hind margins except on T6. They are longest on T6 (Fig. 135). Venter hairs very small and very fine fine. Hypopygium as Figs 133-135. Legs with femora and tibiae brown and the tarsi only weakly tinged. Front tarsus with posterodorsal hair palisades on segments 1 to 4 and segment 5 longer than 4. Hind femur as Figs 136-137. Wing $1.42 \mathrm{~mm}$ long. Costal index 0.67. Tips of costa and vein 3 as Fig. 138. Veins light brown, except 7 pale gray, and membrane tinged brownish gray. Haltere brown.

\section{Material}

Holotype male, Indonesia, Irian Jaya, Wapoga Camp, $3.14^{\circ} \mathrm{S}, 136.57^{\circ} \mathrm{E}, 1050 \mathrm{~m}, 19-26$ June 1998, R. Snelling (LACM, 26-70).

Etymology: the name refers to the type locality.

\section{Chonocephalus kauensis sp. nov.}

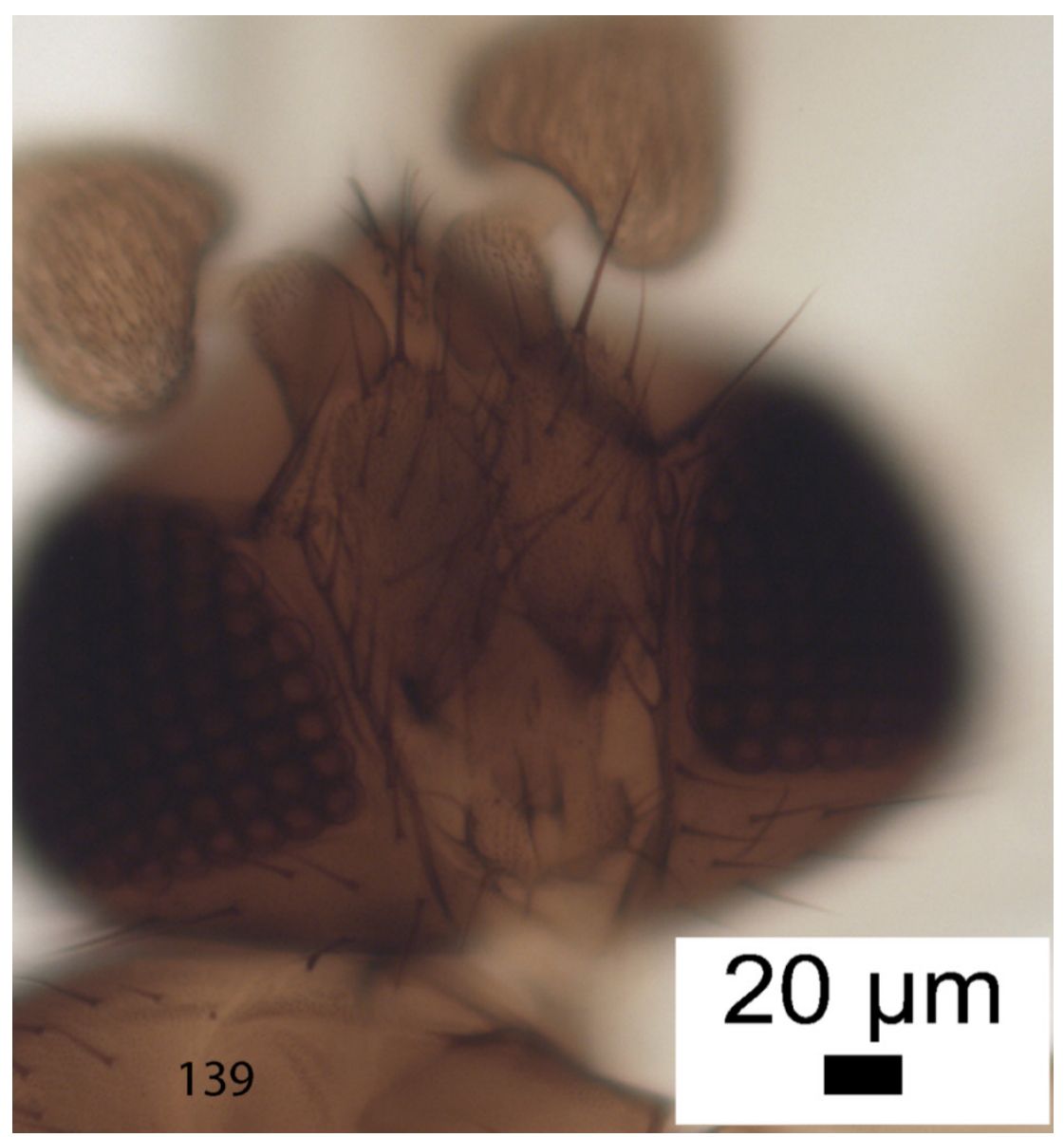



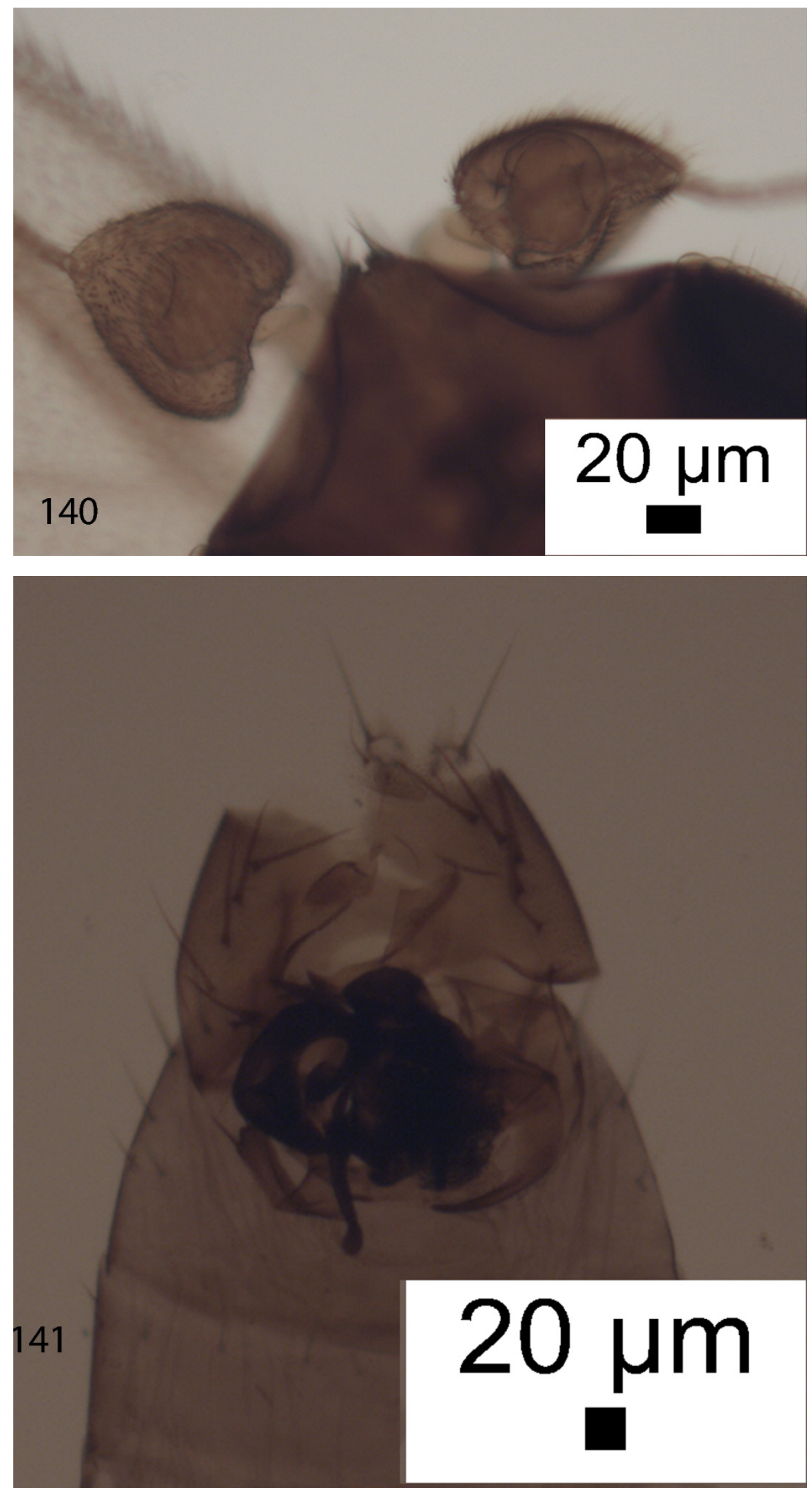

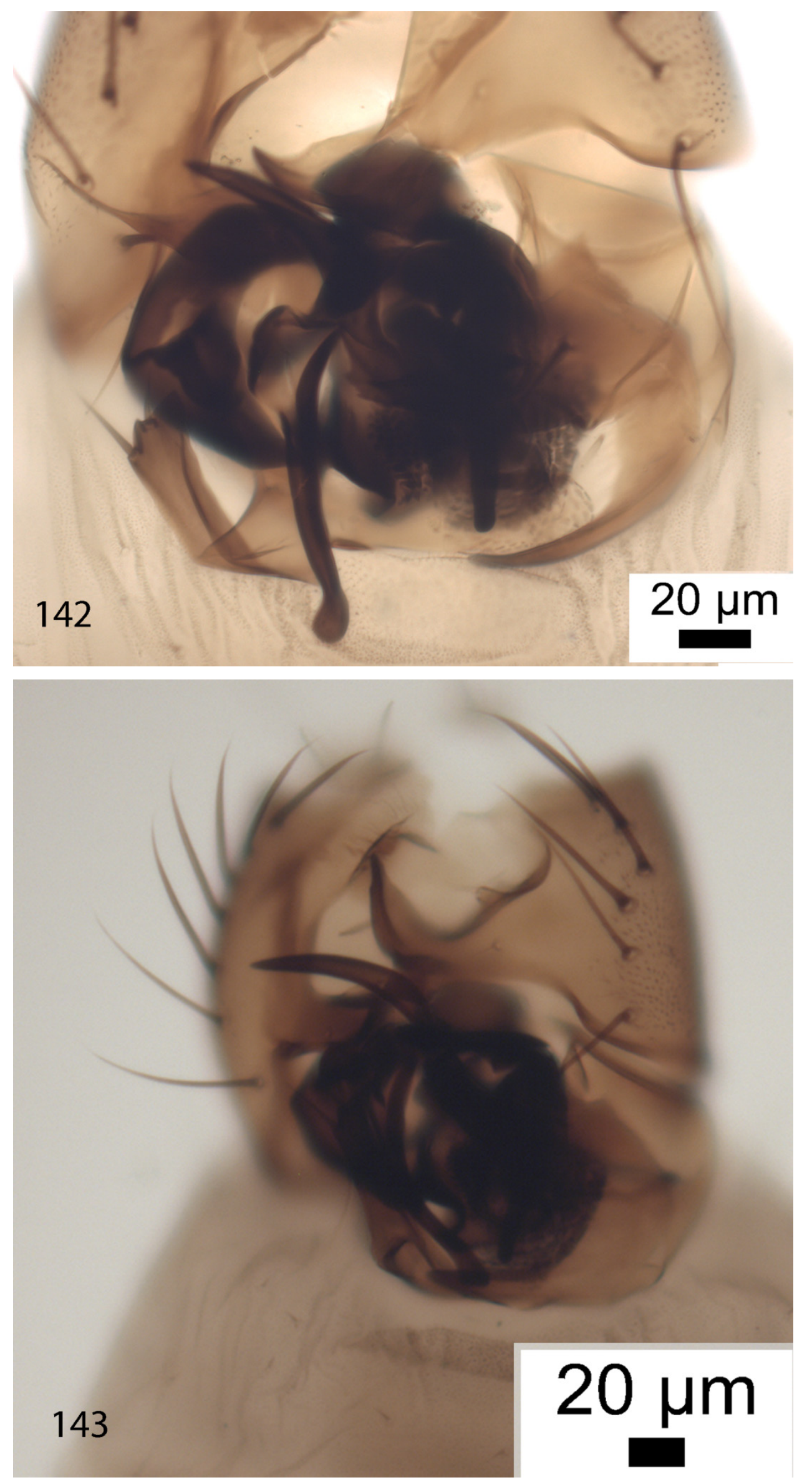

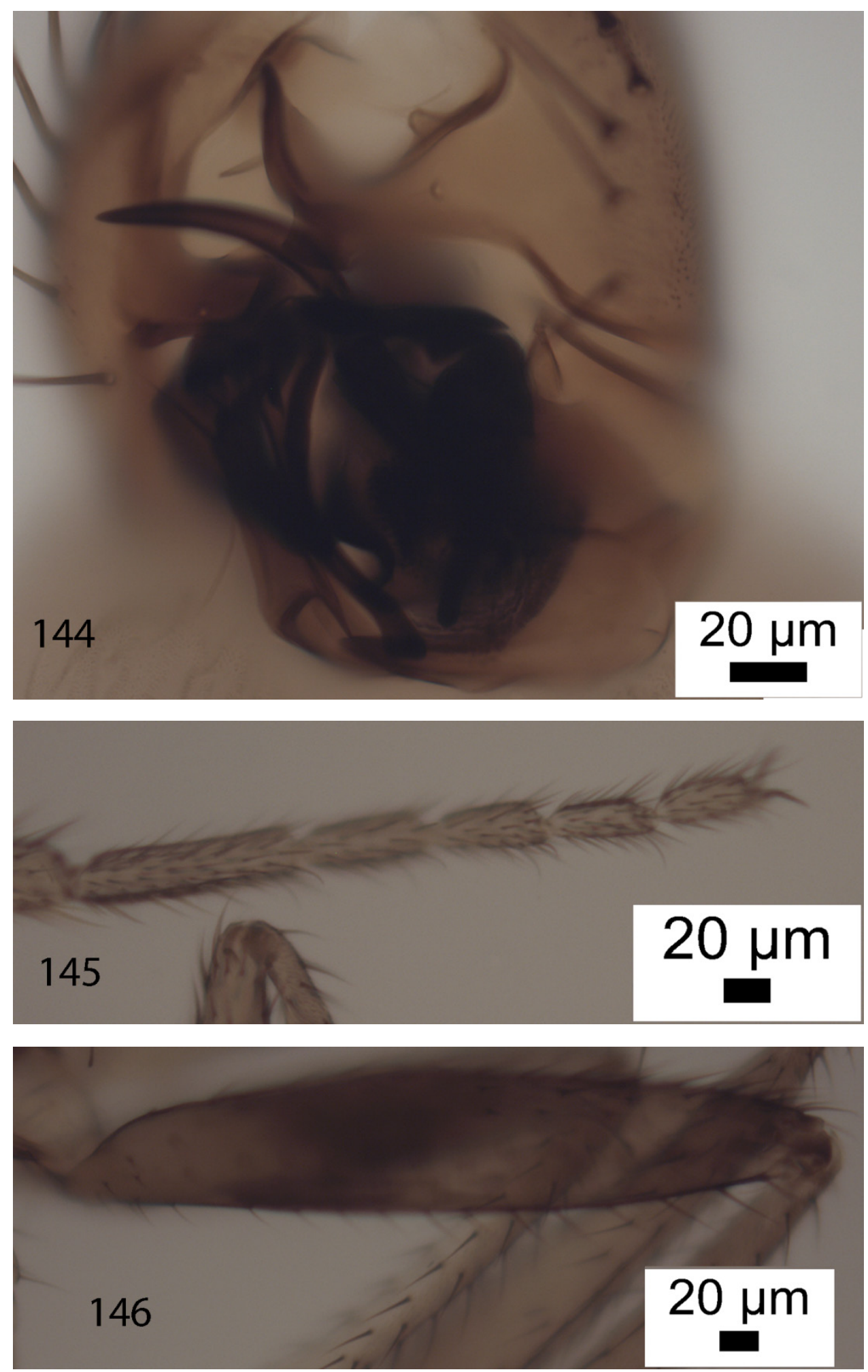


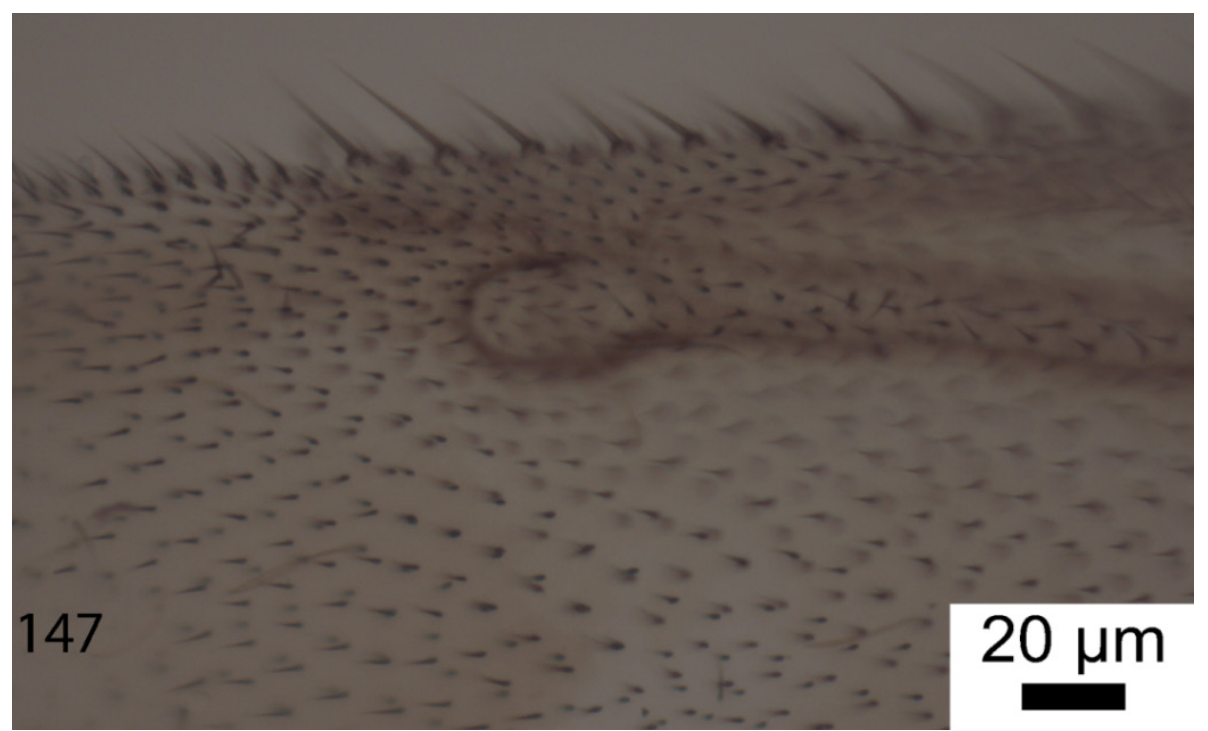

Figures 139-147. Chonocephalus kauensis male. (139) palps; (140) postpedicels; (141-144) hypopygium; (145) front tarsus; (146) hind femur; (147) tips of costa and vein 3 .

\section{Male}

A generally brown but not dark species with pale sides to the thorax and a very pale brown abdominal venter. Postpedicels as Fig. 139. Palps as Fig. 140. The hairs of the abdominal tergites 2 to 6 are fine and are not restricted to the hind margins. They are longest at rear of T6.Venter hairs very small and very fine. Hypopygium as Figs 141 to 144. Legs with mid and hind femora brown, the former being darker in the third and fourth fifths. The rest paler brown to only very lightly tinged brown, except mit tibia is white. Front tarsus as Fig. 145, with posterodorsal hair palisades on segments 1-4. Hind femur as Fig. 146. Wing $0.52 \mathrm{~mm}$ long. Costal index0.63. Tips of costa and vein 3 as Fig. 147. Allveins light brown or paler, vein 7 being palest. Membrane lightly tinged brownish grey. Haltere brown.

\section{Material}

Holotype male, Papua New Guinea, Mandang Province, Baitabang Village, Kau Wildlife Area, 50 m, primary forest, $5^{\circ} 08^{\prime}$ S, $145^{\circ} 46^{\prime} \mathrm{E}, 10$ October to 8 November 1999, L. Cízek (CUMZ, 29-65). Paratype male as holotype.

Etymology: the name refers to the type locality.

\section{Chonocephalus longisetarum sp. nov.}

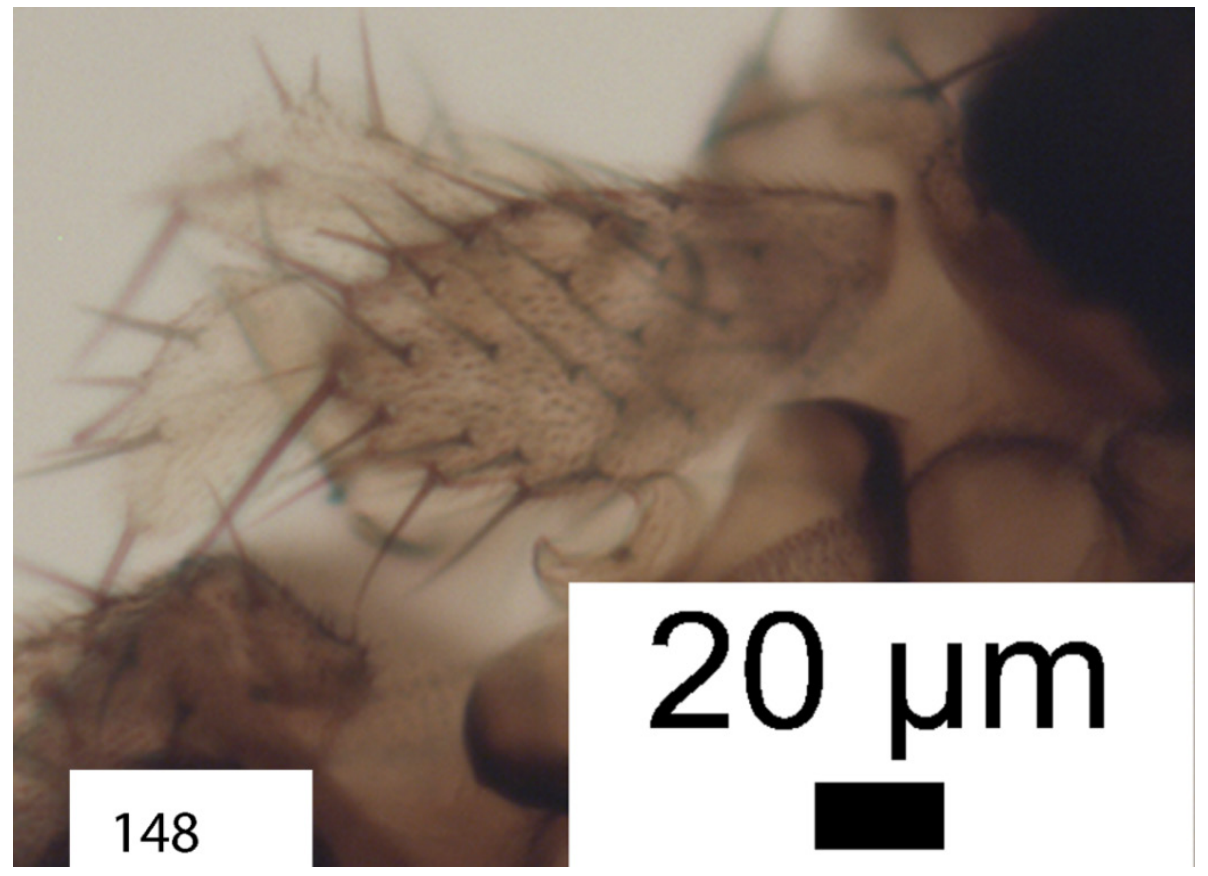



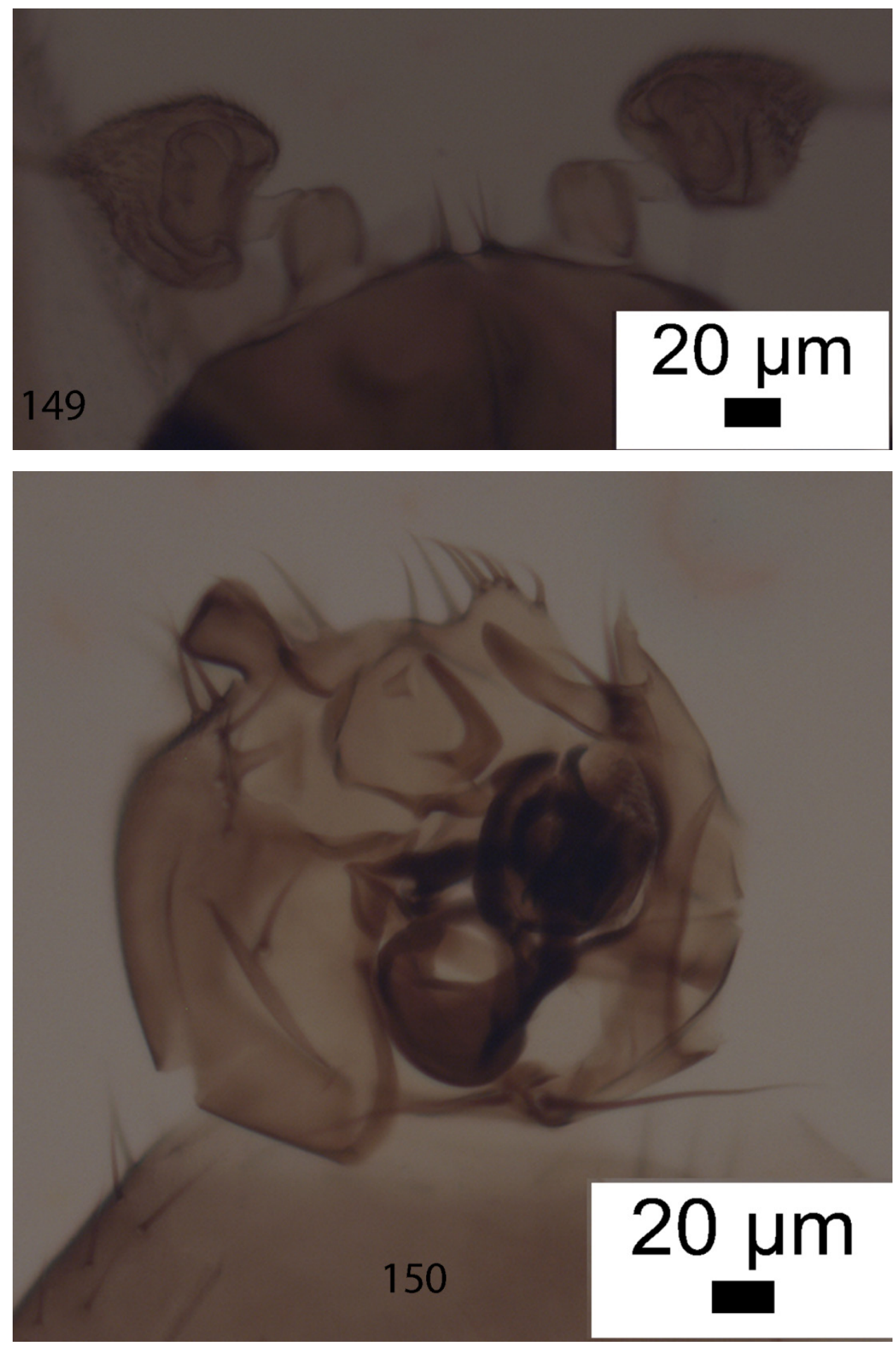


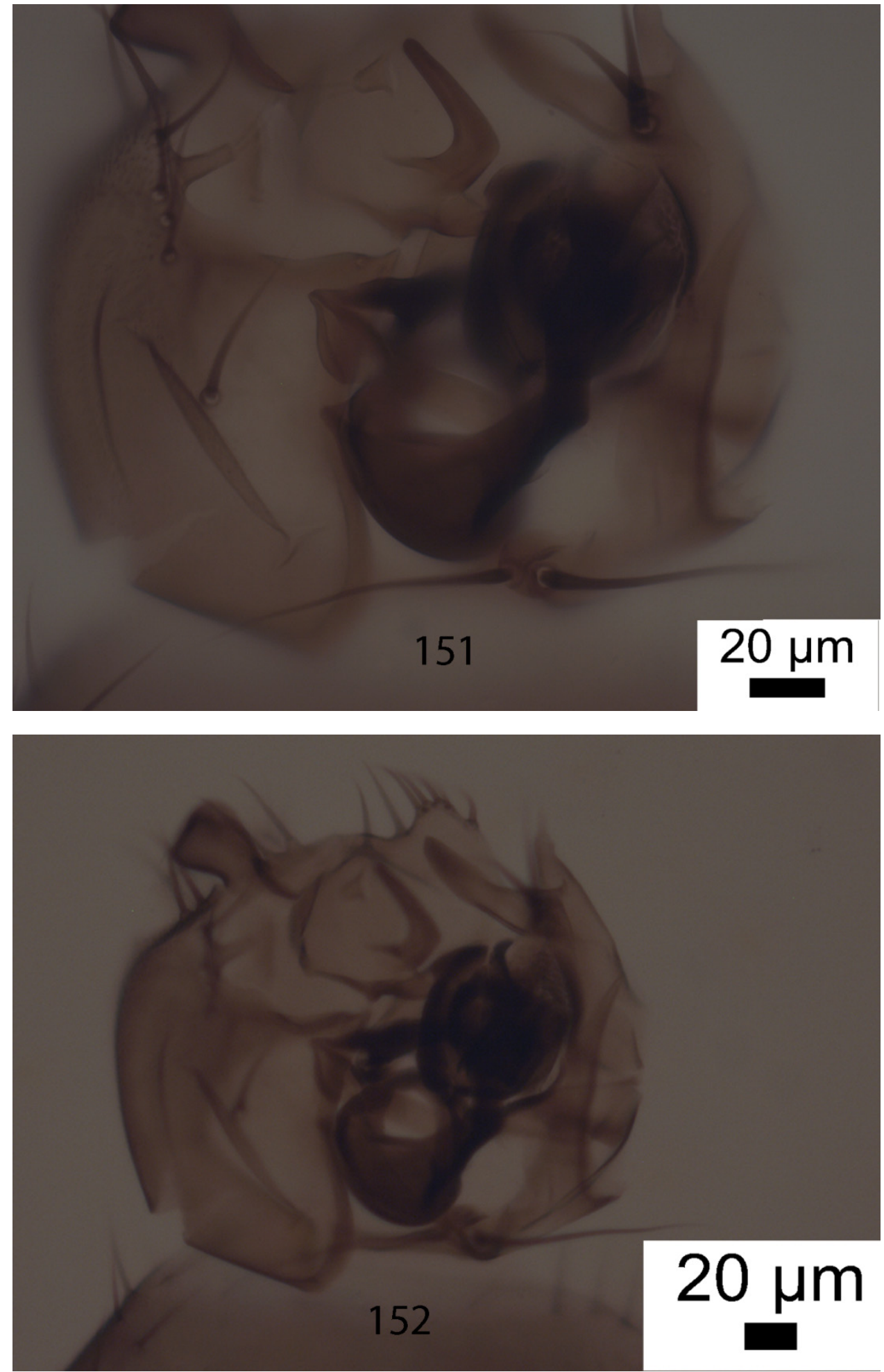



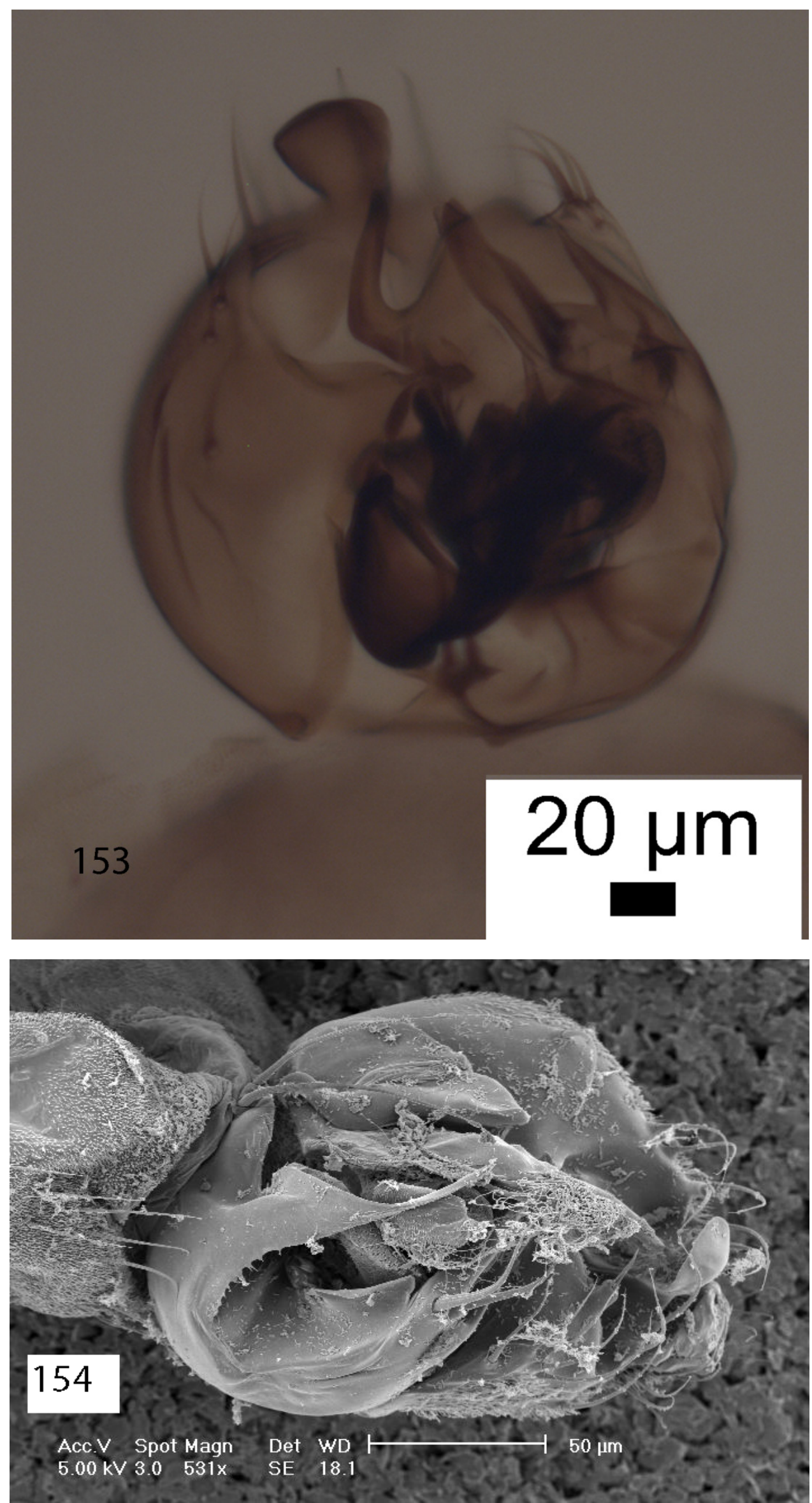

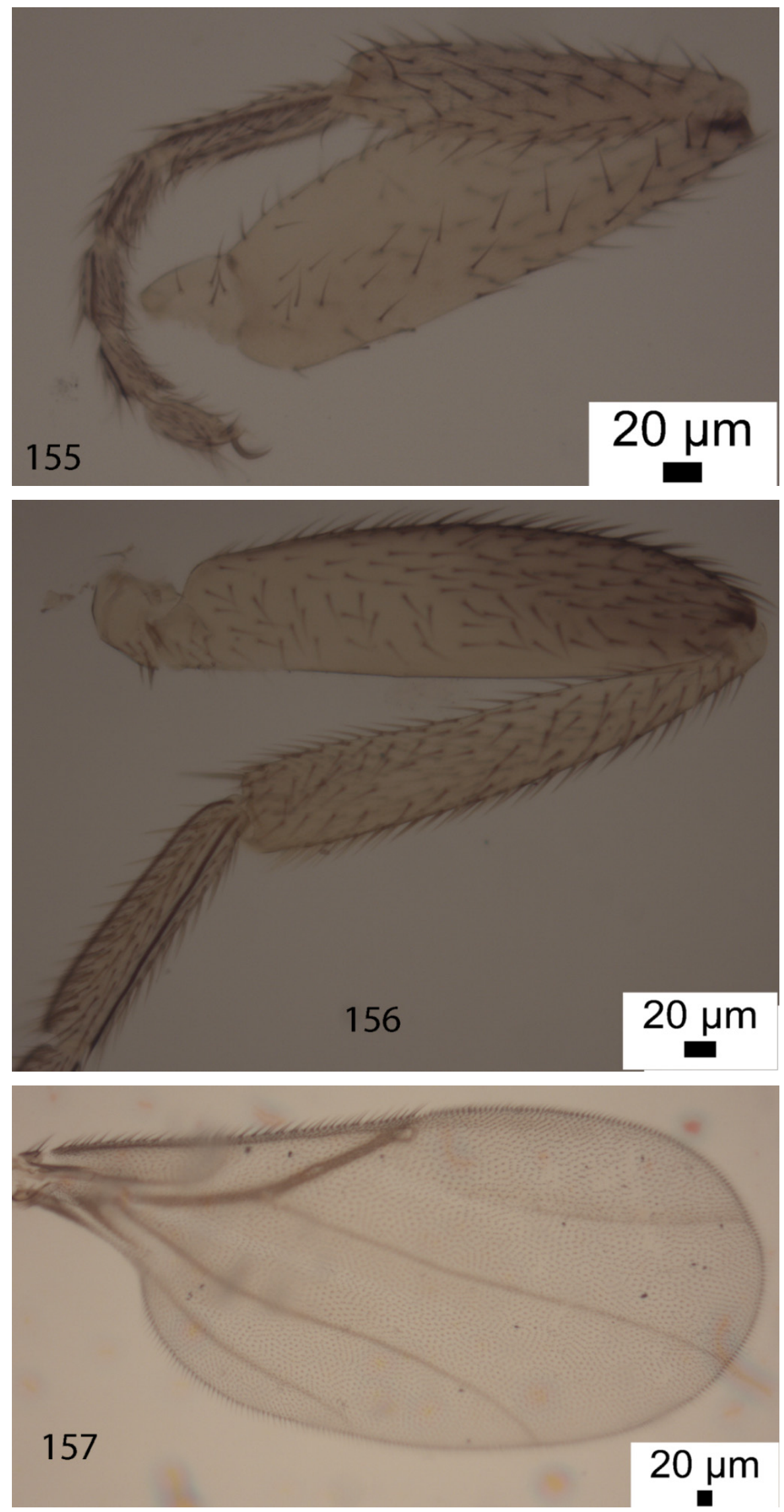

Figures 148-157. Chonocephalus longisetarum male. (148) palp; (149) postpedicels; (150-154) hypopygium; (155) front leg; (156) hind femur, tibia and basitarsus; (157) wing. 


\section{Male}

A generally light brown species with pale sides to the thorax and a very pale abdominal venter. However, the male from Henderson Island has a darker thoracic dorsum and abdominal tergites. Postpedicels as Fig. 149. Palp as Fig. 148. The hairs of the abdominal tergites 2-6 are fine and are largely restricted to the hind margins. They are only slightly longer at the rear of T6. Venter hairs smaller, very fine and few in number. Hypopygium as Figs 150-154. Legs dusky yellow (but the outer half of the hind femur is light brown in the specimen from Henderson Island). Front leg as Fig. 155. Hind femur, tibia and basitarsus as Fig. 156. Wing (Fig. 157), 0.8-0.9 mm long. Costal index 0.54. Haltere light brown (but darker in the specimen from Henderson Island).

\section{Material}

Holotype male, Fiji, Suva, April to May 1995, Malaise trap, A. van Harten (CUMZ, 2-72). Paratypes, 11 males, same data as holotype except dates, November to December 1994, January to May 1995, August-October 1996, January 1997(CUMZ, 2-61-62, 68-72). 3 males, Henderson Island, North Beach, $24^{\circ} 04^{\prime}$ S, $129^{\circ} 07^{\prime} \mathrm{W}, 17-20$ May 1987, W. N. Mathis (CUMZ, 7-23). 1 male, Tonga, Tongatapu, Government Experimental Farm, Malaise trap, 27 March 1975, W. H. Pearce (CUMZ, 4-94).

Etymology: the name refers to the long bristles on the vestigial left gonopod.

\section{Chonocephalus madangensis sp. nov.}

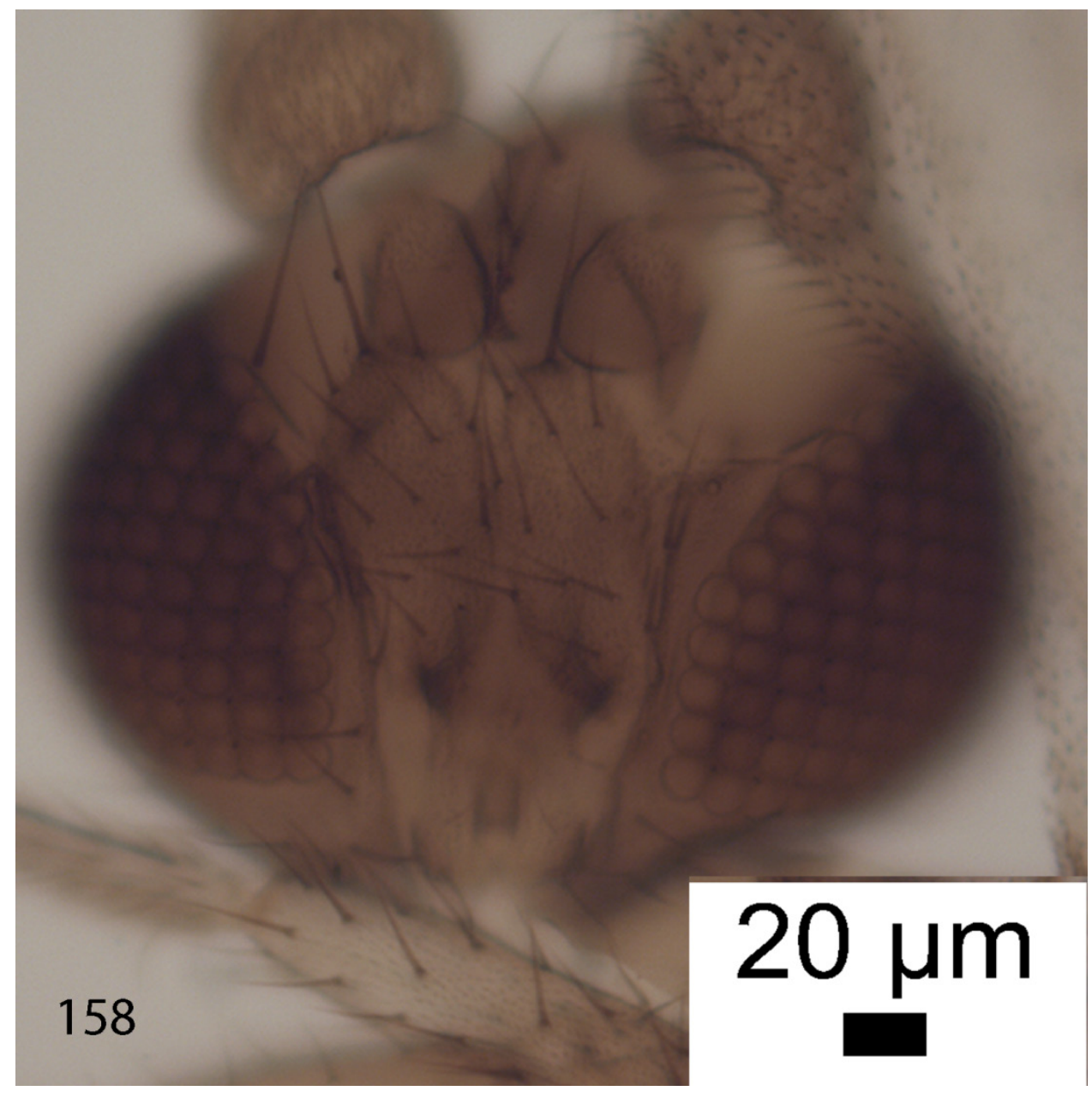




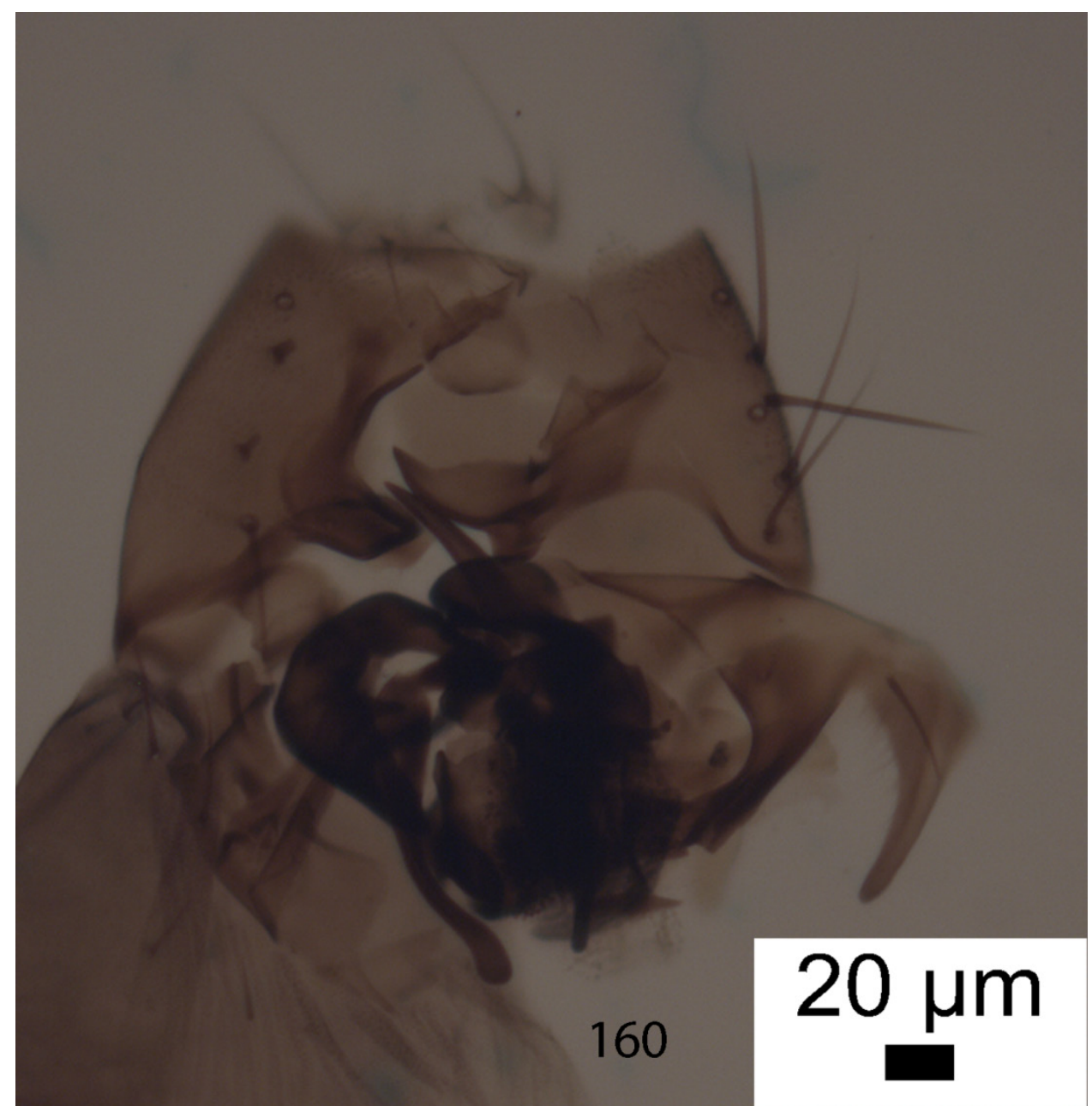




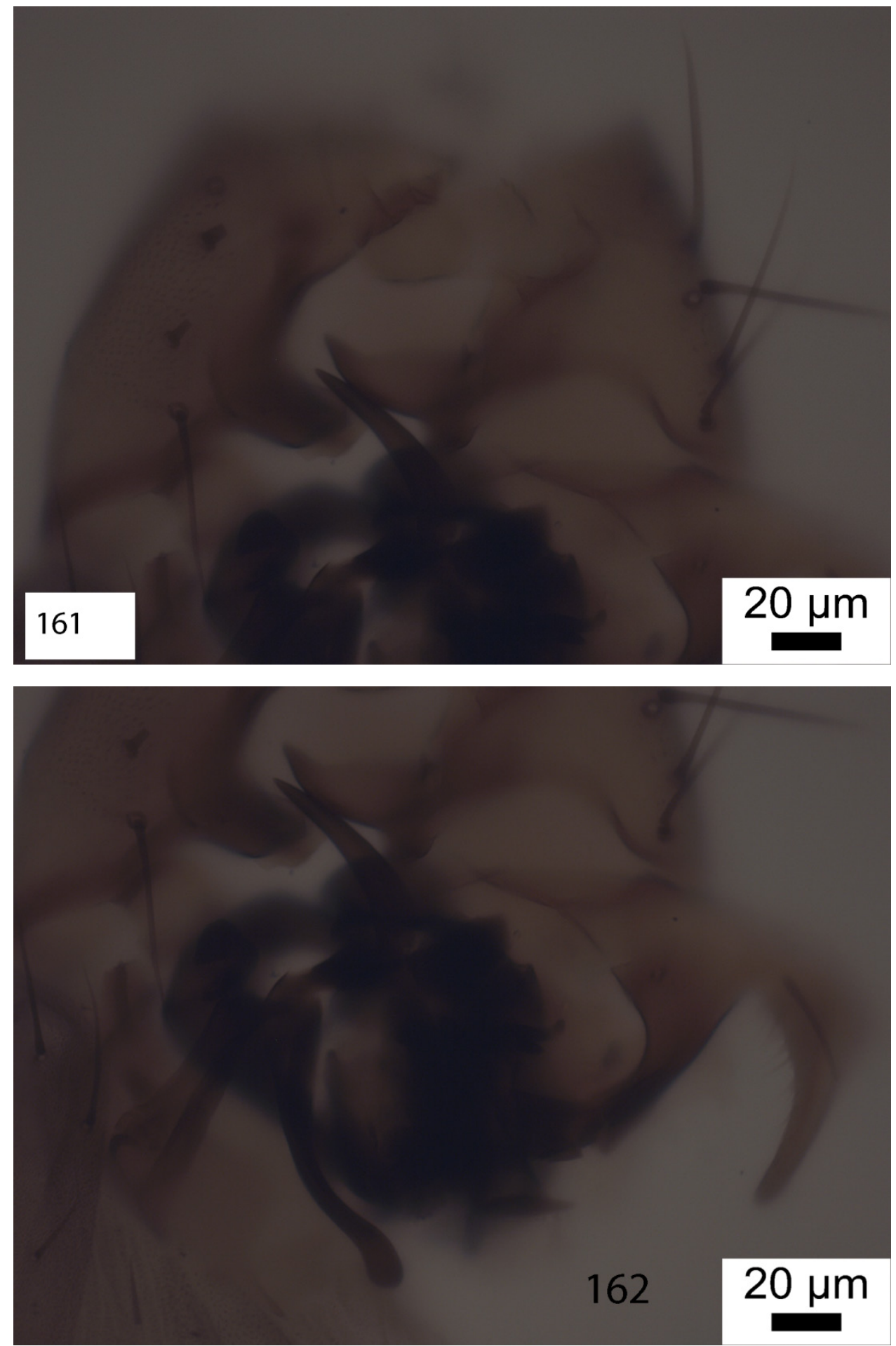



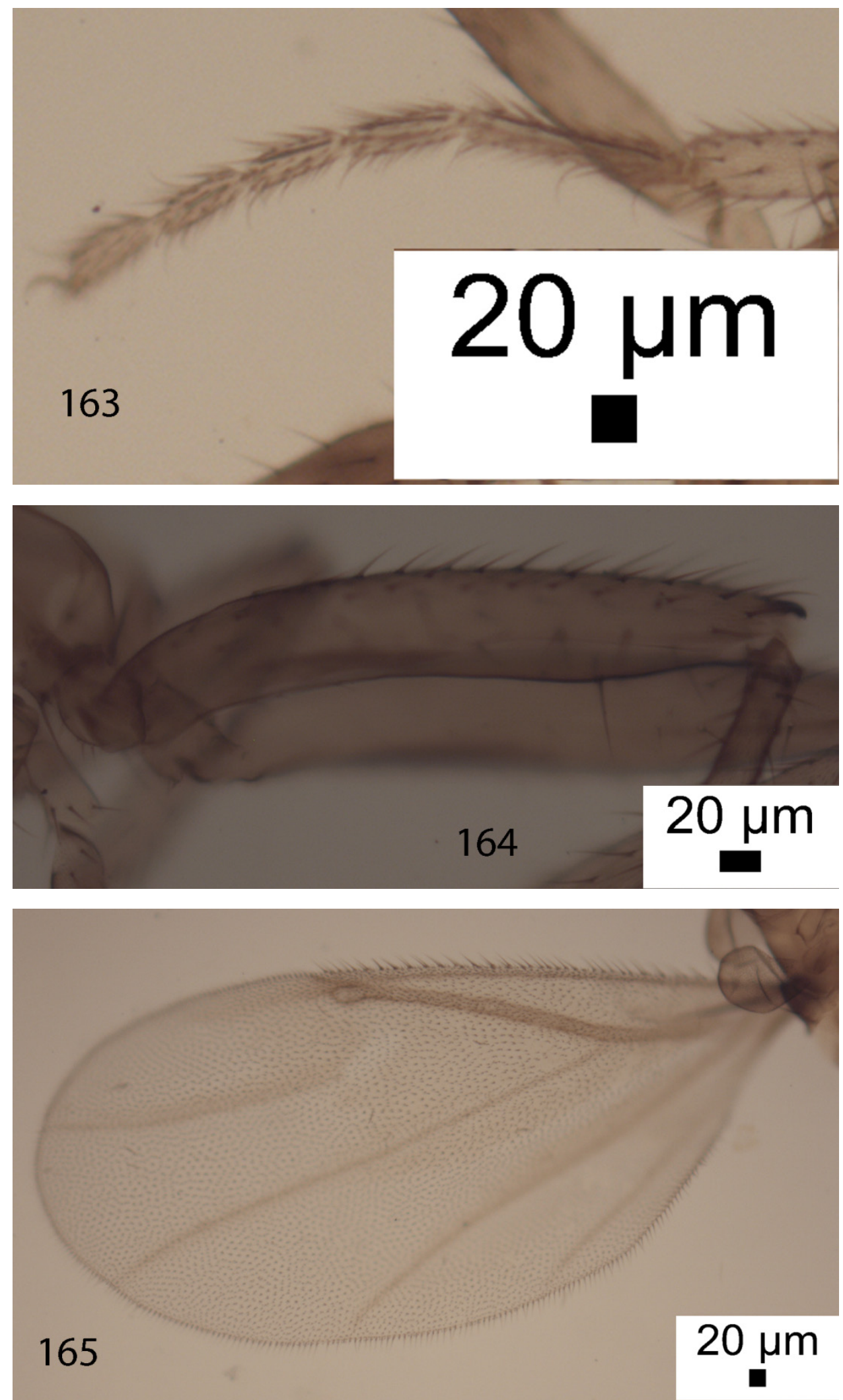

Figures 158-165. Chonocephalus madangensis male. (158) palps; (159) postpedicel; (160-162) hypopygium; (163) front tarsus; (164) hind femur; (165) wing.

\section{Male}

A generally pale brown species, with pale sides to the thorax and a pale abdominal venter. Postpedicel as Fig. 159. Palps as Fig. 158. The hairs of the abdominal tergites on segments 2 to 6 are fine and are largely restricted to the hind margins except 
on T6, where they are longest at its hind margin. Venter hairs extremely small and fine and few in number. Hypopygium as Figs 160-162. Legs with mid and hind femora and hind tibia brown, and with a darker patch in the third quarter of the mid femur. The rest of the legs only lightly tinged, especially the mid tibia and all the tarsi. Front tarsus as Fig. 163, with posterodorsal hair palisades on segments 1 to 4 . Hind femur as Fig. 164. Wing (Fig. 165) 0.93-0.94 mm long. Costal index 0.65-0.66. Haltere brown.

\section{Material}

Holotype male, Papua New Guinea, Mandang Province, Baitabang Village, Kau Wildlife Area, 50 m, primary forest, $5^{\circ} 08^{\prime}$ S, $145^{\circ} 46^{\prime}$ E, 10 October to 8 November 1999, L. Cízek (CUMZ, 29-65).

Etymology: the name refers to the type locality.

\section{Chonocephalus major Schmitz}

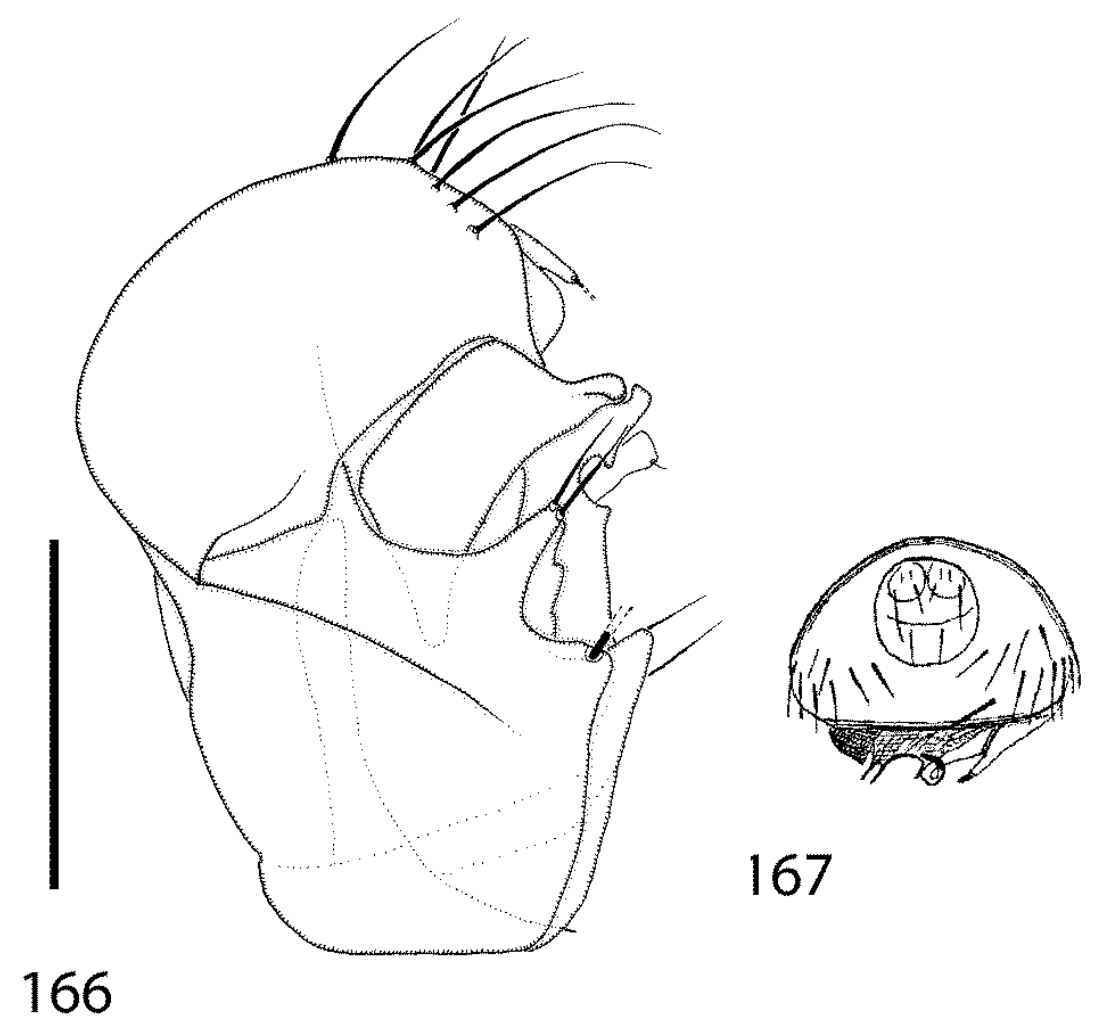

Figures 166-167. Chonocephalus major male, hypopygium: (166) left face with dorsal face tilted away from viewer (Scale bar $=0.1 \mathrm{~mm})$; (167) rear view (after Schmitz, 1929).

Chonocephalus major Schmitz, 1928 [19]: 92.

The hypopygium of the type is damaged and mounted so that the left face is tilted at an angle away from the viewer.

\section{Material}

Male type (on 2 slides), Bismarck Archipelago, Lowon auf Neupommern, near carrion, 28 May - 1 June 1896 (MKB 27-135).

\section{Natural history}

The holotype was reported on carrion (Schmitz [19]).

\section{Chonocephalus mergi sp. nov.}


168

\section{$20 \mu \mathrm{m}$}

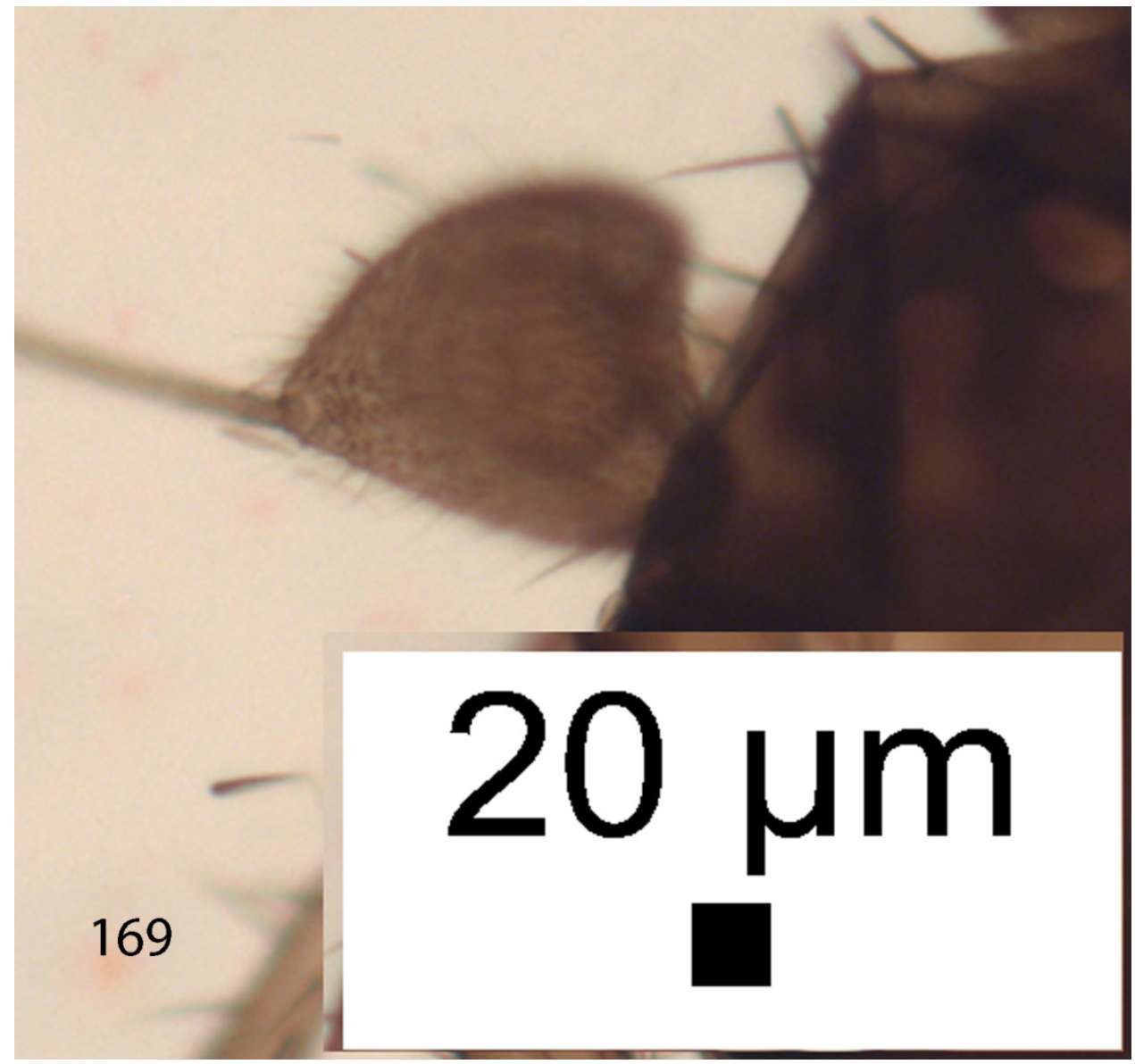



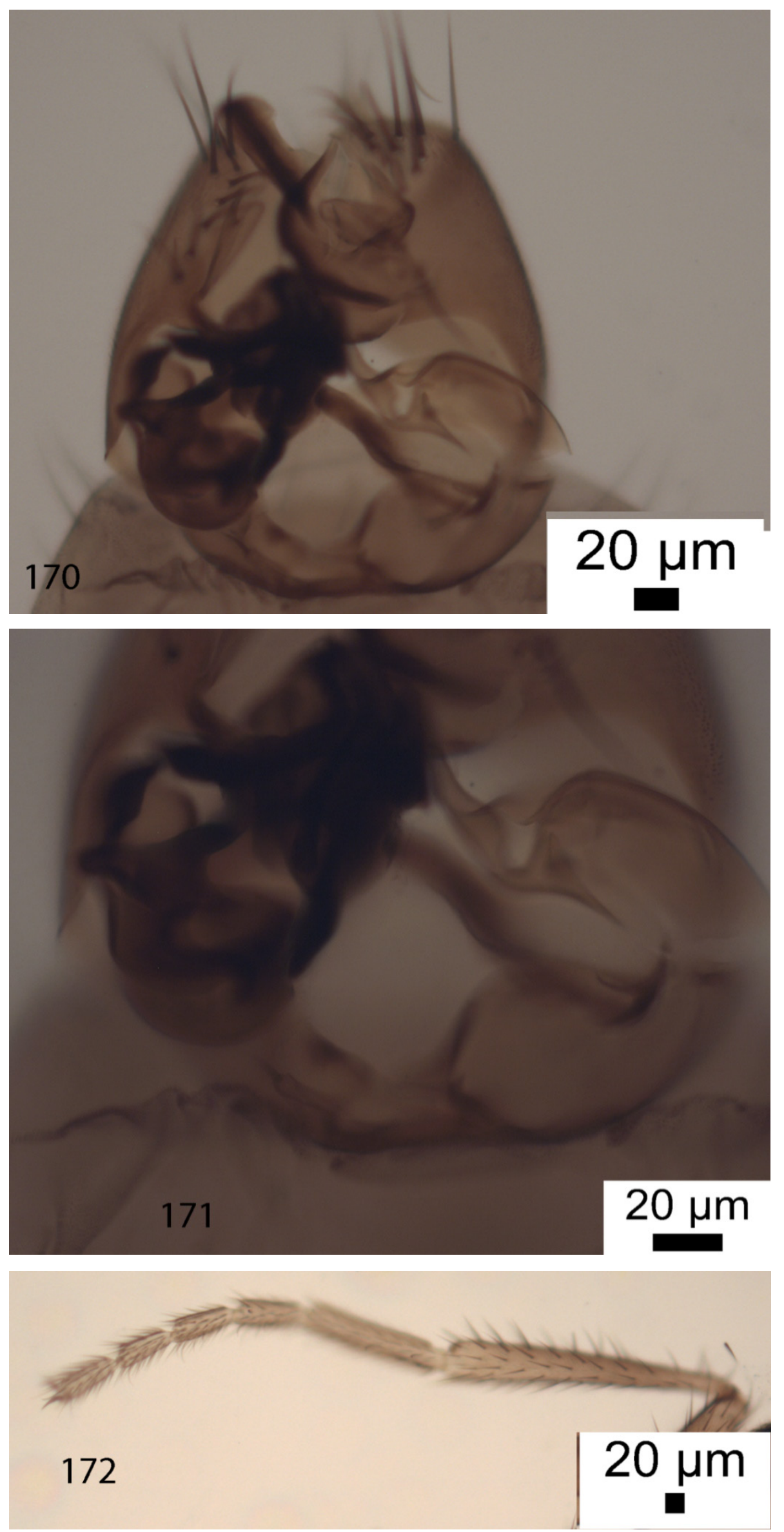

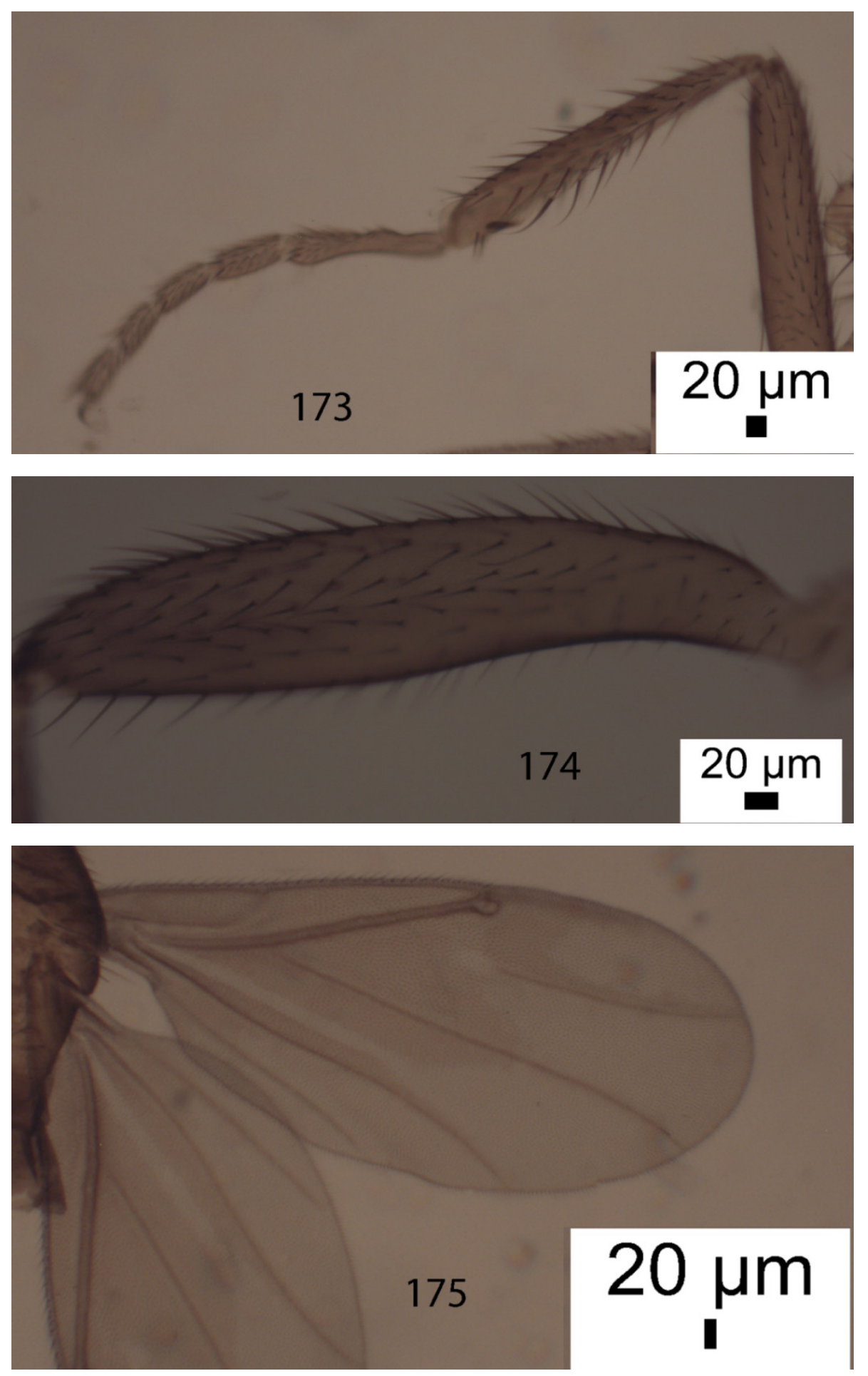

Figures 168-175. Chonocephalus mergi male. (168) palps; (169) postpedicel; (170-171) hypopygium; (172) front tibia and tarsus; (173) mid tibia and basitarsus; (174) hind femur; (175) wing.

\section{Male}

A generally brown, but not dark, species with a light brown abdominal venter. Postpedicel as Fig. 169. Palps as Fig. 168. The hairs of the abdominal tergites are moderately fine and not restricted to the hind margins. They are longest at rear of T6. Venter hairs very fine, minute and few in number. Hypopygium as Figs 170-171. Legs brown, but not dark, and tarsi only lightly tinged. Front tibia and tarsus as Fig. 172. Mid tibia and basitarsus as Fig. 173. Hind femur as Fig. 174. Wing (Fig. 175) 1.30-1.31 mm long. Costal index 0.53-0.54. Haltere brown.

\section{Material}


Holotype male, Papua New Guinea, Gulf of Ivimka, $7.73^{\circ} \mathrm{S}, 146.76^{\circ} \mathrm{E}$, Malaise trap, 9 December 1996 to 10 January 1997 , K. Merg (CUMZ - 26-84). Paratypes, 11 males as holotype; 4 males as holotype except 10-20 March 1997 (CUMZ, LACM, 26-72 \& 83); 1 male, as holotype except, 110 m, 11-20 November 1996, R. Snelling (CUMZ, 26-82). 1 male as holotype except 1-8 December 1996, R. Snelling (LACM, 26-70); 1 male, 20 February to 1 March 1997, R. Snelling (LACM, 26-58).

Etymology: the name refers to the collector of the holotype.

\section{Chonocephalus palposus Schmitz}
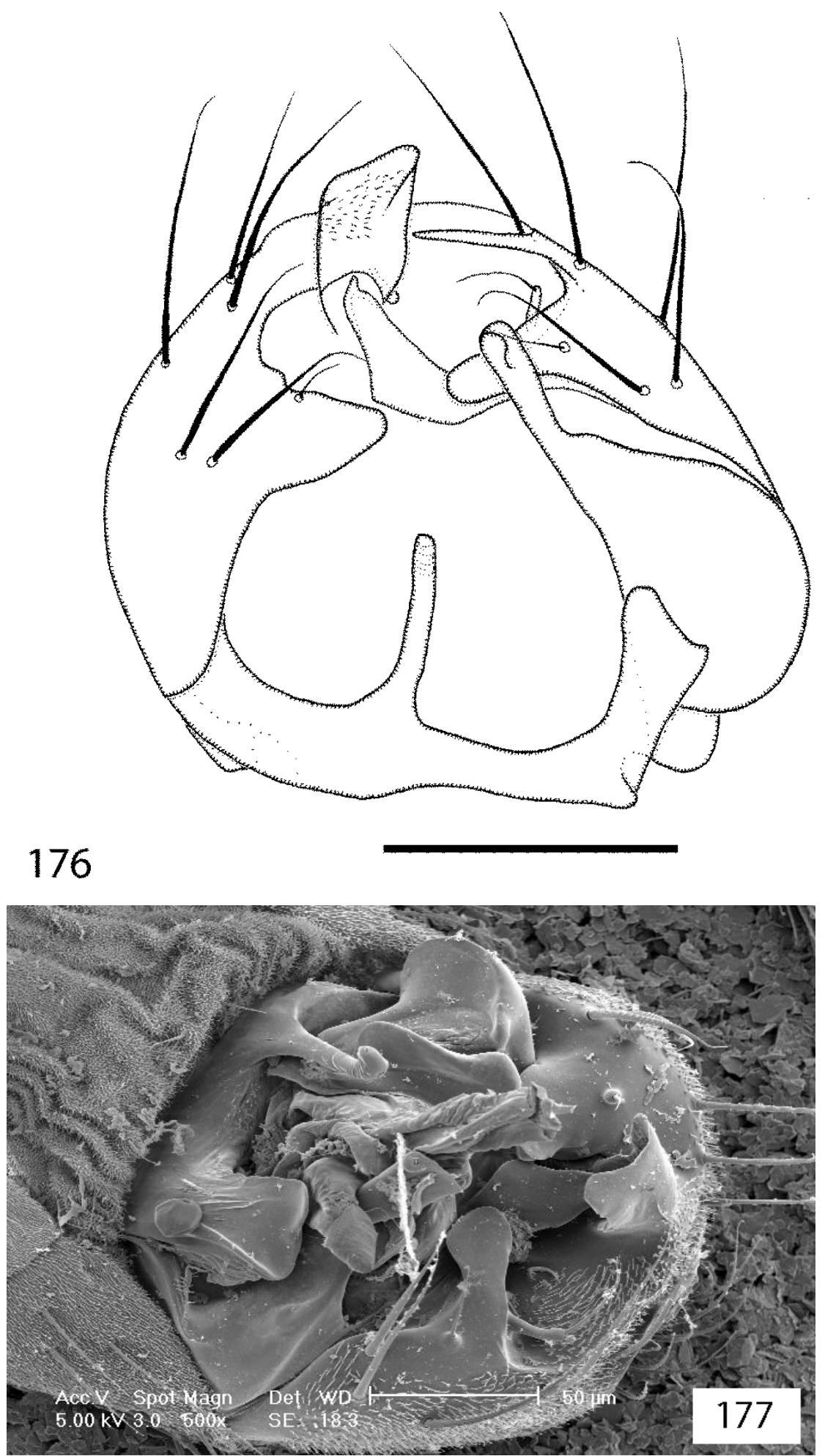


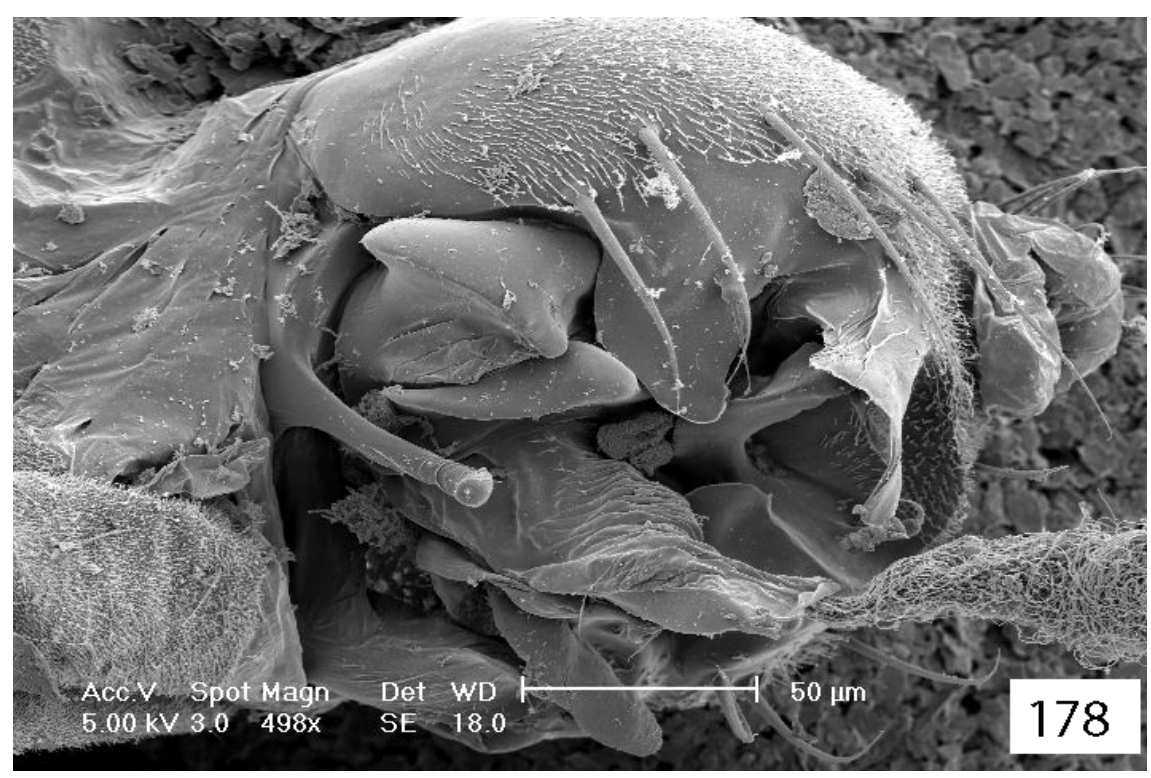

Figure 176-178. Chonocephalus palposus male, ventral views of hypopygium.

Chonocephalus palposus Schmitz, 1928 [19]: 101.

The female has yet to be recognised, but $C$. primus (see below), which is only known in the female sex, has been caught at the same times and in the same localities both in the Bismarck Archipelago and in Fiji.

\section{Material}

Male from type series, Bismarck Archipelago, on carrion (MKB - 27-136). 3 males, Fiji, Suva, November-December 1994, A. van Harten (CUMZ, 2-61); 1 male, January 1995 (CUMZ, 2-61); 46 (7 on slides) males, April to May 1995 (CUMZ, 2-72); 4 males, August 1996 (CUMZ, 32-68); 5 males November 1996 (CUMZ, 32-67); 17 males (3 on slides), January 1997 (CUMZ, 32-71). 1 male, Papua New Guinea, Gulf of Ivimka, $7.73^{\circ} \mathrm{S}, 146.76^{\circ} \mathrm{E}$, Malaise trap, 9 December 1996 to 10 January 1997, K. Merg (LACM - 26-84). 1 male, Tonga, Tongatapu, Government Experimental Farm, Malaise trap, 27 March 1975, W. H. Pearce (CUMZ, 4-94).

\section{Chonocephalus papuaensis sp. nov.}

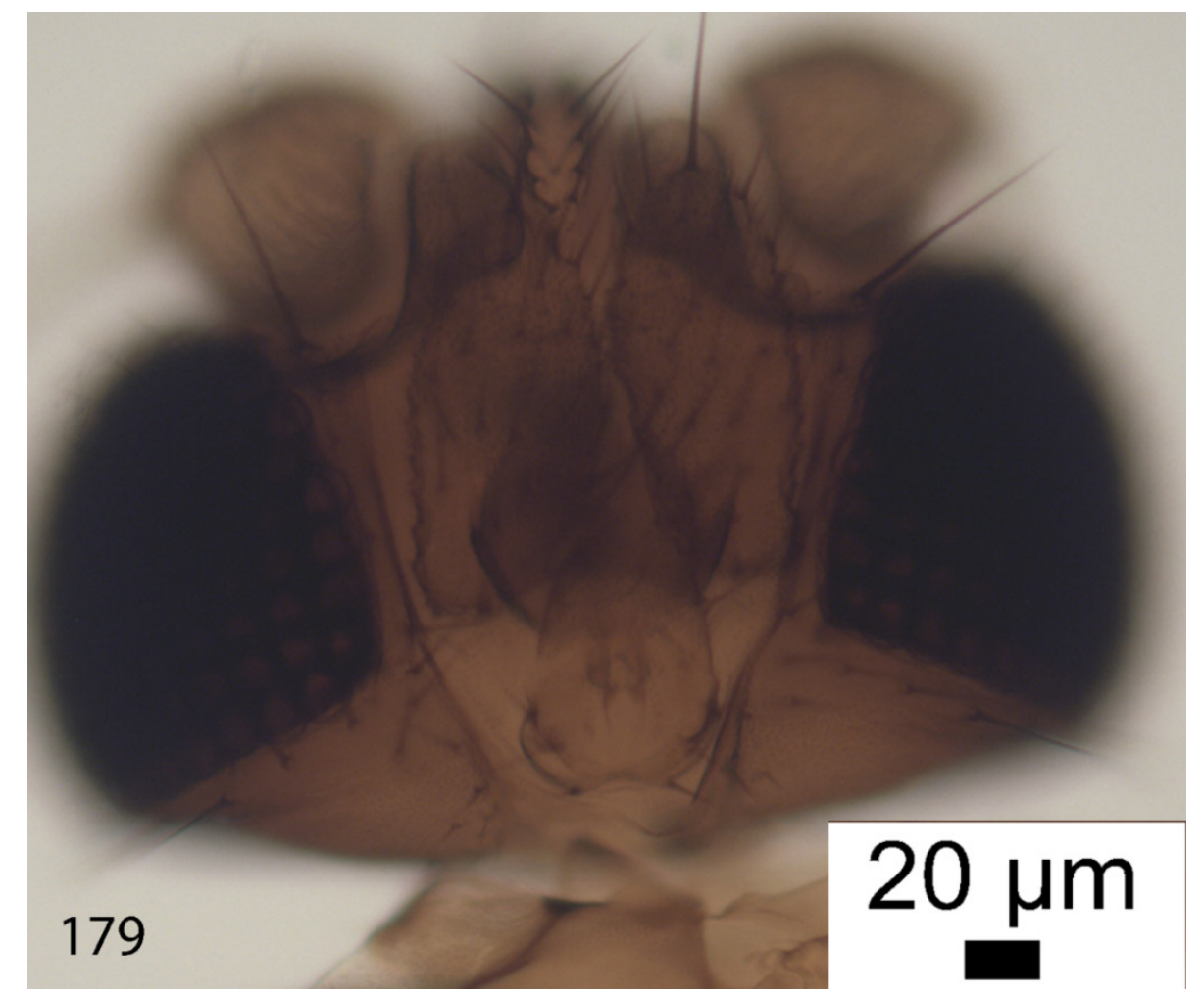



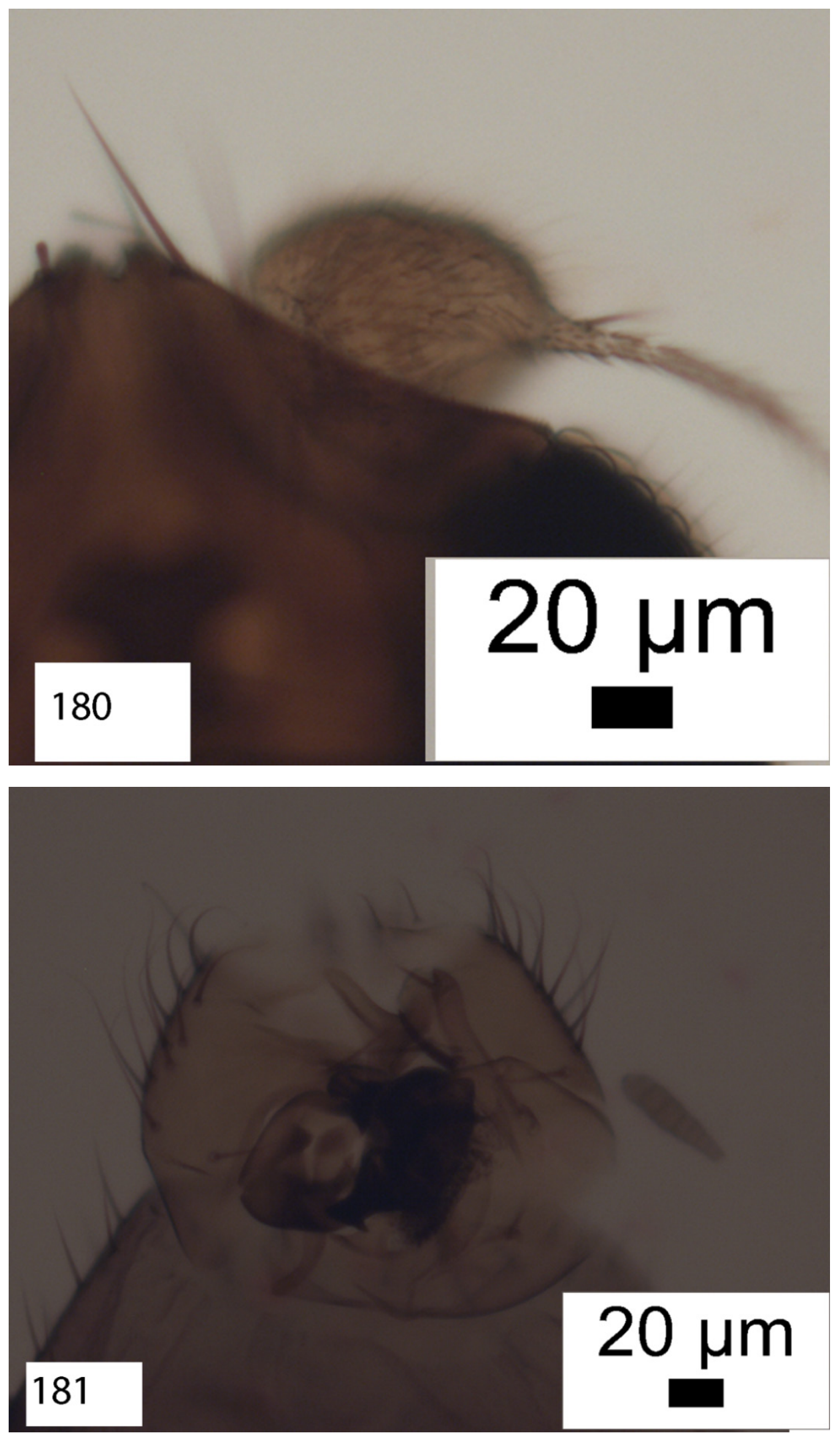

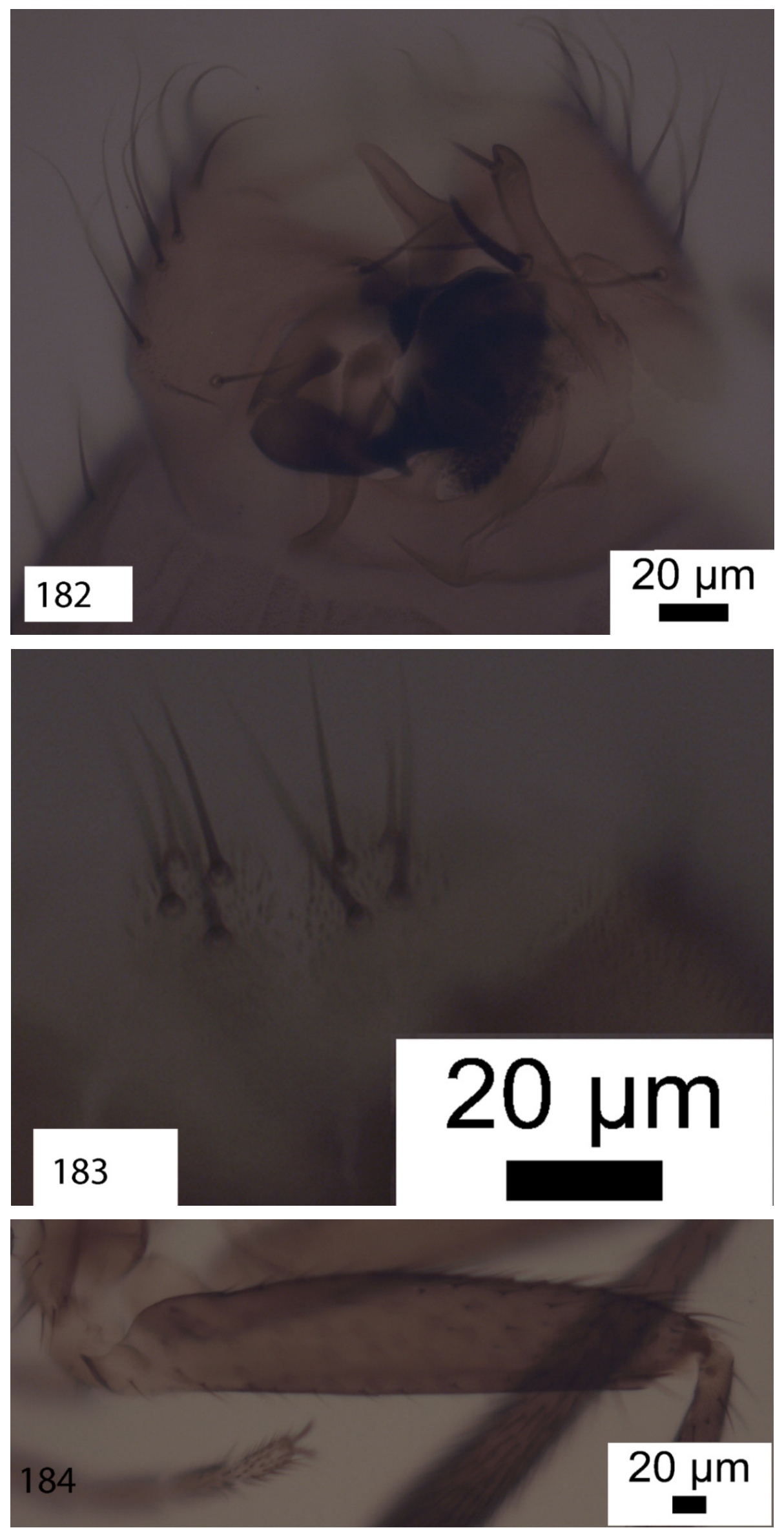


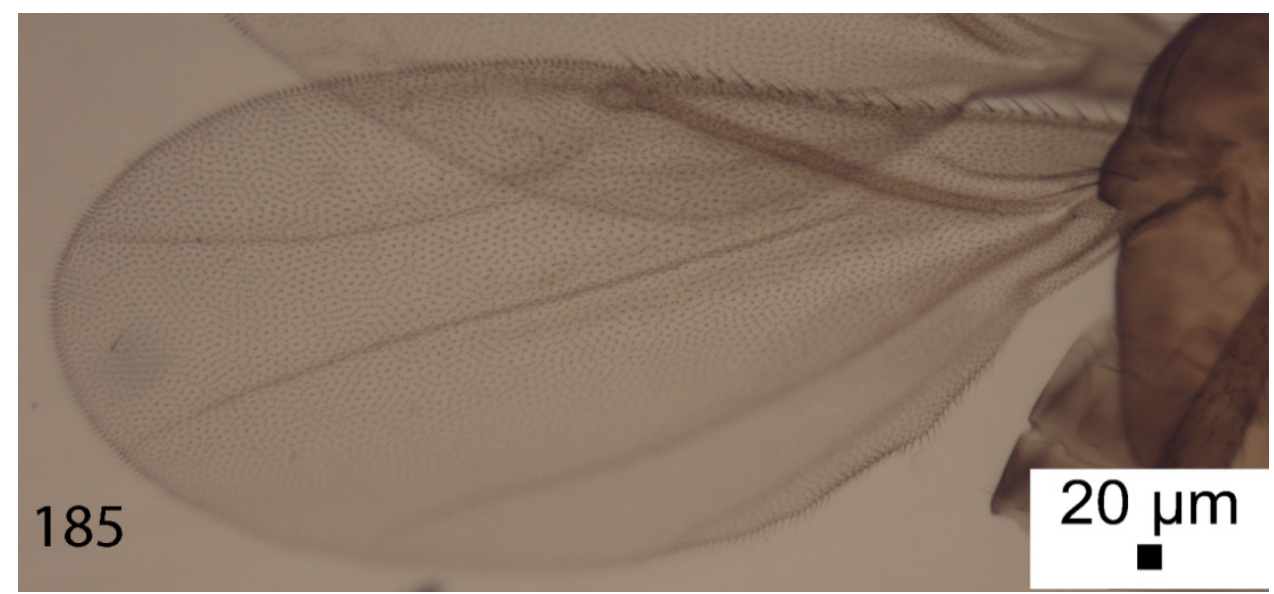

Figures 179-185. Chonocephalus papuaensis male. (179) palps; (180) postpedicel; (181-182) hyopopygium; (183) cerci; (184) hind femur; (185) wing. Male

A generally brown, but not dark, species with a pale brown abdominal venter. Postpedicel as Fig. 179. Palps as Fig. 180. The hairs of the abdominal tergites are moderately fine and not restricted to the hind margins. They are longest on T6. Venter hairs fine and small. Hypopygium as Figs 181-183. Legs brown with pale tarsi. Front tarsus with posterodorsal hair palisades on segment 1 to 4 and segment 5 longer than 4. Hind femur as Fig. 184. Wing (Fig. 185) 0.92-0.93 mm long. Costal index 0.49-0.50. Haltere brown.

\section{Material}

Holotype male, Papua New Guinea, Gulf of Ivimka, $7.73^{\circ} \mathrm{S}, 146.76^{\circ} \mathrm{E}$, Malaise trap, 10-20 February 1997 , K. Merg (LACM, 26-72).

Etymology: the name refers to the type locality.

\section{Chonocephalus parvupalpus sp. nov.}



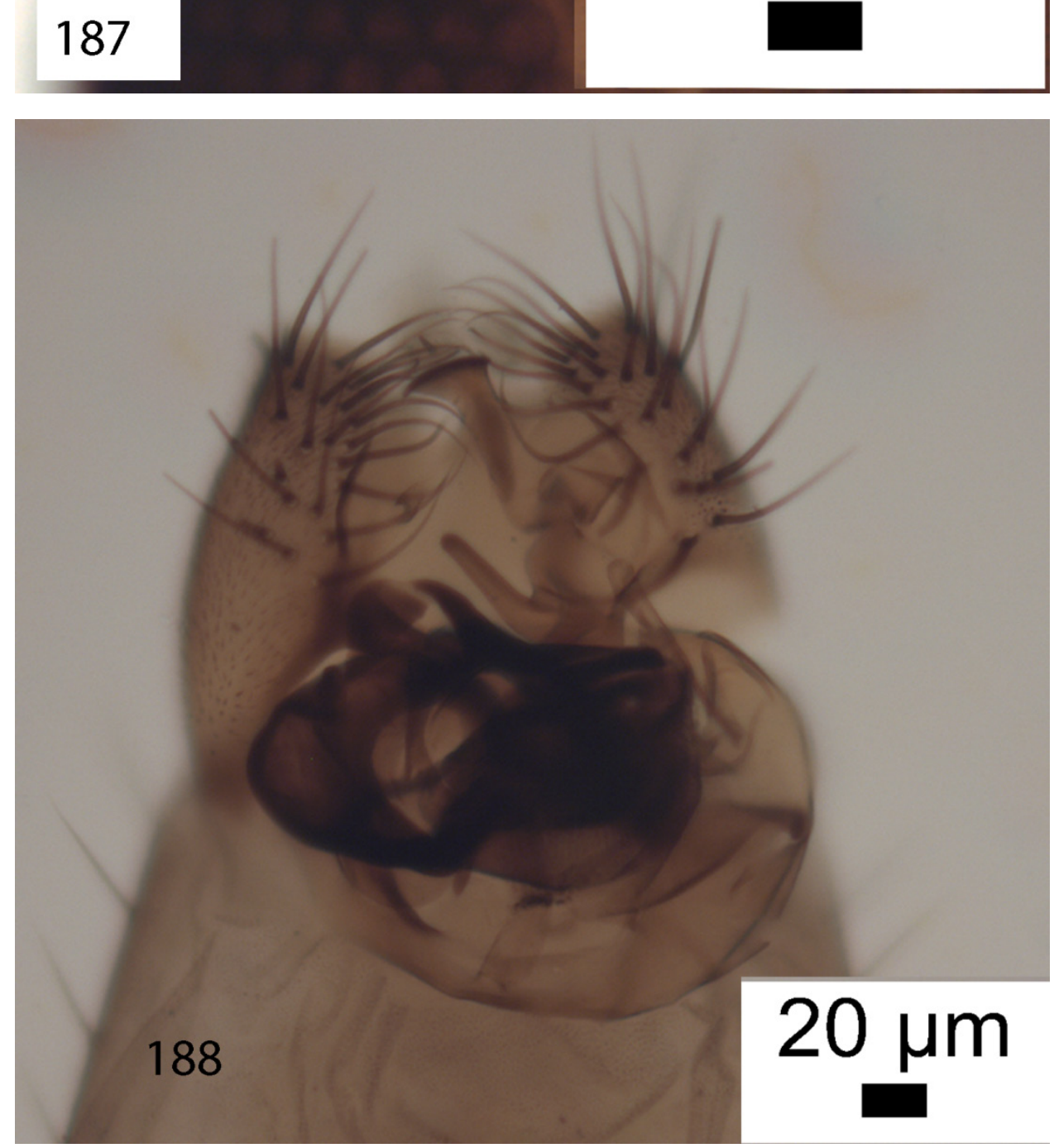

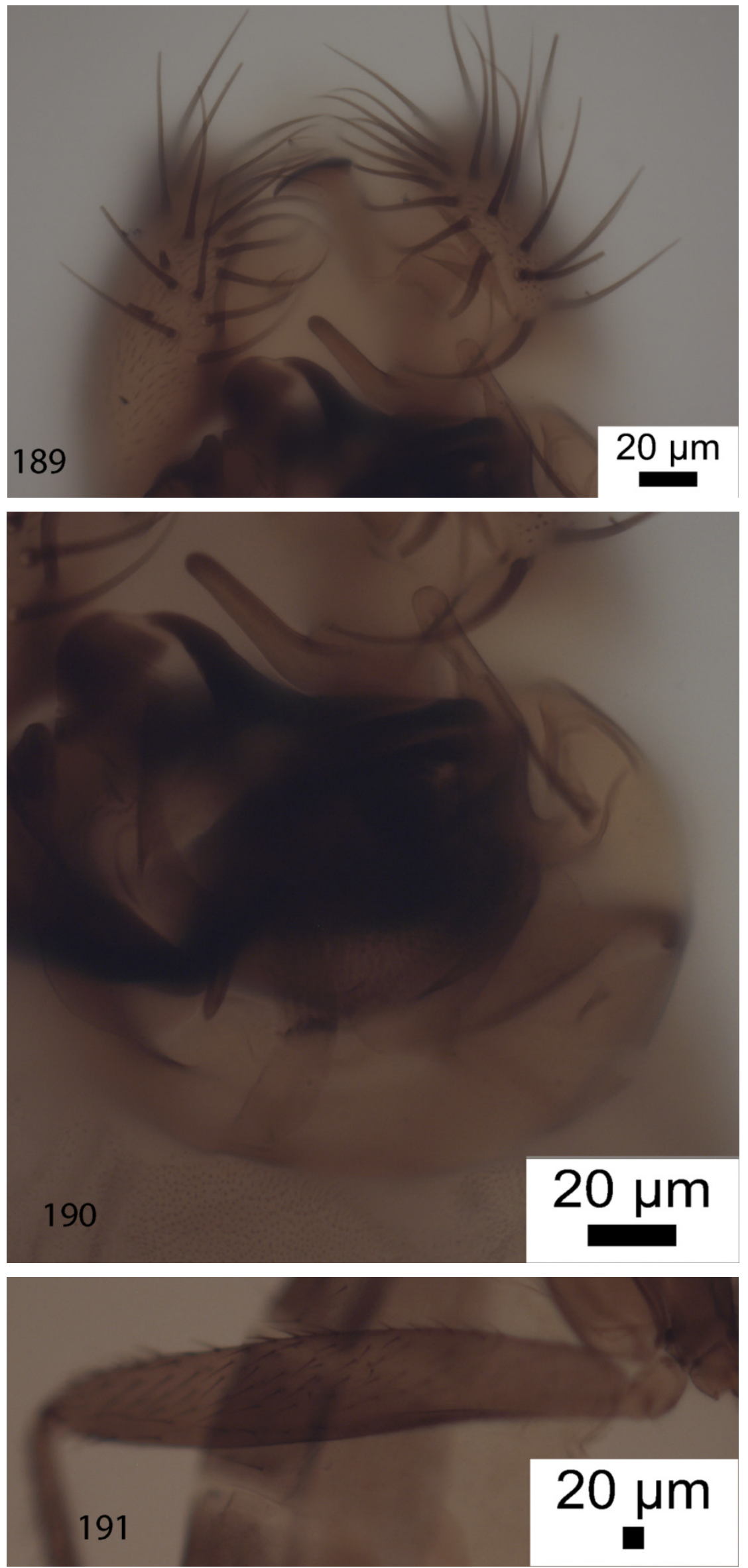


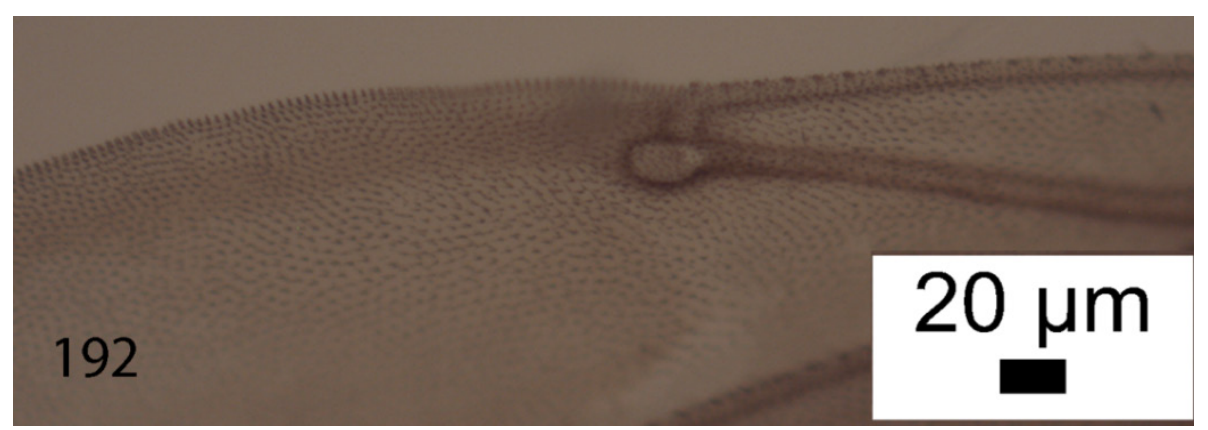

Figures 186-192. Chonocephalus parvupalpus male. (186) palps; (187) postpedicel; (188-190) hypopygium; (191) hind femur; (192) tips of costa and vein 3 (the costal cilia were mostly broken off during handling by the collector).

\section{Male}

A generally brown, but not dark, species. With a pale abdominal venter. Postpedicel as Fig. 187. Palps as Fig. 186. The hairs of the abdominal tergites are moderately fine and not restricted to the hind margins. They are longest on T5 and T6. Venter hairs fine and few in number. Hypopygium as Figs 188-190. Legs mainly light brown but tarsi pale. Front tarsus with posterodorsal hair palisades on segments 1 to 4 and segment 5 longer than 4 . Hind femur as Fig. 191. Wing $1.6 \mathrm{~mm}$ long. Costal index 0.53-0.54. Thick veins light brown, thin veins paler with 7 palest. Tip of costa and vein 3 as Fig. 192. Membrane tinged brownish grey. Haltere brown.

\section{Material}

Holotype male, Papua New Guinea, Kokoda Trail, Iora Cr., 23 km S. of Kokoda, dung trap, 6-8 August 1976, O. Kukal (DEBU, 14-57)

Etymology: the name refers to the unusually small palps.

\section{Chonocephalus pilositerga sp. nov.}

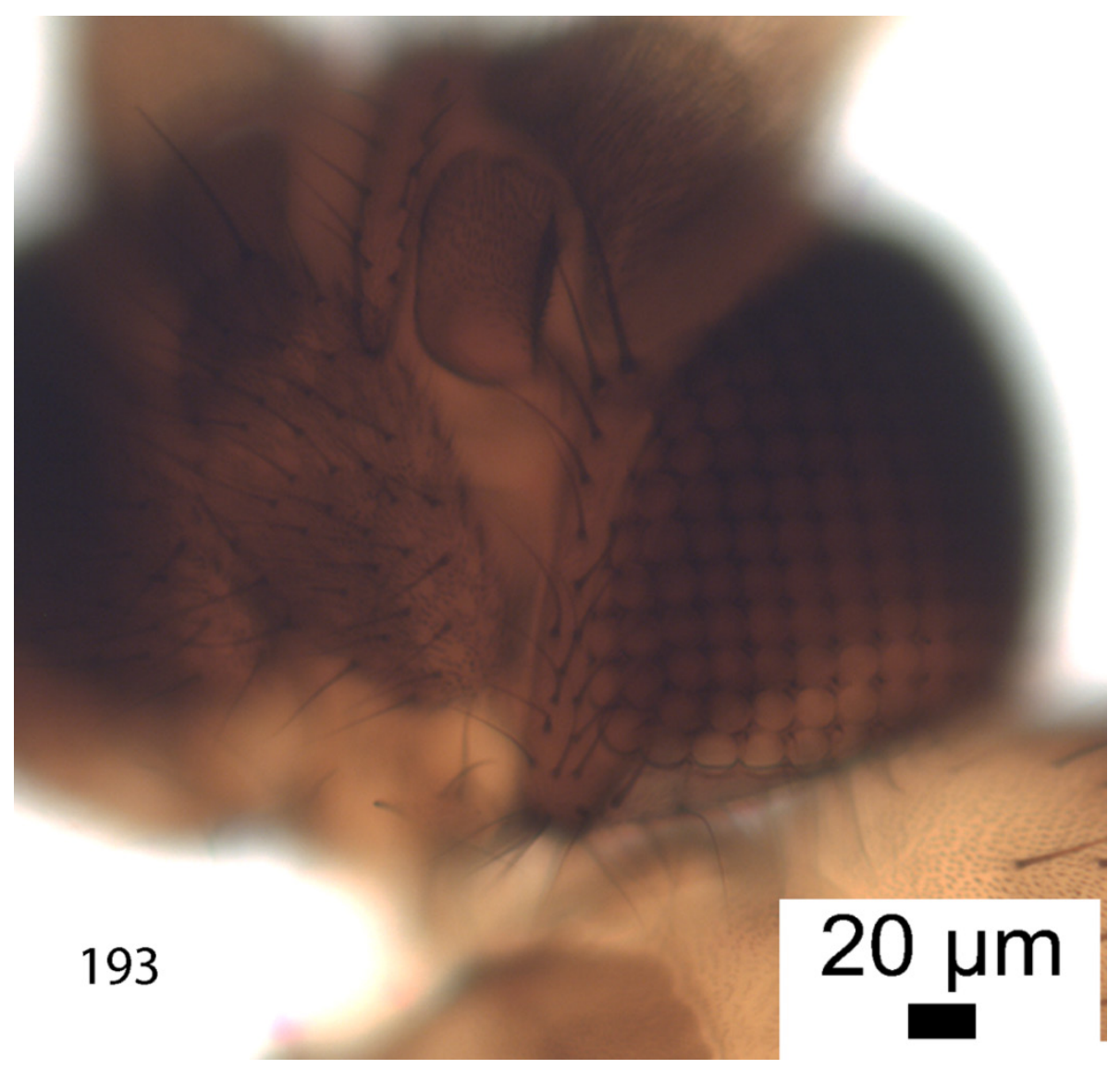



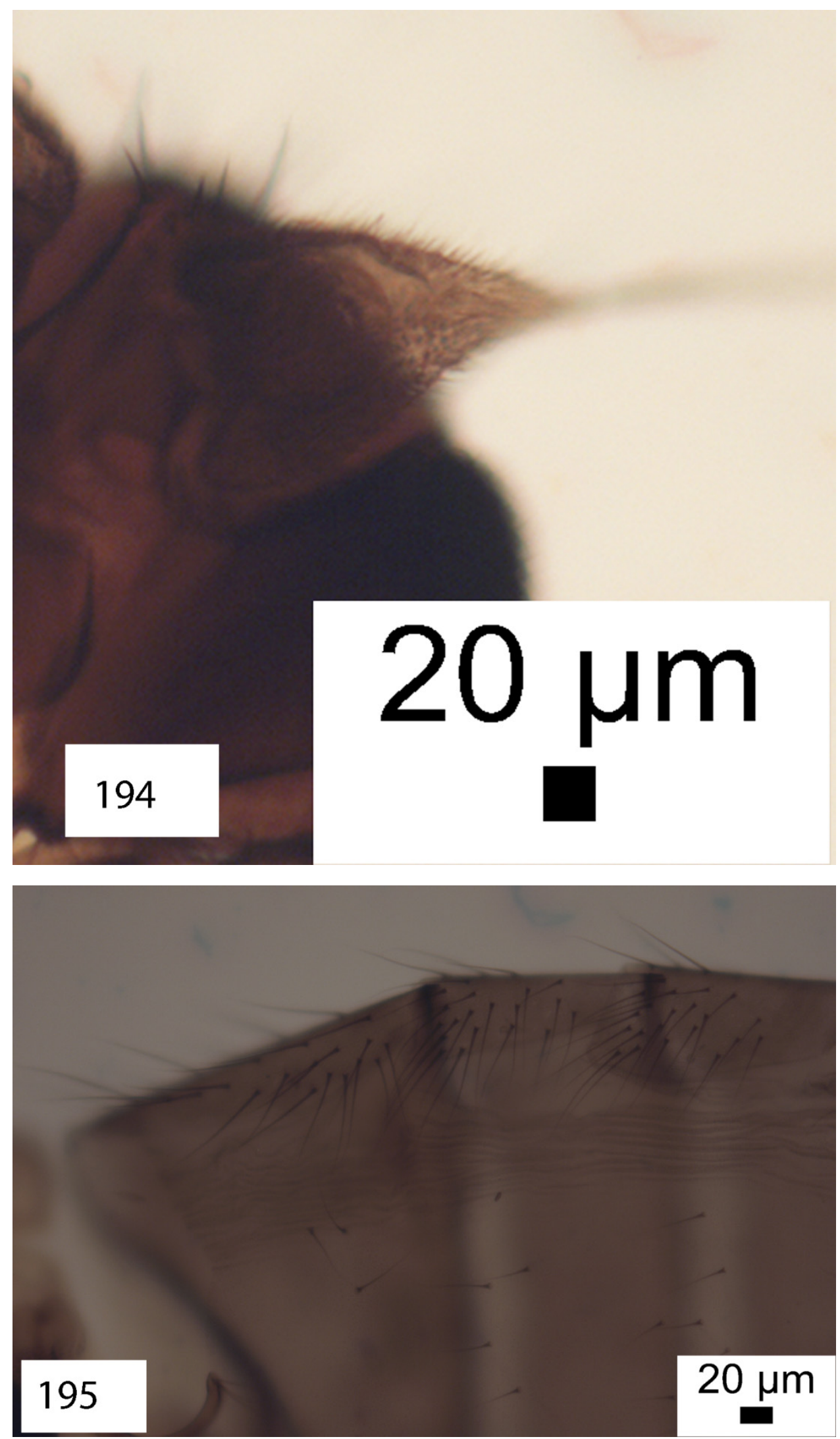

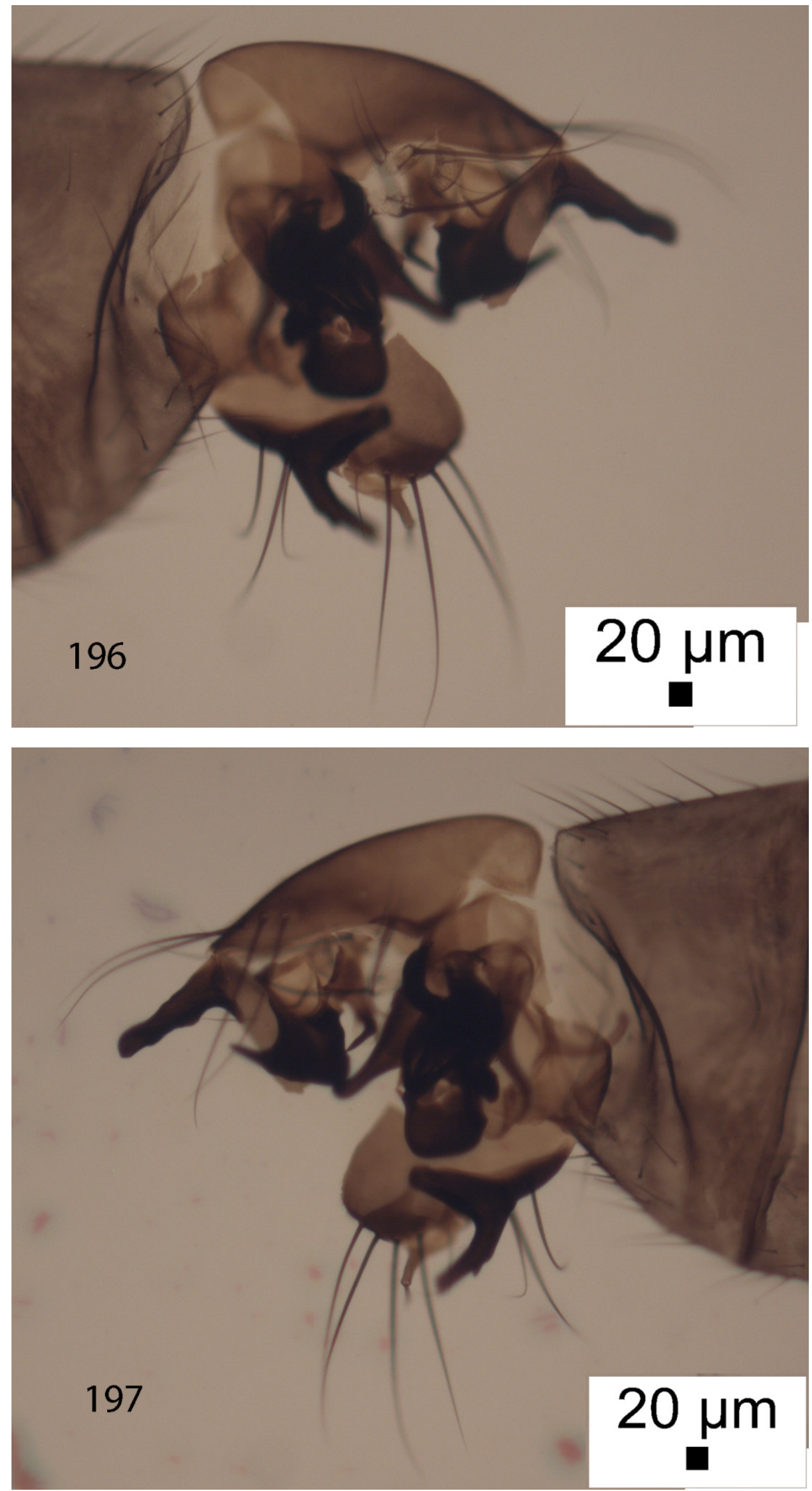

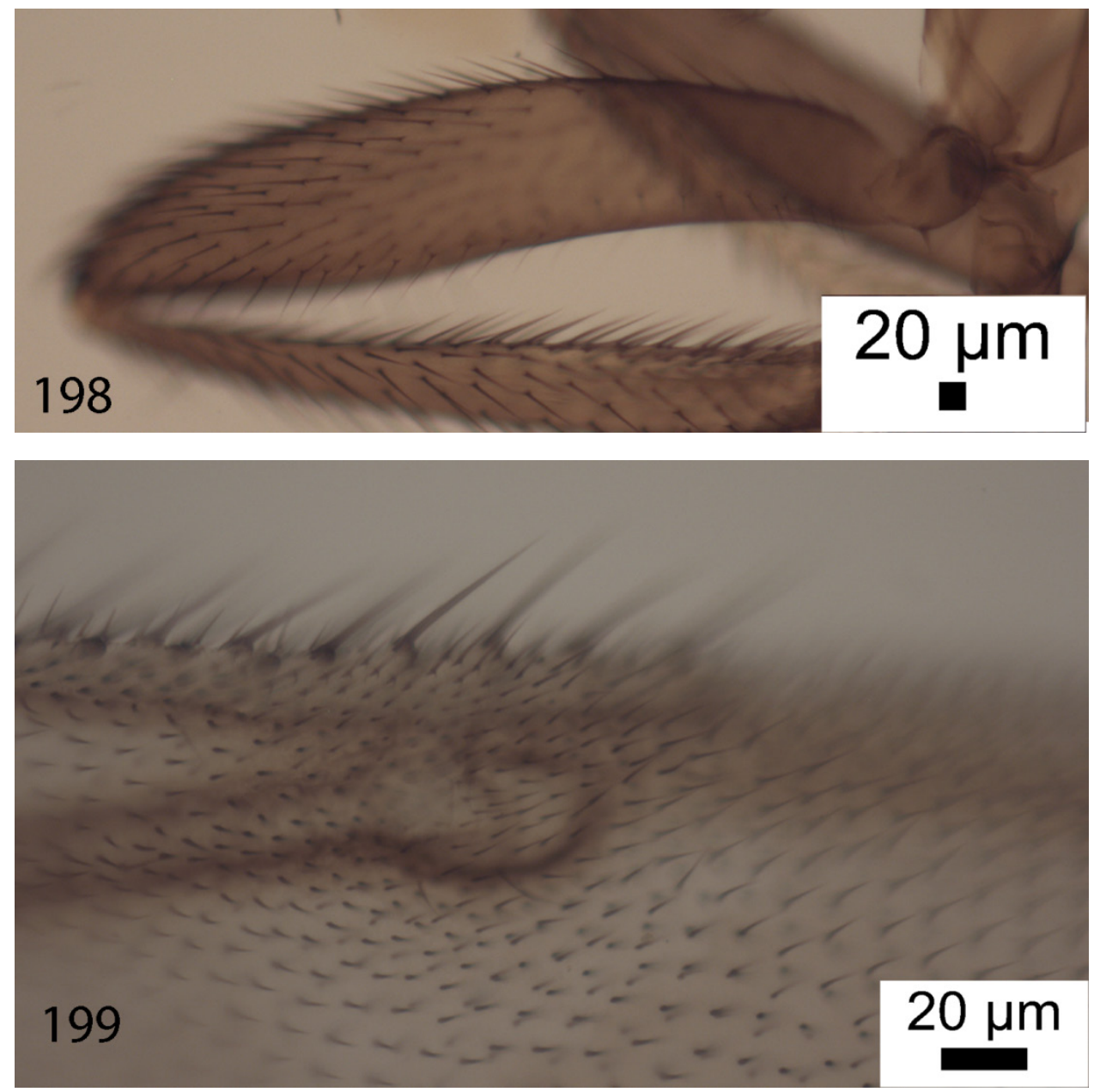

Figures 193-199. Chonocephalus pilositerga male. (193) palp; (194) postpedicel; (195) right face of abdominal segments 4-6; (196-196) hypopygium; (198) hind femur; (199) tips of costa and vein 3.

Male

A generally brown but not dark species with a pale abdominal venter. Postpedicel as Fig. 194. Palp as Fig. 193. The hairs at the sides of abdominal tergites are more numerous and longer than usual, those on T4 to T6 being more than $0.15 \mathrm{~mm}$ long (Fig. 195). Venter hairs fine and much smaller (Fig. 195). Hypopygium as Figs 196 \& 197. Legs with coxae to femora brown along with the front and hind tibiae, the mid tibia white and the tarsi only lightly tinged. Front tarsus with a posterodorsal hair palisade on segments 1 to 4 and segment 5 longer than 4. Hind femur as Fig. 198. Wing 1.6-1.7 mm long. Costal index 0.68. Tips of costa and vein 3 as Fig. 199. All veins light brown. Membrane tinged brownish gray. Haltere brown.

\section{Material}

Holotype male, Indonesia, irian Jaya, Wapoga Camp, 3.14 $\mathrm{S}, 136.57^{\circ} \mathrm{E}, 1050 \mathrm{~m}, 19-26$ June 1998, R. Snelling (LACM, 26-70).

Etymology: the name refers to unusually long hairs on the abdominal tergites.

\section{Chonocephalus primus Schmitz}




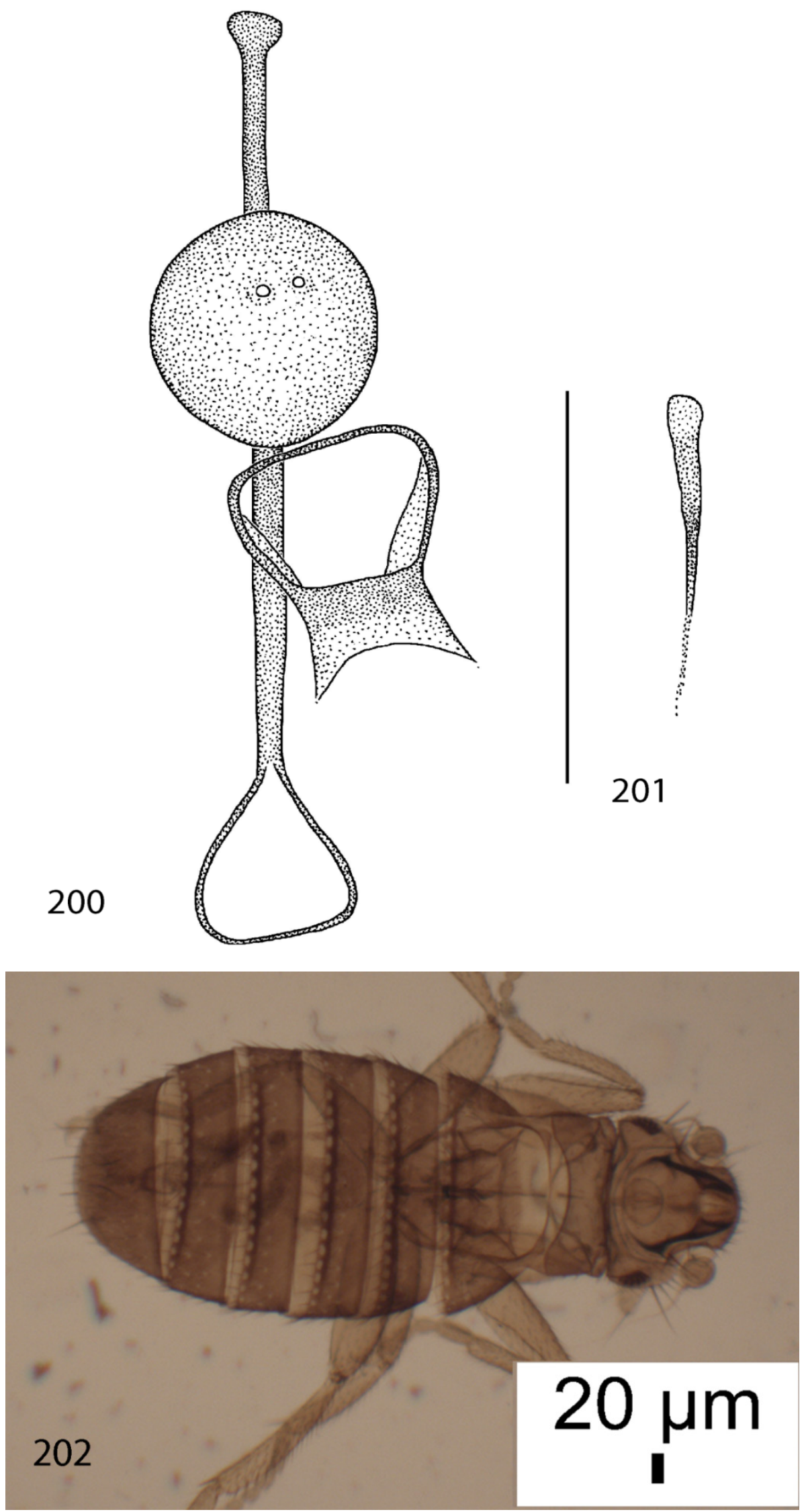

Figures 200-202. Chonocephalus primus female. (200) abdominal sternite 8 , furca and spermatheca and (201) tergite 8 (Scale bar $=0.1 \mathrm{~mm})$; (202) dorsal view of whole fly. 
Chonocephalus primus Schmitz, 1928: 101.

Chonocephalus quartus Schmitz, 1928: 104. Disney, 2002: 30.

This may be the unrecognised female of $C$. palposus (see above). If this proves to be the case then C. primus would become a synonym of $C$. palposus.

\section{Material}

Female lectotype, Bismarck Archipelago (MKB - 27-135); female of C. quartus, Neupommern, 28 May-1 June 1896; variety 'Nr 1a (MKB)', 1 female, Lowon W., 23 October-3 November; 1 female, Waldtal W., 2-10 February 1897 (MKB);1 female, Fiji, Suva, November-December 1994, A. van Harten (CUMZ, 2-61); 5 females, same locality, April to May 1995 (CUMZ, 2-62 \& 72).

\section{Chonocephalus procerus sp. nov.}
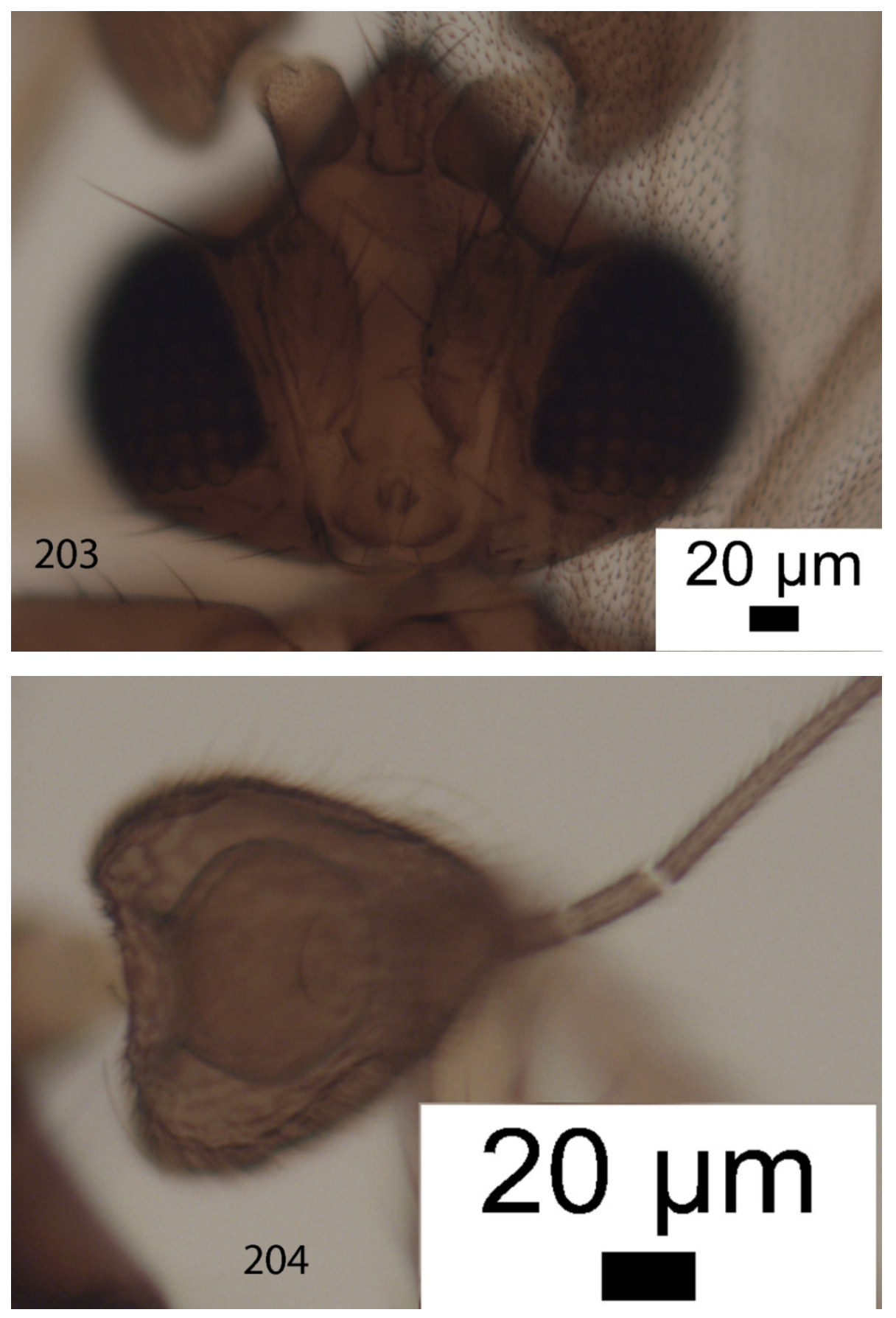

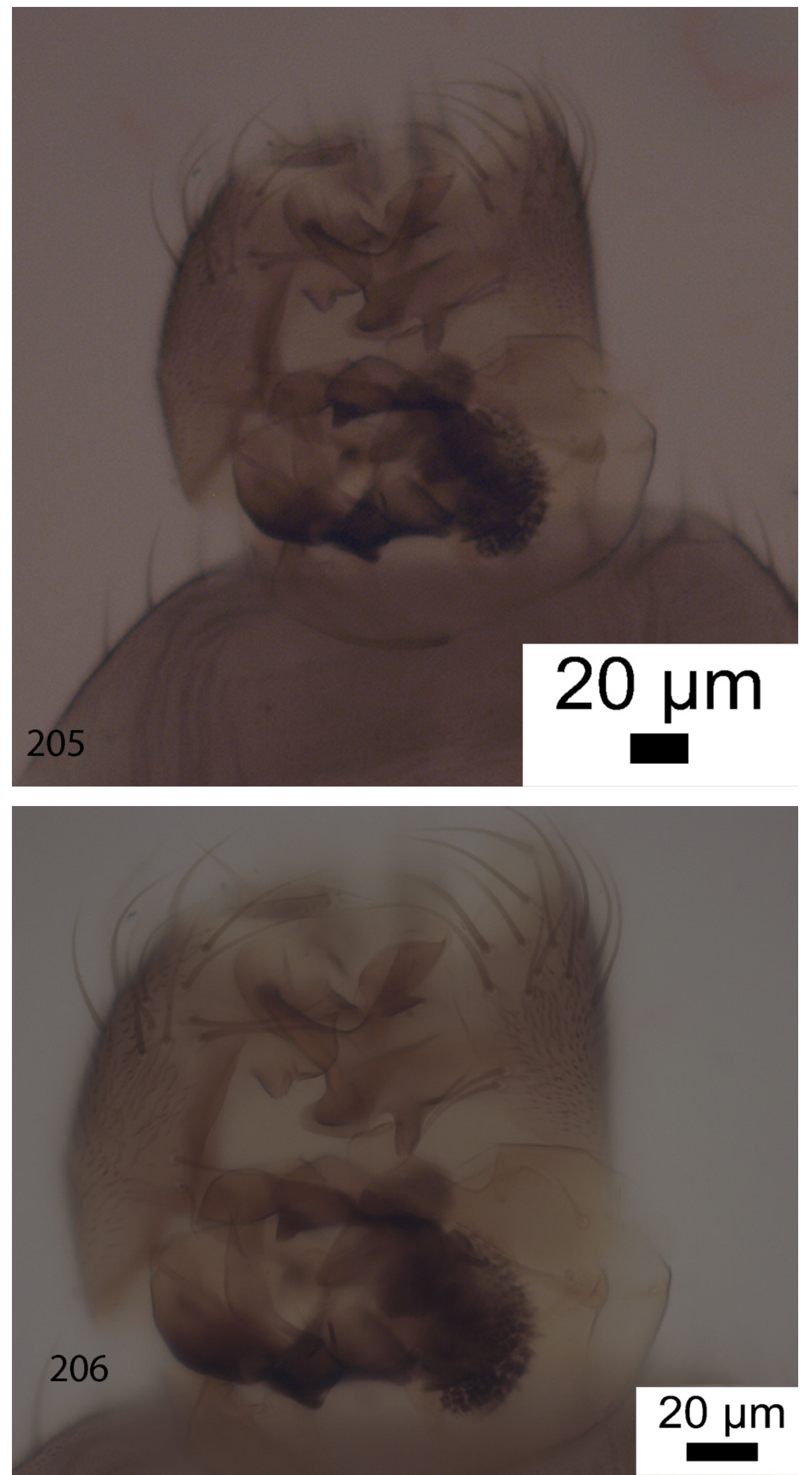

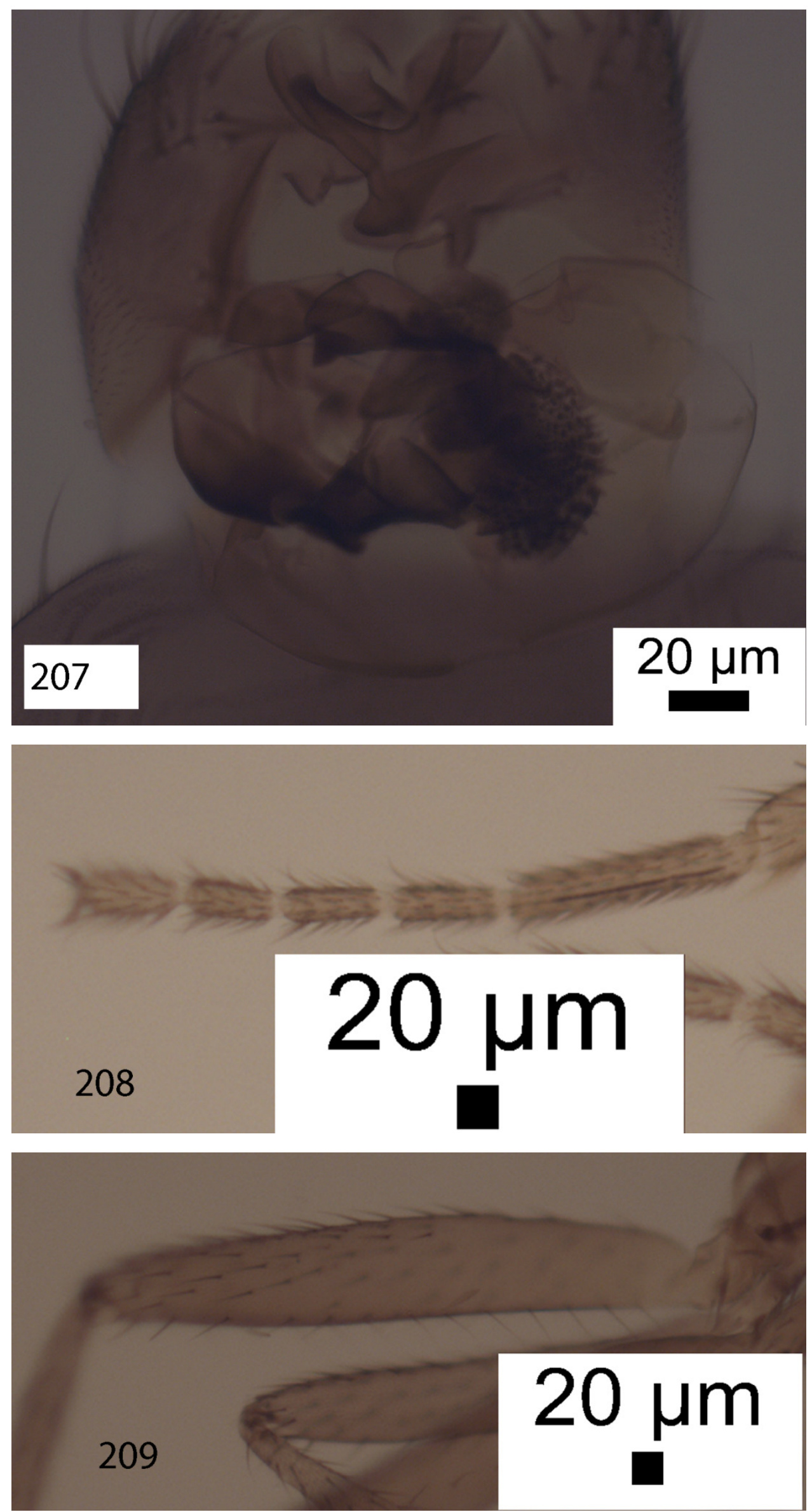


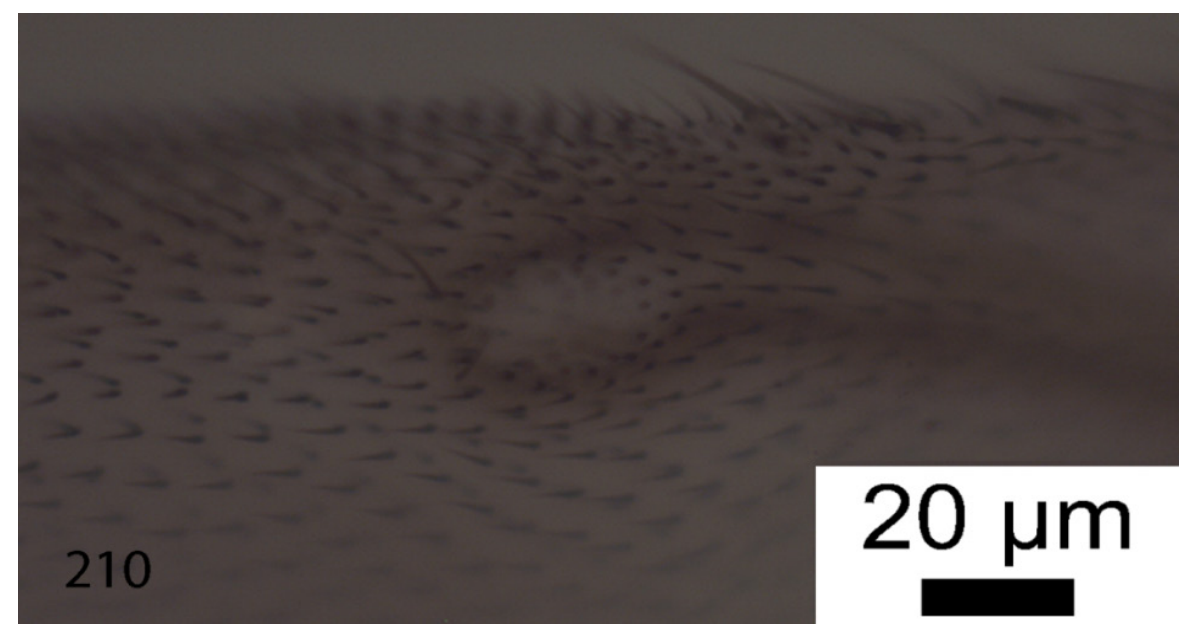

Figures 203-210. Chonocephalus procerus male. (203) palps; (204) postpedicel; (205-207) hypopygium; (208) front tarsus; (209) hind femur; (210) tips of costa and vein 3 .

\section{Male}

A generally brown but not dark species with pale sides to the thorax and pale abdominal venter. Postpedicel as Fig. 204. Palps as Fig. 203. The hairs of the abdominal tergites are fine and restricted to the hind margins of T2 to T6. They are longest on T6. Venter hairs lacking. Hypopygium as Figs 205-207. Legs with coxae to femora, front and hind tibia brown, the mid tibia white and all tarsi only lightly tinged. Front tarsus as Fig. 208. Hind femur as Fig. 209. Wing 1.02-1.03 mm long. Costal index 0.47. Tips of costa and vein 3 as Fig. 210. Veins lightly tinged brown apart from pale gray vein 7 . Membrane tinged brownish gray. Haltere grayish brown.

\section{Material}

Holotype male, Papua New Guinea, Mandang Province, Baitabang Village, Kau Wildlife Area, 50 m, primary forest, $5^{\circ} 08^{\prime}$ S, $145^{\circ} 46^{\prime} \mathrm{E}, 10$ October to 8 November 1999, L. Cízek (CUMZ, 29-65).

Etymology: the name refers to the long process of the right gonopod.

\section{Chonocephalus quadratus sp. nov.}

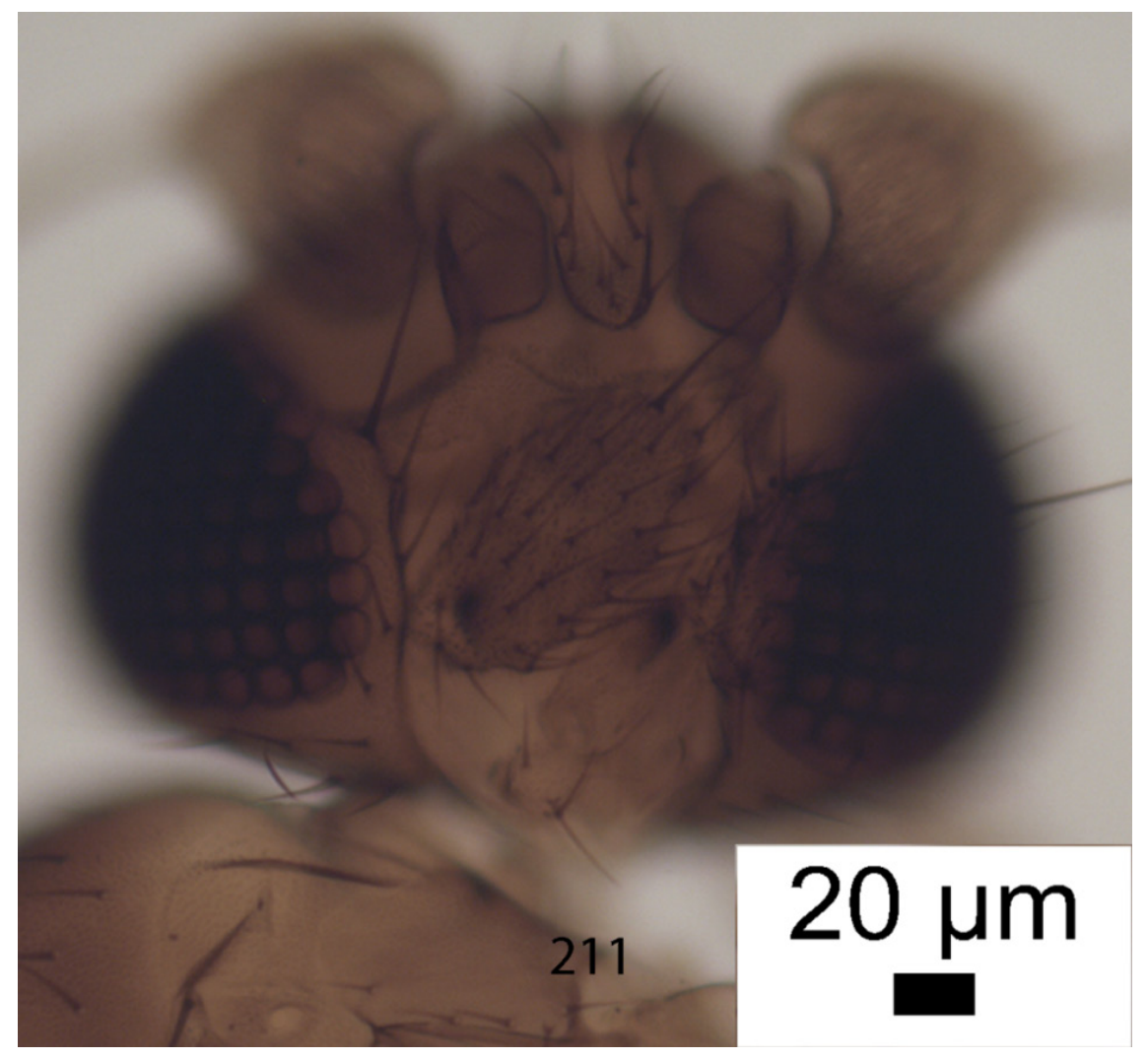



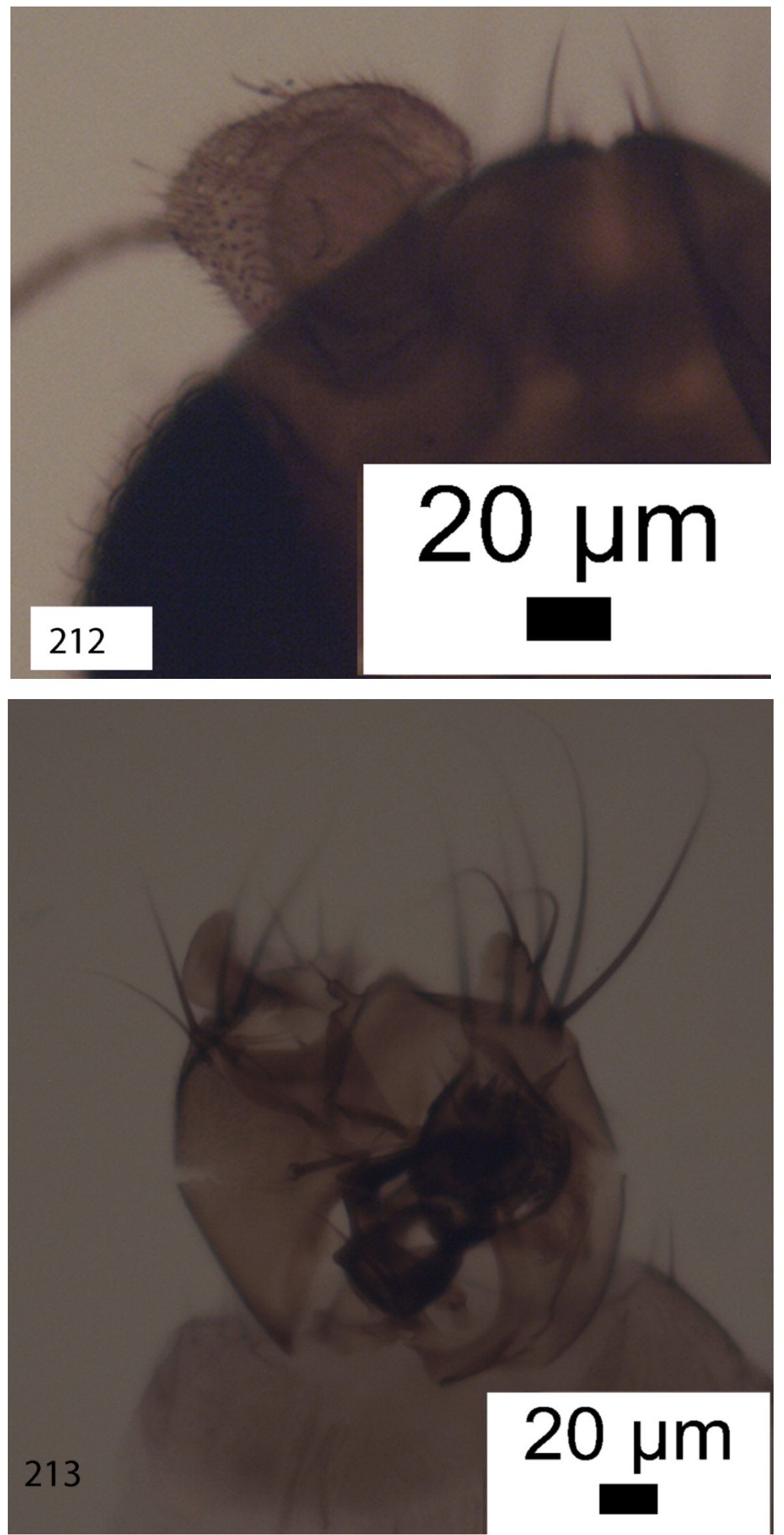

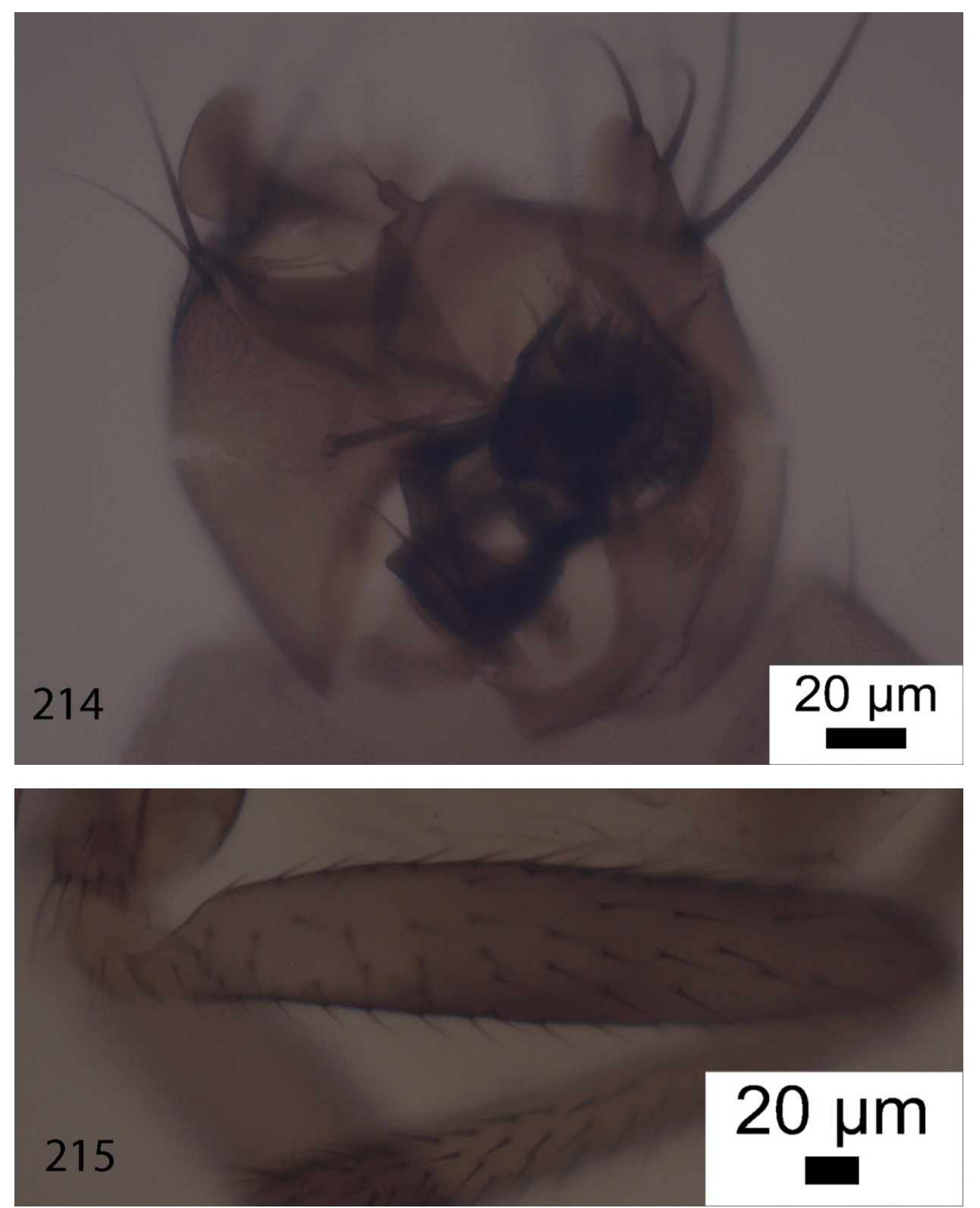

Figures 211-215. Chonocephalus quadratus male. (211) palp; (212) postpedicel; (213-214) hypopygium; (215) hind femur.

Male

A generally light brown species with pale sides to the thorax and abdominal venter. Postpedicel as Fig. 212. Palp as Fig. 211. The hairs of the abdominal tergites are fine and are largely restricted to the hind margins on T2 to T5. They are longest on T6. Venter hairs even finer and smaller. Hypopygium as Figs 213 and 214. Legs with coxae to tibiae light brown and tarsi pale. Front tarsus with posterodorsal hair palisades on segments 1 to 4 and segment 5 longer than 4 . Hind femur as Fig. 215 . Wing $0.8 \mathrm{~mm}$ long. Costal index 0.52-0.53. Tip of vein 3 just overreaches tip of costa. Thick veins light brown, thin veins pale gray, with 7 being paler still, and membrane slightly tinged brownish gray. Haltere grayish brown.

\section{Material}

Holotype male, Papua New Guinea, Mandang Province, Baitabang Village, Kau Wildlife Area, 50 m, primary forest, $5^{\circ} 08^{\prime}$ S, $145^{\circ} 46^{\prime}$ E, 10 October to 8 November 1999, L. Cízek (CUMZ, 29-65).

Etymology: the name refers to the almost square anterior processes of the epandrium.

\section{Chonocephalus secundus Schmitz}




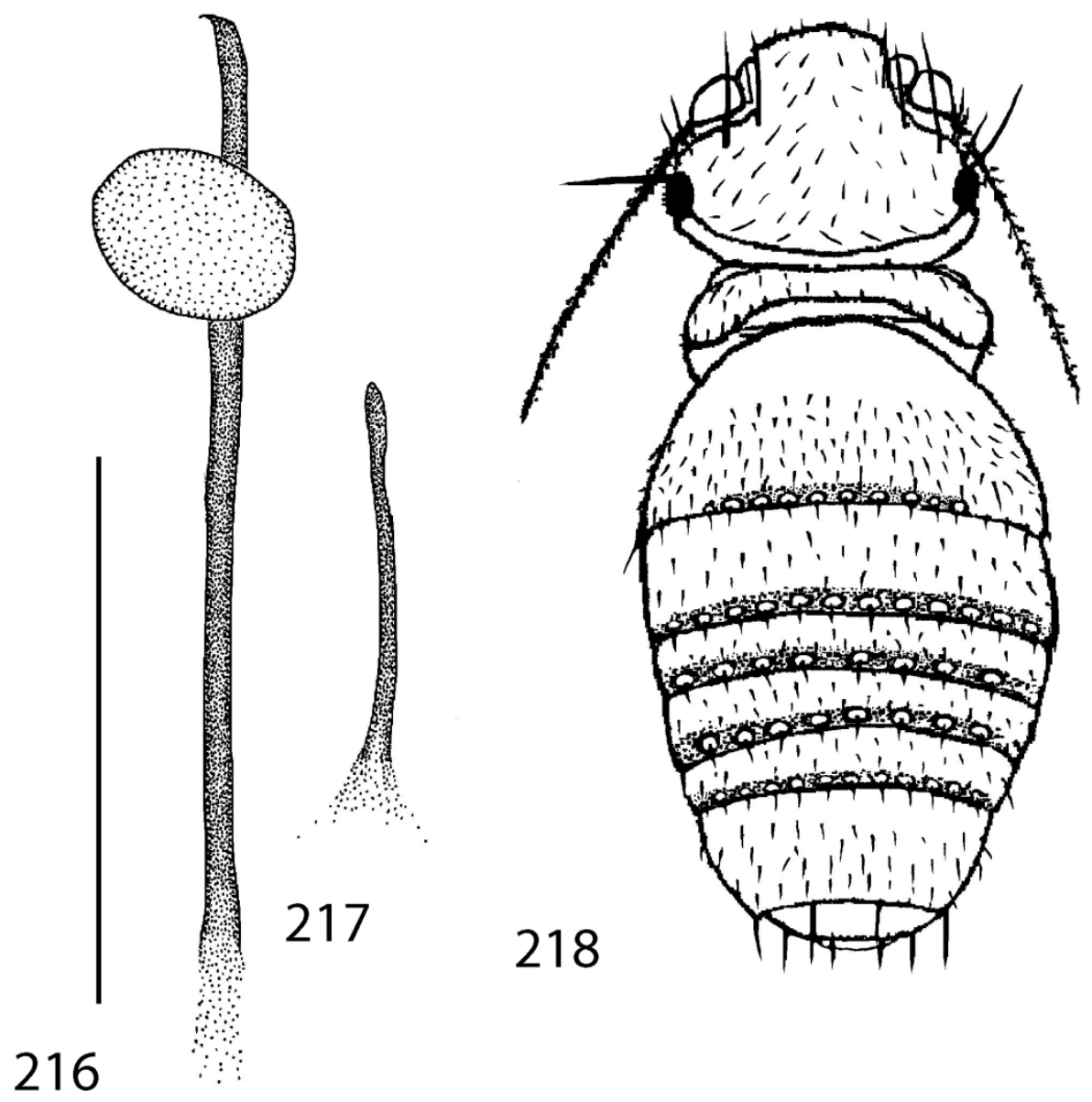

Figures 216-218. Chonocephalus secundus female. (216) abdominal sternite 8 and spermatheca; (217) tergite 8; (218) whole fly from above (after Schmitz, 1929). Scale bar for 216 and $218=0.1 \mathrm{~mm}$.

Chonocephalus secundus Schmitz, 1928 [19]: 102.

Chonocephalus tertius Schmitz, 1928: 103 [19]. Syn. nov.

The lectotype of $C$. tertius proves to be a teneral specimen of $C$. secundus. The former is therefore proposed as a synonym of the latter. Furthermore, a specimen attributed to C. tertius was reported at carrion (see below) at the same time and place as a male of $C$. dahli (see above). This species may, therefore, be the unknown female of $C$. dahli. If this proves to be the case then $C$. secundus would become a synonym of $C$. dahli.

\section{Material}

Lectotype female, Bismarck Archipelago (MKB - 27-135); Lectotype female of C. tertius (MKB - 27-129).

\section{Natural history}

A female was recorded at the stinking flower of Amorphophallus (Araceae) and another (attributed to C. tertius) was on carrion (Schmitz [19]).

\section{Chonocephalus signumpedalis sp. nov.}



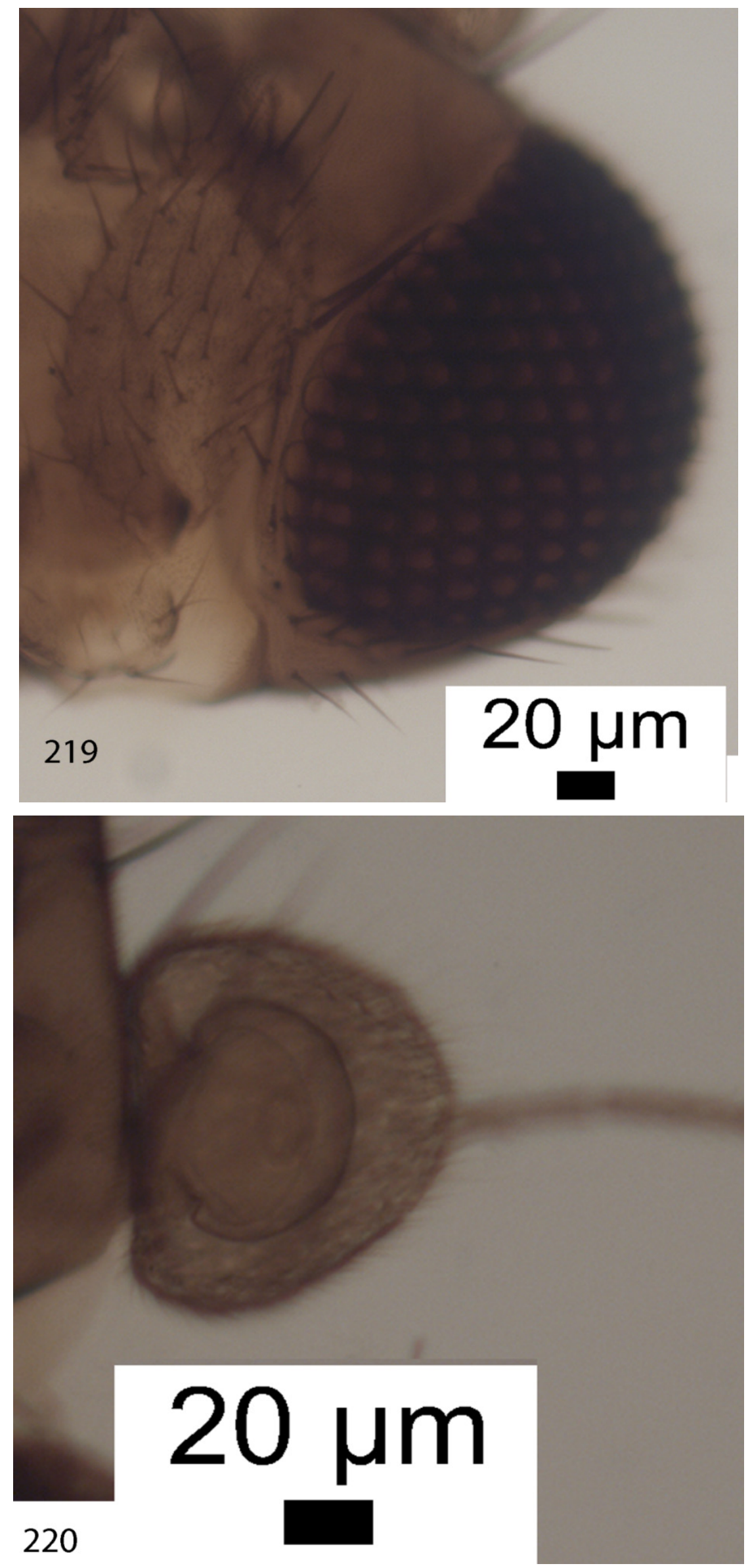


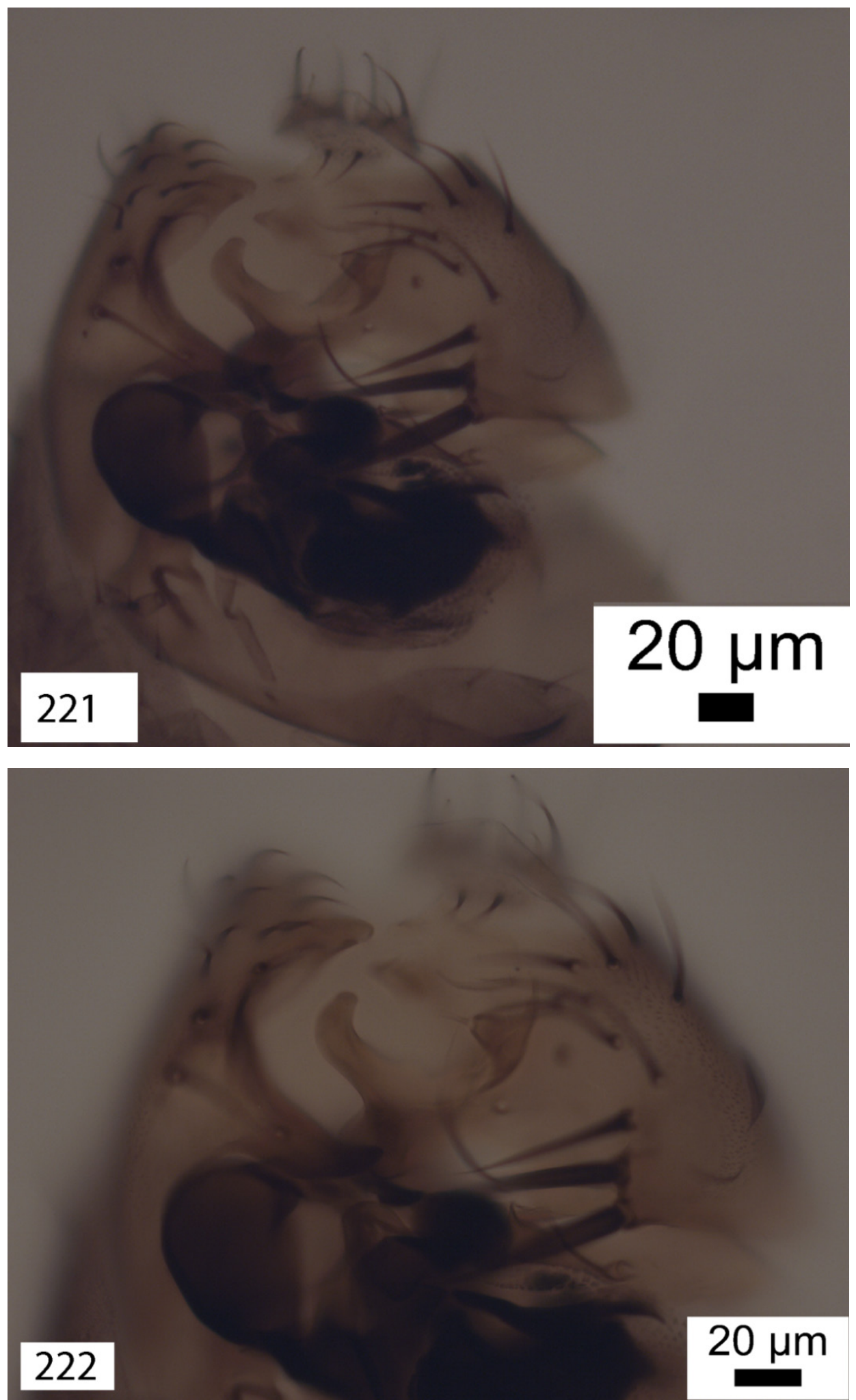



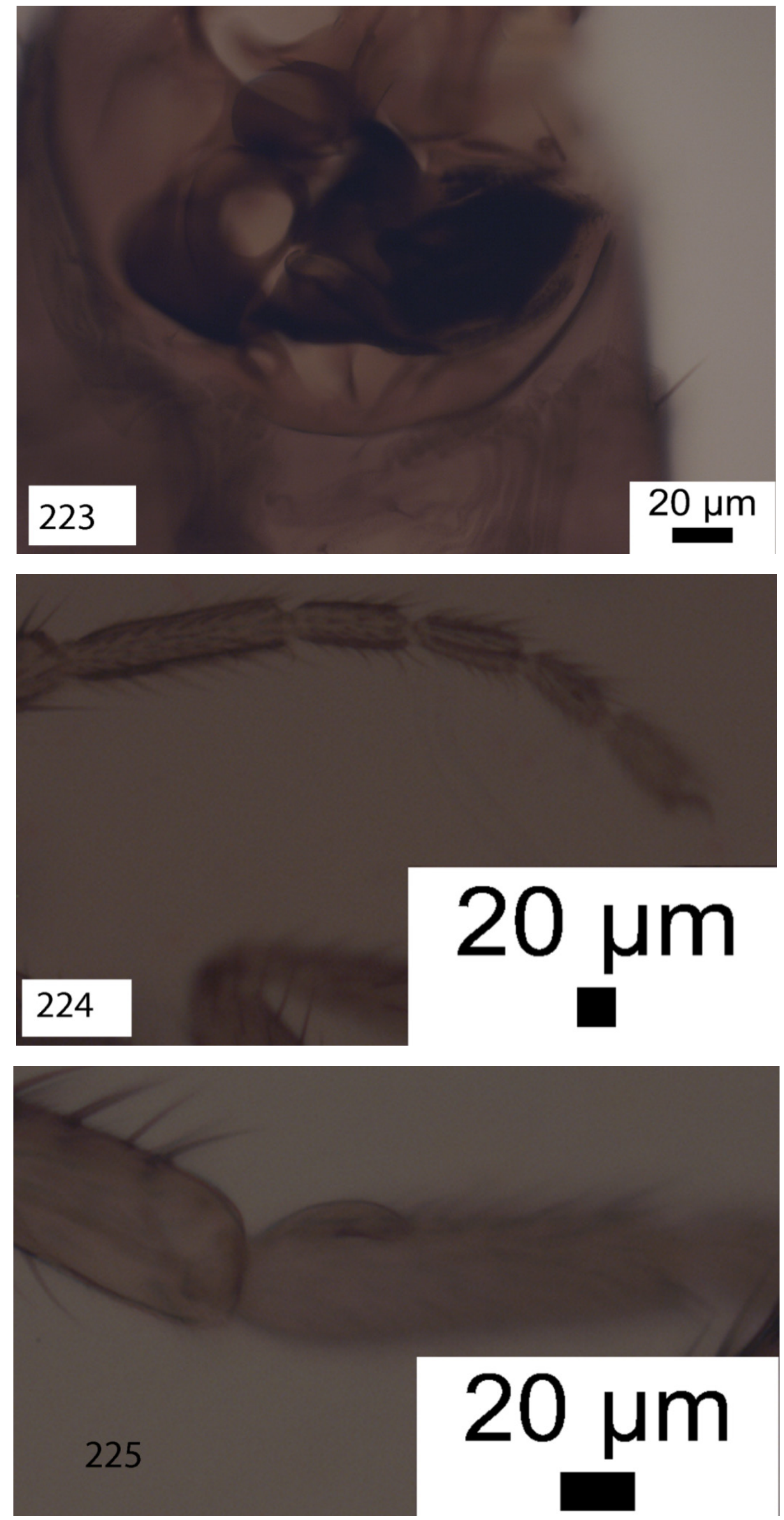

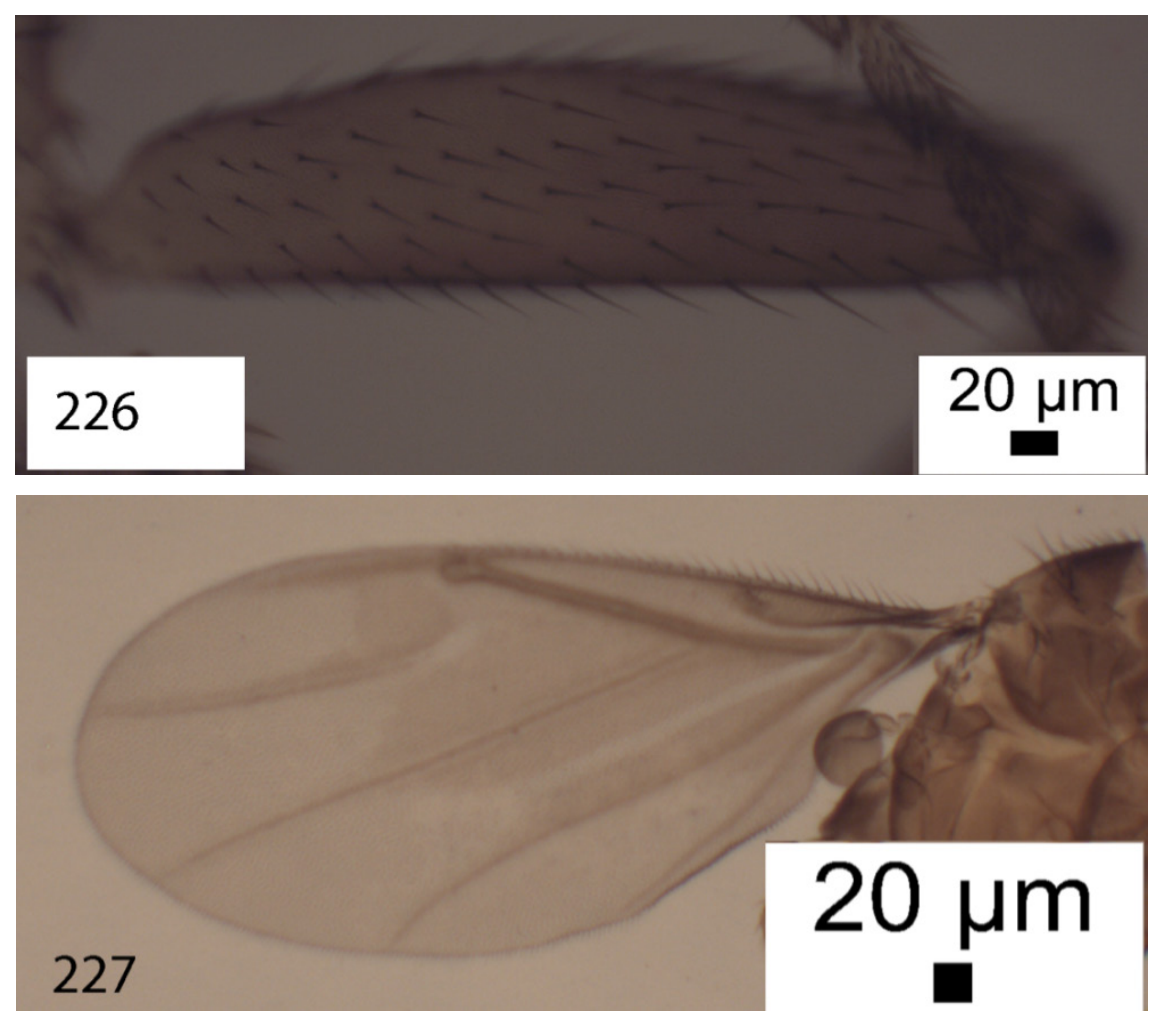

Figures 219-227. Chonocephalus signumpedalis male. (219) palp; (220) postpedicel; (221-223) hypopygium; (224) front tarsus; (225) mid basitarsus; (226) hind femur; (227) wing.

Male

A light brown species with pale sides to the thorax and abdominal venter. Postpedicel as Fig. 220. Palp as Fig. 219. The hairs of the abdominal tergites are fine and, apart from on T1 and T6, are largely restricted to the hind margins. They are longest on T6. Venter hairs very fine and much smaller. Hypopygium as Figs 221 to 223. Legs, apart from hind femora, mainly pale brown with pale tarsi. Front tarsus as Fig. 224. Mid basitarsus as Fig. 225. Hind femur as Fig. 226. Wing (Fig. 227) $0.55 \mathrm{~mm}$ long. Costal index 0.55. Haltere as Fig. 227.

\section{Material}

Holotype male, Papua New Guinea, Gulf of Ivimka, $7.73^{\circ} \mathrm{S}, 146.76^{\circ} \mathrm{E}, 200 \mathrm{~m}$, Malaise trap, 11-20 November 1996 , R. Snelling (CUMZ - 26-83). Paratype male, same locality, 1-10 March 1997, K. Merg (CUMZ, 26-83).

Etymology: the name refers to the pennant like process on the mid basitarsus.

\section{Chonocephalus simplex Schmitz}
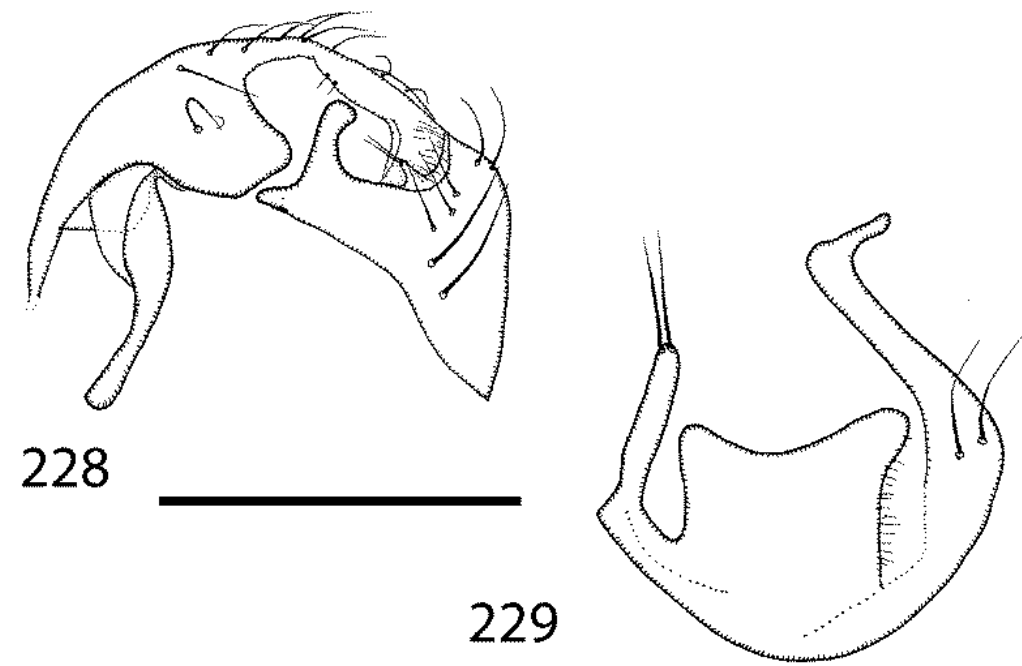

Figures 228-229. Chonocephalus simplex male hypopygium. (228) epandrium from below; (229) hypandrium and gonopods from below. Scale bar $=0.1$ $\mathrm{mm}$. 
Chonocephalus simplex Schmitz, 1928 [19]: 101.

\section{Material}

Male paratype (cotype), Bismarck Archipelago, Lowon, on carrion, 1-6 June 1896 (MKB - 27-135).

\section{Natural history}

A male was reported on carrion (Schmitz [19]).

\section{Chonocephalus sinuosus sp. nov.}
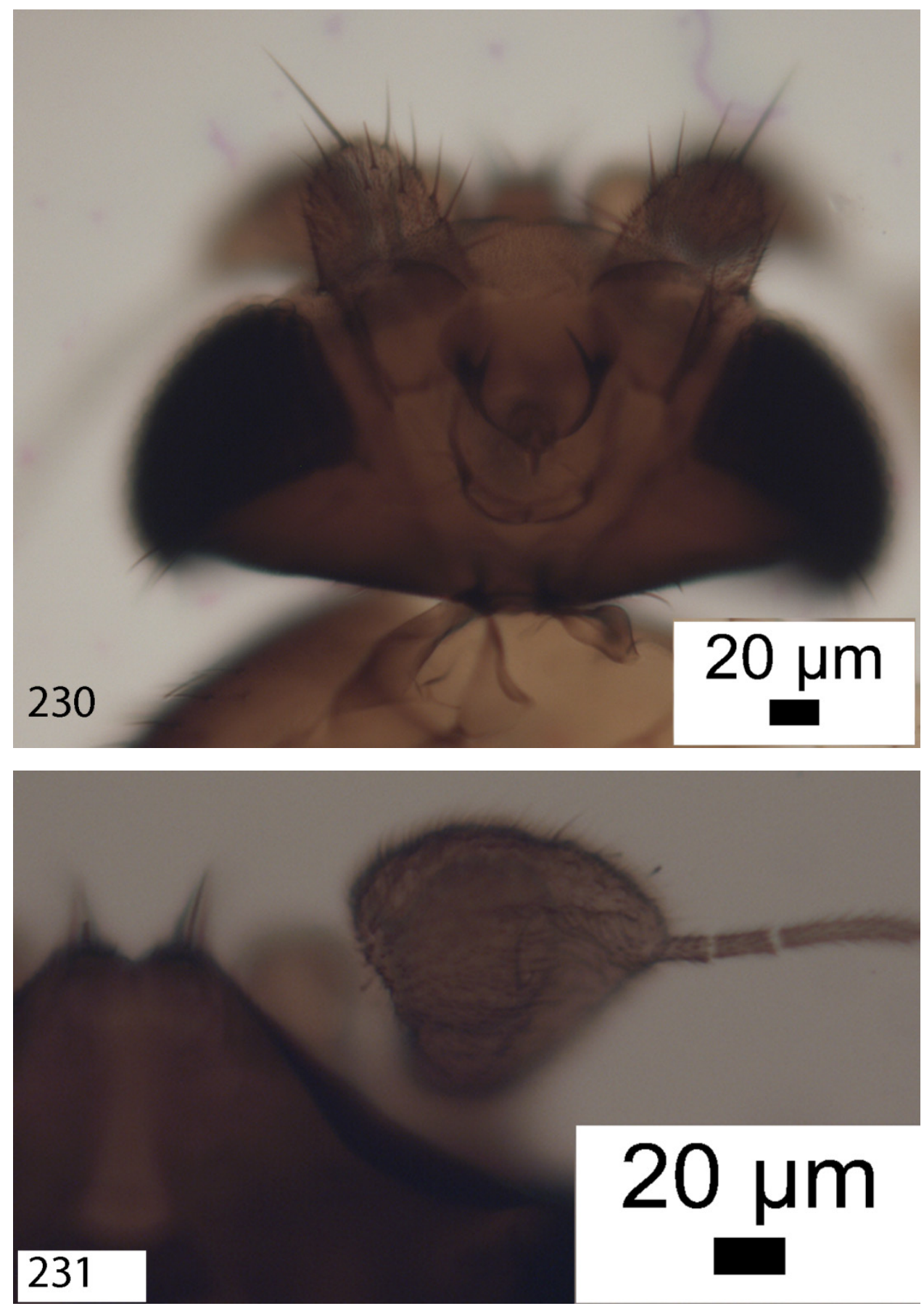

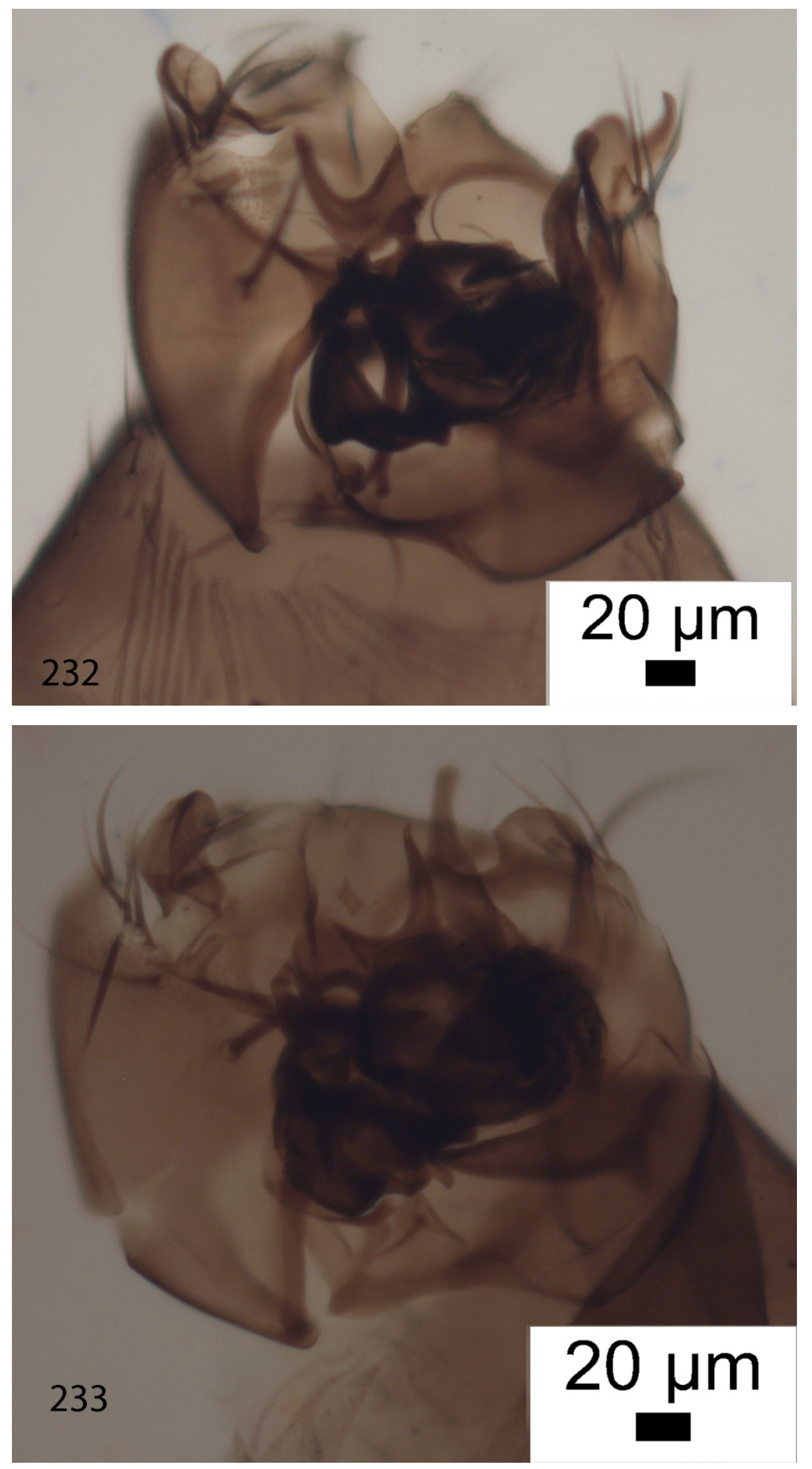

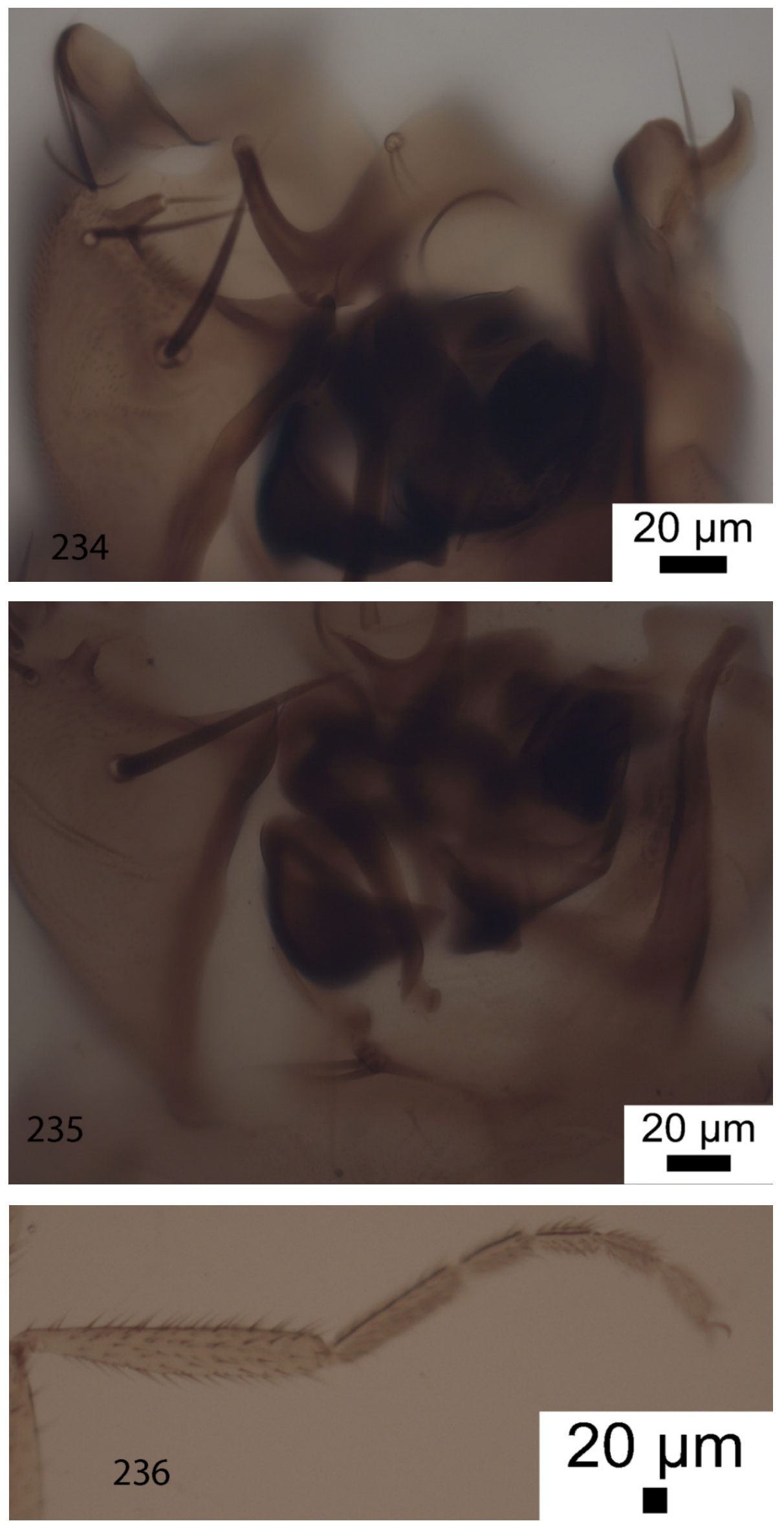

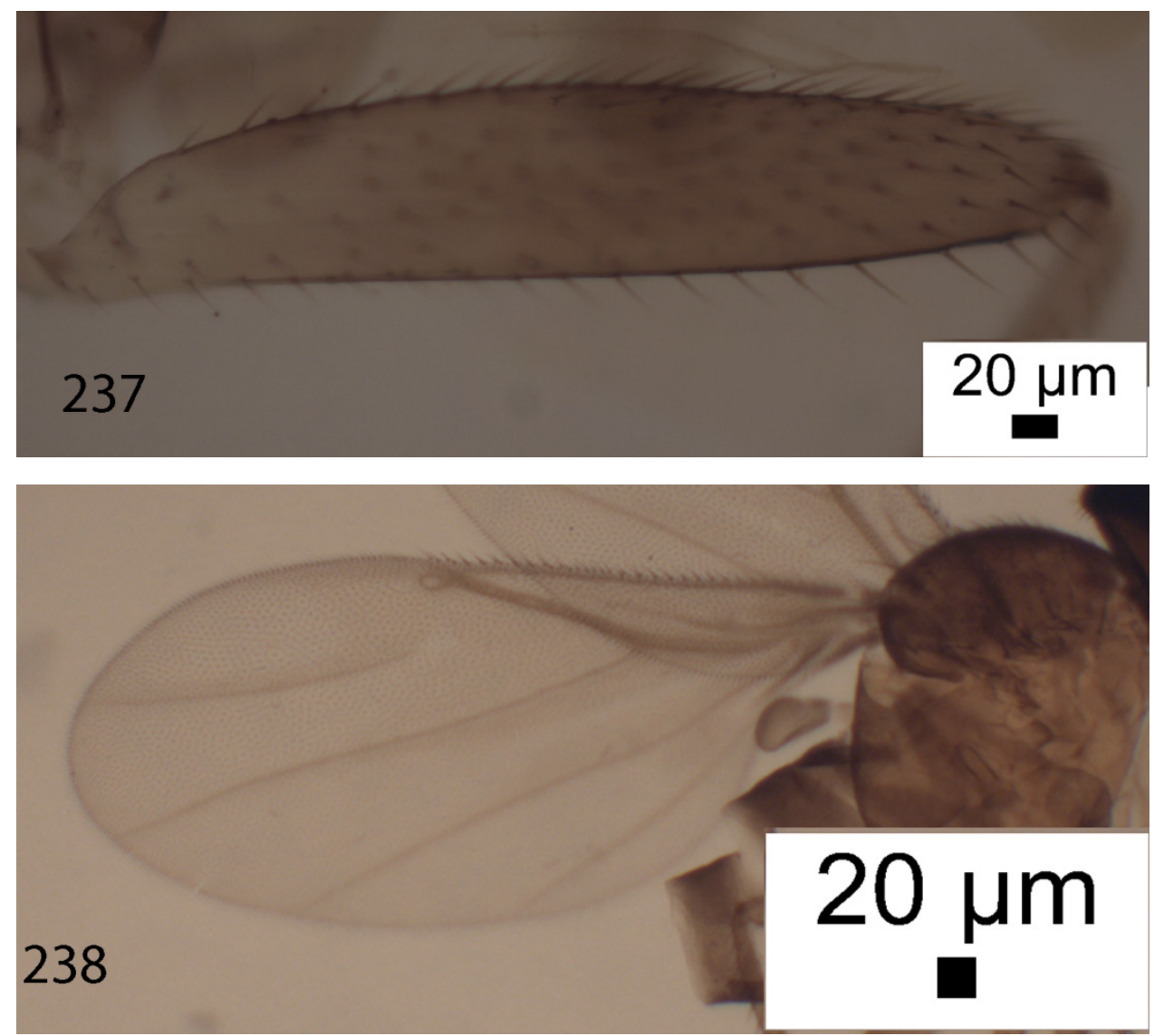

Figures 230-238. Chonocephalus sinuosus male. (230) palps; (231) postpedicel; (232-235) hypopygium; (236) front tarsus; (237) hind femur; (238) wing and haltere.

Male

A generally brown but not dark species with pale sides to the thorax and a pale abdominal venter. Postpedicel as Fig. 231. Palps as Fig. 230. The hairs of the abdominal tergites are fine and are not restricted to the hind margins. They are longest on T6. Venter hairs also fine but smaller. Hypopygium as Figs 232 to 235. Legs with coxae to tibiae brown but not dark and tarsi pale. Front tarsus as Fig. 236. Wing (Fig. 238) 0.9-1.0 mm long. Costal index 0.55. Haltere as Fig. 238.

\section{Material}

Holotype male, Papua New Guinea, Gulf of Ivimka, $7.73^{\circ} \mathrm{S}, 146.76^{\circ} \mathrm{E}, 110 \mathrm{~m}$, Malaise trap, 11-20 November 1996, R. Snelling (CUMZ - 26-82). Paratypes, 2 males, Wau, dung trap, 30 June to 3 July 1974, S. Peck (DEBU, 14-57); 1 male, Mandang Province, Baitabang Village, Kau Wildlife Area, $50 \mathrm{~m}$, primary forest, $5^{\circ} 08^{\prime} \mathrm{S}, 145^{\circ} 46^{\prime} \mathrm{E}, 21$ November to 22 December 1999, L. Cízek (CUMZ, 29-65).

Etymology: the name refers to the sinuous long left lobe of the hypandrium.

\section{Chonocephalus snellingi sp. nov.}




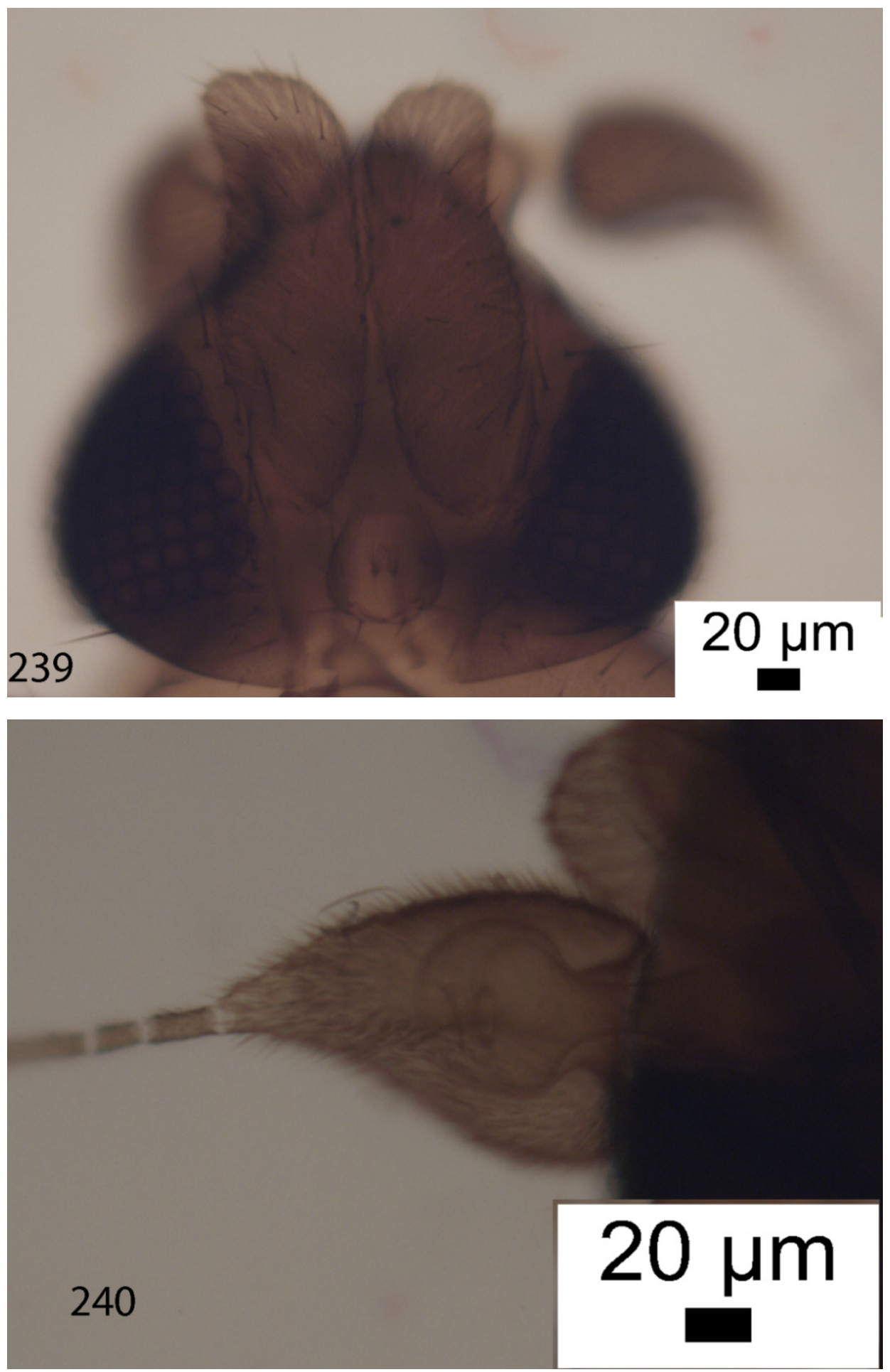



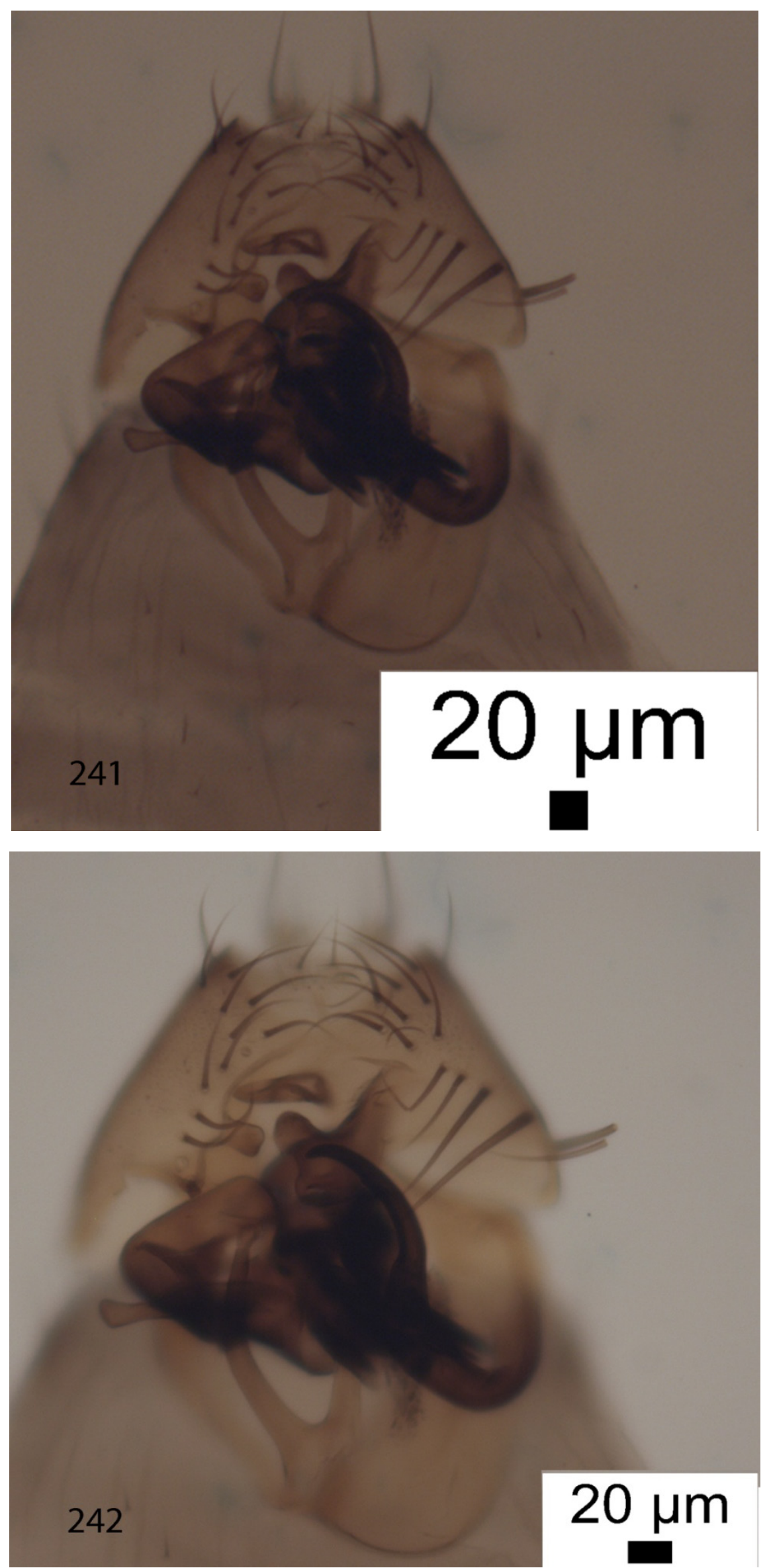

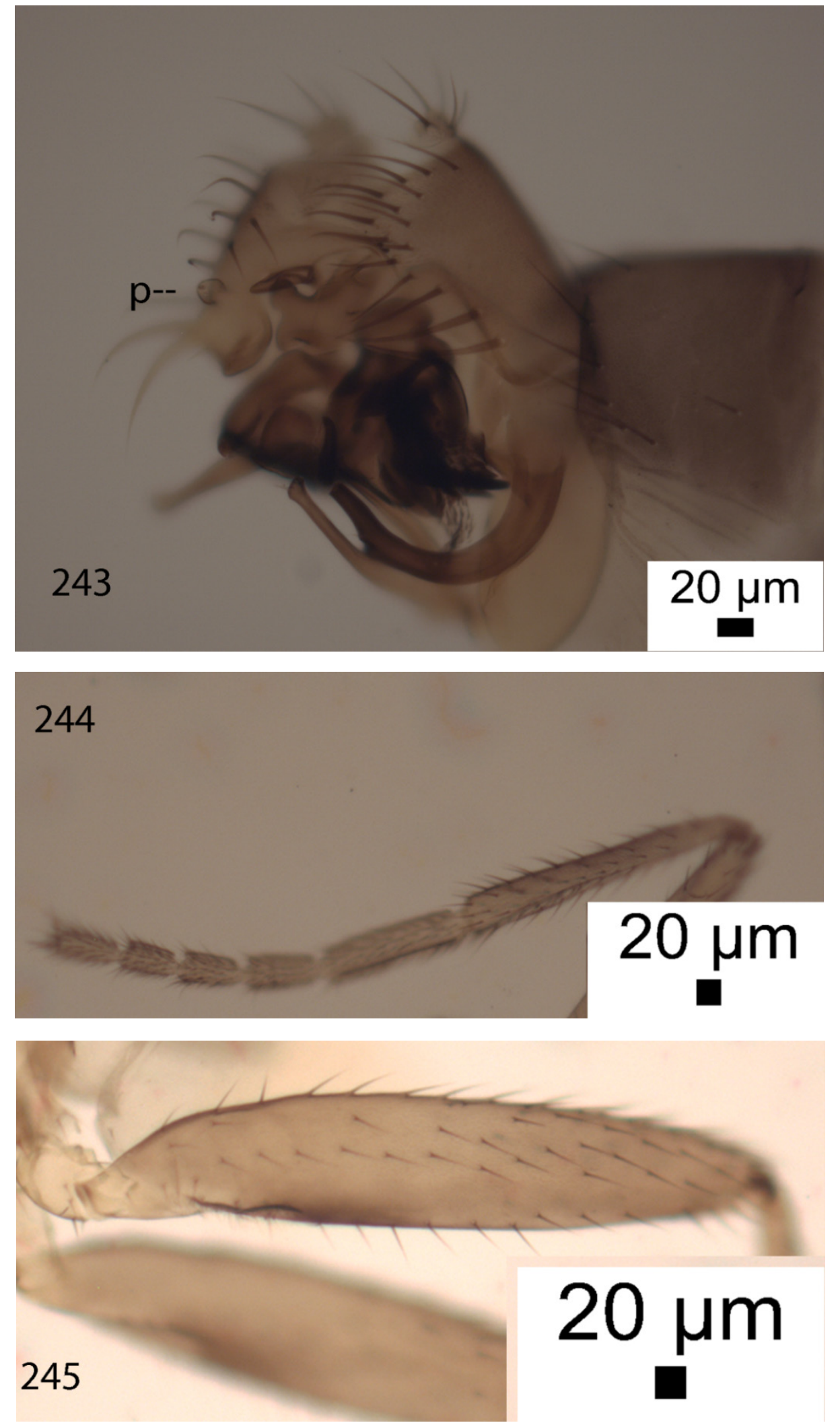


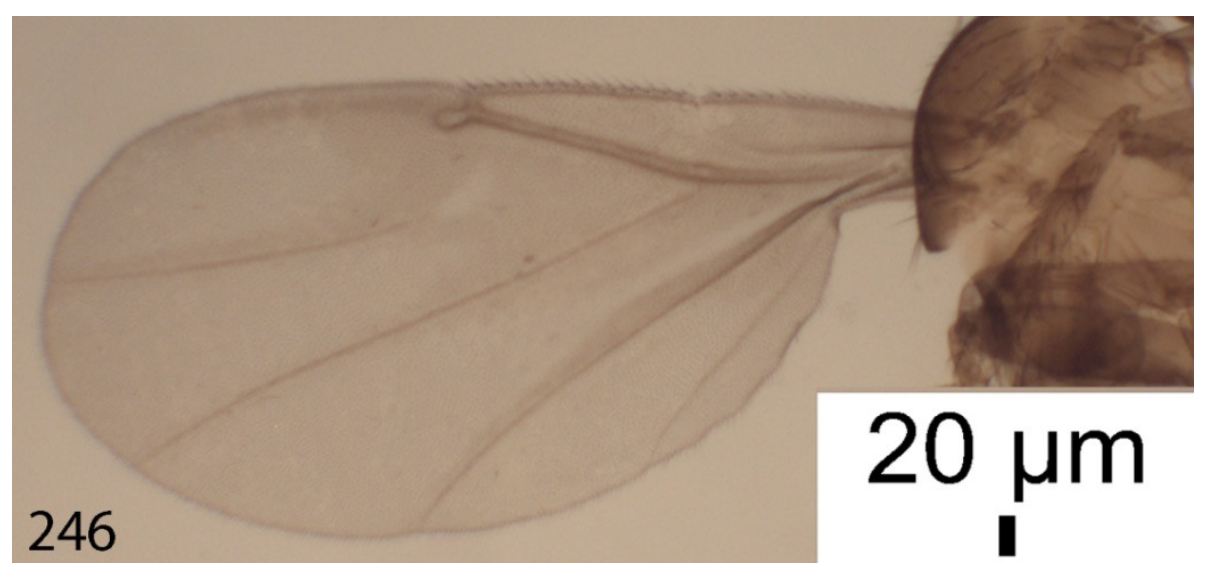

Figures 239-246. Chonocephalus snellingi male. (239) palps; (240) postpedicel; (241-243) hypopygium ( $\mathrm{p}=$ projection at base of LAP); (244) front tarsus; (245) hind femur; (246) wing.

Male

A generally light brown species with pale sides to the thorax and a pale abdominal venter. Postpedicel as Fig. 240. Palps as Fig. 239. The hairs of the abdominal tergites are fine and not restricted to the hind margins. They are longest on T6. Venter hairs also fine and mostly smaller. Hypopygium as Figs 241 to 243. Legs with coxae to tibiae, except mid tibiae, brown but not dark. Front tarsus as Fig. 244. Mid tibia and tarsi only weakly infuscated. Hind femur as Fig. 245. Wing (Fig. 246). 1.20-1.21 mm long. Haltere brown.

\section{Material}

Holotype male, Papua New Guinea, Gulf of Ivimka, $7.73^{\circ} \mathrm{S}, 146.76^{\circ} \mathrm{E}, 110 \mathrm{~m}$, Malaise trap, 11-20 November 1996 , R. Snelling (CUMZ - 26-82). Paratypes, 1 male as holotype; 4 males, same locality, 9 December 1996 to 10 January 1997 , K. Merg (CUMZ, 26-84); 2 males, 1-8 December 1966, R. Snelling (LACM, 26-70); 1 male, 120 m, 20 February to 1 March 1997, R. Snelling (LACM. 26-58); 2 males, 180 m, 26-31 October 1966, R. Snelling (LACM, 26-59); 3 males, same locality, 110 m, 1-8 December 1996, R. Snelling (LACM, 26-71).

Etymology: the name refers to the collector of the holotype.

\section{Chonocephalus subglaber Bohart}
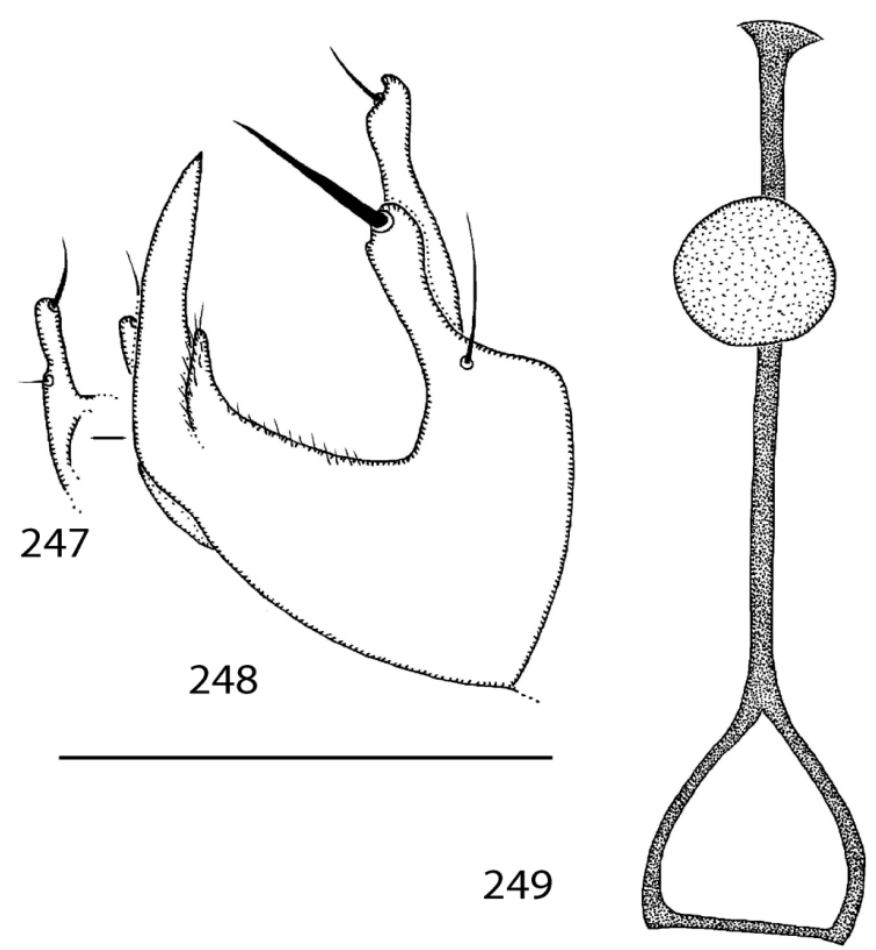

Figures 247-249. Chonocephalus subglaber: (247-248) male hypopygium; (247) left gonopod; (248) right gonopod and hypandriunm; (249) female, abdominl sternite 8 and spermatheca. Scale bar $=0.1 \mathrm{~mm}$. 
Chonocephalus subglaber Bohart, 1947: 410.

\section{Material}

Holotype female, Guam, Point Oca, from bread fruit, 15 June 1945, G. E. Bohart (USNM - type No. 57995 - 26), paratype ('allotype') male, as holotypeexcept 1 June 1945.

\section{Natural history}

Reared from rotting stump and from decaying fruit of papaya (Carica papaya) (Bohart \& Gresitt [1]).

\section{Chonocephalus sursumdigitus sp. nov.}
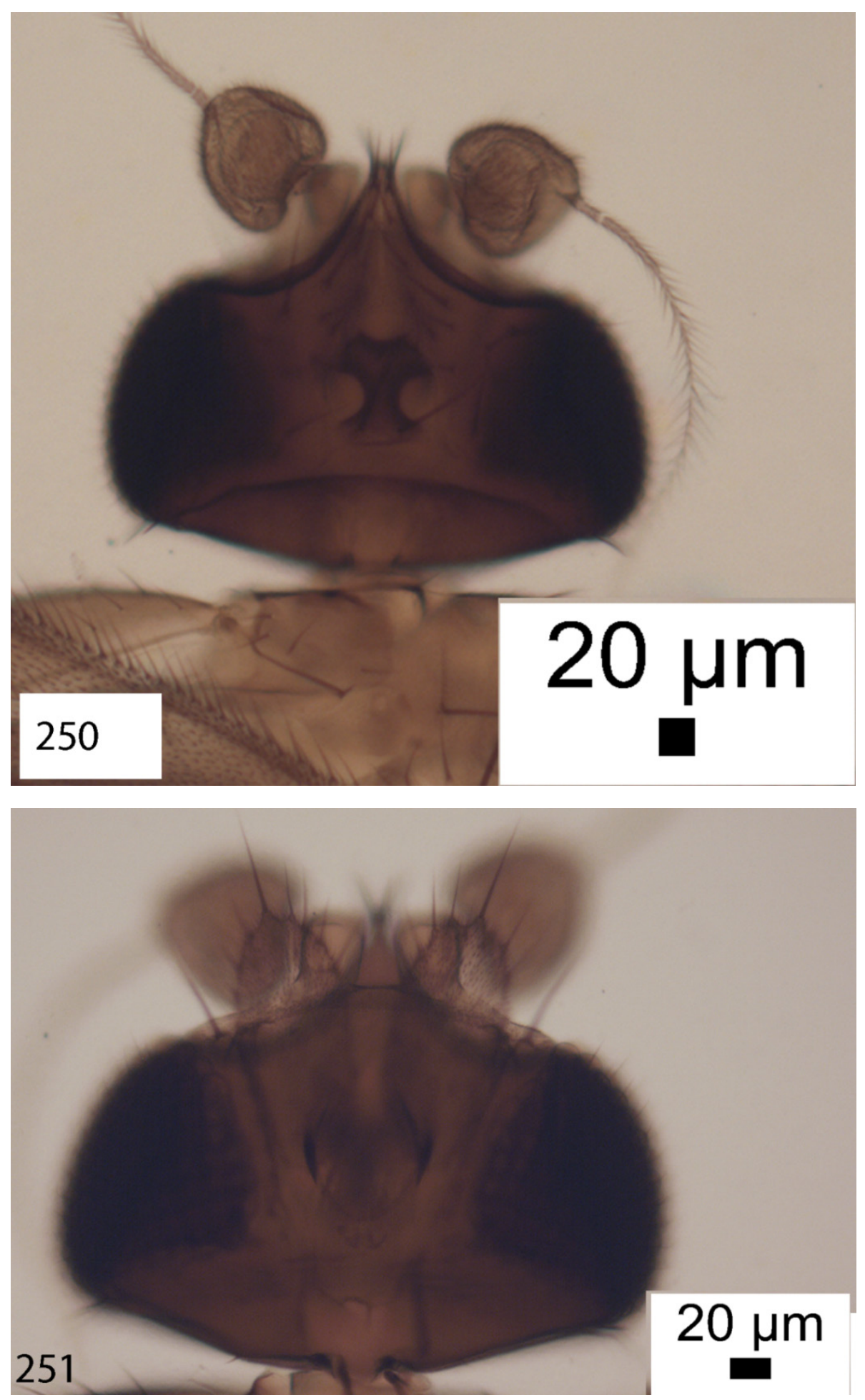

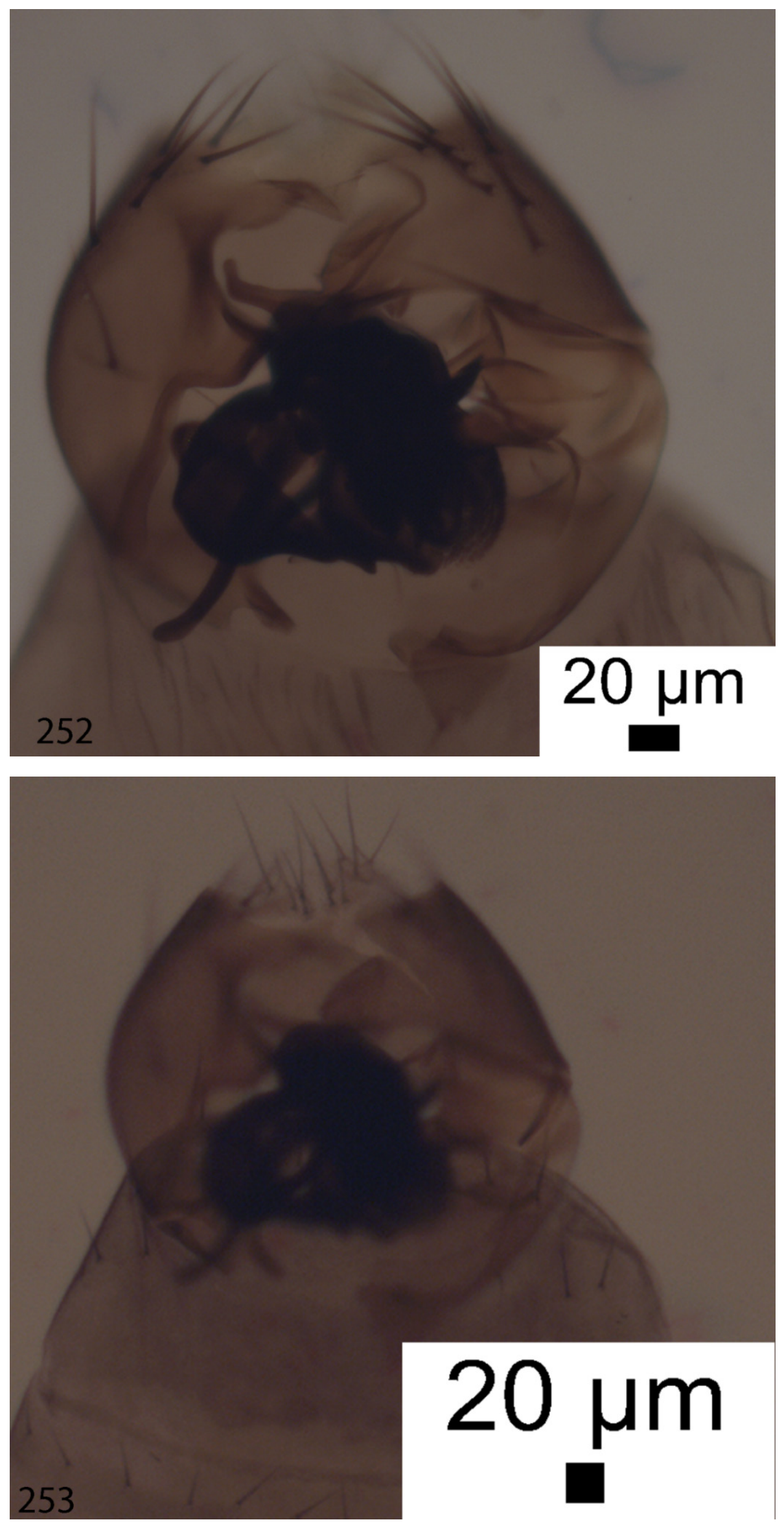

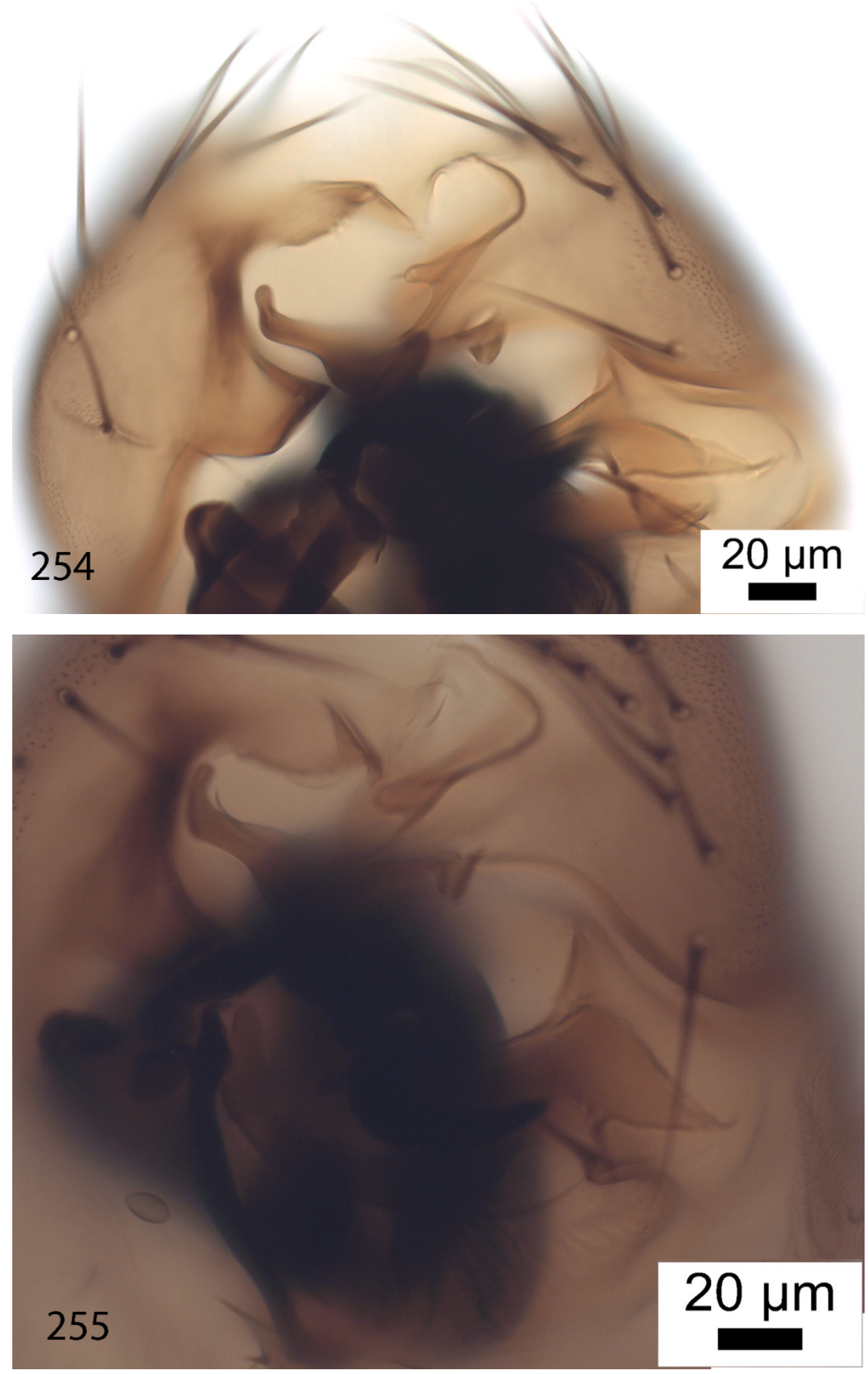

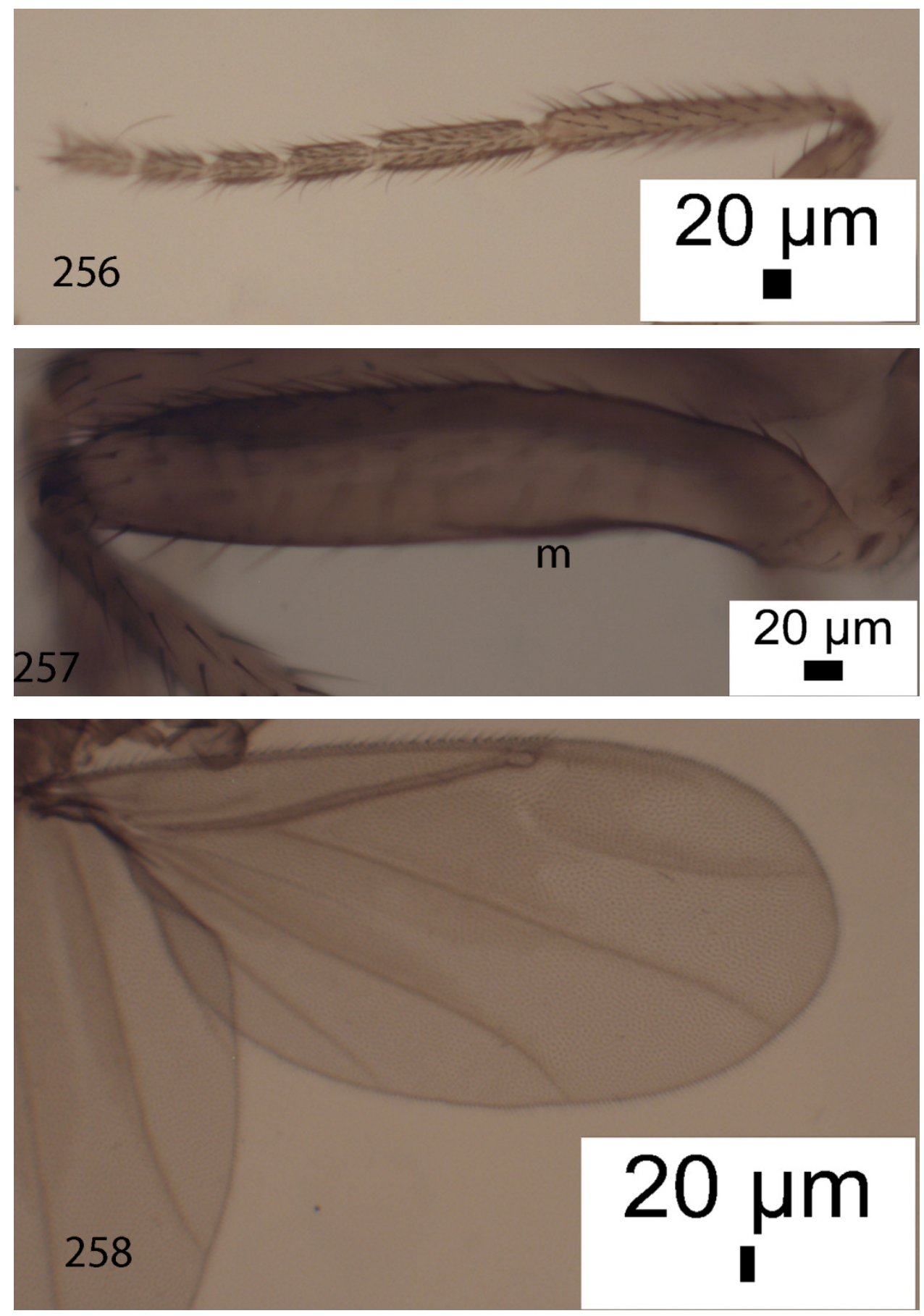

FIGURES 250-258. Chonocephalus sursumdigitus male. (250) head; (251) palps; (252-255) hypopygium; (256) front tibia and tarsus; (257) hind femur ( $\mathrm{m}=$ row of minute microsetae); (258) wing.

\section{Male}

A generally light brown species with pale sides to the thorax and a pale abdominal venter. Head as Fig. 250. Palps as Fig. 251. The hairs of the abdominal tergites are moderately fine and are not restricted to the hind margins. They are longest on $\mathrm{T} 6$. Venter hairs fine and much smaller. Hypopygium as Figs 252-254. Legs with coxae to tibiae, except mid tibiae, light brown. Mid tibiae white and all tarsi only lightly infuscated. Front tibia and tarsus as Fig. 255. Hind femur as Fig. 257. Wing (Fig. 258) 1.1-1.2 mm long. Costal index 0.63. Haltere brown.

\section{Material}

Holotype male, Papua New Guinea, Gulf of Ivimka, $7.73^{\circ} \mathrm{S}, 146.76^{\circ} \mathrm{E}$, Malaise trap, 10-20 March 1997, K. Merg (CUMZ - 26-83). Paratypes, 1 male, as holotype except (LACM, 26-72); 1 male, same locality, 110m, 11-20 November 1996, R. 
Snelling (CUMZ, 26-82); 1 male, 120, 20 February to 1 March 1997, R. Snelling (LACM. 26-58); 2 males, same locality, 110 m, 1-8 December 1996, R. Snelling (LACM, 26-71).

Etymology: the name refers to the upturned big toe of the foot like right anterior process of the epandrium.

\section{Chonocephalus transversalis (Schmitz)}
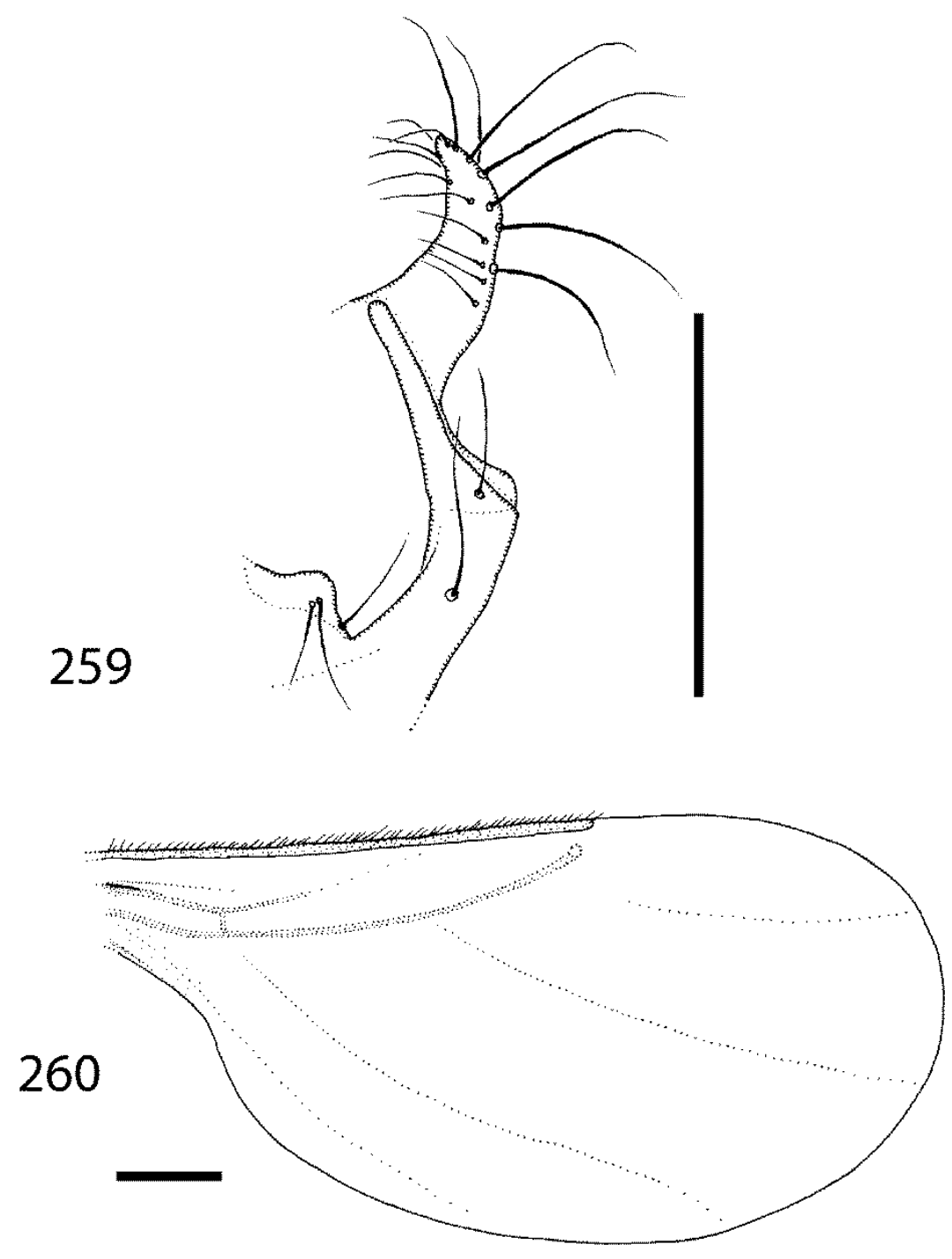

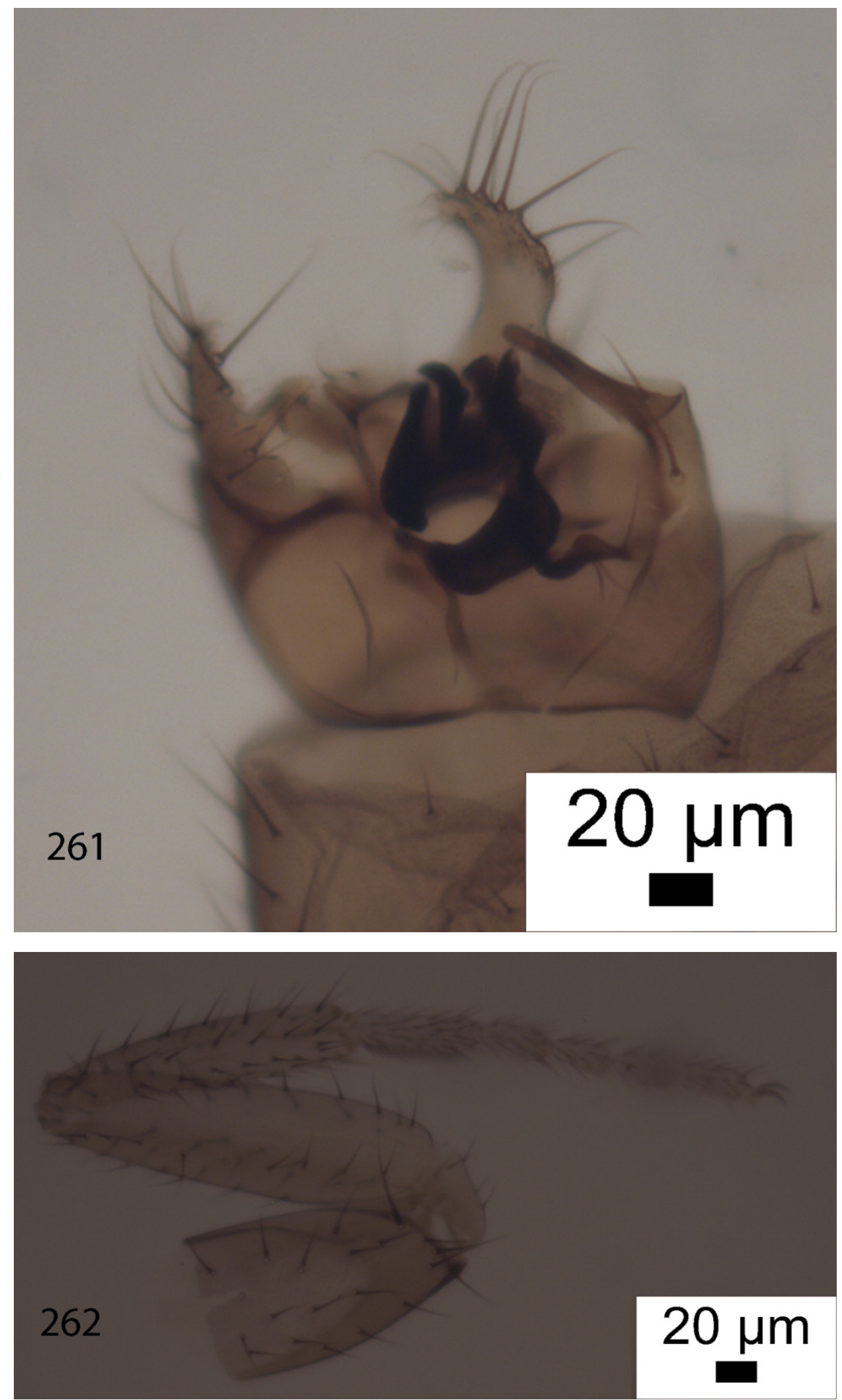

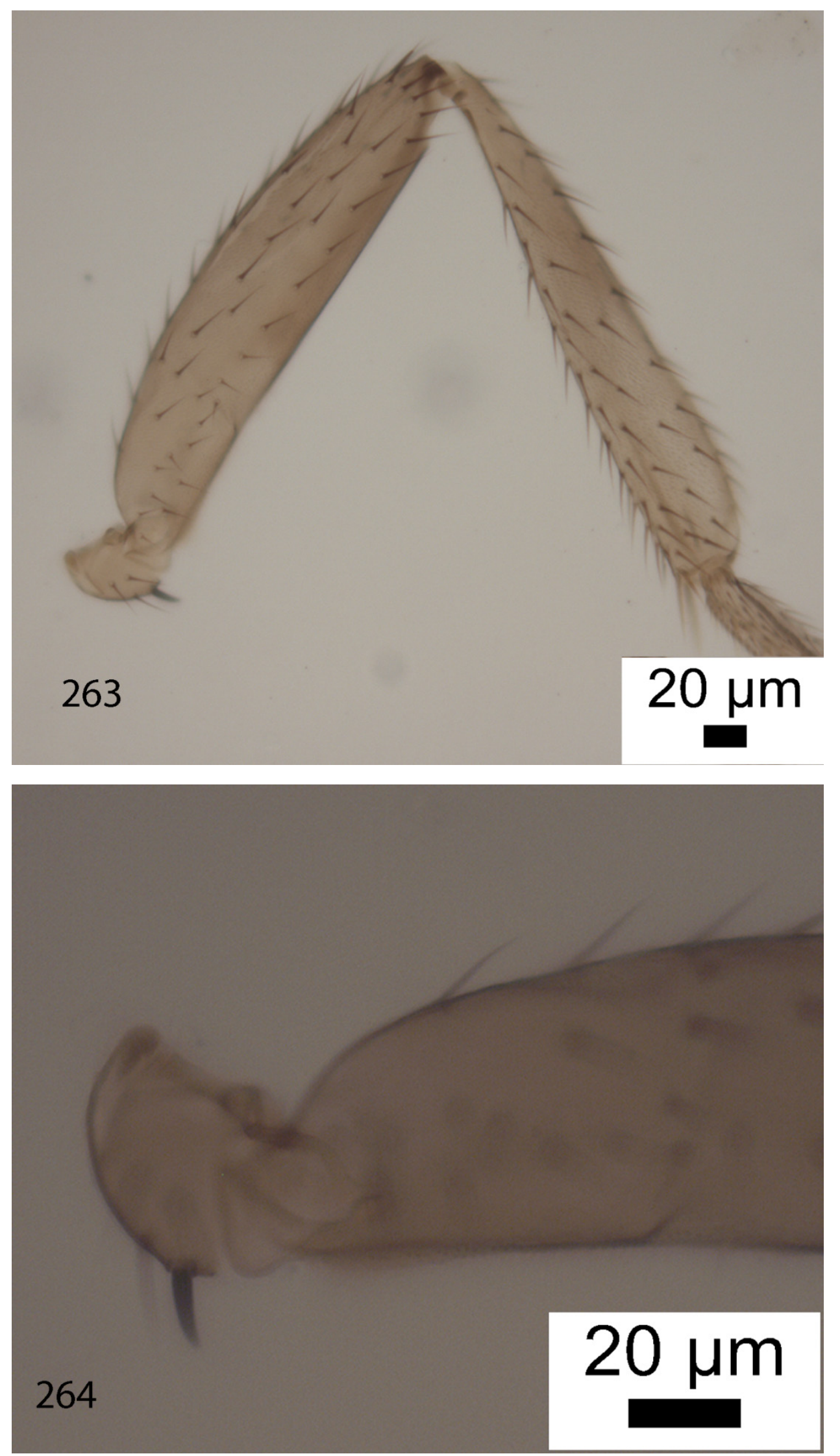

Figures 259-264. Chonocephalus transversalis male. (259) right side of hypopygium from below; (260) right wing. Scale bars $=0.1 \mathrm{~mm}$. (261) hypopygium; (262) front leg; (263) hind trochanter, femur and tibia; (264) hind trochanter and base of hind femur. 
Epichonocephalus transversalis Schmitz, 1928 [19]: 105

Chonocephalus transversalis (Schmitz).Disney, 2002 [10]: 32.

\section{Material}

Holotype male (wing only), Bismarck Archipelago, Neupommern, Lewon, 3-9 November (MKB). 1 male, Papua New Guinea, Baiyer R., Goroka, 1200 m, 4-12 August 1985, T. Anderson (leg. R. S. George) (CUMZ, 3-143).

Chonocephalus wapogaensis sp. nov.
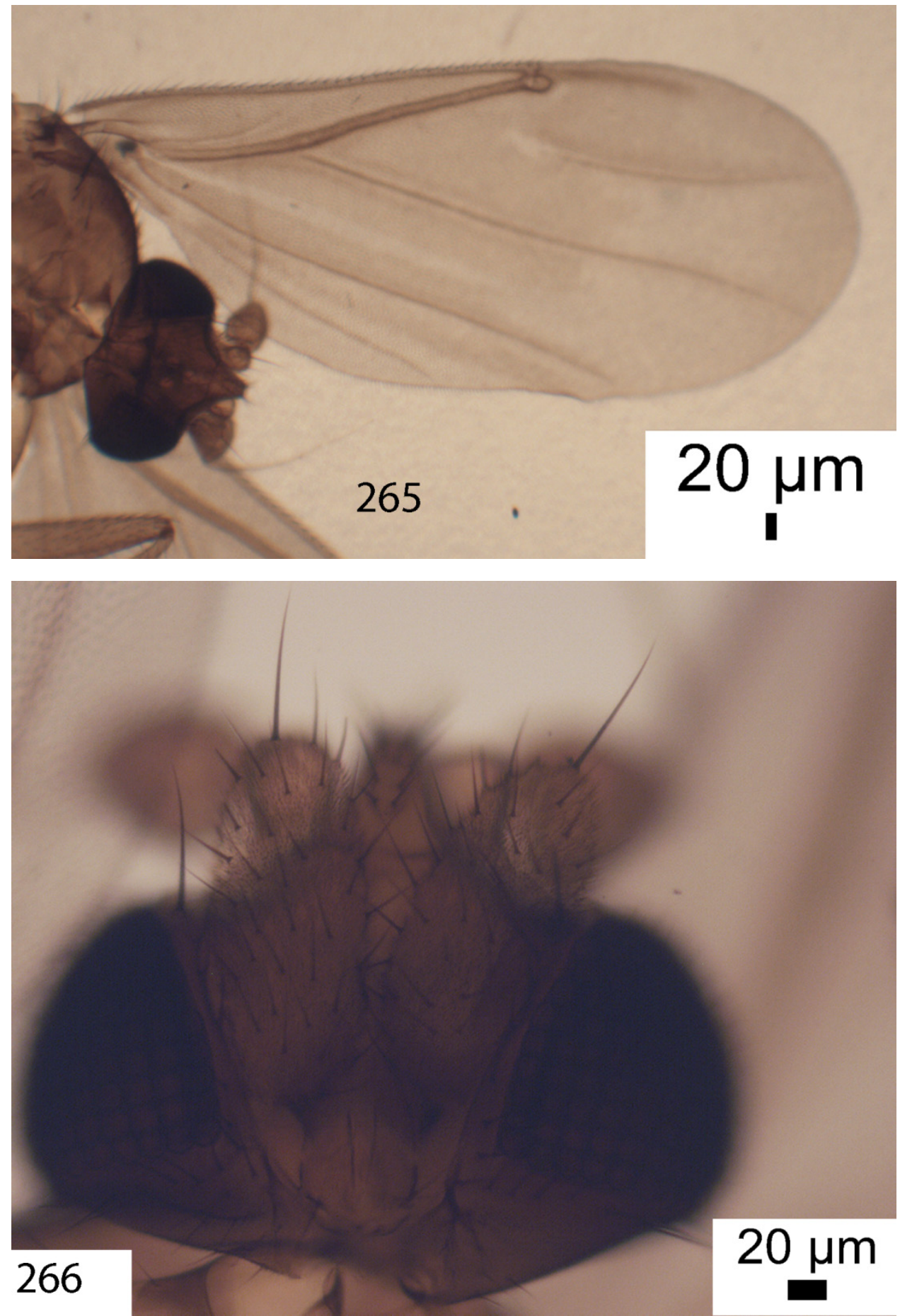

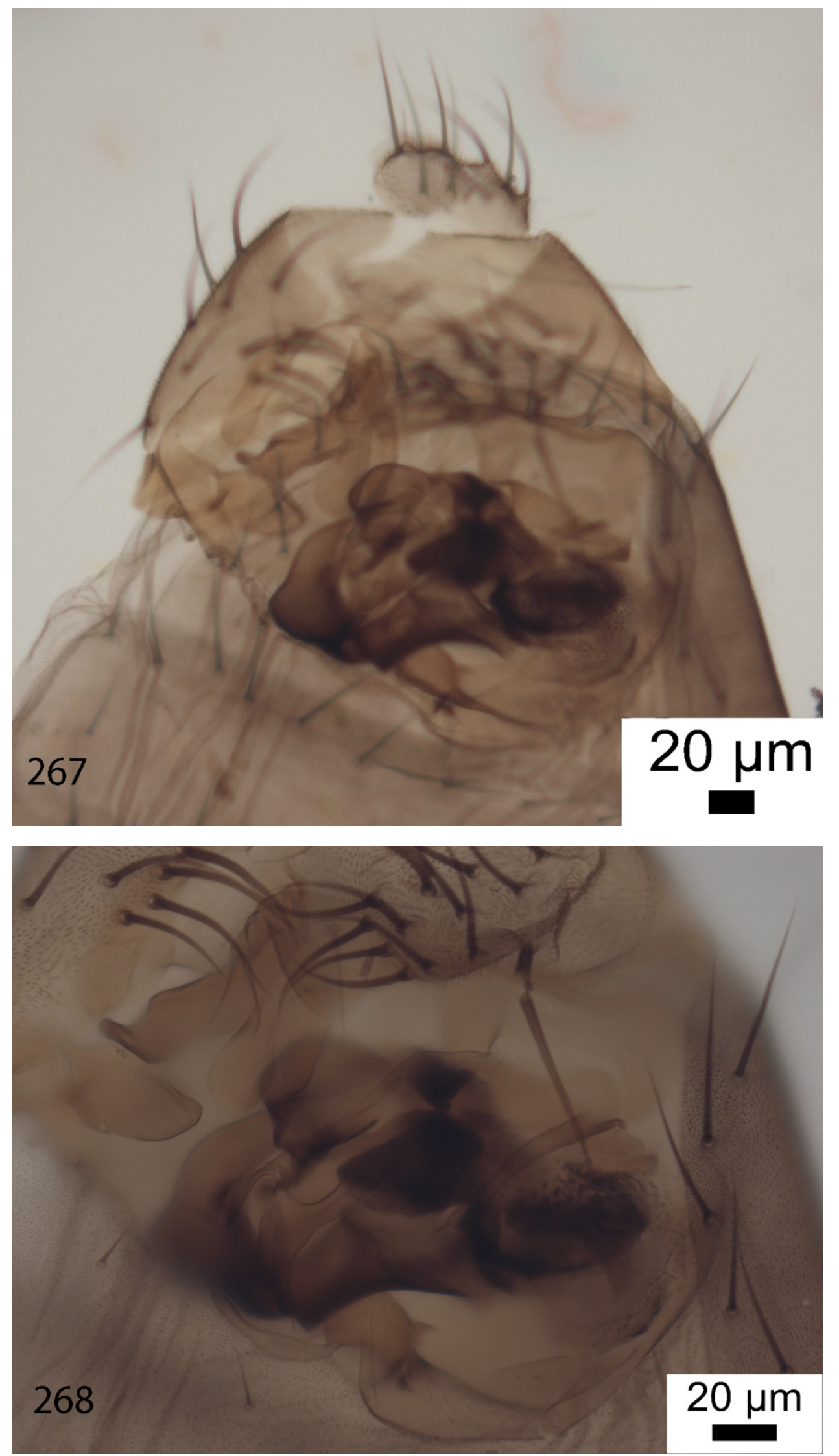


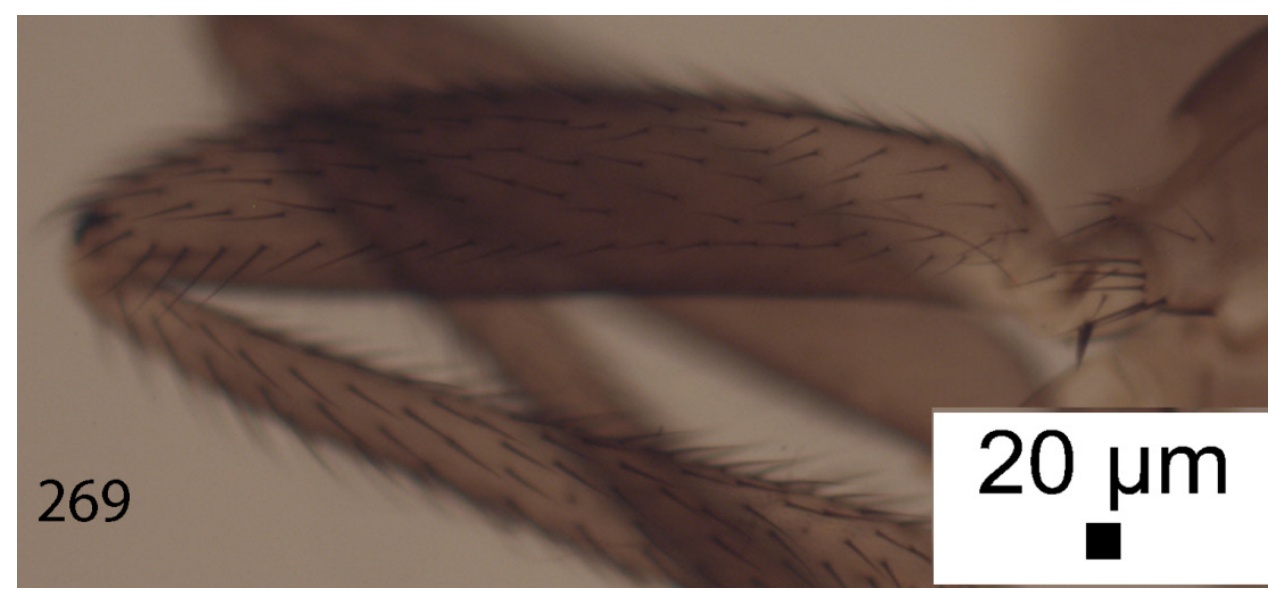

Figures 265-269. Chonocephalus wapogaensis male. (265) head and wing; (266) palps; (267-268) hypopygium; (269) hind femur.

Male

A generally brown but not dark species with pale sides to the thorax and a very pale abdominal venter. Postpedicels as Fig. 265. Palps as Fig. 266. The hairs of the abdominal tergites are moderately fine and not restricted to the hind margins. They are a little longer at rear of T6. Venter hairs very fine and much smaller. Hypopygium as Figs 267 and 268. Legs with coxae to tibiae light brown and tarsi pale. Front tarsus with posterodorsal hair palisades on segments 1 to 4 and segment 5 longer than 4. Hind femur as Fig. 269. Wing (Fig. 265) 0.60-0.61 mm long. Costal index 0.60. Haltere brown.

\section{Material}

Holotype male, Indonesia, irian Jaya, Wapoga Camp, $3.14^{\circ} \mathrm{S}, 136.57^{\circ} \mathrm{E}, 1050 \mathrm{~m}, 19-26$ June 1998 , R. Snelling (LACM, 26-70).

Etymology: the name refers to the type locality.

\section{Key to the males of the Australasian Region}

The males of $C$. elongatus, $C$. primus and $C$. secundus remain unknown or not yet associated with their males.

1 Surstylus (C) present and the most anterior bristle of the left side of the edpandrium differentiated (i.e. it is an S) so that is clearly more robust than the rest and may be spine like (e.g. Figs 45 and 81 ).................................

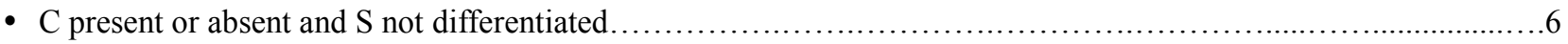

$2 \quad \mathrm{~S}$ is short and blunt tipped (Fig. 43) dimidiatus Borgmeier

- $\mathrm{S}$ is long and tapers to a point. .3

$3 \mathrm{~S}$ is spine like and there is a spine on RG also (Figs 45-47)...... dorsalis Wandolleck

- $\mathrm{S}$ is a bristle (but still more robust than the rest on the left side of the epandrium) 4 LL broad and long (Figs $81 \& 82$ ).

- LL narrow, long and sinuous (Figs 39, 40 \& 232). guineaensis sp. nov.

LL strongly tapered and with a more pointed tip (Figs $39 \& 40)$ dahli Schmitz

- LL less strongly tapered and with a rounded tip (Figs $232 \& 235$ ). sinuosus sp. nov.

6 The posterolateral regions of the epandrium tapered and projecting rearwards (Figs $259 \& 261$ ). The vesicle at tip of wing vein 3 ill defined (Fig. 260). A fringe of fine, pale, minute hairs below basal third of hind femur (Fig. 264). transversalis (Schmitz)

- Without this combination...... ivimkaensis sp. nov.

Mid femur narrowed in its basal half (Fig. 128). Hypopygium as Figs 124-126. .8

$8 \quad$ Mid tibia with a pre-apical posteroventral patch of hairs longer than rest (Figs 111 and 173)..... .9

- Mid tibia without this feature. 10

9 Tip of mid tibia and basitarsus as Figs 111 and 112. Hind femur with an irregular row of long fine hairs (longer than the more robust hairs on the anterior face) below the second and third fifths (Fig. 113). C absent 
(Figs108-110).

immutotibia sp. nov.

- Mid tibia as Fig. 173. Hairs below hind femur as Fig. 174. C present (Fig. 170) mergi sp. nov.

10 The hairs at the sides of abdominal tergites longer than usual, those on T4 to T6 being more than $0.15 \mathrm{~mm}$ long (Fig. 195). Hypopygium as Figs 196 and 197, with the longest hair on each cercus exceptionally long (being about 0.40 $\mathrm{mm}$ in length.

- Apart from those at the rear of T6 these hairs clearly shorter and hypopygiumotherwise pilositerga sp. nov.

11 Palps long and more rectangular than usual (Fig. 239). Postpedicel clearly longer than its greatest breadth (Fig. 240). The LL and RL long and narrow, the darker RG longer and sinuous (Figs 241 \& 242) and the base of the LAP with two minute pale hairs at then tip of a thumb like projection (Fig. 243) snellingi $\mathrm{sp}$. nov.

- Palps not so. Postpedicel frequently (but not always) only about as long as its greatest breadth. Details of hypopygium otherwise .12

12 Hind femur (Fig. 136) with a posteroventral row of long, fine hairs that are longer than hairs on the anterior face (Fig. 137). Hypopygium as Figs 133-135. jayaensis sp. nov.

- No such row of hairs on hind femur. Hypopygium otherwise. 13

13 Postpedicels exceptionally long (Fig. 68). The pale LAP is narrow in middle but expands to its truncate (Fig. 71) or slightly concave tip....fastigatus sp. nov. -Postpedicels shorter. LAP otherwise................................14

14 Ventral edge of hind femur with a fringe of short, very fine, pale hairs in the basal half or more....................15

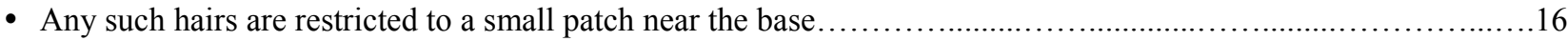

15 Mid tibia almost entirely white. RAP resembles a foot (Fig. 6) aduncus Schmitz

- Mid tibia largely pale brown. RAP as Fig. 19 andersoni sp. nov.

16 Vein 3 extends beyond tip of costa which is joined to the former by a small cross vein (Fig. 23). Postpedicel clearly longer than its greatest breadth. Each side of epandrium with more than 17 fine hairs, LAP is a backwardly

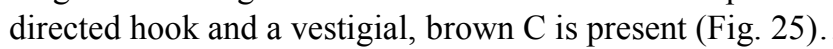
baitabagensis sp. nov.

- Without this combination. 17

17 Near the base of hind femur there is a small patch of pale, minute, microsetae (m in Fig. 257) .....................18

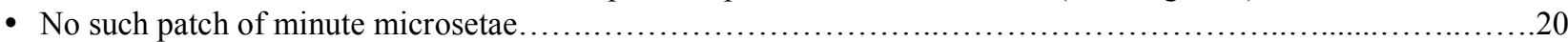

18 With more than 6 hairs on each side of the epandrium. 19

- With less than 6 hairs on each side of the epandrium (as Figs 160 \& 161). madangensis sp. nov.

19 Cercus with one hair clearly longer than the rest (Fig. 141). LAP narrower and the foot-like RAP with its 'big toe' straight (Fig. 143). kauensis sp. nov.

- Cerci as Fig. 253. LAP broader and RAP with the 'big toe' upturned (Figs 252 \& 255)........sursumdigitus sp. nov.

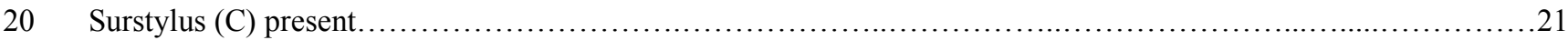

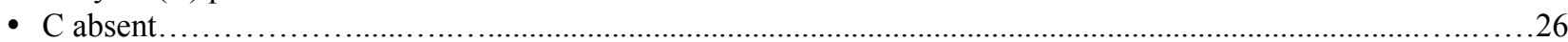

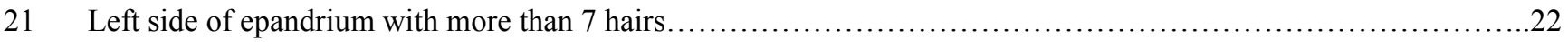

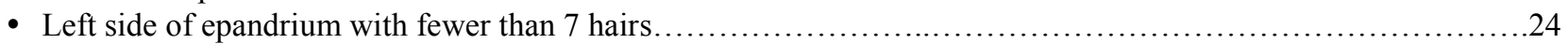

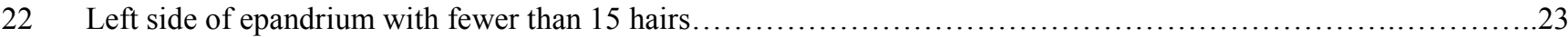

- Both sides of epandrium with at least 18 strong hairs (Fig. 188)...........................................parvupalpus sp. nov.

23 LG long with an expanded tip bearing two short hairs and RG with hook tip dark brown (Figs 100 \&

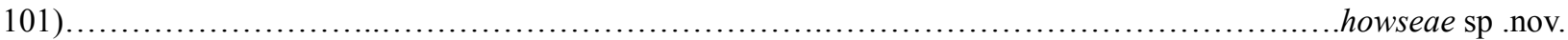

- LG a short protruberance bearing two long bristles and RG entirely pale straw coloured (Fig. 150).

longisetarum sp. nov.

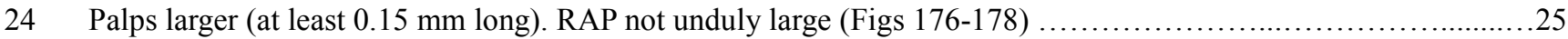

- Palps smaller, at most $0.10 \mathrm{~mm}$ long (Fig. 211). RAP very large and irregularly quadrate (Figs 213 \& 214). quadratus sp. nov. 
26 The microtrichia of the left side of the epandrium below the hairs are modified into pointed scales ( $\mathrm{m}$ in Fig. $11)$...... americanus Borgmeier

- Microtrichia of left side near margin absent or neare st ones are not modified. .27

27 Mid basitarsus with a small dorsal appendage at its base (Fig. 225). Two spine-like bristles on the right side of the epandrium (Fig.221).

- No such appendage on mid basitarsus. No spine-like bristles on the right side of the epandrium. signumpedalis $\mathrm{sp}$. nov.

30 More than 20 hairs on left side of epandrium. Details of hypopygium as Figs 247-248. subglaber Bohart

- Less than 20 hairs on left side of epandrium (Figs $181 \& 182$ ). .papuaensis sp. nov.

31 More than 14 hairs on left side of epandrium...... . .32

- Fewer than 14 hairs on left side of epandrium. .34

32 LAP long and narrow and with the 2 hairs at its base well clear of the other bristles on the edpandrium (Fig. 206)

procerus sp. nov.

- LAP otherwise (Figs 76 and 85). . .33

33 LAP with a narrow apical portion that is curved rearwards (Fig. 76) and RG is a long and U-shaped (Fig. 77).....

- LAP simple and RG straight but with an asymmetric tip (Fig. 85)..heymonsi Stobbe ...gonocurvatus sp. nov.

34 The hairs of the epandrium longer and more robust than those on cerci, although one hair on cercus may be almost

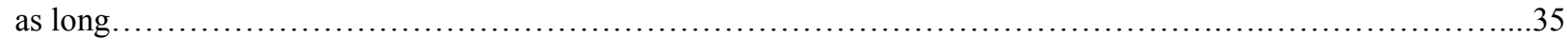

- The hairs of epandrium about as strong and either about as long or shorter than those on cerci.....................36

35 With more than 10 hairs on left side of epandrium (Figs $117 \& 118$ ).

- With fewer than 10 hairs on left side of epandrium (Fig. 166). irianensis sp. nov. ..major Schmitz

36 LG almost pear shaped and RAP complex and directed forwards (Figs 267 \& 268). wapogaensis sp. nov.

- LG and RAP otherwise. .37

37 LL and RL long and relatively slender (Figs 30 \& 31) brevisetarum sp. nov.

- LL and RL as Fig. 229 or even more reduced. .38

38 B well developed in middle, with dense covering of small hairs, and a small sclerotised (dark brown to black) lobe (possibly a vestigial C) at its left edge (Fig. 36)..

- B less developed and with some weak hairs at its right end only (Fig. 228)........ contrarius sp. nov. simplex Schmitz

\section{Key to the known females of the Australasian Region}

The females of most species are unknown or not yet associated with their males.

1 Most abdominal tergites with dark bands bordering hind margins (e.g. Figs. 59 and 90)..... .2

- No such bands. (The microsetae adjacent to the hairs of the tergites are large as in Fig. 93. Abdominal sternite 8 with a spatula like tip - Fig. 18)..... americanus Borgmeier

2 The posterior tip of sternite 8 fades away (Figs $51 \& 216$ ). 3

- The tip of sternite 8 forms a loop (e.g. Figs 10, $61 \& 249$ ) .4

3 As Fig. 52, sternte 8 as Fig. 51. (Tergites 9 and 10 as Fig. 49). dorsalis Wandolleck

- As Fig. 218, sternite 8 as Fig. 216. secundus Schmitz

4 Tip of sternite convex behind or with a straight hind margin (e.g. Figs 59 \& 249) .5

- Tip of sternite 8 strongly concave (Fig. 10). aduncus Schmitz

5 Furca extended behind and ending with a point either side of its concave hind margin (Fig. 200). (Whole fly as Fig. 
202)...

- Furca circular (Figs 61 \&92).

..primus Schmitz

6 Hind margin of sternite convex (Fig. 10). 7

- Hind margin of sternite 8 straight (Fig. 249) subglaber Bohart

7 Tergite 8 narrow and well sclerotized (Fig. 60). (Whole fly as Fig. 59, sternite 8 etc. as Fig. 61)......elongatus Schmitz

- Tergite 8 broadens posteriorly but is very pale (Fig. 91). (Whole fly as Fig. 90, sternite 8 etc. as Fig. 92)... heymonsi Stobbe

\section{Discussion}

Six species were reported from the Holarctic Region, with none being restricted to the Western Palaearctic, one being recorded from Japan and Pacific islands further East and the other five being tramp species transported across the world by man. 14 species were recorded from the Afrotropical Region, with 7 being restricted to this Region and 7 being tramp species of which 6 were the same such species reported from the Holarctic Region (Disney [11], [13]). 27 species known in the male sex were recorded from the Neotropical Region including the same 5 of the tramp species reported from the Afrotropical Region; but an additional 11 species were reported in the female sex only and some of these are likely to be species whose males have yet to be described (Disney [12]). With 56 named species reported from the Oriental Region (Disney [14]) it is evident that this genus is most species rich in this region, being richer than the fauna reported for the Australasian Region above, with 41 species, of which 27 are new. But these lists are likely to be augmented by future collecting, as is especially likely for the Neotropical Region.

\section{Acknowledgements}

For the loan of specimens I am grateful to Dr Brian Brown (Natural History Museum, Los Angeles), to Dr Matthias Buck (then at the University of Guelph, Canada) and to Dr Ximo Mengual (Museum Koenig, Bonn).

My work on Phoridae is currently funded by the Balfour- Browne Trust (University of Cambridge).

\section{REFERENCES}

[1] Bohart, G. E. \& Gressitt, J. L. Filth-inhabiting flies of Guam. Bulletin of the Bernice P. Bishop Museum, vol. 204, 1-152. 1951.

[2] Borgmeier, T. Sobre o cyclo evolutivo de Chonocephalus Wandolleck e uma nova espécie de Melaloncha Brues, endoparasita de abelhas. Archivos do Instituto de Biologia Vegetal, Rio de Janeiro, vol. 2, 255-65. 1935.

[3] Borgmeier,T. New or little known phorid flies, with description of two new genera. Anais da Academia Brasileira de Ciências, Rio de Janeiro, vol. 39, 195-210. 1967.

[4] Disney, R. H. L. An exotic scuttle fly, Chonocephalus heymonsi Stobbe (Dipt., Phoridae) from Middlesex. Entomologist's Monthly Magazine, vol. 116, 207-212 (1980). 1981.

[5] Disney, R. H. L. Scuttle Flies - Diptera, Phoridae (except Megaselia). Handbooks for the Identification of British Insects, Vol. 10(6), 1-81. 1983.

[6] Disney, R. H. L. Morphological and other observations on Chonocephalus (Phoridae) and phylogenetic implications for the Cyclorrhapha (Diptera). Journal of Zoology, London, (A). vol. 210, 77-87. 1986.

[7] Disney, R. H. L. Scuttle Flies: The Phoridae (London: Chapman \& Hall). 1994.

[8] Disney, R. H. L. Two New Termitophilous Phoridae (Diptera) from Australia. Sociobiology, vol. 34, 87-97. 1999.

[9] Disney, R. H. L. The preservation of small Diptera, Entomologists’s Monthly Magazine, vol. 137, 155-159. 2001.

[10] Disney, R. H. L. Revisionary notes on Chonocephalus Wandolleck (Diptera: Phoridae) with keys to species of the Holarctic Region. Zootaxa, vol. 60, 1-36. 2002.

[11] Disney, R. H. L. Revision of Afrotropical Chonocephalus Wandolleck (Diptera: Phoridae). Journal of Natural History, vol. 39, 393-430. 2005. 
[12] Disney, R. H. L. Review of Neotropical Chonocephalus Wandolleck (Diptera: Phoridae). Zootaxa, vol. 1772, 1-54. 2008.

[13] Disney, R. H. L. A further synonym in Chonocephalus Wandolleck (Dipt., Phoridae). Entomologist's Monthly Magazine, vol. 145: 33-34. 2009.

[14] Disney, R. H. L. (in press) Revision of Oriental Chonocephalus Wandolleck (Diptera: Phoridae). Annales Zoolgici, vol.

[15] Disney, R. H. L. \& Aguiar, A. M. F. A note on two similar tramp species of Chonocephalus Wandolleck (Dipt., Phoridae). Entomologist's Monthly Magazine, vol. 146: 167-168 (2010). 2011.

[16] Lincoln, R. J., Boxshall, G. A. \& Clark, P. F. A dictionary of ecology, evolution and systematics. (Cambridge: Cambridge University Press). 1982.

[17] Oosterbroek, P. (1998) The families of Diptera of the Malay Archipelago. (Leiden: Brill). 1998.

[18] Rostaman \& Disney, R. H. L. A new species of Chonocephalus Wandolleck (Diptera: Phoridae) that is a secondary pest of oyster mushrooms (Poriales: Lentinaceae) in Indonesia. Fragmenta faunistica, vol. 47, 73-80. 2004.

[19] Schmitz, H. Revision der Phoridengattungen, mit Beschreibung neuer Gattungen und Arten, Natuurhistorisch Maandblad, vol. 17, 12, 20-2, 38-41, 49-54, 66-70, 87-92, 101-5. 1928.

[20] Schmitz, H. Chonocephalus elongatus n. sp. (Diptera, Phoridae), Natuurhistorisch Maandblad, vol. 39, 21-24. 1950.

[21] Upton, M. S. Aqueous gum-chloral slide mounting media: an historical review, Bulletin of Entomological Research, vol. 83, $267-274$. 1993.

[22] Wandolleck, B. (1898) Die Stenopathidae, eine neue fluegel- und schwingerlose familie drer Diptera, Zoologische Jahrbücher abteilung für systematik, vol. 11, 412-441. 1898. 